\title{
Assessing the Alignment of Preparatory Year Program Vision, Mission, and Goals Statements with First-Year Student Success Principles
}

Atiyah A. Alghamdi

Follow this and additional works at: https://researchrepository.wvu.edu/etd

\section{Recommended Citation}

Alghamdi, Atiyah A., "Assessing the Alignment of Preparatory Year Program Vision, Mission, and Goals Statements with First-Year Student Success Principles" (2017). Graduate Theses, Dissertations, and Problem Reports. 5063.

https://researchrepository.wvu.edu/etd/5063

This Thesis is protected by copyright and/or related rights. It has been brought to you by the The Research Repository @ WVU with permission from the rights-holder(s). You are free to use this Thesis in any way that is permitted by the copyright and related rights legislation that applies to your use. For other uses you must obtain permission from the rights-holder(s) directly, unless additional rights are indicated by a Creative Commons license in the record and/ or on the work itself. This Thesis has been accepted for inclusion in WVU Graduate Theses, Dissertations, and Problem Reports collection by an authorized administrator of The Research Repository @ WVU. For more information, please contact researchrepository@mail.wvu.edu. 
Assessing the Alignment of Preparatory Year Program Vision, Mission, and Goals Statements with First-Year Student Success Principles

\author{
Atiyah A. Alghamdi \\ Thesis submitted to the \\ College of Education and Human Services \\ at West Virginia University \\ in partial fulfillment of the requirements for the degree of \\ Master of Arts in \\ Educational Psychology/Evaluation and Research \\ Reagan Curtis, Ph.D., Chair \\ Nathan M. Sorber, Ph.D. \\ Patricia A. Haught, Ed.D. \\ Department of Learning Sciences and Human Development \\ Morgantown, West Virginia \\ 2017
}

Keywords: Content Analysis, Saudi Higher Education, Preparatory Year Program, First-Year Experience, First-Year Theory, Vision, Mission, Goals, and Students' Success

Copyright 2017 Atiyah A. Alghamdi 


\begin{abstract}
Assessing the Alignment of Preparatory Year Program Vision, Mission, and Goals Statements with First-Year Student Success Principles

Atiyah A. Alghamdi

Using student development theories to develop and deliver first-year students programs is critical to ensure program quality and to understand students actual needs (Cubarrubia and Schoen, 2010; Upcraft \& Gardner, 1989). The majority of Saudi universities established the Preparatory Year Programs for firstyear students in 2005 or beyond. This study answers the following four research questions: 1) For each university, to what extent do the Preparatory Year Programs' vision, mission, and goals statements align with the Seven Principles of Students' Success in the first-year of university?; 2) What common key elements cited in the Seven Central Principles of Students Success are most often included in the Preparatory Year Programs' vision, mission, and goals statements?; 3) For all Saudi public universities, what is the format and frequency of the Preparatory Year Programs' vision, mission, and goals statements?; and 4) How do the Preparatory Year Programs' vision, mission, and goals statements compare or contrast in content between universities, according to geographical location, size, the Preparatory Year Programs' date of establishment, and gender?
\end{abstract}

This study used the nine steps of Content Analysis (CA) developed by Neuendorf (2002) to assess the alignment of the Preparatory Year Program's vision, mission, and goals statements with the Seven Central Principles of Student Success advanced by Cuseo (2014), and to also explore universities trends in developing the Preparatory Year Programs' students. The nonrandom sampling process, purposive sampling, was utilized for all 28 Saudi public universities. The Unit of Thoughts (UT) extracted from the vision, mission, and goals statements was counted, coded, and used to assess the alignment extent. A pilot study was conducted on seven Preparatory Year Program's (25\%) to test the codebook and coding for reliability, validity, and consistency, which resulted in $100 \%$ agreement between the researcher and two coders. The descriptive statistics were then reported. The Self-Efficacy (S.E.) Principle was cited the most in the vision, mission, and goals statements; also, the Social Integration (S.I.) Principle in the second level of alignment. Preparing students for university study was the common format and frequency of vision, mission, and goals statements associated with the seven principles.

Furthermore, this study found that different universities, founded in different regions and under different conditions, have similar mission and vision statements; with this, each university or Preparatory Year Program should have a unique need and identity, and its students should have different needs. The study's finding suggests that the Preparatory Year Programs may articulate and develop its vision, mission, and goals statements based on the Students Success Principles, Students' Development Theory, and First-Year Theory to create a shared vision toward better understating of the programs components. 


\section{Acknowledgment}

I would like to acknowledge Allah Almighty, the God for all things given to me in my life and for guiding and for providing me the strength, inspiration, motivation, and wisdom to achieve what I have done so far in my journey in life. I would like to thank the Saudi Arabian government and King Saud University for giving me a learning chance to study abroad in the great country of the United State of America at a respectable university, West Virginia University.

This study could not have been conducted without the guidance of an outstanding dissertation committee, to which I am indebted thanks and gratitude. To Professor Reagan Curtis, my advisor, for all the support and encouragement he provided to me. I would like to thank him further for facilitating and supporting me to overcome all challenges encountered during my study. I thank him for encouraging me to apply for this degree although my study is done in a different major. I had several courses with Dr. Reagan in quantitative, qualitative, and mixed methods research methodology, which attracted me and gave me necessary knowledge and skills to conduct this study.

Additionally, I would like to thank Dr. Nathan M. Sorber for his agreement to serve on the thesis committee. I had several courses with Dr. Sorber, which expanded my knowledge, experience, and skills in higher education and policy studies. In addition, I appreciated his constructive comments and feedback on my work.

I am grateful to Dr. Patricia Haught for kindly agreeing to serve on the thesis committee. Dr. Haught is a supportive and kind person. Her comments on my thesis and direction helped to improve this study's structure and outcomes. All thanks and gratitude for those who had a positive impact on my life and supported me in different ways, although I did not include their names in this acknowledgment. 


\section{Table of Contents}

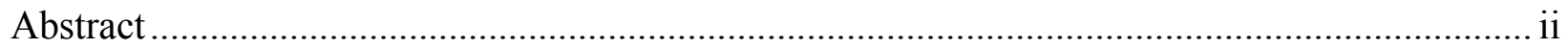

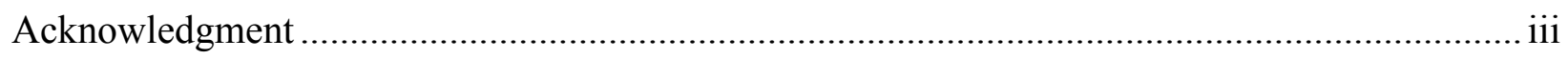

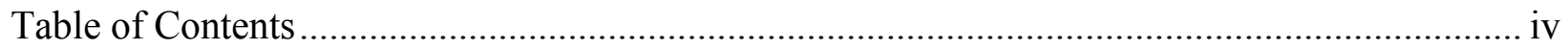

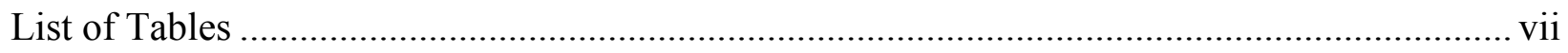

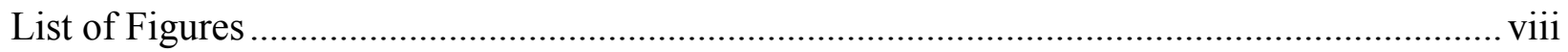

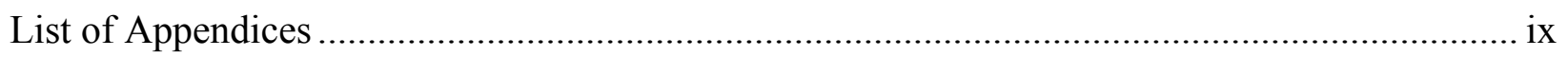

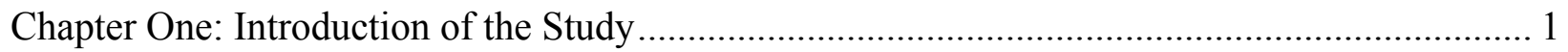

Brief History of Saudi Higher Education..................................................................... 1

Saudi Higher Education Reform Movement................................................................ 3

Statement of the Problem............................................................................................... 7

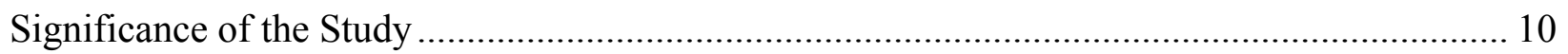

Purpose of Study and Research Questions........................................................................ 12

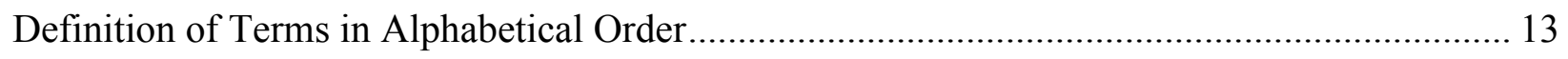

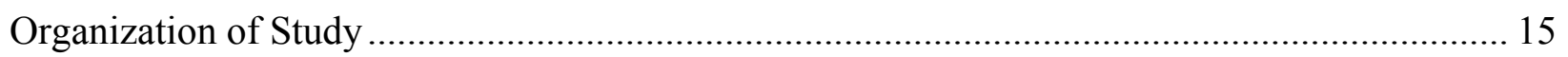

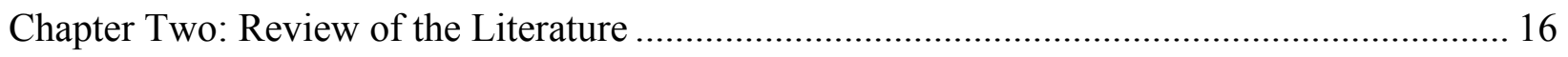

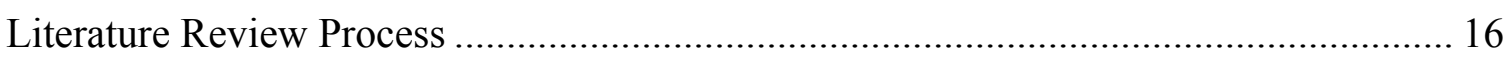

Organization of Review of Literature ......................................................................... 18

Theoretical Foundations of Student Development and First-Year Experience Theories . 19

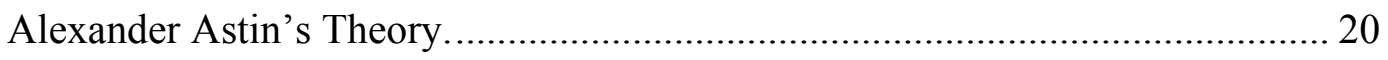

Vincent Tinto Theory............................................................................. 28

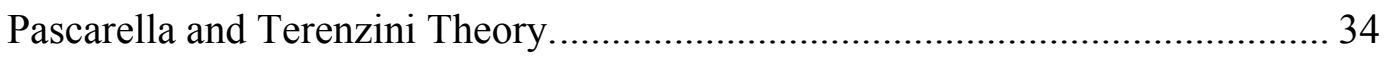

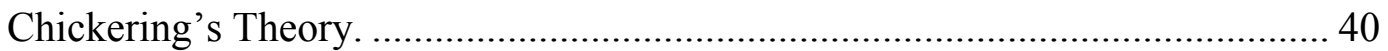

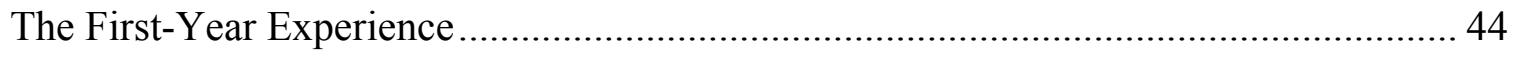

The History of First-Year Experience Concept. ............................................... 45

First-Year Experience Issues. ................................................................... 51

The First-Year Experience: An International Perspective. ................................. 56

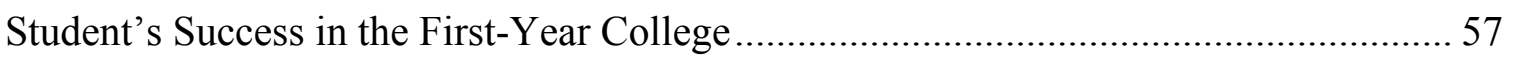

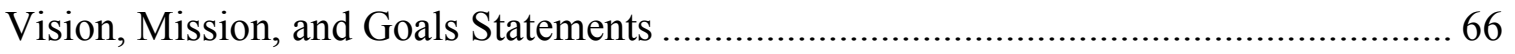

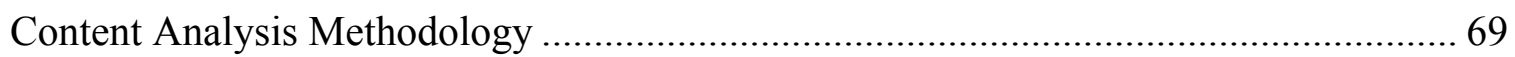

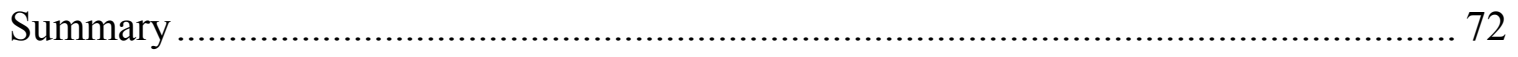

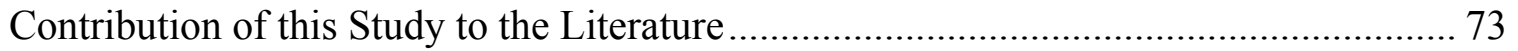

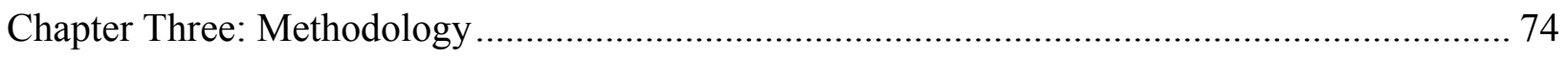




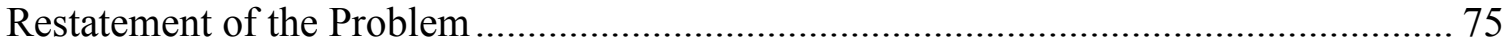

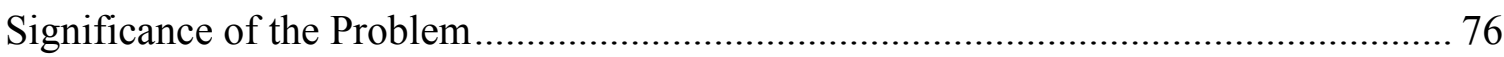

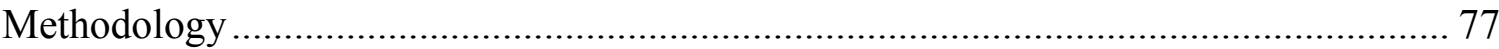

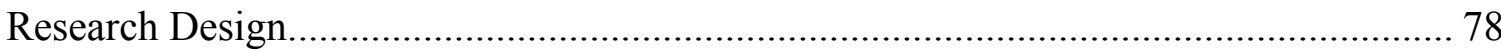

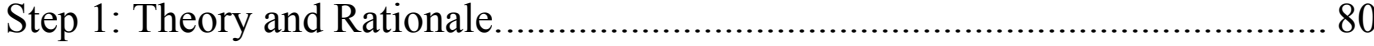

Step 2: Conceptualizations and Operationalization (measures)............................. 86

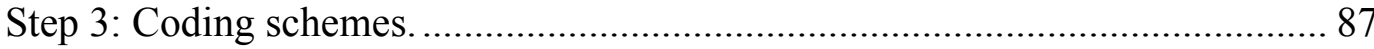

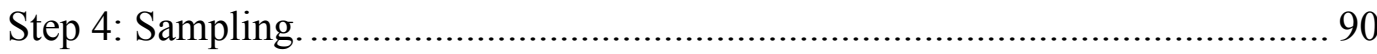

Step 5: Training and pilot reliability............................................................ 90

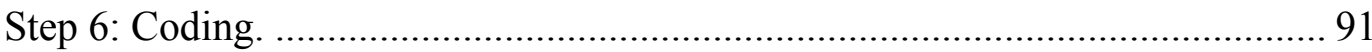

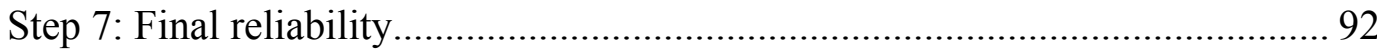

Step 8: Tabulation and reporting..................................................................... 94

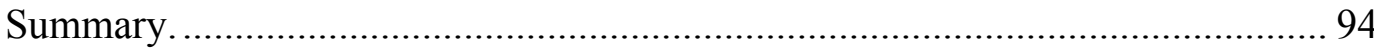

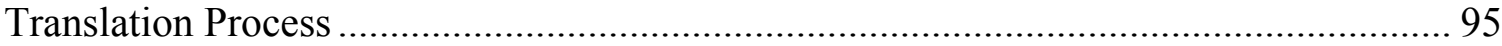

Limitations of the Methodology ……………………................................................... 97

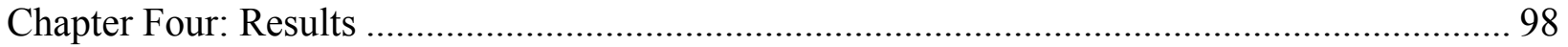

Purpose of the study and Research Questions ............................................................. 98

Description of the Sample......................................................................................... 99

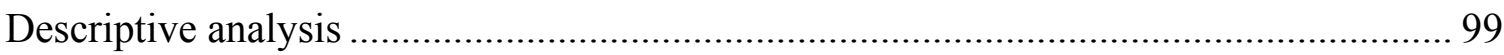

Finding for the First Major Research Question ........................................................... 103

Finding for the Second Major Research Question........................................................ 128

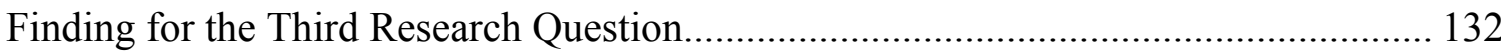

Finding for the Fourth Research Question............................................................. 140

Additional Limitations of the Study ........................................................................... 145

Chapter Five: Summary, Discussion, Implications, and Future Research.................................. 147

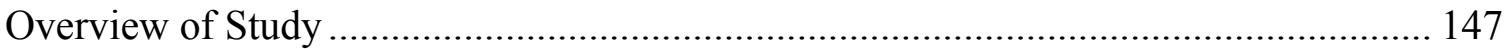

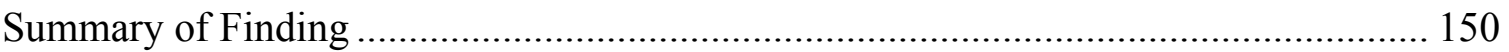

Summary of Results for Research Question One. …….................................. 152

Summary of Results for Research Question Two............................................. 153

Summary of Results for Research Question Three........................................... 153

Summary of Results for Research Question Four............................................... 158

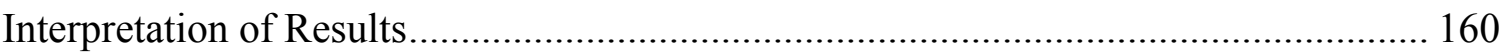

The Alignment of Preparatory Year Programs' Vision, Mission, and Goals Statements to the Seven Principles of Students' Success.................................... 161

Lack of Focus on Student Success as Preparatory Year Programs Vision and

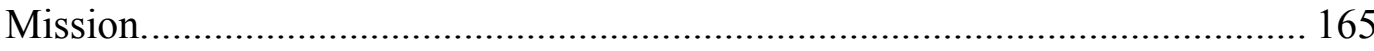

Different Preparatory Year Programs with Similar Vision, Mission, and Goals

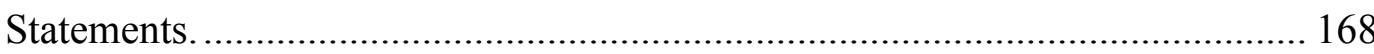

The Gap between Theory and Practice (Personal Reflection)............................. 170 


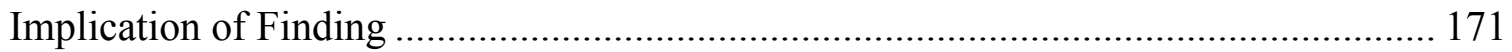

Implication for Saudi Universities.......................................................... 171

Implication for Preparatory Year Programs.................................................. 172

Implication for Saudi Educational Policymaker. .......................................... 173

Recommendations for Future Research .................................................................. 173

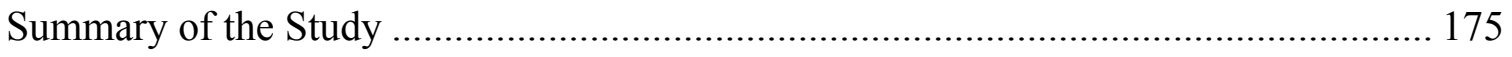

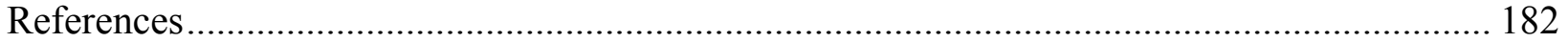

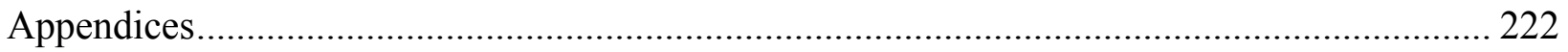




\section{List of Tables}

Table 1: The Descriptions of the Seven Variables, Operational Definition, and Applications Adapted from Cuseo (2014)

Table 2: Displays the First-Year Students Enrollment in Saudi Public Universities in 2014-2015

Table 3: Preparatory Year Programs Date of Establishment .............................................. 101

Table 4: The organizational structure of Preparatory Year in Saudi Public Universities.......... 103

Table 5: Shows the application policy of the Preparatory Year Programs.............................. 103

Table 6: Summarizes the alignments of each university with the Seven Principles of Student's

Success and the alignment total for the vision, mission, and goals statements combined ......... 127

Table 7: The Seven Principles of Student's Success as the most appeared in the Preparatory Year

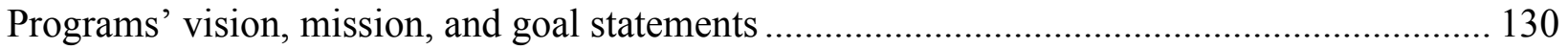

Table 8: Displays the format and the frequency of vision, mission, and goals statements of the

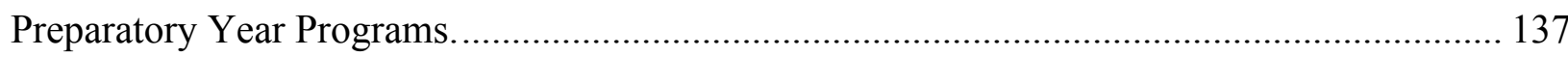

Table 9: The Similarity and Differences of Vision Statements Based on geography location, size, Preparatory Year Programs date of establishment, and gender ........................................... 142

Table 10: The List of Saudi Universities that Aligned with Self-Efficacy Principle. ............... 144 


\section{List of Figures}

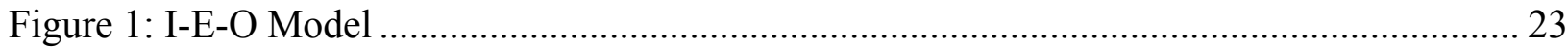

Figure 2: Tinto's longitudinal model of institutional departure ............................................... 30

Figure 3: The General Model for Assessing Change................................................................. 38

Figure 4: A comprehensive model of influences on student learning and persistence................ 40 


\section{List of Appendices}

Appendix A: The PYPs' Vision, Mission, and Goals Statements in Saudi Public Universities 222

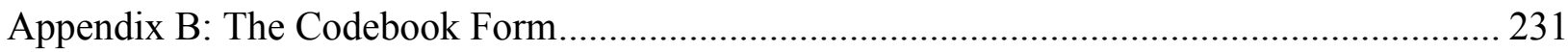

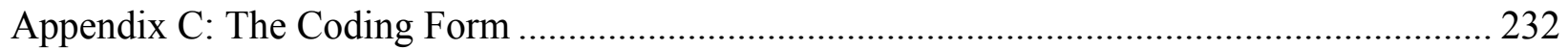

Appendix D: Saudi Public Universities List and the Links to Preparatory Year Programs ....... 233 


\section{Chapter One}

\section{Introduction of the Study}

\section{Brief History of Saudi Higher Education}

On January 15,1902, King Abdulaziz established the third Saudi country, naming this country the Kingdom of Saudi Arabia on September 23, 1932. Higher education began with the approval of King Abdulaziz to send 14 students of various fields of specialization to Egypt in 1927. However, the actual beginning of institutional higher education in the kingdom occurred in 1949, when the first college called (Shari'a) or (College of Islamic Law) in Makkah was founded (Information, 2013).

In general, Saudi higher education history can be divided into three phases:

1. Foundation (1949-1960); this phase contains the first blocks of higher education, which was the College of Islamic Law (Shari'a) in Makkah established in 1949, followed by the Teachers College in 1952. In 1953 and 1954 respectively, a second College of Islamic Law (Shari'a) and a College of Arabic were established in Riyadh, the capital city of Saudi Arabia. These two colleges in Riyadh were the nucleus of the establishment of the King Saud University in 1957, and were followed by additional colleges within the university such as Colleges of Arts, Science, Administrative Sciences, and Pharmacy.

2. Expansion (1961-1980); this phase involved an expansion in the establishment of universities on the country level in different provinces of the Kingdom. For example, the Islamic University in Medina in 1961; King Abdulaziz University in Jeddah in 1967; Imam Muhammad Ibn Saud Islamic University in Riyadh in 1974; King Fahd University of Petroleum and Minerals in Dhahran and King Faisal University in AlHassa in 1975; and finally Umm Al-Qura University in Makkah in 1980. These universities together consisted of 58 colleges of various disciplines. During that era, 
some of these universities had campuses in other provinces besides the main campuses. For example, King Saud University established branches at Abha, which is located in the south of the Kingdom and Qassim, located in the middle of the Kingdom; similarly, Imam Muhammad Ibn Saud Islamic University branch is at AlHassa in the east of the Kingdom; and King Abdulaziz University branch is at AlMedina in the west of the Kingdom. Moreover, this expansion phase was characterized by an increasing diversity of higher education specialists and establishing numerous teachers' colleges in different cities (Information, 2013, p. 19).

3. Comprehensiveness (1981-2012); this phase can signify the mass education of Saudi Arabia when the country's government was clearly intent on spreading the institutions of higher education in all the provinces and districts of the Kingdom. The goal was to enable people in small cities, towns, and villages to pursue their higher education without having to move to major cities such as Riyadh, Jeddah, and Dammam to find education opportunities. Between 1957-2011, the number of universities public or private grew rapidly from 8 universities in 2001 to 33 in 2011 (Information, 2013). Since its establishment, Saudi higher education system is centralized, meaning the Ministry of Higher Education plans and manages, while universities rely on the government for most funding and infrastructure (Al-Eisa \& Smith, 2013). However, Saudi higher education is a relatively modern phenomenon with the first university institution being established in 1957 (Al-Eisa \& Smith, 2013).

Consequently, the Saudi government has been developing many regulations covering all aspects of higher education, including the "number of students to be enrolled, student admission procedures and personnel policies for faculty members" (e.g., salaries, promotion, reappointment and retirement age) (Alkhazim, 2003) as cited in (Al-Eisa \& Smith, 2013). Eventually, in January 29, 2015 Saudi government made a decision to combined higher 
education and public education ministries into one ministry named Educational Ministry and assigned one minister for both sectors.

\section{Saudi Higher Education Reform Movement}

In recent years, the Kingdom of Saudi Arabia has emphasized the educational sector both secondary and postsecondary, to develop human capital and to increase the knowledge society. The transition from an oil-based economy to a knowledge society requires the population to develop its level of human capital (Corneo, 2011; Gallarotti, Filali \& Yahia 2013). Currently, Saudi Arabia supplies 60 percent of the world's oil, and policymakers in Saudi government are aware that decreasing the dependence on oil for the supply of energy is the priority of research and government policy (Smith \& Abouammoh, 2013).

Hence, the government's Ninth National Development Strategic Plan (2010-2014)

states "Knowledge has become a critical requirement for enhancing competitiveness of countries in the twenty first century" (Planning, 2010, p. 94).

Additionally, the ninth plan stresses the following:

To establish a learning pattern that develops analytical thinking, advances acquirement of practical skills, and promotes initiative and entrepreneurship, the system of education needs to address a set of issues ranging from curriculum development, lifelong learning, linking education with development, Arabization of knowledge, to privatization (Planning, 2010, p. 94).

The ninth plan defines Arabization of knowledge as requiring that "knowledge and scientific and technical information should be in Arabic" and Privatization of education means "to maintain values, heritage and particularities of society, educational policies and objectives remain the responsibility of the State" (Planning, 2010, p. 95). Thus, the quest for educational reforms became part of ninth-plan development. Such a strategic transition from 
the current oil-based economy to a knowledge society requires an enhanced effort to improve both cognitive and non-cognitive skills.

Consequently, in 2006, the Ministry of Higher Education launched its future strategic plan named AAFAQ2029 (translated to English: "Horizons2029”) in alignment with the national strategic plan, which aimed to shift toward a knowledge society and a more diverse economy. AAFAQ2029 adopts the government trend, launching its educational reform plan on the following basis: "Expansion of higher education in the Kingdom of Saudi Arabia with an integrated quality, excellence, and competing for global leadership to contribute effectively in building a knowledge society" (AAFAQ, 2013, p. 15).

AAFAQ2029 incorporates a comprehensive reform process for Saudi Arabia's postsecondary system for developing a long-term plan for the next 25 years (Al-Swailem \& Elliott, 2013). Due to Saudi Arabia's postsecondary system being a centralized system of control in terms of policy and educational support, the AAFAQ2029 project defines the mission and outcomes for the higher education system as a whole. The plan suggests a mechanism through which methods of strategic planning are to be adopted by all public universities in the country (Smith \& Abouammoh, 2013).

To provide support to AAFAQ2029, the Ministry of Higher Education launched the complementary plan entitled Achieve Excellence in Science and Technology2025 (AEST2025). AEST2025 emphasizes various dimensions of educational reform. One of these dimensions is developing students' skills to prepare knowledge workers who could participate effectively in the nation's movement toward a knowledge society through merging necessary knowledge, hard and soft skills, and job market skills (Information, 2010).

Furthermore, AEST2025 created new initiatives and programs for students' development, which aimed to achieve the following goals: 
1. Developing basic student skills that are needed in the job market and society in general;

2. Improving the students' ability to continue their education, find appropriate solutions to problems, and develop their thinking skills;

3. Developing graduates' vocational, social, and personal skills, and;

4. Enabling students to broaden their knowledge bases (Information, 2010, p. 26). The AEST2025 plan consolidates student skills and improves the quality of postsecondary graduates through two paths: 1) an academic knowledge path to prepare students to be qualified in a specific area of study, and 2) a professional skills path, which focuses on soft and hard skills, technology utilization, research skills, self-learning skills, and lifelong learning skills (Information, 2010).

The AEST2025 plan suggests programs that Saudi universities, either public or private, could apply to achieve the knowledge society, such as the Preparatory Year Program and Centers of Developing and Improving Personal Skills. The new postsecondary policy allows universities to collaborate with the business sector such as educational companies to operate and provide educational service such as training and teaching on the required skills and knowledge (2010). In other words, the business sector is taking the responsibility of teaching and preparing students through agreements and business contracts consistent with the university vision, mission, and policy.

According to the Ministry of Higher Education report: The Current Status of Higher Education (2013), between 1999-2012, the number of new students who enrolled in first-year of college/university increased from 109,049 to 329,696, or approximately (300\%). Similarly, from 2000-2012 the total of all students in all public universities increased (250\%) from 404,094 to 1,116,230. Additionally, in 2012 the total number of degrees graduate was 111,852 students. This number represents 66,860 females $(59.8 \%)$, and 44,992 males 
$(40.2 \%)$. These percentages indicate higher participation of females in higher education (Information, 2013). Despite the high percentage of female participation in postsecondary education, the gender segregation culture is still considered a challenge for the educational reform movement, which has a goal to achieve equality of educational opportunity for females and achieve the knowledge society (Jamjoom \& Kelly, 2013; Smith \& Abouammoh, 2013). For example, the curriculums that are used to teach male or female at these institutions are the same, with the exclusion of topics in physical education and home economics for female.

In addition, in many cases male-only departments are responsible to plan and select curriculum materials and content without sharing it with female departments. Furthermore, establishing equality in terms of leadership positions, where some of female departments still manage through male departments, remains a challenge, as well as equity matters concerning access to knowledge resources or highly qualified teachers (Jamjoom \& Kelly, 2013; Smith \& Abouammoh, 2013). Therefore, more attention is required to meet male and female prerequisites with respect to religion, culture and privacy, especially in programs such as Preparatory Year Program.

However, higher education policy makers stress that such educational strategic reform should take into account the necessity of building human capital by instilling the values of work, commitment, lifelong learning skills, accountability, collaboration, creativity, and innovation to participate effectively in building a knowledge society. Therefore, universities are responsible to ensure that students who are transferred from secondary to postsecondary education will be ready with the essential knowledge, skills, and attitudes for a successful transition into postsecondary education (AAFAQ2029, 2013; Corneo, 2011; Smith \& Abouammoh, 2013). 
In responding to these needs, Saudi universities established during the past ten years a Preparatory Year Programs to support the First-Year students and to provide them with essential skills, knowledge, and attitudes to achieve success and excellence, especially for those who are not ready for college. Preparatory Year Program attempts to fill the gap between secondary education outcomes and university requirements and also ensures students' readiness for job market and knowledge society (Alatas, 2012; Alhosin, 2010 Bagazi, 2010; Dow \& Alnassar, 2013; Habib, 2010). While internal evaluation reports addressing these aspects have yet to be released publicly, there do exist secondary journalistic accounts that provide evaluative insights into the Preparatory Year Program.

\section{Statement of the Problem}

As a response to higher education trends in developing first-year students, the educational policymakers in Saudi universities are interested transforming the program into a new era, where it can meet higher education's standards, government's vision, and student's actual needs. Such a trend is required to better understand the current practices of the Preparatory Year Programs to identify the theoretical base and pedagogical philosophy that leads the current models of Preparatory Year Program's that are applied in Saudi public universities.

The Saudi higher education community including policymakers, administrators, faculty, parents, and business markets feel that the incoming students from high schools are extremely unready for college and they need more preparation in terms of the English language, hard and soft skills, math skills, science skills, and writing and reading skills. Thus, a need exists for a comprehensive support system such as the Preparatory Year Program to assist university's in reaching its goals and to help students successfully transition into postsecondary education. 
A meditation on the current practices of preparatory year programs in all Saudi public universities revealed that most Saudi public universities operate the program through the business sector, educational or training institutions, and this practice is considered unprecedented on the international level (Alaqeeli, Abouammoh, \& Alghamdi, 2014). The majority of these private sectors are new in the educational and training market in general, and in the field of first-year program operation in particular. In other words, these private sectors may not have enough previous experience to operate such programs or to deal with first-year students, and may have no pedagogical philosophy or theory base to design and operate the program. Furthermore, Alaqeeli et al. note a lack of qualified faculty selected by the business sector to teach or deal with first-year students, which causes miscommunication between first-year students and university faculty. One disadvantage of relying on the business sector to operate the Preparatory Year Program is known as the "Commodification of Higher Education", which leads to learning and teaching quality problems. Schroeder (1998) advocates that collaboration with the business sector is considered the most challenging trend encountered by postsecondary institutions.

Furthermore, in most of the Saudi universities, the Preparatory Year Program has been launched to fulfill institutional needs to improve universities inputs and outputs. Therefore, the Preparatory Year Programs are designed based on the best international practices with no consideration about the theoretical base or pedagogical philosophy that fit the culture of Saudi students. However, most of the Preparatory Year Program models in Saudi public universities have a main challenge that lack a governing philosophy, theoretical and pedagogical base of the program, "the preparatory year in most American universities is based on a theoretically and practical structured vision. This is in terms of goals, programs, skills, strategies, learning dimensions, teaching strategies, and assessment styles" (Alaqeeli, 2014, p. 60). 
Close examination of the current models of Preparatory Year Program at all Saudi public universities proved that there are no documents that could be used to report or describe the theoretical base of the program or its philosophical base. Although the Preparatory Year Program has been in existence for ten years at most Saudi public universities, there is a lack of research and evaluation studies to explore the Preparatory Year Programs' models or to define an overall theoretical foundation or pedagogical philosophy of the programs. Furthermore, Saudi first-year or Preparatory Year Program literature reported that very few studies have been conducted about the Preparatory Year Program, in either the Arabic or English languages, to evaluate specific aspects of the program. For instance, most of the research was conducted to assess the English skills program. Furthermore, although the large size of the Preparatory Year Deanship in Saudi public universities in general, there is no evaluation or research unit or research center for first-year experience to assess the Preparatory Year Program's progression.

Consequently, exploring and understanding a theoretical base of the current models of the Preparatory Year Programs and assess their alignment with the First-Year Student Success Principles is critical for the program's development in the future. Thus, this study attempted to explore the theoretical base of the program through studying the vision, mission, and goals statements of all Preparatory Year Programs at all Saudi public universities and assessing their alignment with the Seven Principles of Students Success. This study employed the Seven Central Principles of Students Success advanced by Cuseo (2014) as a guideline to identify the theoretical base of the Preparatory Year Programs due to their comprehensiveness, which includes most of student's success themes that appear in student's development theories, first-year theory such as "intellectual development, emotional development, social development, ethical development, physical development, and spiritual development" (Cuseo, 2014, p. 2). Furthermore, the Seven Principles of Students Success 
provided a wide ground for theories selection. As this study's aim was to explore and assess the theoretical base of the current practices of the Preparatory Year Programs, the seven principles are considered an appropriate tool to achieve such a goal and to provide a better understanding of the current practices. Moreover, this study added to the weak body of existing literature, especially in the Saudi higher educational culture where the first-year practices and student's development theories need more investigation.

The authorized information published on the official Preparatory Year Programs' websites including the programs vision, mission, and goals statements that express the programs purpose, philosophy, and trends were used to assess the Preparatory Year Programs' alignment with the Seven Principles of Students Success. In addition, this research investigated how Saudi universities are different or similar in terms of program theory and philosophy, according to various variables, such as university size, locations, program's date of establishment, and gender. This study is considered the first attempt to discover the compatibility of these principles with the Preparatory Year Programs' mission in Saudi public universities context.

\section{Significance of the Study}

Research studies on first-year students agree that the first-year of university is critical for developing a foundation for successfully transitioning into college, and students' success is largely based on their first-year experiences (Ben-Avie, Kennedy,Unson, Li, Riccardi \& Mugno, 2012; Clark, 2005; Frazier, 2007; Mutch, 2005; Noel, Levitz, \& Saluri, 1985; Tinto \& Pusser, 2006; Upcraft, Gardner \& Barefoot, 2004). A new trend of postsecondary education policy and practice is to provide equal opportunity for all students, which is considered fundamental for students' success and develop first-year programs to meet students actual needs and university requirements (Johnston, 2010). 
As the Preparatory Year Programs at the majority of Saudi public universities are considered a new phenomenon, which began in 2004 or after for most, this study is significant because it explored the Preparatory Year Program's theoretical base in all 28 Saudi public universities by analyzing the vision, mission, and goals statements of each university and assessed its alignment with the First-Year Experience Theory represented by the Seven Principles of Students Success advanced by Cuseo (2014). Furthermore, this study represented significant research for several reasons.

First, this study responded to the call of Saudi Education Ministry to develop the Preparatory Year Program to improve learning quality and student's performance. Thus, this study has significance giving a better understanding for the program's purpose, philosophy, and trend, which can lead the development effort in the future.

Second, the current working model of the Preparatory Year does not have any published documents to identify its theoretical and pedagogical bases. This issue may affect the curriculums design, teaching methods, and student outcomes. In other words, "the preparatory year in Saudi universities lacks a Governing Concept philosophy" (Alaqeeli, 2014, p. 60). This study achieved a step toward exploring the theoretical foundation of the Preparatory Year Program that could connect theories and learning pedagogy instead of only relying on the best global practices.

Third, the current working model is designed for all students, male and female, and for students from different backgrounds with different needs, meaning it is contrary to the fact that one-size does not fit all. The Content Analysis of the Preparatory Year Programs' vision, mission, and goals statements used in this study was beneficial for the future program design by exposing these issues.

Fourth, this study compared and contrasted the Preparatory Year Program's vision, mission, and goals statements for all Saudi public universities according to universities' size, 
location, program date of establishment, and gender variables. The comparison represented the trend of Preparatory Year Programs in Saudi public universities and how Saudi universities design its programs.

Finally, this study is significant due to the research methodology that was utilized, Content Analysis (CA), developed by Neuendorf (2002). Generally, the preferred methodology in the Saudi Arabian educational context is quantitative studies, and thus, studies utilizing Content Analysis are rare. Using such methodology will contribute positively to transferring such research experience overseas.

\section{Purpose of Study and Research Questions}

The main purpose of this study was to analyze the vision, mission, and goals statements of all 28 Preparatory Year Programs and assess whether the Preparatory Year Programs incorporate the principles of Student Success in the first-year of university outlined in the Seven Central Principles of Student Success advanced by Cuseo (2014). Additionally, this study explored the themes and formats of the Preparatory Year Programs in all 28 universities and the differences among all these programs based on university size, location, program date of establishment, and gender. Finally, this study explored the Preparatory Year Programs trend in Saudi universities through the most common key elements of the Seven Principles of Students Success included in the Preparatory Year Program's vision, mission, and goals statements.

To accomplish the study's goals, the researcher used the government information published on the Preparatory Year Program's official websites expressing the vision, mission, and goals statements in each public university. The nine steps of Content Analysis (CA) developed by Neuendorf (2002) was used for data collection and analysis. This study attempted to answer the following research questions: 
a. For each university, to what extent do the Preparatory Year Programs' vision, mission, and goals statements align with the Seven Principles of Students' Success in the first-year of university?

b. What common key elements cited in the Seven Central Principles of Students Success are most often included in the Preparatory Year Programs' vision, mission, and goals statements?

c. For all Saudi public universities, what is the format and frequency of the Preparatory Year Programs' vision, mission, and goals statements?

d. How do the Preparatory Year Programs' vision, mission, and goals statements compare or contrast in content between universities, according to geographical location, size, the Preparatory Year Programs' date of establishment, and gender? Finally, for clarification, this study was not to evaluate the content or structure of the vision, mission, and goals statements of Preparatory Year Program itself, but to assess its alignment with the First-Year Theory.

\section{Definition of Terms in Alphabetical Order}

Alignments. Alignment is "the degree to which expectations and assessments are in agreement and serve in conjunction with one another to guide the system toward students learning what they are expected to know and do" (Webb, 1997, p. 3). In the content analyses, "Alignment can be judged by coding and analyzing the documents that convey the expectations and assessments." (Webb, 1997, p. 10).

Content Analysis. This study used the Content Analysis definition as a research technique that Neuendorf (2002) advanced, "summarizing, quantitative analysis of messages that relies on the scientific method (including attention to objectivityintersubjectivity, a prior design, reliability, validity, generalizability, replicability, and 
hypothesis testing) and is not limited as to the types of variables that may be measured or the context in which the message are created or represented" (p. 10).

Goals Statement. Phrases used to express the performance level of all university or school components, either educational professional, students, curriculums, professional development, etc. (Gurley, Peters, Collins, \& Fifolt, 2014). For this study, 'goal statement' is used to define the Preparatory Year Program's objectives and the key specification's actions in each university and the programs actual practices.

Mission Statement. For this study, 'mission statement' is used to define the Preparatory Year Program's purpose, creed, values, and belief.

Preparatory year program. Within the Saudi higher education context, the Preparatory Year Program is an academic year that aims to provide students with foundation courses in essential soft and hard skills before entering their colleges. Student success. For this study, 'student success' is more likely to be experienced and evidenced when students: 1) feel personally validated and they matter to the college; 2) believe that their effort matters and that they can influence or control the prospects for success; 3 ) develop a sense of purpose and perceive the college experience as being personally relevant; 4) become engaged in the learning process and in the use of campus resources; 5) become socially integrated or connected with other members of the college community; 6) think reflectively about what they are learning and connect it to what they already know or have previously experienced; and 7) are self-aware and remain mindful of their learning styles, learning habits, and thinking patterns (Cuseo, n.d.). 
Vision Statement. Generally, vision is an expression of the desired future, "it is a picture of excellence, something that the person, team or organization wants to create in its best possible future" (Papulova, 2014, p. 13).

\section{Organization of Study}

The first chapter of this study begins with an overview of the status of Saudi postsecondary education and its reform movement with a historical brief about the Preparatory Year Program and its importance in Saudi higher education. Next, the study states the research problem and its significance to postsecondary education. Finally, the chapter concludes with the definitions of terms in alphabetical order.

The second chapter is divided into five sub-sections. First, an extensive review of the literature of the theoretical foundations of student development and first-year experience is provided. Second, the history of the first-year experience and the literature on the international and national levels. The third discussed the student's success in the first-year college literature. The fourth section includes a review about the vision, mission, and goals statements definition and its use in the organization. Finally, a brief explanation about the Content Analysis methodology that is utilized in this study is given.

The third chapter of this study provides a detailed explanation for the research methodology that will be utilized. The research methodology explanation includes the data collection and analysis process and any limitations related to the methodology.

The fourth chapter illustrates in detail the study's procedures and results which responds to the four research questions of this study. The research questions are answered separately for each group of stakeholders, male and female. The fifth chapter reports the research findings and conclusion, including a discussion of the study's outcomes and implementations, followed by recommendations for future studies and a summary of the study. 


\section{Chapter Two \\ Review of the Literature}

\section{Literature Review Process}

The concepts of First-Year College, Preparatory Year, Vision, Mission, and Goal statements in general and for university in particular were searched using different database and academic libraries to fulfill the current study literature review needs. First, through the West Virginia University (WVU) library, peer reviewed and scholarly academic research papers were collected electronically using library catalogs. Online search of EBSCOhost's Education Research Complete Database with the phrase first-year experience as a key search with no other limitations reported 7,359 citations were retrieved, the oldest with a publication date of 1981. By limiting the search using the subject field higher education, the citations number decreased to 30 citations since 1998.

A similar search in EBSCOhost's Academic Search Complete Database with the phrase first-year experience with no other limitations resulted in 20,574 citations. The oldest had a publication date of 1924. By limiting the search results using the subject field higher education, 1,430 citations were retrieved. Both databases have no results by using the Arabiclanguage as a limitation of the search. A parallel search was done using the ProQuest Dissertations and Theses (PQDT) Database, limiting to the phrase first-year experience to higher education, citation, and abstract, retrieved 34,400 English-language dissertations and theses published between 1914 and 2014 .

Using Google search tools such as Scholar with the phrase first-year experience reported about 1,040,000 results. Further, Google Scholar revealed 40,200,000 results for the concepts of vision, mission, and goals statements. Limiting this number to phrase "university vision, mission, and goal statements" resulted in 568,000 outcomes. 
In addition, a search was completed on an Arabic database named Saudi Digital Library (http://sdl.edu.sa/SDLPortal/en/Publishers.aspx) and King Saud University Library using Arabic language as a limitation. This search resulted in ten studies conducted in Arabic language most of them to assess a specific aspect of Preparatory Year Program such as English language program and academic accreditation of the program. Additionally, most of these studies represented a master or doctoral student research.

Moreover, an electronic copy of the Saudi Journal of Higher Education was referenced on Google search engine. This is a peer-refereed, bi-annual journal published by the Center for Higher Education Research and Studies (CHERS) Ministry of Higher Education. Three articles related to the first-year experience were retrieved from issue No.11 - Rajab 1435 AH - May 2014. One of these article is titled: A History of the First-Year Experience in the United States during the Twentieth and Twenty-First centuries: Past Practices, current Approaches, and Future Directions, written by Professor. Andrew K. Koch and Professor. John N. Gardner.

Another database utilized was the National Resource Center for the First-Year Experience and Students in Transition at the University of South Carolina. The National Resource Center specializes in the first-year experience and students-in-transition issues, which "serves as the trusted expert, internationally recognized leader, and clearinghouse for scholarship, policy, and best practice for all postsecondary student transitions" ("About the Center", 2015) http://sc.edu/fye/center/index.html.

The National Resource Center has several publications in the First-Year Experience $\&$ Students in Transition. One of its publications is the Journal of The First-Year Experience \& Students in Transition, which has published 26 volumes divided into 52 issues, beginning with the first volume in 1989 to the most recent volume in fall 2014. All these materials are available electronically (“About the Center”, 2015). Furthermore, numerous books and 
annotated bibliographies have been published about the first-year experience. Moreover, the National Resource Center has conducted 34 annual conferences discussing first-year issues and development (“About the Center”, 2015).

The last search was done using the International Journal of the First-Year in Higher Education (Int J FYHE), which is published by Queensland University of Technology in Australia. The Int J FYHE published its first volume in 2010. The most recent volume which has been published is volume six, in the beginning of 2015. The Int J FYHE "focuses on research and practice about enhancing the experience of commencing students" ("Int J FYHE”, 2015) https://fyhejournal.com.

In addition, the search process took into account the type of research, including both positivist and postpositivist research for better understanding of first-year students' practices. Consequently, in preparation for conducting this study, a systematic review of literature associated to the application of first-year experience practices and theories to postsecondary education was performed. Expanding the literature review domain of search allows for more understanding and provides a researcher with new information and experience regarding his/her topic, and elucidate the relationship between different subjects within a research problem (Boylan, Bonham, \& White, 1999).

\section{Organization of Review of Literature}

For the purpose of this study, the literature review starts with an outline of the most common and leading cited documents associated with the first-year experience discipline that established the foundation for several theoretical, practical and research publications in the most recent years. Thus, the literature review has been divided into five main sections attempting to cover all issues and topics related to study domains.

The first section provides an inclusive description of theoretical foundations of students' development and first-year experience theories. This section discusses the most 
common theories inspiring the first-year experience movement and its development in the literature. These theories include Alexander Astin Theory, Pascarella and Terenzini Theory, Vincent Tinto Theory, and Chickering's Theory. Each theory has been discussed in detail, comprising its roots, development, issues, and critical analysis of theory.

The second section illustrates first-year experience topics, including a wide review of first-year history development, first-year experience issues, first-year intervention strategies and functions, first-year organizational structures, and first-year experience: an international perspective. The third section illustrates student's success in the first-year college literature. This section provides information regarding first-year interventions initiatives that could foster student's success in first-year colleges and make their transition into postsecondary education successfully. The fourth section discusses vision, mission, and goals statements. This section clarify the importance of these three domains that use as guidelines for any institute to leads its effort towards desire goals. Finally, the fifth section involves a brief history of Content Analysis Methodology in general and in particular for the Content Analysis Approach developed by Neuendorf (2002) used in this study.

\section{Theoretical Foundations of Student Development and First-Year Experience Theories}

Several research studies were conducted over the last four decades related to various issues associated with student development in general, and first-year students and transition topics. The earlier studies discussed general issues related to college students' success and the factors that impacted students' persistence and retention. Other studies established new concepts and definitions such as first-year students, students' success, retention, readiness, persistence, etc. In the last thirty years, new issues manifested such as diversity, gender, racial, sexual, economic situation, higher education trends, etc.

Student development theories became part of the first-year movement, with numerous theories attempting to study students' success and transition issues within a theoretical 
perspective. According to Cubarrubia and Schoen (2010), "intentionally using student development theory to develop and deliver new students programs is critical to ensure that the needs of diverse students populations are addressed" (p. 167). In other words, applying the best practices of first-year programs at postsecondary institutions is inadequate to ensure program quality and success if we ignore the foundational theories of student development.

Due to differences in student characteristics from one community to another, a wide range of research on student development has worked to establish new models or programs to meet students' needs and to fulfill the postsecondary mission. Therefore, an analysis of the most common student development theories are vital for the current study, a process that will give insights about the student development movement and its applications. This analysis will help to understand the current theoretical base of Preparatory Year Programs in the Saudi higher education context.

In this context, this section will discuss four theories of student development according to two criteria:

1. Relationship to student development theories in college/university.

2. Contribution to first-year experience literature according to the particular theory's citation in Google Scholar.

The discussion of these theories will assist as a fundamental background when assessing a Preparatory Year Programs' vision, mission, and goal statements at all 28 Saudi universities.

Alexander Astin's Theory. Astin has conducted numerous research studies, but the most important are published in his books, Four Critical Years. Effects of College on Beliefs, Attitudes, and Knowledge (1977), and What Matters in College? Four Critical Years (1993), cited by 2,145 academic studies, Astin's Student Involvement: A Developmental Theory for 
Higher Education (1984), was cited by 2,767 studies; both research studies citations according to Google Scholar.

The purpose of What Matters in College? is to provide faculty, student affairs, educational policy-makers, and professionals a better understanding of "how undergraduate students are affected by their college experiences" (Astin, 1993, p. xix). To assess how students are affected by their college experiences, Astin cited three major activities that are used in his study: 1) understanding the nature and meaning of student change; 2) select or develop a model or theoretical or conceptual framework to study student performance; and 3) "designing the analyses of college impact" (p. 5).

Astin $(1977,1993)$ argues the majority of research studies on first-year experience measures students' change or growth academically rather than studying the impact of the college itself on students' experience. For example, some postsecondary institutions survey student's perceptions at the first day of college and at the end of year, or after four years of study. In this case, students' change in perception is assessed by comparing two measures. The weakness of this measurement approach refers to the weakness of this measure to predict a student's change if he/she attends different colleges, or does not attend a college. Astin states that a student's change occurs due to two major mechanisms: college impact and the outside environment of college.

To measure the impact of college activities, Astin's study (1993) utilized the Cooperative Institutional Research Program Survey (CIRP). CIRP involves several measurements, thus Astin developed a conceptual scheme to organize and guide these measurements. The "taxonomy of student outcomes" (p. 9) contains three dimensions: 1) type of outcomes, which involves cognitive outcomes (called intellective) such as mental process (e.g. reasoning and logic), and non-cognitive outcomes (called affective) such as attitudes, values, self-concept, aspirations, and everyday behavior; 2) type of data, which 
describes type of information collected to evaluate cognitive and non-cognitive outcomes; these data involve Psychological (e.g. attitude, values, etc) and Behavioral (e.g. personal habits, occupations, citizenship, etc.); and 3) time dimension, which refers to two points of time during college and after college (e.g. satisfaction with college represents a during college point of time, and job satisfaction represents an after college point of time) (p. 9-11).

Furthermore, Astin's studies $(1977,1993)$ utilized some standardized tests to recognize Student Input Characteristics such as the Scholastic Aptitude Test (SAT), American College Test (ACT), and Graduate Record Examination (GRE). Moreover, for Environment Measures, Astin utilized 192 environmental measures, including 16 measures of institutional characteristics (e.g. size, control, type); 35 measures of student peer group characteristics (e.g. socioeconomic status, academic preparation, values, etc.); 34 measures of faculty characteristics (e.g. teaching methods, moral, etc.); 15 measures of the curriculum; 15 measures of financial aid; 16 measures of freshman major field choice; 4 measurements of place of residence; and, 57 different measures of student involvement (p. 15). Essentially, the main difference between Astin's studies (1993) and (1977) is the number of environmental measures that were utilized in 1993 study.

The 1977 study used longitudinal data with a sample size of more than 200,000 students and tested more than 80 different student outcomes. Moreover, it gave more attention to students" involvement applications such as "place of residence, honors programs, undergraduate research participation, social fraternities and sororities, academic involvement, student-faculty interaction, athletic involvement, and involvement in student government" (Astin, 1984, p. 524).

The data analysis of these studies involves two stages: 1) the data of each freshman is entering through multiple-regression techniques to get a predicted score on each outcome measure under study; and 2) compare predicted scores for each freshman characteristic in 
different college environments with the actual outcome measures. This study has one important limitation in that this study has no separate analysis according to "gender, race, ability, socioeconomic status, or other key students' characteristics" variables (Astin, 1993, p. 29). In other words, the "studies focus on individual programmatic interventions" (Terenzini, 2005, p. 1). Astin (1993) developed the Input-Environment-Outcome Model (I-E-O) as a conceptual framework to study college student development.

Inputs refer to the characteristics of the student at the time of initial entry to the institution; environment refer to various programs, polices, faculty, peers, and educational experiences to which the student is exposed; and outcomes refers to the student's characteristics after exposure to the environment. Change or growth in the student during college is determined by comparing outcome characteristics with input characteristics... studying student development with the I-E-O model provides educators, students, and policy makers with a better basis for knowing how to achieve desired educational outcomes (Astin, 1993, p. 7).

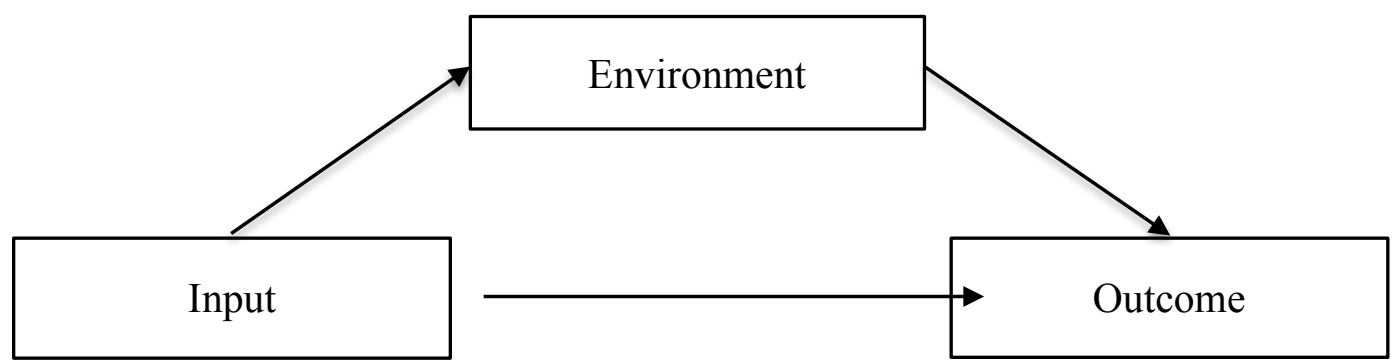

Figure 1: I-E-O Model. (Astin, 1993, p. 18)

Astin's study, Student Involvement: A Developmental Theory for Higher Education (1984), represented a development of his theory, the Theory of Student Involvement, which is found in student development research of postsecondary education during recent years. The theory dates back to a longitudinal study conducted by Astin in 1975, to identify the environmental factors impacting students' academic persistence (Astin, 1984). 
According to Astin, (1984), "student involvement refers to the amount of physical and psychological energy that the student devotes to the academic experience" (p. 518). Astin provides some examples of involvement practices such as study hard, engage in campus activities and student organizations, and interact with faculty. On the other hand, uninvolved is a term used to represent the opposite practices.

Furthermore, Astin defines the involvement concept as an active term in literature the student develops discipline, which expresses the following (e.g. attach oneself to, engage in, show enthusiasm for, take a fancy to, etc.). In other words, he defines involvement as a behavioral practice. The involvement theory also has five basic postulates:

1. Student involvement requires investment of psychosocial and physical energy.

2. Involvement is continuous, and each student, as an individual, has a different amount of energy.

3. Involvement can be measured qualitatively or quantitatively.

4. The quality and quantity of involvement is related to the amount of learning acquired.

5. Policy effectiveness depends on its capacity to stimulate students' involvement (Astin, 1984, p. 519).

In addition, Astin (1984), uses "black box" (p. 519) as a metaphor to describe academic practices toward students' treatment. Black box, according to Astin, contains various policies, programs, etc., and the black box outcomes are students' GPA, etc. Astin mentions a factor missing in academia is "how these educational programs and policies are translated into student achievement and development" (p. 520).

Additionally, Astin (1984) identified three implicit pedagogical theories, which can help policy makers, faculty, college staff, etc. to understand their actions and the impact on students' development. 
1. Subject-matter theory: Student learning and development depend primarily on exposure to the right subject matter. In practice, students receive knowledge from faculty or experts. In other words, a student could be considered an inactive participant, a follower- learner.

2. Resource theory: Different resources in one place to improve students' learning, e.g., physical facilities, human resources, financial resources. The crucial factor in this theory is student-faculty ratio, in which a lower ratio leads to better educational opportunity.

3. Individualized (or eclectic) theories: Each student can get an appropriate education according to his/her capacity. In other words, each student has a proper content fit to his/her needs (p. 520-521).

These three traditional pedagogical theories can help to recognize and provide a conceptual framework of the black box metaphor mentioned above. However, the involvement practices are missing in these three pedagogical theories, despite involvement's significance, which is considered "the driving force behind college student retention" (Mertes, 2013, P. 18).

Astin's (1977, 1993, \& 1984) studies have provided postsecondary education with several practical applications. For example, developing students' peer group programs plays an important role in improving students' performance (Reason, 2009). Astin (1993) concludes, "Every aspect of the student's development - cognitive and affective, psychological and behavioral - is affected in some way by peer group characteristics, and usually by several peer characteristics" (p. 363). Moreover, "the student's peer group is the single most potent source of influence on growth and development during the undergraduate years" (Astin, 1993, p. 398). In real life, students tend to embrace the dominant beliefs or 
values structured by their peers, which Astin and Panos (1969) called (progressive conformity).

In addition, Astin's model of Input-Environment-Outcomes (I-E-O) is used widely as a theoretical framework to study several issues related to first-year experience at postsecondary institutions. For example, the model is used to study students' retention, persistence, performance, and to design first-year initiatives such as seminar and orientation programs (Krahenbuhl, 2012). Kelly (1996) used the I-E-O model to identify relationships among inputs, environment, and student persistence as outcomes. This study found a statistically significant relationship between input and environment and students' persistence.

On the international level, Yanto, Mula, and Kavanagh (2011) used the I-E-O model for developing Students' Accounting Competencies (SAC). The study population was in Indonesian universities with a sample size 7,500 students. Yanto et al., "utilized student motivation, student previous achievement, student demographic characteristics, learning facilities, and comfort of class size are educational inputs, and student engagement and sac are proxies for environment and outcome respectively" (p. 1). This study reported that all inputs are statistically significant for improving SAC, with one exception, student demographic characteristics. However, this study found the I-E-O model valid to analyze relationships among a single input, but less powerful among multiple inputs.

Using the I-E-O model, Norwani (2005) studied the relationships among inputs, environment, and students' learning based on a final Grade Point Average (GPA) and aptitude development in Australian universities. Norwani found that student input statistically can be used to predict final GPA, while aptitude development was impacted by environmental factors.

Moreover, Astin's (1993) I-E-O model reported that learning communities are considered a significant factor to students' success and involvement. Numerous research 
studies support Austin's point of view about the role of learning community in students' development in general, and in first-year in particular.

Learning community has a high impact in the first-year college, with a strong positive correlation with students' retention, persistence, easiest transition, social and academic integration, develop personal relationship with faculty and students, develop personal habits, develop soft skills/hard skills (e. g., teamwork, collaboration, shared learning, engagement within community, problem solving, critical thinking, writing and reading skills), and improving graduation rate and grade (Bailey and Alfonso, 2005; Blackhurst, Akey \& Bobilya, 2003; Commander, Valeri-Gold, Darnell, 2004; Crissman, 2001; Dillon, 2003; franklin, 2000; Gold \& Pribbenow, 2000; Johnson, 2000-01; Kutnowski, 2005; Tinto, 2000; Walker, 2003). In contrast, some other studies reported no effect of learning community practices over time on students' performance; rather than applying learning community, improving communication strategies between students and their environment lead to better outcomes (Baker, Meyer, Hunt, 2005; Barrows \& Goodfellow, 2005).

However, MacGregor and Smith (2005) state that postsecondary institutions can use learning community practices to connect students and faculty with the institutional mission. According to Giles and Hargreaves (2006), transition toward a knowledge society requires schools to shift toward professional learning communities, because learning communities' applications will promote students' soft/hard skills (e. g., problem solving, systems-thinking, and social networks between society members including educational institution members).

However, despite Astin's theory contributions in the first-year student experience research studies field, his E-I-O theory has limitations. Despite its effectiveness as an assessment theoretical base to recognize the impact of student practices and behaviors, faculty, programs, and environmental components in general on student outcomes, Astin's theory is limited in terms of assessing organizational components impacting students' 
outcomes, e.g., organization culture context impact (Terenzini, 2005). Furthermore, Astin’s theory as a social science theory places emphasis on how involvement makes a difference on students' outcomes, but does not clarify why involvement makes a difference, nor does it illustrate how to help students who are not involved (Torres \& LePeau, 2013).

In short, Astin's (1977, 1993, \& 1984) studies conclude that students' involvement with their environment will lead to better learning. Designing educational programs with more focus on quality and quantity of involvement will lead to better learning. "The more students put into an activity, the more they get out of it" (Barefoot, 1998, p. 3).

Vincent Tinto Theory. Tinto authored a large number of studies in student development discipline. For example, Dropout from Higher Education: A Theoretical Synthesis of Recent Research (1975), which was cited by 4,994 researchers, according to Google Scholar. Tinto also authored Leaving College: Rethinking the Causes and Cures of Student Attrition $(1987,1993)$, which was cited by 8,289 researchers, according to Google Scholar. Tinto $(1975,1987,1993)$ introduces the Theory of Student Departure dominant sociological viewpoint and the common referred model of student retention/dropout literature (Draper, 2005; Kuh, Kinzie, Buckley, Bridges, \& Hayek, 2006).

Tinto's theory was based on the work of cultural anthropologist Arnold Van Gennep. Gennep focused on studying the movement of individuals from one group to another. Furthermore, Tinto's theory is influenced by Durkheim's Theory of Suicide (1951) and Spady's work Dropout from Higher Education: Toward an Empirical Model (1971) (Tinto,1987, 1993, 1988). Additionally, Tinto (1993) highlighted egoistic suicide to justify his relying on Durkheim's Theory of Suicide, which states "the individual is unable to become integrated into society due to values which may deviate from society, or from insufficient personal affiliation between the individual and other persons in society" (p. 102). Tinto explains that the student who is not integrated into college/university academically and 
socially will be at risk of dropping out (Roos, 2012). The theory takes from the educational economy discipline concerning the cost-benefit analysis of individual decisions regarding continuing/dropping out of his/her college (Tinto, 1975).

Tinto’s longitudinal model aims to elucidate the college student attrition process, and is related to Astin's involvement theory (Pascarella and Terenzini, 1991; Skipper, 2005). In addition, Tinto identifies two main paths of the theory of student departure: academic and social integration (Tinto, 1975, $1987 \&$ 1993). Academic integration means that students can meet college/university requirements and standards while embracing college values and beliefs. Social integration means the student feels he/she is part of society beliefs and norms on campus (Comeaux \& Harrison, 2011; Skipper, 2005; Stuart, Rios-Aguilar \& Deil-Amen, 2014). The term integration describes the extent to which a student "shares normative attitudes and values of peers and faculty in institution and bides by the formal and informal structural requirements for membership in that community or in the subgroups of which the individual is a part" (Pascarella and Terenzini, 1991, p. 52-53). The term integration can be defined as a negative or a positive connection between the student and academic or social system.

Tinto hypothesized three dimensions that influence student departure or retention: 1) pre-entry characteristics (e.g., family background, skills and abilities, prior educational experience); 2) goals and commitments; and 3) institutional experiences with academic systems (e. g., academic performance, faculty/staff interaction) and social system (e. g., extracurricular activities, peer interaction) (Tinto, 1975, $1987 \&$ 1993). The nature and power of integration determines departure decision. In other words, a student who could not achieve a level of academic or social integration is probable to leave the college/university. 


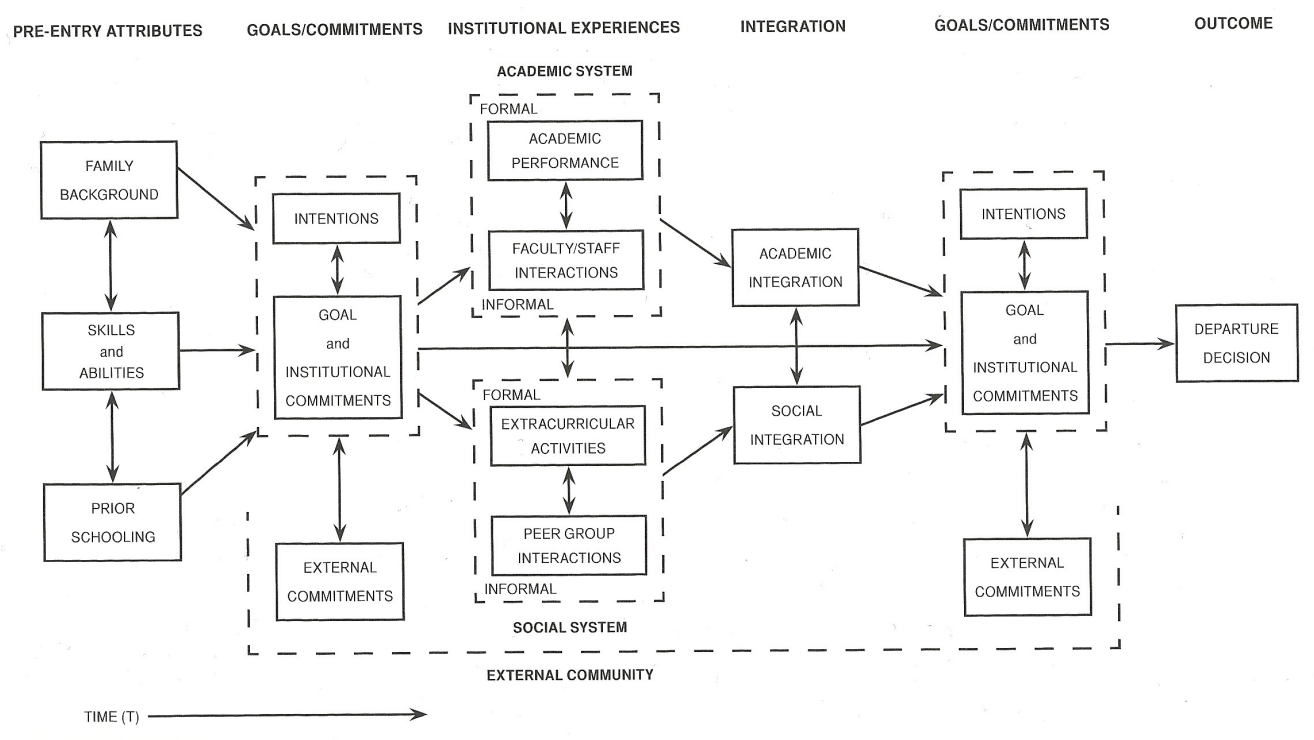

Figure 2: Tinto's longitudinal model of institutional departure. (Tinto, 1993, p. 114).

In 1988, Tinto introduces three stages of students' departure, Separation, Transition to College, and Incorporation in College. Separation stage means that the student requires separating himself from the past community and becoming involved in a new community (university community). This stage contains a difficult process, due to its nature and the relationship to the person's life, choices, belief, and attitude. Transition stage means the period of movement between the old communities to the new one. This stage requires the student to adapt and adjust himself with the new culture.

Tinto (1988) stresses that, at this stage, the student has not yet acquired new community norms and patterns of behavior; therefore, more support, either academic, social, financial, etc., is required to help the student be involved in a new culture. Incorporation stage means the student is ready to become a part of a new community. In other words, the student moved away from the old norms and behavior pattern to the new one.

Further, Tinto's identifies two main paths of the theory of student departure: academic and social integration (Tinto, 1975, $1987 \& 1993$ ). Academic integration means that students can meet college/university requirements and standards while embracing college values and beliefs. Social integration means the student feels he/she is part of society beliefs and norms 
on campus (Comeaux \& Harrison, 2011; Skipper, 2005; Stuart, Rios-Aguilar \& Deil-Amen, 2014). The term integration describes the extent to which a student "shares normative attitudes and values of peers and faculty in institution and bides by the formal and informal structural requirements for membership in that community or in the subgroups of which the individual is a part" (Pascarella and Terenzini, 1991, p. 52-53). The term integration can be defined as a negative or a positive connection between the student and academic or social system (Tinto, 1993).

Despite its popularity, Tinto's theory of student departure has come under a critical or developmental review in students' retention, persistence, and first-year experience field. Tinto's student integration model has changed over the last three decades from the first version that was introduced. For instance, a new variable such as motivation is included (Demetriou \& Sciborski, 2011). Several studies reported other factors outside of Tinto's model cause students to leave their college, such as student inability to adjust, economic and financial difficulties, lack of family emotional and social support, and poor academic performance (Bogard, Helbig, Huff \& James, 2011; De Witz, Woosley \& Walsh, 2009). For example, Tinto himself expanded the theory of student departure to include classroom activities as a variable of student departure. His study utilizes learning community practice as a tool to understand the relationship between classroom activities and retention. The study found that classroom activities in general, and learning community practice in particular, impact student's retention positively (Tinto, 2000).

To provide another example, in his book, Reworking the Student Departure Puzzle, Braxton (2000) dedicated two chapters for criticism of Tinto's theory, which resulted in development of a new theoretical path to recognize student departure factors. Braxton's framework suggests new variables that influence student departure such as socioeconomic and financial impact and tuition. Further, Braxton suggests that the campus climate and 
learning methodology also influence student departure. Moreover, Braxton discusses issues related to student race, color, and identity, which can affect student behavior and persistence.

Pascarella and Chapman (1983) have studied Tinto's theory validation in a multiinstitutional sample. Pascarella and Chapman illustrate three main problems related to the previous studies that tested Tinto's theory validation, as follows: 1) most of these studies focus on the operational variables of academic and social integration (e. g., studying the relationship between pre-college characteristics and student retention); 2) most of these studies were conducted in four-year residential institutions; therefore, more investigation regarding two-year institutions, or on commuter institutions is required; and 3) these studies in general utilized a single sample in one large university, which produces a generalization limitation.

Pascarella and Chapman's (1983) study was conducted on four different types of institutions: residential universities, liberal arts colleges, two-year and four-year commuter institutions. In general, this study supported the predictive validity of Tinto's theory with a comment that student characteristics have "the main-effects influence on persistence" (p. 25). However, Pascarella and Chapman use the concepts of persistence/withdrawal instead of retention concept in their study, despite Tinto (2010) distinguishing between two concepts.

Retention refers to the perspective of the institution. Institutions seek to retain students and increase their rates of institutional retention. By extension the term student retention refers to that process that leads students to remain within the institution in which they enroll and earn a certificate or degree. By contrast, persistence refers to the perspective of the student. Students seek to persist even if it may lead to transfer to another institution. By extension, the term student persistence refers to that process that leads students to remain in higher education and complete 
their certificate or degree regardless of the institution from which the certificate or degree is earned (p. 53).

Moreover, Rendón, Jalomo, and Nora (2000) criticized Tinto’s theory according to the issue of the non-white students variable. The purpose of their study was to; 1) provide a critical analysis of Tinto's theory with a specific focus on the separation and transition stage mentioned earlier; 2) critique Tinto's concepts of academic and social integration; and 3) provide some recommendations to develop Tinto's theory into a higher level of student development research (p. 131).

Rendón et al. (2000) sees the separation stage of Tinto's theory as utilizing a negative interpretation of a native culture, which requires a student to abandon his/her culture and embrace the new culture of institution or community to be integrated socially or academically. Rendón et al. state "The assumption made is that an individual's values and beliefs rooted in his or her cultural background must be abandoned to successfully incorporate the values and beliefs not only of the institution but of the majority population upon which they are based" (p. 132).

To overcome this issue, Rendón et al. (2000) offer a concept of "Biculturalism” (p. 133 ) in where the student can move between two or more cultures that are separate and diverse. In fact, understanding student ability to fit between and within two cultures is important, especially for the first-year students. Therefore, "culture translators, mediators, and role models become critical to the socialization process" (Skipper, 2005, p. 72). However, moving from theoretical perspective to practical action, Tinto (1993) suggests action principles for development of retention programs:

1. Postsecondary institutes require providing adequate resources to develop intervention programs. 
2. Postsecondary institutes are obligated to plan a long-term process to develop and adjust these programs according to students' needs and institutional mission.

3. Postsecondary institutes that plan such changes are required to identify and allocate tasks and responsibility across the campus to implement that change.

4. Postsecondary institutions require coordinating efforts to insure a systematic campuswide approach to achieve retention goal.

5. Postsecondary institutes require insuring that faculty and administration staff members have the necessity skills to teach and assist students.

6. Postsecondary institutions require giving more attention to student retention issues.

7. Postsecondary institutes require focusing more on assessment of its process and actions about retention programs for development purposes.

In sum, Tinto's theory provides a wide understanding of student retention issues and includes suggestions to improve student retention. Moreover, Tinto's theory provides a new perspective about factors and variables that can influence students' persistence and retention. For example, new perspectives emerged as a result of applying Tinto's theory in different contexts such as economic, cultural, psychological, organizational, social perspectives, especially for the first-year student. Furthermore, Tinto's theory stresses that developing and implementing a comprehensive student retention program requires a commitment from university/college leaders, faculty, and staff.

Pascarella and Terenzini Theory. Pascarella and Terenzini have conducted a comprehensive analysis of student development research, for example, How College Affects Students: Findings and Insights from Twenty Years of Research (1991), and How College Affects Students: A Third Decade of Research (2005), which were cited by 9,020 researchers, according to Google Scholar. 
In a longitudinal analysis of how college affects students, Pascarella and Terenzini (1991, 2005) have conducted an exhaustive review of the literature on first-year students using variables such as GPA, retention, graduation and self-reported student satisfaction (Jamelske, 2009). The purpose of these studies was to answer the following questions, "Do students change in various ways during the colleges year? To what extent are changes attributable to collegiate experience and not to other influences (like growing up)? And finally, what college characteristics and experiences tend to produce change?" (Pascarella and Terenzini, 1991, p. xvi-xvii). These studies attempted to answer six research questions:

1. What is the evidence that individuals change during the time in which they are attending college?

2. What evidence exists to indicate that change or development during college is the result of college attendance?

3. What is the evidence that different kinds of postsecondary institutions have a different influence on student change or development during college?

4. What evidence exists on the effect of different experiences within the same institution?

5. What evidence shows that the collegiate experience produces conditional, as opposed to general, effects on student change or development?

6. What are the long-term effects of college? (Pascarella \& Terenzini, 1991, p. 7-8). To answer these research questions, Meta-Analysis methodology was utilized to synthesize research findings. In the first version of their study, Pascarella and Terenzini (1991) conducted a search covering the period, 1969-1980, by reviewing about 2,600 studies, representing 1,300 studies per decade. In the 2005 research, the number of studies increased to 2,400 studies during ten years in the 1990s (Pascarella, 2006). 
Chapter Two of Pascarella and Terenzini (1991) study; Theories and Models of

Student Change in College helps to clarify the difference between change and development terminologies. "Change refers to alternations that occur over time in students' internal cognitive or affective characteristics" (p. 16). Moreover, change can be measured quantitatively or qualitatively. "Development on the other hand, has generated considerable philosophical and theoretical debate among psychologists, sociologists, and others for some time" (p. 16).

Pascarella and Terenzini (1991, 2005) classified two families of theories and models of student change and developed directed college impact studies in the last three decades. The first family category, Developmental Theories, involves psychological aspects of human growth, or in other words intra-individual development. The second family category, College Impact Models, regularly focus on "the environmental or sociological origins of student change" (p. 17). Some examples of this family of theories are Astin $(1985,1993)$, Tinto (1993), and Pascarella (1985) models and theories.

The College Impact Models family category emphasizes environmental factors that change or develop one or more student aspect (e. g., academic aptitude, performance, socioeconomic, race. etc.) and on structural and organizational aspects (e. g., size, policy, administration, etc.) Pascarella and Terenzini (1991, 2005). In other words, "how does the environment of the college or university affect the student's development? How do the background and individual characteristics of the student foster or impede development?" (Long, 2012, p. 51).

Pascarella and Terenzini $(1991 ; 2005)$ identified four clusters of theories and models of student change in college:

1. Psychosocial theories (e. g., Erikson theory, Arthur Checkering theory, Cross's model of Black Identity Formation, etc.). 
2. Cognitive-structural theories (e. g., Jean Piaget theory, Perry's Scheme of Intellectual and Ethical Development, Kohlberg's theory of Moral Development, etc.).

3. Typological models (e. g., the Myers-Briggs typology, etc.).

4. Person-environment interaction models (e. g., Physical model, Human Aggregate model, Perceptual model. etc.).

In 1985, Pascarella suggested a general casual model to understand student change in college. The General Model for Assessing Change emphasizes two dimensions: an institution's structural features/organizational characteristics and its environmental factors. In detail, Pascarella's model comprises five clusters for assessing college student change: 1) student background and precollege characteristics (e. g., aptitude, achievement, etc.); 2) organization structure and characteristics (e. g., selectivity, faculty-students ratio, etc.); 3) clusters $1 \& 2$ together shape cluster 3 , which consists of college environment; 4) the three clusters impact student interaction with campus components including peers, agents of socialization, etc.; and 5) cluster 5 is shaped by the quality of student effort, which is also shaped by student background and interaction with environment (Moon, Sullivan, Hershey, Walker, Bosangue, Filowitz, Fernandez, Unnikrishnan, and Delgado, 2013). Pascarella's model assumes that student learning and cognitive development is impacted directly and indirectly by institutional characteristics and environment (Pascarella and Terenzini, 1991, 2005).

Despite the efforts to classify theories and models of student change in college, Pascarella and Terenzini $(1991,2005)$ admitted that "the important lesson is to understand what the constraints are on any approach and to bear in mind that reliance on developmental models may lead to misspecification of the origins of student change and growth" (p. 49-50).

Finally, in their article: Studying College Students in the 21st Century: Meeting New Challenges, published in 1997, Pascarella and Terenzini state that "the knowledge base for 
How College Affects Students permitted us to draw conclusions about a population of students that no longer dominates American postsecondary education” (p. 2).

Ironically, just as analysis of the experiences of college students reached an apex in terms of quantitative technique and vigor," the population of interest began shifting.

Now at the end of the two decades, our college campuses are no longer predominantly populated by the students described in this book" (Educational Research, Stage 1993, p. 22) as cited in (Pascarella and Terenzini, 1997, p. 2)

This conclusion gives an insight about the necessity of studying these theories and models in a different cultural context such as Saudi postsecondary education. Moreover, the fact of student change may make postsecondary institutions reconsider before transferring first-year programs or experiences from one culture to another under the best practices title, without sufficient knowledge about students' needs. However, Pascarella and Terenzini statement supports the current study goals to recognize first-year students and other stakeholders' needs in preparatory year program.

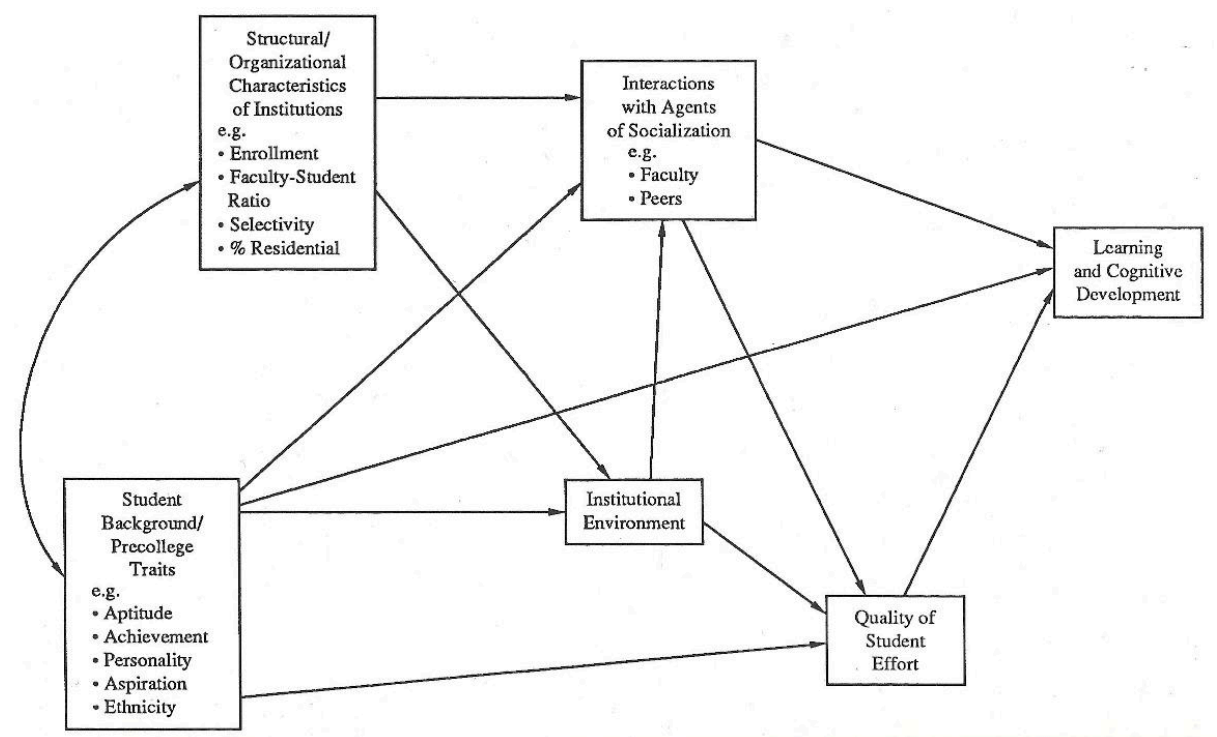

Figure 3: The General Model for Assessing Change. (Pascarella and Terenzini, 1991, p. 54).

In 2005, Terenzini and Reason argued that most student development theories or models provide theoretical illustrations of student and faculty behaviors, attitudes, and 
cultures. However, it doesn't explain the influence of organizational structure and characteristics on student outcomes. One notable exception, Berger and Milem Model (2000), suggests that organizational structure and characteristics (Internal Organizational Features) impact students' college experiences directly or indirectly. An example is university/college curricular structure, financial issues, educational policies, faculty recruiting, selectivity, etc.

Therefore, Terenzini and Reason (2005) proposed a new framework to identify the nature and dynamics of factors that impact first-year college experiences. The new framework is best classified in the second family of student development theories and models “college impact model” (p. 2), despite its diversity of components between psychology and social psychology theories, cognitive development theory, and the Foundations of Excellence $^{\circledR}$ of two years postsecondary institutions. Terenzini and Reason's (2005) model assumes that students come to college with diverse backgrounds, including experiences, knowledge and skills (academic and social background) that prepare him/her to become involved with the numerous formal and informal learning opportunities offered by his/her institution. Moreover, student interaction with the institution's environment will shape his/her experience and reflect on his/her learning.

The model has three main factors that impact student learning; college/university internal organization context, the peer environment, and student experiences. However, the Terenzini and Reason (2005) model relies on different theoretical components including Foundations of Excellence ${ }^{\circledR}$ of two-year postsecondary institutions. Therefore, applying such a model to four-year postsecondary institutions requires more study to check its validity in the research university. Due to the current study's focus on the four-year research university, a short description of the model is provided. 


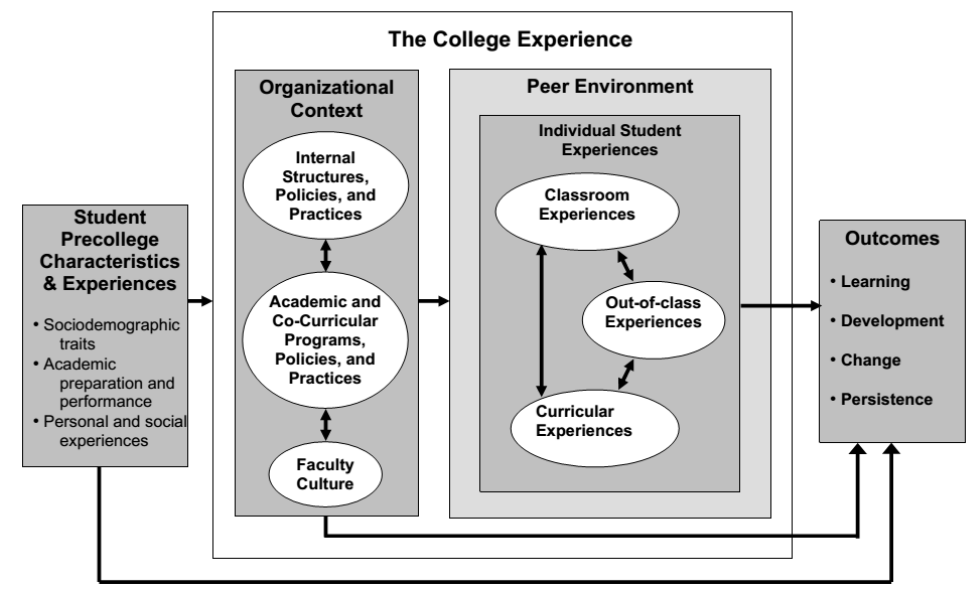

Figure 4: A comprehensive model of influences on student learning and persistence.

(Terenzini and Reason, 2005, p. 21).

Chickering's Theory. The first outline of Chickering's theory was in his book, Educational and Identity (1969), which focused on studying the college environment's impact on the development of students. In 1993, Chickering revised the theory by including new variables as follows: 1) merging research findings on student development such as gender, race, etc. into his theory; 2) including new resources students have in their college such as specialists, finance aid, etc.; 3) adjusting the theory to fit students age and to also include adult learners; and 4) introducing an alternative definition of seven vectors of his theory. Thus, Chickering and Reisser (1993) revised the theory (Evans, Forney, \& GuidoDiBrito, 1998; Rode \& Cawthon, 2010). In fact, Chickering and Reisser's (1993) work relied on Pascarella and Terenzini's research (1991) mentioned earlier in this section (DeVilbiss, 2014).

Chickering mentions that the big challenge encountered by college students is establishing their identity (Rode \& Cawthon, 2010). Chickering (1969) states "because each seems to have direction and magnitude.... even though the direction may be expressed more appropriately by a spiral or by steps than by a straight line" (p. 8) as cited in (Rode \& Cawthon, 2010, p. 37-38). 
In this context, Chickering and Reisser (1993) illustrate that a person's environment, culture, and background impact the ways he or she will deal with future issues or tasks. Therefore, Chickering and Reisser (1993) introduce seven vectors or developmental tasks that contribute to build student identity. The vectors are described as "maps to help us determine where students are and which way they are headed" (p. 34). According to Rode and Cawthon (2010) "vectors built on each other, leading to greater complexity, stability, and integration" (p. 14). In other words, each vector has its own direction and measure.

According to Chickering and Reisser (1993), the seven vectors are as follows: 1) developing competence, which includes intellectual (e. g., knowledge and skills acquisition), interpersonal (e. g. communication, leadership, and teamwork skills), and physical (e. g., through athletic and recreational activities); 2) managing emotions (e. g., anxiety, depression, shame, caring, optimism, and inspiration); 3) moving through autonomy toward interdependence; 4) developing mature interpersonal relationships (e. g., tolerance, respect differences, empathy); 5) establishing identity (e. g., self-esteem, self-concept); 6) developing purpose (e. g., personal interest in future plan, commitment behavior toward study or family); and 7) developing integrity (e. g., values and responsibility behavior).

Chickering and Reisser (1993) argue that the educational environment has a high impact on student development. Chickering and Reisser proposed seven main educational factors that play an important role on students' transitions:

1. Institutional goals. The clarity of university/college objectives will shape its policy, programs, and practices.

2. Institutional size. The number of students plays a crucial role on the amount of development that each student can receive. 
3. Student-faculty relationship. Chickering and Reisser (1993) suggest that a student needs to deal faculty in different situations, which make student-faculty interaction effective and useful for student.

4. Curriculum. An appropriate curriculum is needed, which meets student needs and differences.

5. Teaching. Timely feedback, an appropriate interaction between student-faculty, uses different teaching methods such as learning collaboration, etc.

6. Friendship and student communities. Involvement in community, either formal or informal, helps students develop personal skills such as collaboration, teamwork, confidence, etc.

7. Student development programs and services. Chickering and Reisser suggest a collaborative effort between academic and student affairs to design ideal services and programs to fit students' needs.

Some research studies have been conducted to check the validity of this theory. For example, on women's development, Taub and McEwen's (1991) study found that “women's development differ from men's, particularly regarding the importance of interpersonal relationships in fostering other aspects of development" as cited in (Evans, Forney \& GuidoDiBrito, 1998, p. 46). As well, some studies demonstrate a critique for the theory. For example, Evans et al., 1998 sees vectors definitions as quite general, and state "it lacks specificity and precision" (p. 51). Moreover, Rode and Cawthon (2010) suggest that it is better for researchers to focus on one or two vectors rather than all of the vectors in one study and use qualitative research methodology to test theory validation in terms of psychosocial development.

In summary, Chickering's theory or identity development theory is often a favorite option of the student affairs community (DeVilbiss, 2014). The seven vectors of theory can 
be used as categories for student development issues mentioned earlier in this chapter, especially the issues related to first-year students, or in other words, related to students in transition. Examples include, 1) developing competence; 2) managing emotions; 3) moving through autonomy toward interdependence. These three vectors manifest usually in the firstyear students as other studies show earlier in this chapter (e. g., Evans, Forney, \& GuidoDiBrito, 1998; Gardner, \& Barefoot, 2005; Pascarella \& Terenzini, 1991; Tinto 1975, 1993; Upcraft \& Gardner, 1989)

Overall, this section of literature review discusses the most common student development theories that have a relationship to first-year student experience and how these theories can be applied to help to restructure first-year programs. Astin's $(1977,1993)$ involvement theory or I-E-O model describes the importance of an interaction between the student and educational environment. Increased interaction will lead to more involvement and learning. Moreover, Astin suggests learning community as a perfect strategy to help firstyear students become involved in university/college environment.

Pascarella and Terenzini Theory $(1991,2005)$ discuss student change in college. They suggest that much interaction between the student and his or her university environment will lead to better learning. Furthermore, the theory is revised to align with the Foundations of Excellence $^{\circledR}$ dimensions to be more practical.

Tinto's $(1975,1987,1993)$ student departure theory or the retention theory represents a new perspective about factors and variables that can influence students' persistence and retention. Tinto's theory also examines factors that effect student learning in the first-year. His investigation found different variables that can impact student decisions about continuing or leaving their college. These variables include economic, cultural, psychological, organizational, social perspectives. Tinto called for the necessity of implementing a comprehensive student retention program at colleges. 
Chickering's (1993) Theory, or the identity development theory, is a practical tool for the student affairs division at any college, providing practical categories for student development transition issues through the seven vectors theory. Finally, we can observe that these theories and models attempt to understand how students change in college or how college affects students? Each theory built on the previous one or on part of it. Moreover, each theory could be utilized to deal with part or all of first-year challenges. Understanding these theories and their applications will help to understand and analyze content analysis outcomes of this study. As this study is qualitative in nature it requires deep understanding of the first-year and students"' success theories to illustrate the current practices of Preparatory Year Programs in Saudi public universities.

\section{The First-Year Experience}

First-year is a critical period of transition into postsecondary education. Besides, firstyear is "not grade 13" (Hunter, 2006, p. 4) where the student usually relies on his/her teacher to direct him/her to do school work. The university study requires the student to be more responsible and commit toward his/her study and future. Therefore, the events happening at this period of transition between high school and university and during the first-year of college will affect students' success positively or negatively in coming years (Gardner, 1998; Raymond \& Napoli, 1998; Soldner \& Duby, 1999; Tinto, 1996; Upcraft \& Gardner, 1989; Upcraft \& Gardner, 1989; Upcraft, Gardner, \& Barefoot, 2005). On the other hand, despite the postsecondary institutions commitment to support students to earn their degrees and achieve their goals, postsecondary institutions are a business, which has high interest in its graduate quality and retention rate (Curtis \& Harte, 1991; Johnston, 2010).

According to Upcraft and Gardner (1989), postsecondary institutions should embrace ten beliefs to help first-year students be successful. These beliefs are as follows: 1) institutions have an obligation to support and enhance the first-year students, 2) institutions 
can intentionally and successfully help first-year students to achieve their academic and personal goals, 3) involvement is the key to success of first-year students, 4) help first-year students to engage with others such as faculty, students, etc., 5) institutions should take into account the diversity issue such as racial, cultural, ethnic, etc., 6) dignity and respect is a basis of student treatment, 7) establishing deliberate goals for first-year students, 8) ensuring an institutional commitment to enhance first-year student success, 9) utilizing the Freshman Seminar to improve student success, and 10) necessity of faculty involvement (p. 4-5). In their first-year college, students learn the language and culture of their institution. They develop minimally successful study skills. They also develop certain attitudes towards faculty. A student's attitude towards faculty is an important indicator as to whether or not a student will be retained (Gardner, 2007).

In this context and for better understanding of first-year students, this section of literature review will illustrate first-year experience in detail to recognize first-year history, issues, organizational structures and functions, and the first-year experience from an international perspective.

The History of First-Year Experience Concept. The concept of first-year has historical roots, beginning with the "freshman" concept, which has gradually been replaced by the term, "first-year student," at colleges and universities. In 1998, the concept of FirstYear Experience and Students in Transition was introduced by the University of South Carolina's National Resource Center (Watts, n.d.).

Historically, the first use of the freshman concept dates back more than 800 years ago, when the first Italian young men went to Bologna in the twelfth century for study (Dwyer, 1989). Freshmen students were responsible for organizing the lecture and examinations schedule. In France, in the "renaissance" (p. 26) era, the famous liberal arts teachers tried to attract some freshmen to come to Paris. These students' parents encouraged their sons, 
especially boys who were between thirteen and sixteen, to join the nearest universities.

Dwyer noted that, the renaissance era created an undergraduate curriculum that was used until the middle of nineteenth century in Western higher education.

During that time, students who engaged with university at those early ages lived with the other first-year students in a dorm or "hall" (p. 26). The dorm was managed by freshmen students themselves, or by the oldest students, or by a master. In addition, students were required to attend some lectures and select courses as a prelude to choosing a teacher (Dwyer, 1989). At the beginning of their arrival at university, the older students looked at a freshman as a "victim" (p. 27) upon arrival, but then welcomed the freshman later. In addition, the university celebrated new students in a ceremony called "depositio" (p. 27) as a part of a semiofficial university function. This celebration was conducted to celebrate the new arrivals; however, freshmen "might be subject to discrimination" (p. 27).

In Europe during the fourteenth and fifteenth centuries, universities required students to register for some courses that helped them to adjust to university life and manage personal affairs. According to Dwyer (1989), freshmen could register for "Ars Dictaminis, or business Latin" (p. 28) courses to learn how to draft a letter or document. After completing these courses, each freshman started to study subject by subject with his master until the master determined the student's readiness for the next level of study. Dwyer (1989) points out that, at this phase of study, students can take notes, memorize and retrieve information, work in groups, and engage in public debate. When approved by the master, freshmen became eligible to be a "sophister" (p. 28), which means "sophomore, in English universities later" (p. 28).

In the sixteenth century, the new technology of printing increased the availability of books especially for freshmen, which provided more opportunity for students to access printed educational resources. In 1550, the concept of first-year manifested in the English 
language to describe a new novice in any field of work, and in 1590 was used officially in English universities to describe new students (Dwyer, 1989, p. 28). In 1638, the new Harvard College in North America used the concept of freshmen for the first time (Dwyer, 1989).

Because those students in 1638 were the first group of students at Harvard and there were no sophomore students, they struggled to adapt to their masters. Harvard also created "freshmen counselors" (p. 30), which established the first system to help students' transition into college.

Dwyer (1989) mentioned that Harvard empowered its freshmen to get grants for doing some work such as serving the college, taking care of the college bell, etc. These tasks paved the way to appoint the first "President's freshman" (p. 30). Ralph Waldo Emerson was the first appointed to this position in 1817. In 1655, Harvard College raised admission criteria for freshmen, whereby students were required to have Latin speaking, reading, and writing skills. The admission process was changed, with an entrance exam conducted by Harvard's president (Dwyer, 1989).

In 1735, Harvard College invented "the College Customs" (Dwyer, 1989, p. 31), and assigned freshmen advisors. The College Customs document contained a series of ethical and educational statements, and sophomore students were required to read it publicly for freshmen. Later, Harvard's faculty opposed the College Customs because they thought it was unsuccessful and replaced it with the first protection record of freshmen, which outlined the freshmen students' rights and responsibilities (Higgins, 2010).

Despite the spread of freshman culture and initiatives, Dwyer noted that some freshmen at some universities were still suffering for their rights. For example, at some universities, freshmen were responsible for cleaning rooms and building the fireplace, while in other universities, they were not permitted to use a library. 
In the nineteenth century, an educational development movement unfolded in secondary and postsecondary education, which caused universities and secondary schools enrollment numbers to expand and the student bodies to become more diverse. During that era, admission policy and standards changed to be more "selective" (p. 32). Further, universities such Harvard required pre-courses for their freshmen such as mathematics. The secondary schools tried to prepare students for college, especially after the movement to standardize curriculum and teaching. Dwyer noted that the most important feature of that era is faculty involvement with freshmen, through which they tried to improve freshmen life. For example, faculty arranged "freshmen week" (p. 33). Additionally, in 1889 Harvard established "A Board of Freshman Advisors" (p. 33), which was responsible to take care of freshman affairs such as students' support out of the classroom, to provide an orientation plan for new students, arrange social events, and provide advice to help freshmen become more independent (1989).

The Board of Freshman Advisors realized that freshmen advising and orientation are necessary to help students transition into college because transition phase students encounter difficulties making correct decisions, understanding the campus environment, and are often missing required skills for college (Higgins, 2010). Higgins noted that the Board of Freshman Advisors at Harvard identified three main principles for orientation of freshmen: 1) students need guidance rather than only specific instruction, 2) students need a support system regarding choices and skills to make correct decisions, and 3) students need more support from faculty to ensure success (2010).

One of the important features of nineteenth century education is that women newly participated in higher education as freshmen students, such as "the seven sisters" (Dwyer, 1989, p. 33) at Mount Holyoke College in 1837, which is considered the first group of women in postsecondary education in the United States. According to Dwyer, "Freshman 
women there were more members of a city community than a college campus" (p. 34). In other words, freshmen women were not subject to campus restriction or specific rules or direction such as males.

In the twentieth century, higher education functions were changed due to changes in social culture, the industrial revolution, need for qualified laborers, and emergence of new variables, especially among freshmen diversity, identity, behavioral problems, technology revolution, etc. (Dwyer, 1989). Dwyer divided freshmen development during the first half of the twentieth century into two stages: 1) "the freshman as parishioner" (p. 35), in which freshman learned from directions that were outlined by the university. Freshman were also required to learn time management and some soft skills, and 2) the freshman under the "microscope" (p. 35), in which freshman studies concentrated on problems encountered by freshman such as identity, curriculum adjustment, financial problems, beliefs, culture, religion, and successfully transitioning into college.

During the second half of twenty century, freshman research studies further evolved, with new methods invented to help freshman. For example, General Alarm was a new system utilized to indicate students' needs or problems at many universities. Universities developed a more involved role to better provide students required tools for adjustment (Higgins, 2010). Additionally, mid-century freshmen research studies indicated that freshman students have different problems and needs. For example, some need guidance; others need counselor or social support, while some need information that helps with adjustment to university life (Dwyer, 1989). In short, Dwyer identified two services that can help universities or colleges provide support to first-year students as they transition to postsecondary education: 1) consular system, and 2) orientation programs.

The expression "freshman" is gradually replaced by the term, "first-year student," at colleges and universities. In 1998, the concept of First-Year Experience and Students in 
Transition was introduced by the University of South Carolina's National Resource Center (Watts, n.d.). In the last twenty years, the first-year discipline received large-scale interest by scholars and postsecondary institutions. In their preface to Challenging and Supporting the First-Year College Student, Upcraft, Gardner, and Barefoot (2005) highlighted the most important first-year accomplishments in the last twenty years. To illustrate a few examples, colleges and universities:

1. Increased campus-wide, national, and international conversation and action about the first-year of college.

2. Introduced more initiatives designed to help first-year students succeed, for instance, more flexible and varied first-year seminars, more comprehensive development educational programs, etc.

3. Expanded research and scholarship on the first-year of college, for example, Pascarella and Terenzini (1991) How College Affect Students, Astin (1993) What Matters in College?, and Tinto (1993) Principles of Effective Retention. The contributions of these scholars and others provide better understanding of students' characteristics, assessment and development tools of first-year, and more approaches to help students to transition into colleges successfully.

4. Developed closer collaboration between academic affairs and students affairs.

5. Integrated technology into first-year initiatives.

6. Included diversity in first-year initiatives as a permanent feature of the first-year student landscape.

7. Made the classroom central to efforts to promote first-year students' success (p. 2-7). Moreover, Upcraft, Gardner, and Barefoot (2005) mentioned some challenges encountering first-year experience movements. For instance:

1. There is no consensus about a clear sense of purpose in the first-year. 
2. Building first-year initiatives that are responsive to today's increasingly diverse students is still a challenge.

3. The link from research and assessment to policy and practice is still weak.

4. Institutional efforts to help first-year students succeed are still not sufficiently integrated.

5. Efforts to help first-year students succeed are too often focused on retention rather than students learning.

6. First-year students' out-of-class experiences are still a double-edged sword (p. 2-7).

Besides, Upcraft et. al. outlined some important issues encountered by students as they transfer from secondary to postsecondary education. For example, discovering identity, determining self-concept, making decisions about future careers, building interpersonal relationships, developing academic competency, and developing responsible behaviors, beliefs, and spirituality.

Despite these developments in first-year, Skipper (2005) mentions "many institutions already design and deliver interventions that assist students in resolving these and other tasks in the first college year and beyond, but these programs are frequently divorced from the student's classroom experiences and intellectual development" (p. 5). Barefoot (2004) states "Campuses have lacked any systematic, valid definition of, or standards for, first-year excellence that go beyond a single best-practice program to a broader characterization of a campus's total approach to the first-year" (p. 5).

Overall, this study will establish a new scientific context of first-year within Saudi postsecondary education and may result in new or similar functions of preparatory year with respect to the international level.

First-Year Experience Issues. "Where am I now, what am I doing, what has my schooling prepared me to do?" (Johnston, 2010, p. 1). Comments and questions about 
students' first-year were shared at most postsecondary institutions. These questions and others required clear answers and support to make students transition successfully into university/college. Thus, Johnston states that each student has his or her own perception of first-year transition, which can have an effect on his/her academic future and life.

The positive common characteristics of new first-year students include high skills and knowledge to use technology, a trend toward social work and team activity, ability to access and acquire information, focus less on school work and emphasize future career plan, improve familial/parental involvement, and passion to learn more with high expectations (Keeling, 2003; Newton, 2000). However, several issues and challenges related to students' transition into postsecondary education still exist (e.g., Astin, Oseguera, Sax, \&Korn, 2002; Bauer \& Liang, 2003; Crissman Ishler, 2005; Gordon \& Steele, 2003; Howe \& Strauss, 2000; Johnston, 2010; Pryor, Hurtado, Saenz, Lindholm, Korn \& Mahoney, 2005). For example:

1. Cultural barrier: students move from high school or familiar cultural environment to university or a more diverse cultural environment. Furthermore, students' move from theoretical fields to professional fields.

2. Personal change: some students feel academic disengagement, decreased social activism, difficulty understanding his/her capacity (self-assessment), weak decisionmaking skills, especially about his/her major, and lack of some life skills. Personal change has a direct effect on performance of first-year students.

3. Increase in emotional and mental health disorders among new students, either male or female.

4. Family background, type of relationship between students and his/her parents, some come from divorced family, and some are first generation students.

5. Increase in university cost and decrease in financial aid.

6. Number of students with disabilities, who require more attention. 
7. Finally, Gender differences involving different needs.

Alexander, Garcia, Gonzalez, and Grimes (2007), conducted a study to identify barriers in the transfer process for Hispanic and Hispanic immigrant students. This study is determined several barriers encounter such students: 1) economic difficulties; 2) culture barrier on two levels; engagement with dominant white students' body and norms that do not support women in higher education; 3) lack of family and students awareness about postsecondary education importance and values; 4) lack or no English language or life skills; 5) no preparation courses prior university enrollment; and 6) lack or no support from faculty and administration staff for those students.

Furthermore, Upcraft, Gardner, and Barefoot (2005), in their book, Challenging and Supporting the First-Year College Student, identified several developmental matters encountered by first-year students. For example, discovering their identity, making a decision regarding future career, developing civic obligation, emerging intellectual feeling, promoting a confident feeling in academic competence, and developing beliefs, faith, and spirituality.

Erickson and Strommer (2005) conducted a study to recognize the issues that are encountered by first-year students inside the first-year classroom. Erickson and Strommer classify the most common problems in first-year classroom as four categories:

1. Academic preparation, in which a number of high school graduates are not ready for college academically, especially in English, science, math, writing skills, etc.

Moreover, most of those students have no experience about the nature of studying in college, in which students' need to spend more time for study and doing assignments. In addition, some academic skills such as taking notes, summarizing content, participating in classroom activities, etc. are missing.

2. Expectations and motivation for learning, in which some students have course expectations higher or less than his/her capacity. These expectations are the result of 
his/her perception about college or coursework, correlated to his/her motivation to study. Thus, establishing a positive relationship with faculty or academic adviser will help a student to recognize his/her aptitude and manage his expectations, while improving his motivation to learn.

3. Learning style. First-year classroom experience differs; for example, students come from high school with different backgrounds, and teachers are responsible to guide students to do tasks/assignments, according to specific steps. Furthermore, each student has a different learning style and he/she may prefer a specific way of teaching. Therefore, faculty is required to recognize student diversity and to design learning activities in a way that ensures all students can participate and engage in classroom community.

4. Stage of intellectual development. Erickson and Strommer state "students also differ in their stage of intellectual development... with some significant differences for women" (246). This research fact suggests that teaching students who are in different stages of intellectual development require using various teaching methods. According to Studdert (2013), utilizing supplemental instruction or peer-assisted support programs, academic advising, learning community to share experiences, and participation in service learning to enhance civic responsibility will help to overcome these challenges and problems.

Other challenges and problems of first-year students are outside of the classroom. For example, first-year residential environments must facilitate and develop an interaction between students themselves, between students and faculty, and students and the external community. Moreover, the learning environment such as the library should be comfortable and facilitate learning. Finally, development of some social activity to promote student 
engagement in society, promote student diversity, and working part time on campus (Astin, 1993; Pascarella \& Terenzini, 1991).

Mullendore and Banahan (2005) see orientation programs for student and their family as an effective solution to overcome previous challenges. Moreover, Mullendore and Banahan provide several recommendations for an effective orientation program, for example:

1. Develop and support an orientation process that continues at least throughout the first semester.

2. Develop an orientation program that introduces and reflects the mission and goals of the institution.

3. Balance between technology utilization and person-person interaction.

4. Encourage collaboration between student affairs and academic affairs in the orientation program.

Some other issues are related to gender. Christensen (1990) found strong correlation between gender and retention (as cited in Ishler \& Upcraft, 2005). Hill and Sedlacek's (1995) study on male and female first-year students found that men are more interested in improving their academic skills than women. On the other hand, females are more interested in receiving counseling about educational vocational concerns and emotional/social issues. Perrine's (2001) study, College Stress and Persistence, which was focused on first-year students, found that females demonstrated more stress than males, and the attrition rate is higher as well. Perrine recommended that an intervention program is required at this stage of college before students become stressed.

This conclusion supports the need for developing first-year intervention programs with more attention to gender issues, taking into account that females have different needs than males. As Preparatory Year deanship at King Saud University provides male and female students with one content program, this may require redesigning a program to fit their gender 
needs. The current study will provide information regarding both male and female perceptions about first-year program at King Saud University.

Barefoot (2000) in her article, The first-year experience: Are we making it any better?, stresses the necessity of continuing to recognize the new challenges that affect students' transition and enhance the first-year programs and initiatives, with more focus on factors that influence students' future work during first-year. In addition, postsecondary institutions need to create flexible solutions that can respond to the diversity of students, to promote their learning, and to make their transition experience successful, while improving persistence and retention through systemic efforts with an appropriate pedagogy fitting local culture and supporting international trends (Johnston, 2010).

In summary, this section shows the most important issues related to first-year students and mentions some first-year solutions that can be utilized to overcome these issues or reduce their impact on students' development. Therefore, understanding students' problems and needs prior to establishing or developing first-year programs is crucial.

The First-Year Experience: An International Perspective. Outside the United State of America, first-year experience and students in transition topic has high interest (Nutt \& Calderon, 2009). In the United Kingdom, Yorke's (1999) research about the students' departure and postsecondary institutions roles in this phenomenon had a significant output to shape first-year researches in the UK. Furthermore, Yorke and Longden (2007) conducted a study across UK's postsecondary institutions to identify first-year initiatives and programs. These studies provided insights about the critical factors that influence first-year programs in the UK (Nutt \& Calderon, 2009).

In Australia, the McInnis, James, and Hartley (2000) study contributed positively to disseminate first-year culture across the country. Moreover, it directed first-year research toward specific issues related to student transition, retention, persistence, and to develop 
English aptitude of student who has such problem. Furthermore, Krause, Hartley, James, and McKinnis (2005) conducted a longitude study to explore first-year movement during 10 years in Australia. This study directed research toward specific issues of first-year as well (Nutt \& Calderon, 2009).

In 2009, the European First-year Experience Conference took place in Groningen in the Netherland. Numerous researchers from several countries participated in the conference, e. g., Belgium, Denmark, the Netherlands, and Norway. The main theme of the conference was Researching the Fist-Year Experience. The conference discussed several issues related to the first-year experience such "student support services collaborating with academic staff preentry work to better prepare students for their studies, skills development for students in the first-year, institutional fist-year strategies, and fist-year assessment” (Nutt \& Calderon, 2009, p. 5).

In the Arabic postsecondary educational context, the literature review did not find an organized research project to search for first-year issues and trends. There is a limited number of individual research studies as mentioned earlier at the beginning of this chapter. The first conference about first-year experience in Saudi Arabia and in the region named First National Conference for Prep Year in Saudi Arabia took place in University of Dammam on 22-23 April 2015 (http://prep1sa.ud.edu.sa).

However, by observing the first-year movement and development globally, which most of international university has a clear theoretical base to develop its program, more attention is required to explore and identify a theoretical base of the program in Saudi universities, and this is what this study achieved.

\section{Student's Success in the First-Year College}

The literature review provides specific components that universities may take into account for developing effective first-year programs that can facilitate students' success in 
their first-year of college. Most of the research on first-year programs stress the importance of developing initiatives that encourage students to become involved academically and socially, and facilitate their transition into postsecondary education.

Several research studies focus more attention on the factors that can influence students' success in college/university, such as psychological factors (e.g. motivation, selfunderstanding, mental health, self-efficacy, lifelong learning skills, personal goals, etc.). Other postsecondary institutions develop intervention programs that aim to improve student retention, performance, and graduation rates which can also contribute to students' success. In general, the first-year experience literature suggests that each institution has unique student needs and goals. Therefore, several different first-year intervention programs have been developed, and a wide debate that relates to the benefits of the first-year intervention programs has emerged.

For example, some researchers reported usefulness of these programs and others reported limited benefits. For example, some studies reported a high impact of learning community practice as an intervention program benefiting student retention and performance (Bailey and Alfonso, 2005; Blackhurst, Akey \& Bobilya, 2003; Commander, Valeri-Gold, Darnell, 2004; Crissman, 2001; Dillon, 2003; franklin, 2000; Gold \& Pribbenow, 2000; Johnson, 2000-01; Kutnowski, 2005; Tinto, 2000; Walker, 2003). In contrast, others reported little or no effect from the learning community practices over time on students' performance (Baker, Meyer, Hunt, 2005; Barrows \& Goodfellow, 2005). They suggest some intervention practices, such as improving communication between students and faculty to make students' transition into college successful, instead of using the learning community strategy.

Furthermore, Pascarella and Terenzini (2005) observed a lack of assessment studies that explore the weaknesses and strengths of the first-year intervention programs; or, the studies that evaluated some of these intervention programs did not mention the program's 
characteristics, which created difficulties predicting whether these programs can work in different environments or not. Despite such limitations, first-year intervention programs continue to play an important role in preparing students for college/university life (Upcraft, Gardner, \& Barefoot, 2005).

First-year interventions are classified into three main categories: curricular strategies, co-curricular strategies, and institutional strategies (Barefoot, 2005; Miller, 2011; Storey, 2010; Upcraft, Gardner, \& Barefoot, 2005). Curricular strategies include initial courses, seminars, counseling, service learning, faculty development, and supplemental instruction. Co-curricular strategies include learning communities, first-year experience programs, campus activities, membership in social clubs or academic association, etc. Finally, institutional strategies include curricular and co-curricular interventions, which can create opportunities for students or institutional decision-makers to make adjustments or changes in specific areas of the first-year programs to ensure their effectiveness. For example, providing financial support for students from lower socioeconomic backgrounds (Upcraft, Gardner \& Barefoot, 2005).

Crosling, Thomas, and Heagney (2008) identify several functions for the first-year program that may foster student success: 1) recruiting; 2) admissions selectivity; 3) financial aid; 4) orientation and academic advising; 5) teaching/learning; 6) academic support; 7) supplemental instruction; 8) academic enrichment; 9) residential living; 10) learning communities; 11) service learning; 12) counseling; 13) extracurricular activities; 14) underrepresented students/specialty sub-populations; 15) undecided students; 16) early alert; 17) policies/procedures; 18) faculty/staff development; 19) internal marketing programs; 20) first-year experience courses; 21) sophomore strategies; 22) technology utilization; 23) students' engagement and satisfaction; 24) quality service; and 25) adult learning strategies. 
Conley (2008) suggests four dimensions for postsecondary institutional improvement to make students' transition into college successful. These dimensions express the first-year functions in college/university.

1. Key Cognitive Strategies:

a. Problem formulation and problem solving.

b. Research skills.

c. Reasoning, argumentation, and proof.

d. Analyzing and interpreting data or information.

e. Precision and accuracy for tasks achievement (p. 7-8).

2. Academic Knowledge and Skills: associated with academic subjects (e.g. English, mathematics, science, social studies, world languages, and the arts).

3. Academic Behaviors: "self-awareness, self-monitoring, and self-control of processes and actions necessary for academic success... self-management skills... time management, stress management, task prioritizing, using information resources, taking class notes, and communicating with teachers and advisers" (p. 9-10).

4. Contextual Skills and Awareness: "the information students need to apply successfully to college, gain necessary financial aid, and then, subsequent to matriculation, understand how college operates as a system and culture" (p. 10-11). Adding to these four dimensions, Evenbeck, Jackson, Smith, Ward, and Associates (2010) explain that the first-year experience establishes its functions by linking faculty members, student affairs, student services, policies, and academic advising, and then utilizes the first-year programing such as first-year seminars, learning communities, etc.

In general, Koch and Gardner (2014) divided the current practices, initiatives, and programs for first-year students into three categories: 
1- Pre-University Programs for First-Year Students: new student orientation programs, parent/family orientation programs, summer bridge programs, and summer or common reading programs.

2- First-Year Initiatives Focused on the Curriculum and/or the Faculty: academic advising, developmental education, distance education and online first-year courses, faculty development, first-year seminars, learning communities, service learning, and supplemental instruction.

3- Structures, Services, and Activities that Benefit First-Year Students: early alert/warning systems, learner analytics, first-year activities such as athletics, institutional policies, attendance and mid-term reporting, and living-learning communities/first-year living environments (p. 23-33).

"How is the first-year different in institutions of varying type, size, and mission? Is there evidence that the first-year is being designed in ways that are consistent with existing principles of good practices that promote learning and retention?” (Barefoot, 2005, p. 47). Additionally, "How can colleges and universities improve their first-year academic encounters? How can they enhance the impact of their programs upon student retention?" (Tinto, 1996, p. 1).

Several studies attempted to answer these questions regarding the first-year program structure that could support student's success in their first-year of college. For example, Barefoot's (2005) study Current Institutional Practices in the First-Year, developed two separate surveys: first-year curricular practices and first-year co-curricular practices survey. The surveys' items investigated the ways that postsecondary institutions structured first-year programs. For instance, some items asked about the institutional mission, resources, role, programs, student body size, location, student life, policy, structure, etc. The surveys were used for description purposes, not for diagnosing problems or recommending solutions. The 
surveys used a random sample of 621 postsecondary institutions. The directors of academic and student affairs were asked to fill out the surveys in each institute. The sample is stratified by the Carnegie Classification with a response rate of $54 \%$.

This study concluded that the first-year experience is "more than seminar course, orientation program, or learning community" (Barefoot, 2005, p. 62). Barefoot suggested that developing the first-year experience, as a whole program, including interacting components, is better than separate parts or initiatives. Moreover, the type, size, mission, student, internal and external environmental components are key factors for structuring the first-year experience. Furthermore, Barefoot mentioned important issues related to higher education trends in general, "to be transformed by market pressures, changing levels of external financial support, and the impact of technology" (p. 63). These results are consistent with Braxton and McClendon's (2001-2) study outcomes, which suggest that students' success and retention in the first-year is a campus-wide responsibility, not only the task of one division's department. Moreover, (Cuseo, n. d.; Studdert, 2013) suggest that a comprehensive and centralized first-year program is more effective than decentralized or fractured programs.

However, Skipper (2005), states that "many institutions already design and deliver interventions that assist students in resolving these and other tasks in the first college year and beyond, but these programs are frequently divorced from the student's classroom experiences and intellectual development" (p. 5). Therefore, more attention has been devoted to the structure of first-year programs to help students' success in their transition into postsecondary education.

For example, Cutright (2002), determined several themes, which influence research universities in developing student's success in the first-year: 1) diffusing the first-year programs on a university level; 2) housing first-year initiatives on the colleges' level or in departments; 3) adopting varied strategies or approaches for first-year programs; 4) adopting 
learning communities as a main strategy for first-year programs; 5) assessing and developing learning and teaching strategies of the first-year; 6) developing the relationship between academic and student affairs, especially in terms of the admission policy; and 7) using benchmark and assessment tools to evaluate the first-year experience.

Hossler, Kuh, and Olsen (2001), in their research, Finding (more) fruit on the vines, introduce three strategies to foster first-year student success: 1) expanding collaboration between university diffusion, colleges, and departments regarding first-year initiatives; 2) developing and integrating academic and social experiences; and 3) establishing a strong academic foundation. Cubarrubia and Schoen (2010), in their study Creating a Developmental Framework for New Student Orientation to Address the Needs of Diverse Population, offer a framework for delivering a first-year experience that can meet students' diverse developmental needs. They suggest two levels for the program's design: the assessment and planning level and the implementation level.

The assessment and planning level requires answering three main questions: "what do I know about my student population?, what does current research say about my student population?, and what is the balance between creating programs for some students and creating programs for all students?” (p. 173-174). In the implementation level, three main questions need to be answered: "how does my program address challenges related to accessibility and affordability? How does my program address challenges related to inadequate preparation?, and how does my program address students' need for adequate support networks?” (p. 174-175).

In their study, University College: Flexible Structure for Serving Undergraduate Students, Swing and Alexander-Hamilton (2010) describe the five-category typology of firstyear organizational structures created by the staff of the Policy Center on the First-Year of 
College, now called John N. Gardner Institute for Excellence in Undergraduate Education. The typology is divided into two levels:

1. Single administrative unit structures comprise comprehensive and non-comprehensive structure. The comprehensive structure contains a campus-wide organizational chart, director/senior leader, a recurring operational budget; the non-comprehensive single unit structure meets some of previous components, but not all.

2. Multiple unit administrative structures contain three types of structures; a) multiple units that are coordinated by a formal standing committee or official coordinating form; b) multiple units that intentionally but informally collaborate to provide firstyear resources and services; and c) multiple units that operate separately with limited coordination (p. 1-2).

By relying on the research published over the past 30 years (e.g., Astin, 1977, 1993; Pascarella \& Terenzini, 1991, 1998, 2005; Whitt \& Associates, 1991), on professional experience, and developmental theories, Barefoot, Gardner, and Swing utilized the typology as a resource for Foundations of Excellence ${ }^{\circledR}$ in the First College Year Institute (Miller, 2011). The Foundations of Excellence ${ }^{\circledR}$ in the First College Year Institute (http:// http://www.jngi.org), established the First-Year Focus - Foundational Dimensions ${ }^{\circledR}$ for Four-Year Colleges.

Foundational Dimensions statements constitute a model that provides institutions with a means to evaluate and improve the first-year of college. As an evaluation tool, the model enables institutions both to confirm their strengths and to recognize the need for improvement. As an aspirational model, the Dimensions provide general guidelines for an intentional design of the first-year ("John N. Gardner Institute", 2015). 
The dimensions are normative statements representing the issues related to postsecondary institution cultures, policy, mission, structure, activities, and programs that shape student learning and success in the first-year (Terenzini, 2005).

1- Foundations Institutions approach the first-year in ways that are intentional and based on a philosophy/rationale of the first-year that informs relevant institutional policies and practices (Philosophy).

2- Foundations Institutions create organizational structures and policies that provide a comprehensive, integrated, and coordinated approach to the first-year (Organization).

3- Foundations Institutions deliver intentional curricular and co-curricular learning experiences that engage students in order to develop knowledge, skills, attitudes, and behaviors consistent with the desired outcomes of higher education and the institution's philosophy and mission (Learning).

4- Foundations Institutions make the first college year a high priority for the faculty (Faculty).

5- Foundations Institutions facilitate appropriate student transitions through policies and practices that are intentional and aligned with the institutional mission (Transitions).

6- Foundations Institutions serve all first-year students according to their varied needs (All Students).

7- Foundations Institutions ensure that all first-year students experience diverse ideas, worldviews, and cultures as a means of enhancing their learning and preparing them to become members of pluralistic communities (Diversity).

8- Foundations Institutions promote student understanding of the various roles and purposes of higher education, both for the individual and society (Roles and Purposes). 
9- Foundations Institutions conduct assessment and maintain associations with other institutions and relevant professional organizations in order to achieve ongoing firstyear improvement (Improvement) (“John N. Gardner Institute”, 2015).

The dimensions were developed for self-assessment and to assist postsecondary institutions in measuring performance and impact on student learning to compare on-campus programs and to improve the current structure of the program if needed. Moreover, the dimensions were "formulated in a general manner to enable academic institutions to articulate their own beliefs for the preparatory year within the institutional guidelines" (Alaqeeli, 2014, p. 47).

\section{Vision, Mission, and Goals Statements}

The root of the word "vision" originates from "the Latin videre, to see" (Senge, 1994, p. 302). A vision statement should answer the questions: "what do we hope to become?" (DuFour \& Eaker, 1998, p. 62) or “what do we want to create?" (Senge, 2006, p. 192). Thus, the vision statements of universities are considered to be a philosophical guide for what a particular university or college works toward achieving (Abelman \& Dalessandro, 2008). In his article, Vision and Education, Pekarsky (2007) explains how vision guides education. Pekarsky stresses that vision must be measurable, clear, and meaningful for all stakeholders. Therefore, all schools function via commitment and are linked to achieve its vision and make desired change. Clayton (1997) describes six characteristics of institution vision:

1- Powerful: Although a vision statement expresses the future, the statement is also important to understand the present. The tension that comes from comparing the desired future with the current reality is what drives actions toward achieving the vision. A vision statement can become disconnected and powerless if the organization does not include the current reality. 
2- Purposeful: Vision cannot be understood in isolation; in particular, it has to be connected to the purpose and the core values. The vision emerges from the fundamental values of the organization's individuals, the fundamental purpose, and awareness of today's reality, melded together to produce a shared future.

3- Self-determining: Vision is not relative. If the vision is connected to competition then it may prove that the vision stops achieving greatness because that is what the competition has done.

4- Concrete: The vision statement is concrete, having a specific destination, presenting an image of the desired future.

5- Multifaceted: The vision includes key aspects, such as personal facets (health, integrity) and altruistic facets (helping the community, serving the customer).

6- Emotional: The vision statements are developed using values. This implies that the visions are emotionally charged (p. 54). This is very helpful because these emotions become the driving forces towards achieving the vision as cited in (Brătianu \& Bălănescu, 2008, p. 21).

The vision is developed based on ideas about future dominant factors and their impacts that will create a new reality that is different from the past or present (Papulova, 2014). In contrast to vision, the word "mission" originated "from the Latin word mittere, meaning: to throw, let go, or send", also, "derived from Latin the word: purpose (originally proponere) meant to declare" (Senge, 1994, p. 303). Whether you title a statement in terms of mission or purpose, the statement is used to answer the questions, "what are we here to do together?" (Senge, 1994, p. 303) or "why an organization exists, a statement of its fundamental purpose" (Gurley, Peters, Collins, \& Fifolt, 2014, p. 222).

The mission statements of universities or schools illustrate a set of values, principles, purpose, directions for individuals, and program functions (Boerema, 2006). Furthermore, 
"the school mission provides the context for governance, decision making, and the way the school is managed"' (p. 182). Thus, articulating the university's or school's mission in clear detail is crucial to make all stakeholders have a clear understanding of what the school would actually like to be; otherwise, educational stakeholders may understand the school's purpose differently (Gurley, Peters, Collins, \& Fifolt, 2014).

In the real world, an overlap exists between the vision and mission statements, in some cases. Some institutions declare their vision in the form of a mission statement, or have two statements, one declaring the mission and another declaring the vision. The difference between the two concepts can be described as, "mission statements typically define the physical, social, fiscal, and political contexts in which that institution exists; whereas, vision statements complement these characteristics, but transcend them as well" (Abelman \& Dalessandro, 2013, p. 223).

The goals statement's concept is considered to be the clearest among the three concepts, vision, mission, and goals, which expresses the performance level of all university's or school's components, either educational, professional, students, curriculum, professional development, etc. (Gurley, Peters, Collins, \& Fifolt, 2014). Developing clear goals helps the school to connect the students' performance with its vision and mission (purpose).

In summary, a clear definition of the meaning of each of the three foundational statements (vision, mission, and goals) is imperative for members of the university or school, including educational leaders, teachers, faculty, and parents, to understand the purpose of statement development. Furthermore, analyzing these three components will expose the implicit philosophy, purpose, and future trends of school, which can help to determine the theoretical foundation of the Preparatory Year Program in all 28 Saudi universities and its alignment with the Seven Principles of Students Success in the first-year of college. 


\section{Content Analysis Methodology}

The systemic analysis of text has been traced to the $17^{\text {th }}$ century, where it was used to compare religious books. Despite its historical roots, the terminology of Content Analysis did not appear in English until 1941 (Krippendorff, 2004). According to Krippendorff, the first dissertations to utilize Content Analysis as a research approach was about newspaper content that was defended in 1690, 1695, and 1699 by some academic scholars.

Since that time, use of Content Analysis as a research methodology has grown and expanded, especially in the social science field (Pegoraro, 2006). One of the earliest definitions of Content Analysis was developed by Berelson in 1952 as a "research technique for the objective, systematic, and quantitative description of the manifest content of communication" (Neuendorf, 2002, p. 10). In 1966, Stone, Dunphy, Smith, and Ogilvie defined Content Analysis as "any research technique for making inferences by systematically and objectively identifying specified characteristics within text." Furthermore, Weber (1990) says, "Content Analysis is a research method that uses a set of procedures to make valid inferences from text," as cited in Neuendorf (2002, p. 10). Krippendorff (2004) defines Content Analysis as "a research technique for making replicable and valid inferences from texts (or other meaningful matter) to the context of their use" (p. 18). Neuendorf (2002) expands the definition of Content Analysis as a research technique to:

Summarizing, quantitative analysis of messages that relies on the scientific method (including attention to objectivity-intersubjectivity, a prior design, reliability, validity, generalizability, replicability, and hypothesis testing) and is not limited as to the types of variables that may be measured or the context in which the message are created or represented. (p. 10)

Neuendorf's definition is significant because she viewed Content Analysis as quantitative research, not just as qualitative, and used both to promote the use of scientific 
research methods. In general, the typical Content Analysis is used in human communication including newspapers, TV commercials, novels, music, books, etc.. The Content Analysis is "applicable to many areas of inquiry" or "may be applied to the human production of messages" (Neuendorf, 2002, p. 1-4). According to Ritchie, Burns, and Palmer (2005), Content Analysis is "the fastest growing method in social research" (p. 191) and "the fastest growing technique in quantitative research" (Neuendorf, 2002, p. 1).

In general, the Content Analysis relies on systematic steps, starting with theory and rationale, for conceptualization and operationalization of variables to be measured. The purpose of conceptualization and operationalization is to identify the unit of analysis of content under study, which can enable the researcher to statistically analyze data using descriptive or inferential statistics (Neuendorf, 2002). Moreover, coding of data is essential for Content Analysis. Researchers should take into account the objective of each study or research questions that led to investigation. The coding steps aim is to record the existence or absence of predetermined themes that are defined for each variable in advance, and categorize them manually or by using a computer (Neuendorf, 2002). The "Content Analysis is the ideal method for examining and studying the language of mission statements within appropriate context" (Kempland, 2009, p. 59). Furthermore, "mission statements can be systematically and reliably coded by applying Content Analysis techniques" (Bebell \& Stemler, 2004; Berleur \& Harvanek, 1997; Stemler \& Bebell, 1999; Stober, 1997) as cited in (Stemler, Bebell \& Sonnabend, 2011, p. 391).

Moreover, educational institutions' vision and mission statements are an empirical data source, which can introduce the philosophy, functioning, values, and school culture (Stemler, Bebell \& Sonnabend, 2011). Several studies utilize Content Analysis of vision, mission, and goal statements to explore and understand the school's practices, philosophy, and trends. For example, Kempland (2009) used Content Analysis to assess the alignment of 
academic advising program mission statements of large four-year higher education institutions with the goals and objectives of Council for the Advancement of Standards (CAS) and Guidelines for Academic Advising Programs. Kempland's study recommended the necessity of revision of higher education institutions' mission statements to fit with the CAS standards.

The purpose of Morphew and Hartley's (2006) study was to identify the pattern of difference within the mission and vision statements of hundreds of higher education institutions "to understand what institutions actually say in their missions and by exploring the relationship between these rhetorical elements and institutional type" (p. 456). This study found a significant result that most "public colleges and universities construct their mission statements with combinations of elements more similar to one another than to their private peers of similar focus and institutional type" (p. 466). This conclusion views mission and/or vision statements of colleges or universities as "symbolic artifacts" (p. 466).

Abelman and Dalessandro (2013) conducted a study using Content Analysis to assess the institutional vision and mission of Catholic colleges and universities. This study found that "Catholic schools are vision-driven institutions that communicate their priorities and defining characteristics by employing clear, highly optimistic, and inspirational language" (p. 221). Moreover, this study found that there is a significant difference between the religious colleges' and universities' vision and mission and their secular counterparts where "Catholic schools are vision-driven institutions that communicate their priorities and defining characteristics by employing clear, highly optimistic, and inspirational language" (p. 221).

Wattananimitkul (1991) used Content Analysis of mission statements of two private universities in Thailand to assess how the universities' administrators perceive the relationship between the two universities' mission statements and strategic plans, and to explore the roles and functions of the mission statements in the strategic plans. This study 
utilizes Strengths, Weaknesses, Opportunities, and Threats (SWOT) Analysis, a theoretical framework, in their Mission Development Process Framework to guide the study process. Wattananimitkul's study reported that the universities' mission statements were used as an important element in strategic plans.

A suggestive example of using vision, mission, and goals statements to assess theory validation is presented by Augusta-Dupar (2003) in his study, The Mission and Vision Statements of Ten Historically Black Colleges and Universities: A Content Analysis. The purpose of his study was to assess the validity of Student Development Theory advanced by Checkering (1993), and to identify the academic and social indicators in each school under study. The Augusta-Dupar study reported that $60 \%$ of these institutions' mission and vision statements were committed to academic development, and $40 \%$ were committed to the social development of students. Content Analysis is time consuming, as it requires a long time for data collection, categorizing, and analyzing, but Content Analysis is considered an advantage with the current study for several reasons:

First, Content Analysis can use unstructured themes as data. The vision, mission, and goals statement data has already been created, and there is no need to create a survey or questionnaire for data collection (Krippendorff, 2004). Second, using Content Analysis of the vision, mission, and goals statements to understand and identify higher education institutions' philosophy and purpose is common in research studies. Some studies aim to determine the common themes in these statements, while others go deeper in order to identify the underlying philosophy and its alignment with a specific theory or model (Krippendorff, 2004). The current study plan works on both goals.

\section{Summary}

The role of vision, mission, and goals statements in higher education planning and policy are crucial. These statements provide an excellent venue to build an appropriate 
strategy of education and to design and implement proper programs to fit prospective students' needs, thus achieving educational goals. In Saudi Arabia, the First-Year Experience Program or as in the Saudi context, the Preparatory Year Program is considered a new phenomenon in higher education. This phenomenon requires more scientific investigation. This research attempted to study the Preparatory Year Program through analyzing the vision, mission, and goals statements. This analysis gave insight regarding the Preparatory Year Programs theoretical base in Saudi higher education and reported program alignments with the Seven Principles of Students Success in the first-year of university developed by Cuseo (2014). Therefore, the literature review section applies a systematic review of literature associated with:

- Theoretical Foundations of Student Development and First-Year Experience

- The First-Year Experience

- Students Success in the First-Year of College

- Vision, Mission, and Goals Statements

- Content Analysis Methodology

\section{Contribution of this Study to the Literature}

This study is significant because its findings adde to the weak body of preexisting literature regarding the First-Year Experience in Saudi Arabian postsecondary education. It also attempt to fill in the gap between theory and current practices of Preparatory Year Programs, in terms of the alignment of the Preparatory Year Program at all Saudi public universities with the First-Year Experience Theory. This study comes at an appropriate time since postsecondary education policymakers recently made a decision to restructure the current model of the Preparatory Year Programs in Saudi Arabia. 


\section{Chapter Three}

\section{Methodology}

The purpose of this study was to analyze the vision, mission, and goals statements of the 28 Preparatory Year Programs at all Saudi public universities that published on their official websites, to assess whether their Preparatory Year Program incorporates the principles of student success in the first-year of university as outlined in the Seven Central Principles of Student Success, advanced by Cuseo (2014). Further, this study explored the themes and formats of the Preparatory Year Programs in all 28 universities and the differences among them based on university size, location, program date of establishment, and gender variables. Finally, this study reveals the Preparatory Year Programs trend in Saudi universities through the most common keys elements of the Seven Principles of Students Success included in the Preparatory Year Programs' vision, mission, and goals statements. The nine steps of Content Analysis (CA) developed by Neuendorf (2002) were used for data collection and analysis. This study attempts to answer the following research questions:

a. For each university, to what extent do the Preparatory Year Programs' vision, mission, and goals statements align with the Seven Principles of Students' Success in the first-year of university?

b. What common key elements cited in the Seven Central Principles of Students Success are most often included in the Preparatory Year Programs' vision, mission, and goals statements?

c. For all Saudi public universities, what is the format and frequency of the Preparatory Year Programs' vision, mission, and goals statements?

d. How do the Preparatory Year Programs' vision, mission, and goals statements compare or contrast in content between universities, according to geographical location, size, the Preparatory Year Programs' date of establishment, and gender? 
It is important to note that this study was not to evaluate the content or structure of the vision, mission, and goals statements of the Preparatory Year Program itself but, to assess its alignment with the First-Year Theory.

\section{Restatement of the Problem}

The Preparatory Year Program plays an important role in making student's transitions into postsecondary education successful at Saudi public universities (Alaqeeli, 2014; Al Kathiri, 2014). The current practices of the Preparatory Year Programs at all Saudi public universities concentrate on preparing students academically for university studies (e.g. in math, languages, and business administration), and improving their hard/soft skills (Al Kathiri, 2014). The Preparatory Year Programs will also be required to focus on the future on the "non-cognitive or non-academic skills... e. g., educational commitment, campus engagement, self-efficacy, appreciating creativity, seriousness, teamwork, and discipline" (Alaqeeli, 2014, p. 62).

Globally, the majority of first-year program designs have a theory-base that could help to assess the program's performance and capability to achieve the students' and institutions' needs. Within the Saudi postsecondary education context, the Preparatory Year Programs have unclear educational pedagogy or theoretical base and "the preparatory year in Saudi universities lacks a Governing Concept philosophy" (p. 60).

If we are to help freshmen succeed, we must know how various theories attempt to explain their development. To be sure, the theoretical underpinning of freshman development is a dynamic and constantly changing endeavor. The most recent challenges to include women, minorities, and older students in our theoretical concepts about student development will expand and make more valid our thinking about students. In spite of this continuing uncertainty about student-development theories, everything we do to enhance freshman success must be grounded in one or 
more of these theories. It is important that we take what we know about students from developmental theories and apply it to our teaching, counseling, advising, and programming for freshmen (Upcraft \& Gardner, 1989, p. 52).

This study attempted to assess the extent of the Preparatory Year Programs'vision, mission, and goals statements alignment with the First-Year Experience Theory represented by the Seven Central Principles of Student Success advanced by Cuseo (2014). The outcomes of this study revealed the theoretical base of the program, and provided better understanding to the current practices. The study also exposed the most common themes that appeared in the vision, mission, and goals statements of the program, which provides insights about the program's trend and philosophy.

\section{Significance of the Problem}

It is time to apply the lessons of the past to the present and, in the process of doing so, make necessary structural, policy, curricular, and pedagogical changes to better meet the needs of our students so that they have fuller and richer futures. (Koch \& Gardner, 2014, p. 35)

Saudi universities apply the Preparatory Year Program as one of the best practices to help student success in college/university. Koch and Gardner (2014) clarify that to create a successful Preparatory Year model, it is important to link the program's policy, structure, and practices with the university's mission. Therefore, postsecondary institutions "should work collectively to develop a research-based, comprehensive model of the first-year that is attainable and immediately usable to increase student learning, success, and retention" (p. 36).

Developing theory-based Preparatory Year Programs could be tied to the accreditation process, student learning and performance, and assessment strategies. Among these developmental and operational issues, understanding the current model of Saudi 
Preparatory Year Programs through analyzing the vision, mission, and goals of the programs is essential to identify theoretical base of the program and for developmental purposes in the future. Utilizing Content Analysis allowed recognizing the program's theoretical base and philosophy that may help establish future practices of the program. Further, no previous studies have been found that have utilized Content Analysis of the vision, mission, and goals statements in Saudi public universities, while assessing program alignments with the Seven Principles of Students Success in the first-year of university.

\section{Methodology}

As mentioned in Chapter One and at the beginning of this chapter, the purpose of this study was to assess whether Preparatory Year Programs incorporate the principles of students' success in the first-year of university as outlined in the Seven Central Principles of Students Success advanced by Cuseo (2014). Additionally, this study exposed the most common themes in the vision, mission, and goals statements of the Preparatory Year Programs among Saudi public universities.

Among the available research methods that can be used to analyze universities' vision, mission, and goals statements and assess its alignments with the First-Year Experience Theory, one approach is using a survey as a quantitative method. According to Messman-Mandicott (2012), surveying people will make them respond to specific items that might describe the current situation or what they wish for in the future. The survey will limit participants' opportunity to express or share their perspective about the crucial issues of the Preparatory Year that need to be developed. Therefore, Content Analysis was chosen instead of the survey quantitative method.

Content Analysis is a superior methodology to achieve this particular study's goal for four reasons: 1) Content Analysis can be done without the possibility of influencing the subjects, which can increase the validity of data that will be acquired by using texts or 
documents; 2) Content Analysis reduces the risk of corrupted data because there is no human participation, and the researcher can neglect inappropriate data or recollect data again at any time to ensure validity; 3) data collection is more reliable in Content Analysis due to the robust process that the researcher follows; and 4) data is available at any time (Falduto, 2008).

\section{Research Design}

According to Vega (2010), "a challenge with content analysis is identifying the best model to employ for each study" (p. 91). For this study, the nine steps of Content Analysis developed by Neuendorf (2002) were utilized to guide the study's design: 1) theory and rationale; 2) conceptualizations; 3) operationalizations; 4) coding schemes; 5) sampling; 6) training and pilot reliability; 7) coding; 8) final reliability; and 9) tabulation and reporting. This study adopted the Content Analysis definition advanced by Neuendorf: Summarizing, quantitative analysis of messages that relies on the scientific method (including attention to objectivity-intersubjectivity, a prior design, reliability, validity, generalizability, replicability, and hypothesis testing) and is not limited as to the types of variables that may be measured or the context in which the message are created or represented. (p. 10)

Furthermore, Content Analysis can be applied to all types of written text, verbal, visual images or maps, transcribed text, etc. (Vega, 2010). The content analyzed in this study includes vision, mission, and goals statements of the Preparatory Year Programs at all 28 Saudi public universities. The three data sources were analyzed and coded to assess the program's alignment with the Seven Central Principles of Students Success advanced by Cuseo (2014), and to identify the frequency and themes for each Preparatory Year Program. The research questions of this study were answered by inferences from a systematic reading and reviewing of the content, and verified by a pilot study that was applied on seven 
universities representing $25 \%$ of this study sample by two other analysts (coders).

Furthermore, this study used descriptive statistics and frequency counts to identify patterns and themes for each dependent variable including vision, mission, and goals statements. The reasons for selecting the vision, mission, and goals statements of the Preparatory Year Programs for this study as units of analysis are as follows:

- Preparatory Year Programs lack a "governing concept philosophy" (Alaqeeli, 2014, p. 60), theoretical and pedagogical base, and no clear purpose. "Mission statements represent an important summation or distillation of an organization's core goals represented by concise and simple statements that communicate broad themes. School mission statements are one of the only written documents outlining purpose that nearly all schools have" (Stemler, Bebell, \& Sonnabend, 2011, p. 391).

- Preparatory Year Programs' vision, mission, and goals are easily available and accessible for study, due to these statements being published on the universities' official websites.

- Vision, mission, and goals statements "can be systematically and reliably coded by applying content analysis techniques" (Stemler, Bebell, \& Sonnabend, 2011, p. 9). Additionally, the vision, mission, and goals statements are essential for the university's or Preparatory Year Program's strategic plan, which is considered to be a base for any practices or application in the program.

Before embarking on detailed steps of the Content Analysis used in this study, it is a vital to reveal the role of the researcher in this study. First, the researcher has extensive experience in the field of first-year experience. The researcher has working experience in the Preparatory Year Program at King Saud University that totals eight years as a faculty member. Furthermore, the researcher is the main player in planning, implementing, and reporting this study's process including the nine steps developed by Neuendorf (2002). The 
researcher also has previous experience using the Content Analysis Methodology, where he published a research paper in the $35^{\text {th }}$ Annual Conference on the First-Year Experience in 2015, titled: Exploring First-Year Experience Practices in Saudi Higher Education. This research paper employed Content Analysis to explore the Preparatory Year's practices in Saudi higher education.

Step 1: Theory and Rationale. To explore and assess the theory and rationale behind Content Analysis, it is necessary to define what is to be examined and why it is selected (Neuendorf, 2002). As mentioned in Chapter One, the Preparatory Year Program in all Saudi universities is considered a new phenomenon. The literature review indicates that the Preparatory Year Programs in Saudi postsecondary education have no clear purpose or theoretical base. Therefore, this study attempted to explore the Preparatory Year Programs and assess its alignments with the Seven Principles of Student Success in the first-year of university.

The theory and rationale step is employed to identify variables related to the information that is assessed in this study including the vision, mission, and goals statements of Preparatory Year Programs. The Content Analysis requires an a priori design where "all decisions on variables, their measurement, and coding rules must be made before observation begins" (Neuendorf, 2002, p. 11). Furthermore, Content Analysis is "the systematic, objective, quantitative analysis of message characteristics” (Neuendorf, 2002, p. 1). Neuendorf states, "there are many ways to define a given construct, and there is no one right way" (p. 50). These assumptions express the difficulty of applying Content Analysis for a specific body of knowledge or research, which first requires "determining the nature of the data that shape the variables selected and informs the development of the codebook... full of hours of invention, reinvention, and repeated failures" (Vega, 2010, p. 95). 
Neuendorf suggests four techniques to select Content Analysis variables: 1) a consideration of universal variables; 2) using theory and past research for variables collection; 3) a grounded or "emergent" process of variable identification; and 4) attempting to find medium-specific critical variables ( $\mathrm{p}$ 97). Neuendorf defined variables as "latent or manifest variables and as content or form variables" (p. 95). Manifest variables include content that is explicit in text and that the researcher can observe, such as text and images or diagrams or figures. The latent variables represent unobserved concepts that the researcher can infer through the context, either text or any other types of context. These types of variables contain implicit meaning or messages (Krippendorff, 2004; Neuendorf, 2002). In other words, the latent variables depend on the researcher's interpretation of the context.

Benoit (2011) suggests "quantitative Content Analysis requires a set of categories that coders use to assign numeric values to dimensions of messages". These categories represented variables used in this study. Neuendorf (2002) and Benoit (2011) stress that these categories should meet three criteria to ensure validity and reliability including: 1) exhaustive (no parts of content can be disregarded); 2) mutually exclusive (each part of text can be coded and placed in only one category); 3) and relevant (to research questions or study purpose) (p. 271).

Benoit says, "preferably these categories should be derived from theory, which should help understand the data that arise from application of these categories to texts... if no theoretically based categories can be derived, one may rely on categories found in previous research" (p. 271). Thus, "content analysis as a research method is not standardized regarding selection of categories" (Falduto, 2008, p. 45). Taking into his account all these conditions and criteria for theory selection and coding schema categorization, the researcher used the Seven Principles of Students Success in the first-year as a guiding theory and categories for this study, and for developing the codebook and coding form. 
In this context, Schreiner, Louis, and Nelson (2012) defines "student success" as students who "move beyond the fundamental benchmarks of college completion rates and grades have emerged in recent years. Such expanded definitions have included learning gains, talent development, satisfaction and sense of belonging, and student engagement" (p. xix). Furthermore, Kuh, Kinzie, Buckley, Bridges, and Hayek (2006), define student success as "academic achievement, engagement in educationally purposeful activities, satisfaction, acquisition of desired knowledge, skills and competencies, persistence, attainment of educational objectives, and postcollege performance" (p. 7). Upcraft, Gardner, and Barefoot (2004) determined the most common practices that universities apply for first-year programs to promote students' success:

1- Completing courses registered in the first-year;

2- Persistent courses registration for the second year;

3- Developing academic and intellectual competence;

4- Establishing and maintaining interpersonal relationships;

5- Exploring identity development;

6- Deciding on a career;

7- Maintaining health and wellness;

8- Considering faith and the spiritual dimensions of life;

9- Developing multicultural awareness;

10- Developing civic responsibility (p. 8-9).

Moreover, Cuseo (n.d.) sees that student success is more likely to be experienced and evidenced when students: 1) feel personally validated and they matter to the college; 2) believe that their effort matters and that they can influence or control the prospects for success; 3) develop a sense of purpose and perceive the college experience as being personally relevant; 4) become actively or engaged in the learning process and in the use of 
campus resources; 5) become socially integrated or connected with other members of the college community; 6) think reflectively about what they are learning and connect it to what they already know or have previously experienced; and 7) are self-aware and remain mindful of their learning styles, learning habits, and thinking patterns. Furthermore, Cuseo (2014) states that first-year student success requires higher education institutions to promote three student outcomes concurrently: "(a) student retention (persistence), (b) student learning (academic achievement), and (c) personal development (holistic outcomes)" (para. 1).

The literature of the first-year has several definitions of students' success where each postsecondary institute is different from one another, with specific factors controlling the style of each institution's program structure. In general, the differences among institutions' size, mission, financial budget, students' needs and capacity, and institutional trends and goals are the keys to define students' success and design first-year initiatives to meet the actual needs of the institute and students.

This study employs the Seven Central Principles of Students Success advanced by Cuseo (2014) as a guideline. The reasons for selecting these principles is due to their comprehensiveness, which includes most of students' success themes that appear in student's development theories, first-year theory, and student's success themes mentioned previously. As mentioned in Chapters One and Three, the Preparatory Year Programs in Saudi postsecondary education have no documented theory or philosophical base. This study attempts to explore the theory foundation in Saudi universities; therefore, using the Seven Principles of Students Success to provide extensive ground to understand the program in a better way. The seven principles are grounded in research and theory of students' development. The seven principles represent holistic development dimensions including:

- Intellectual Development: developing skills for acquiring and communicating knowledge, learning how to learn, and how to think deeply. 
- Emotional Development: developing skills for understanding, controlling, and expressing emotions.

- Social Development: enhancing the quality and depth of interpersonal relationships, leadership skills, and civic engagement.

- Ethical Development: formulating a clear value system that guides life choices and demonstrates personal character.

- Physical Development: acquiring and applying knowledge about the human body to prevent disease, maintain wellness, and promote peak performance.

- Spiritual Development: appreciating the search for personal meaning, the purpose of human existence, and questions that transcend the material or physical world (Cuseo, 2014, p. 2).

While the Preparatory Year Programs' vision, mission, and goals statements are considered dependent variables and a unit of analysis in this study, the Seven Principles of Students Success are used as independent variables, "the seven key principles are briefly reiterated and first-year programs or practices are identified that effectively implement these central principles of student success" (Cuseo, 2014, p. 7). Cuseo defines each principle through specific practices that first-year programs could apply to help students' succeed. The seven principles were coded and are defined operationally as appears in Table 1.

\section{Table 1}

The Descriptions of the Seven Variables, Operational Definition, and Applications Adapted from Cuseo (2014) 


\begin{tabular}{|c|c|c|c|}
\hline $\begin{array}{l}\text { Variable } \\
\text { (Code) }\end{array}$ & Category & Definition & Examples of Indications \\
\hline P.V. & $\begin{array}{l}\text { Personal } \\
\text { Validation }\end{array}$ & $\begin{array}{l}\text { Student success is promoted } \\
\text { when students feel personally } \\
\text { significant-i.e. when they } \\
\text { feel welcomed by the college, } \\
\text { recognized as individuals, and } \\
\text { that they matter to the } \\
\text { institution. }\end{array}$ & $\begin{array}{l}\text { Welcome and celebrate new students' entry into } \\
\text { higher education, refer to them by name, and know } \\
\text { about them, communicate with students in a } \\
\text { personalized manner, and acknowledging their } \\
\text { individual achievements inside and outside the } \\
\text { classroom (e.g. personal e-mail messages } \\
\text { congratulating students for their co-curricular } \\
\text { contributions, attaining academic excellence, and } \\
\text { regaining good academic standing following academic } \\
\text { probation). }\end{array}$ \\
\hline S.E. & Self-Efficacy & $\begin{array}{l}\text { Student success is more likely } \\
\text { to be experienced when } \\
\text { students believe that their } \\
\text { individual effort matters, i.e. } \\
\text { when they believe they can } \\
\text { exert significant influence or } \\
\text { control over their academic } \\
\text { and personal success. }\end{array}$ & $\begin{array}{l}\text { College-entry assessment for initial student placement } \\
\text { in skill-building courses, and careful attention to } \\
\text { course pre-requisites in the college curriculum, } \\
\text { developing a summer bridge program, first-year } \\
\text { seminars that extend support to students beyond new- } \\
\text { student orientation, providing timely student support } \\
\text { for college-adjustment issues they encounter during } \\
\text { their critical first term in college, supplemental } \\
\text { instruction in first-year courses that have } \\
\text { disproportionately high failure and withdrawal rates, } \\
\text { and Honors courses and programs that provide } \\
\text { optimal challenges for high-achieving students. }\end{array}$ \\
\hline P.M. & $\begin{array}{l}\text { Personal } \\
\text { Meaning }\end{array}$ & $\begin{array}{l}\text { Student success is enhanced } \\
\text { when students find meaning } \\
\text { and purpose in their college } \\
\text { experience-i.e. when they } \\
\text { perceive relevant connections } \\
\text { between what they're learning } \\
\text { in college and their current or } \\
\text { future life. }\end{array}$ & $\begin{array}{l}\text { Developmental academic advising programs that help } \\
\text { students see the "connection" between their present } \\
\text { academic experience and their future life plans, which } \\
\text { broaden students' perspectives with respect to their } \\
\text { personal life choices, helps students connect their } \\
\text { current college experience with their future } \\
\text { educational and life goals, reality-based learning } \\
\text { experiences, and providing experiential learning } \\
\text { opportunities for first-year students that allows } \\
\text { students to learn directly. }\end{array}$ \\
\hline A.I. & $\begin{array}{l}\text { Active } \\
\text { Involvement }\end{array}$ & $\begin{array}{l}\text { The likelihood of student } \\
\text { success increases } \\
\text { proportionately with the } \\
\text { degree of student engagement } \\
\text { in the learning process, i.e. } \\
\text { with the amount of time and } \\
\text { energy that students invest in } \\
\text { the college experience-both } \\
\text { inside and outside of the } \\
\text { classroom. }\end{array}$ & $\begin{array}{l}\text { Inside the classroom through the use of engaging, } \\
\text { student-centered pedagogy, delivered information by } \\
\text { shifting more opportunity for talking and more } \\
\text { responsibility for learning to the students, and active } \\
\text { involvement in campus life outside the classroom is } \\
\text { promoted by practices that deliver academic support } \\
\text { intrusively. }\end{array}$ \\
\hline P.R. & $\begin{array}{l}\text { Personal } \\
\text { Reflection }\end{array}$ & $\begin{array}{l}\text { Students are more likely to be } \\
\text { successful when they step } \\
\text { back and reflect on what they } \\
\text { are learning and elaborate on } \\
\text { it, transforming it into a form } \\
\text { that relates to what they } \\
\text { already know or have } \\
\text { previously experienced. }\end{array}$ & $\begin{array}{l}\text { This principle is most effectively implemented by } \\
\text { writing-to-learn assignments that encourage students } \\
\text { to reflect on what they are learning and connect it to } \\
\text { their personal experiences or what they have } \\
\text { previously learned. }\end{array}$ \\
\hline
\end{tabular}




\begin{tabular}{|c|c|c|c|}
\hline S.I. & $\begin{array}{l}\text { Social } \\
\text { Integration }\end{array}$ & $\begin{array}{l}\text { Student success is augmented } \\
\text { by human interaction, } \\
\text { collaboration, and the } \\
\text { formation of interpersonal } \\
\text { connections between the } \\
\text { student and other members of } \\
\text { the college community- } \\
\text { peers, faculty, staff, and } \\
\text { administrators. }\end{array}$ & $\begin{array}{l}\text { New-student orientation programs that move beyond } \\
\text { information dissemination and orientation to campus } \\
\text { buildings, and moves towards community-building } \\
\text { practices that connect new students with each other, } \\
\text { with peer leaders and role models, with student } \\
\text { development professionals, and the college's faculty, } \\
\text { and cooperative learning practices inside the } \\
\text { classroom that transform group work into team work } \\
\text { by intentionally creating learning teams composed of } \\
\text { students who can learn the most from each other using } \\
\text { the learning communities strategy. }\end{array}$ \\
\hline S.A. & $\begin{array}{l}\text { Self- } \\
\text { Awareness }\end{array}$ & $\begin{array}{l}\text { Student success is promoted } \\
\text { when students gain greater } \\
\text { awareness of their learning } \\
\text { styles, learning habits, and } \\
\text { thinking patterns. }\end{array}$ & $\begin{array}{l}\text { Encouraging students thinking about their own } \\
\text { thought processes, and to complete self-assessment } \\
\text { instruments designed to promote personal awareness } \\
\text { of learning styles and habits. }\end{array}$ \\
\hline
\end{tabular}

Adopted from: Cuseo (2014) Student Success: Definition, Outcomes, Principles and Practices.

Step 2: Conceptualizations and Operationalization (measures). Conceptualization is to identify "what variables will be used in the study, and how to define them conceptually" (Neuendorf, 2002, p. 50). Operationalization is "the process of developing measures" (p. 118). Neuendorf stresses that measures and conceptualizations must be matched to build internal validation of data. This step involves identifying the unit or units of data. "The unit in a research study refers to what or whom is being studied" (Asta, 2009, p. 9). Neuendorf (2002) illustrates that there are two units of data: collection and analysis. "The unit of data collection is the element on which each variable is measured. The unit of analysis is the element on which data are analyzed and for which findings are reported" (p. 13). The researcher must distinguish between two units and their use (Neuendorf, 2002).

However, in this study, the entire Preparatory Year Programs' vision, mission, and goals statements (dependent variables) in each university serve as the unit of data collection while elements included in each classification either vision, mission, and goals statements serve as the unit of analysis. For this study, the unit of analysis was defined by thought/s extracted from the dependent variables. In other words, each vision or mission or goals statements are analyzed into thoughts named Unit of Thoughts (UT) and used to assess its 
alignment with the Seven Principles of Students Success. In summary, the unit of data collection referred to the vision, mission, and goals statements and the unit of analysis referred to the thoughts extracted from these three classifications. More details will be provided in the next section (Step 3: Coding Schemas).

However, each Preparatory Year Program has unique statements of vision, mission, and goals that express that program's purpose and theoretical base, the data was collected from a primary source, the official website of the program. The researcher performed two rounds of data collection. The researcher performed two rounds of data collection. The first was in July 2016 and the second was around November 2016 for data confirmation. The reason for this was that the new year of study in Saudi Arabia started in September 2016, and the researcher assumed that some universities might make some changes to its Preparatory Year Program's vision, mission, and goals statements (see Appendix A \& D).

Step 3: Coding schemes. The coding schemes consist of two materials: 1) codebook (with all variables measures fully explained), and 2) coding form (Neuendorf, 2002). The codebook was developed to match the codes, which are used on the coding form. For the codebook, each Preparatory Year Program in each university is assigned a form in order to ensure that the university's name remains confidential and all necessary information is included. The codebook was created on Microsoft Excel and the information and variables are determined and coded as follows:

1. University name (UN\#1; UN\#2; UN\#3; etc.) all universities were sorted in alphabetical order from 1 to 28 .

2. University location in Saudi Arabia according to province (UL=North), $(\mathrm{UL}=\mathrm{South})$, $(\mathrm{UL}=$ East $),(\mathrm{UL}=$ West $)$, and $(\mathrm{UL}=$ Middle $)$.

3. University size identified based on new students enrollment total in 2014-2015 (US). 
4. Preparatory Year Program organizational structure. Data analysis revealed seven types of organizational structure for the Preparatory Year Program, sorted from 1 to 7 using (OS\#1; OS\#2; OS\#3; OS\#4; OS\#5; OS\#6; OS\#7) codes.

5. Program Application Policy. Apply for all new students (AFA); Not apply for all new students (NAF); Unreported (UR).

6. Preparatory Year Program establishment date (ED\#year).

7. The researcher also coded the new themes as follows: Vision New Theme/s (NTV1; NTV2, NTV3, etc); Mission New Theme/s (NTM1; NTM2, NTM3, etc.); and Goals New Theme/s (NTG1; NTG2, NTG3, etc.). However, due to the scale-sample, which comprised of only 28 universities, the researcher used a human code (see Appendix B $\& \mathrm{C})$.

For the coding form, the Seven Principles of Students Success were categorized, coded, defined, and provided examples of indications as appeared in Table 1. To answer the two major research questions, "For each university, to what extent do the Preparatory Year Programs' vision, mission, and goals statements align with the Seven Principles of Students Success in the first-year of university?" and "What common key elements cited in the Seven Central Principles of Students Success are most often included in the Preparatory Year Programs' vision, mission, and goals statements?" The Unit of Thoughts (UT) were extracted from the vision, mission, and goal statements to assess its alignment with the Seven Principles of Students Success.

The Unit of Thoughts (UTs) extracted from the unit of analysis were defined by the number of sentences or paragraphs or words that belong or indicate to an existing principle. Any sentence or indication of the vision, mission, or goals statements was extracted and placed under an appropriate principle. The alignment percentage for each classification of the vision or mission or goals statements was calculated separately. For example, UN\#1 vision 
has no UT that could align with any of the Seven Principles of Student's Success. Also, the mission statement has no Unit of Thoughts that aligned with any of these seven principles. The goals statement has three Units of Thoughts that aligned with two principles as follows:

1. Self-Efficacy (S.E.):

a. Preparatory Year Program is for helping and directing students to select the future college that fits his/her abilities and interests.

b. Providing students with the necessary skills for the labor market and developmental plan of government.

2. Self-Awareness (S.A.):

a. Developing student learning, thinking, and scientific discussion skills.

This result means that the goal statement aligned with two $(28.57 \%)$ of the Seven Principles of Students Success calculated as follows: (Total of Principles aligned*100/ 7 Principles) where in this case for goals statement ( 2 principles aligned*100/7 $=28.57 \%$ ).

To assess the alignment of the vision, mission, and goals statements combined for each university with the Seven Principles of Students Success, the researcher used the following formula (vision UTs alignment + mission UTs alignment + Goals UTs alignment/3). For example, in the case of UN\#1 (vision alignment $0+$ mission alignment 0 + goals alignment $28.57 / 3=9.52 \%$ ).

Furthermore, the UTs were used to identify the pattern of the Preparatory Year Programs and the differences and similarities among the 28 universities. Moreover, the other two research questions were answered inductively from data collected using the Content Analysis process individually for each program. The coding form involved specific information about each university including study title, the university's name code e.g. UN\#1, data source, coder number, and open code table to report any new themes that appear through the analysis step. The open code table revealed new themes that were used to report 
the frequency and pattern of the Preparatory Year Program's vision, mission, and goals statements.

Step 4: Sampling. The target population consisted of 28 public universities that are managed and supervised by the Ministry of Education in Saudi Arabia (MOE, 2016). The nonrandom sampling process (purposive sampling) is utilized in this research. All Preparatory Year Program's that reported its vision, mission, and goal statements on the official websites were included in this study. Since all required data is accessible and published on the official websites of the universities, the researcher has no need to obtain permission to conduct the study. In other words, this study did not involve a human subject; therefore, there was no need to acquire the Institutional Review Board (IRBs) approval. In case of any required clarification regarding data, it accomplished by telephone or email communication with the Preparatory Year Deanship or College via official contact information from the website.

Step 5: Training and pilot reliability. Neuendorf (2002) suggests the use of at least two coders to ensure consistency between coders and to improve reliability on each variable. The primary researcher and two assistants coded the data. The qualification of additional coders was based on their educational experience at university and prior experience in the First-Year Experience Program. The researcher and the two coders set up a meeting, using Skype since they were in Saud Arabia, to practice coding and to reach an agreement on the coding form and codebook and to identify the list of variables included. The researcher followed specific steps to ensure training quality as follows:

- Provided coders a full description about the research study's purpose and procedures. This step is essential to ensure all coders have enough knowledge regarding the study's process and context. 
- Introduced coders to the Seven Principles of Students Success in the first-year content and the Preparatory Year Programs' vision, mission, and goals statements to be analyzed.

- Provided a brief explanation about the Content Analysis in general and the research approach utilized for this study.

- Introduced research questions that the researcher aims to answer.

- Defined the dependent and independent variables for coders.

- Provided each coder a portfolio including an electronic copy on Microsoft Excel for the codebook and code form.

To get confirmation of the accuracy of researcher's analysis and to ensure the integrity of the coding schema and form, a copy of the Content Analysis pilot study was given independently to each of the two members and they were asked to respond to the codebook and sample Content Analysis to verify the researcher's coding outcomes. The pilot study was conducted on seven (25\%) Preparatory Year Programs selected randomly including UN\#03, UN\#07, UN\#09, UN\#17, UN\#18, UN\#20, and UN\#28. To ensure consistency and understanding among the coders, the researcher discussed any issue or difficulties the coders encountered. In case the results differed, the researcher worked with the two coders to modify and retest the data. For these seven universities, the validity resulted in $100 \%$ agreement between the researcher and two coders, which means the Content Analysis is valid and reliable (see Appendix C).

Step 6: Coding. After the pilot study, the researcher performed Content Analysis for all remaining universities, using human coding and the codebook and coding form generated in Step 3: Coding Schema. Neuendorf (2002) says to "apply dictionaries to the sample text to generate per-unit (e.g., per-new-story) frequencies for each dictionary" (p. 51). The codebook was designed to help coders in the process of coding the vision, mission, and goals statements 
of the Preparatory Year Program in all public Saudi universities. The coding procedure included:

- Vision, mission, and goals statements for each Preparatory Year Program read by the primary researcher.

- The seven variables relating to the research questions coded into the corresponding area on the coding form. Further, sub-variables such as university location, size, gender, and Preparatory Year Program date of establishment were coded.

- The researcher used an open code to explore any new themes that may not match any of the independent variables under study.

- The codebook corresponded to a coding form that was created on the Microsoft Excel software.

- Some instructions were provided to the coders to increase validity of data during the pilot study (e.g. coders practice code together and independently on some units of data analysis and discussed results) (Neuendorf, 2002).

Step 7: Final reliability. This study used human coding conducted by the primary researcher and two other coders to ensure data validity and "to establish intercoder reliability" (Neuendorf, 2002, p. 51) between two coders "with at least 10\% overlap for the reliability" (p. 51). Reliability data can be obtained "by using several researchers with divers personalities, by working in differing environments, or by relying on different but functionally equal measuring devices.” (Krippendorff, 2004, p. 212). For measuring, Neuendorf suggests some statistical methods to check reliability such as "percent agreement, Scott's pi, Spearman's rho, or Pearson's r" (p. 51). However, to assess the alignment of the Preparatory Year Programs' vision, mission, and goals statements with the Seven Principles of Students Success in the first-year of university, the researcher used the agreement percentage level between him and the two other coders to collect reliability. The reliability 
could be proven through multiple data collections. The percentage of errors could be reduced or eliminated through data reviewing and checking the data multiple times, which can give the data a high degree of reliability and validity.

As mentioned previously in (Step 5: Training and pilot reliability) the researcher set some steps to ensure the integrity, validity, and reliability of the coding process as follows: 1) Provided coders a full description about the research study's purpose and procedures; 2) Introduced coders to the Seven Principles of Students Success (independent variables) and the Preparatory Year Programs' vision, mission, and goals statements (dependent variables); 3) Provided a brief explanation about the Content Analysis; 4) Introduced research questions that the researcher aims to answer; and 5) Provided each coder a portfolio including an electronic copy on Microsoft Excel for the codebook and code form.

The researcher performed the coding process individually several times before they reached the final agreement. For example, the first time coding, the discrepancy among the three coders was high and the agreement percentage was only about $60 \%$. The reason for this high discrepancy was the overlapping among the Seven Principles contents itself. For instance, Active Involvement (A.I.) and Social Integration (S.I.) principles have similar content to a large extent, e.g. helps students to engage in the university environment. The researcher and two coders referred to Table 1 to discuss and clarify the difference between two principles and to make an agreement about each principle's components and which unit of thoughts should be included. The result of this discussion increased the agreement percentage to $90 \%$. Another round of discussion and practice was performed to increase the level of agreement between the researcher and two coders to solve some wording issues regarding translation from Arabic to English for some missions and goals statements, which resulted in $100 \%$ of agreement between the researcher and two coders for seven universities $(25 \%)$ that were used as a pilot study for this research. However, the data analysis of the 
seven universities used for the pilot test was incorporated within the findings of 28 universities.

However, Krippendorff (2004) says, "any content analysis should be validatable in principle" (p. 39). Further, Krippendorff states, "validity standards cannot be divorced from chosen contexts" (p. 317). Notably, Krippendorff mentions that the procedure used for data collection and analysis is essential in creating empirical validity. The construct validity is evidenced by the selected content of the vision, mission, and goals statements that are published on the official websites of the Preparatory Year Programs' in all Saudi public universities.

Step 8: Tabulation and reporting. The results tabulation for each Preparatory Year Program's variables and sub-variables were coded and entered into a Microsoft Excel spreadsheet for analysis. The alignment of the relationship between the Seven Principles of Students Success and the Preparatory Year Programs' vision, mission, and goal statements was calculated using frequencies and ratio of presence. The common key elements of the Seven Principles relevant to the Preparatory Year Programs were described. The descriptive statistics and nonparametric results including frequency and new themes tables are reported in Chapter Four.

Summary. This chapter provides an overview of the methodology used in this study. The nine steps of Content Analysis were explained in detail. Data collection and analyzing, theory and rationale, data sources, coding process, tabulation, and reporting process were described. Further, the literature informed the dependent and independent variables were transpired. The codebook and coding form were mentioned. A pilot study to ensure the codebook and coding form was applied on seven (25\%) universities of the sample of the study was conducted. The agreement level between the researcher and two other coders was used for reliability measurement. The agreement result indicated that the coding process, 
codebook, and coding form are reliable and valid. The next chapter displays the findings of this study.

\section{Translation Process}

As some of the Preparatory Year Programs at some Saudi universities developed its version of the vision, mission, and goals statements solely in the Arabic language. The researcher performed translation from Arabic to English for these Preparatory Year Programs. However, the literature provides several techniques to translate text among different languages from or to the English language. Squires et al. (2013) state,

Researchers generally tend to focus on the technical aspects of language translation and use only forward and back translation. Brislin's (1970) decentering method is perhaps the best-known translation method. It emphasizes the semantics and technical aspects of translation during the forward and back translation process.

The researcher decided to use the cross-culture, forward-backward translation process developed by Brislin (1970) with subjectivity, objectivity, and a pilot assessment test to ensure the quality of the process and measurement in terms of validation and the functional correspondence between the English and Arabic versions of Concept Mapping/Pattern Matching outcomes.

To reduce the discrepancies between the original version of the vision, mission, and goals statements developed in Arabic and the new version created in English for essential main steps, the researcher should take into his/her account the translation quality: (a) A bilingual person has knowledge or experience about a topic understudy to perform translation from the source language document (Arabic version) into the target language (English version); (b) a second bilingual person has no information about the original document (Arabic version) to perform translation from target language (English version) to the original language (Arabic version); (c) comparing and contrasting both versions; and (d) in case of 
indispensable differences appearing between the two versions, Arabic and English, correction and another around of translation should be repeated to reduce such discrepancies (Behling \& Law, 2000).

1- For this study, one bilingual person, fluent in Arabic and English, working as faculty at King Saud University in the Linguistic College (English Department) helped with the translation process.

2- All Arabic statements were transcribed verbatim and inputted into the computer on the Microsoft Excel software.

3- The list of all the vision, mission, and goals statements were translated from Arabic to English by the researcher and this was the first version of translation from Arabic to English.

4- The researcher's translated English version was sent to the bilingual person to confirm the accuracy of the English translation. The original Arabic source was excluded since the researcher did not send it to the interpreter. The interpreter was asked to translate the English version into Arabic and to make any necessary corrections on it.

5- The interpreter sent his translation from English-Arabic including his feedback. A highlight, editing on the English version also was received. The interpreter also asked some questions to clarify some issues regarding some terminology in the Arabic version and its consensus with the English version.

6- The researcher matched the interpreters' versions (Arabic version) with the original Arabic version. Some differences were observed and discussion ensued to improve translation.

7- A new English version of translation was created including all comments and notes. 
8- The interpreters were asked to match and confirm the accuracy of the original Arabic version with the last English version. Several rounds of correspondence were done until both interpreters and the researcher reached a consensus between the Arabic and English versions for all vision, mission, and goals statements.

\section{Limitations of the Methodology}

This Content Analysis has several limitations regarding the research methodology used in this study:

1. A limitation regarding the Content Analysis methodology itself. This study employs the vision, mission, and goals statements of the Preparatory Year Program of each university. As each university has different needs, patterns of students, and different stakeholders, the interpretation and meaning may be different from what their creators intended. Therefore, the results of the Content Analysis may not prove one meaning for each vision, mission, and goals statements (Krippendorff, 2004). The researcher is aware that another researcher analyzing the vision, mission, and goals statements may reveal different outcomes. However, the researcher made an effort to ensure data reliability and validity as mentioned in Steps 5 and 7 in this chapter.

2. As mentioned in Chapter Two and Three, Content Analysis has different definitions and applications. Some scholars define Content Analysis as quantitative approach to research (Krippendorff, 2004; Neuendorf, 2002). In the mixed methods approach, others see Content Analysis as a "quantitative method that happens to be applied to qualitative data" (Tashakkori \& Teddlie, 2003, p. 405). However, despite these different perspectives, all agree that Content Analysis comprises an empirical study (Krippendorff, 2004; Neuendorf, 2002). For this study, the Content Analysis was performed as a quantitative and qualitative research methodology. 


\section{Chapter Four}

\section{Results}

\section{Purpose of the study and Research Questions}

The main purpose of this study was to analyze the vision, mission, and goals statements of all 28 Preparatory Year Programs, which are published on the official websites of all Saudi public universities, to assess whether the Preparatory Year Programs incorporates the principles of student success in the first-year of university as outlined in the Seven Central Principles of Student Success advanced by Cuseo (2014). This study also explored the Preparatory Year Programs trend in Saudi universities by identifying the most common key elements of the Seven Principles of Students Success as appeared in the Preparatory Year Programs' vision, mission, and goals statements. Finally, this study exposed the themes and formats of the Preparatory Year Programs in all 28 universities and reported the similarities and differences among all these programs based on university size, location, program date of establishment, and gender variables.

To accomplish this study's goals, the researcher used the government information published on the official Preparatory Year Programs' websites that express the vision, mission, and goals statements in each public university. The nine steps of Content Analysis (CA) developed by Neuendorf (2002) was used for data collection and analysis. This study consisted of two central research questions ( $\mathrm{a} \& \mathrm{~b}$ ) and two sub-questions (c \& d), articulated as following:

a. For each university, to what extent do the Preparatory Year Programs' vision, mission, and goals statements align with the Seven Principles of Students' Success in the first-year of university? 
b. What common key elements cited in the Seven Central Principles of Students Success are most often included in the Preparatory Year Programs' vision, mission, and goals statements?

c. For all Saudi public universities, what is the format and frequency of the Preparatory Year Programs' vision, mission, and goals statements?

d. How do the Preparatory Year Programs' vision, mission, and goals statements compare or contrast in content between universities, according to geographical location, size, the Preparatory Year Programs' date of establishment, and gender? This chapter contains five sections, starting with a brief review of the purpose of the study and research questions. The second section describes the population employed in the study. The third section reports the descriptive analysis of Preparatory Year Programs including universities' size, universities' locations, Preparatory Year Program's date of establishment, Preparatory Year Program organizational structure, Preparatory Year Program application policy, and gender variables. The fourth section involves the analysis of resulting data as it relates to the research questions of this study. Finally, the fifth section clarifies the additional limitations of the study observed after data analysis.

\section{Description of the Sample}

The target population consisted of 28 public universities that are managed and supervised by the Ministry of Education in Saudi Arabia (MOE, 2016) and represent all Saudi public universities. The nonrandom sampling process (purposive sampling) was utilized in this research. All Preparatory Year Programs that reported its vision, mission, and goal statements on the official websites were included in this study (see Appendix A \& D). All Saudi public universities were identified, coded, and sorted in alphabetical order for data analysis.

\section{Descriptive analysis}


In the $\mathrm{N}=28, \mathrm{n}=21(75.00 \%)$ universities reported their Preparatory Year Program vision statements on its website, while only seven (25\%) have no vision statements. For mission statements, $\mathrm{n}=24(85.71 \%)$ universities have a mission statement, while four $(14.29 \%)$ have no mission statement. For goal statements, $n=23(82.14 \%)$ universities have a goal statement, while five $(17.86 \%)$ have no goal statements.

For university size (US), $\mathrm{N}=28$ for the number of students enrolled in the Preparatory Year Program in 2014-2015 was used to classify universities into three groups. Group (1), $>10,000$ recorded nine (32.14\%) universities. Group (2), 10,000<5,000 recorded nine (32.14\%) universities. Group (3), 5,000<1000 assigned 10 (35.71\%) universities.

Table 2

Displays the First-Year Students Enrollment in Saudi Public Universities in 2014-2015

\begin{tabular}{|c|c|c|c|c|}
\hline University & Male & Female & Total & Classify \\
\hline UN24\# & 10,678 & 10,909 & 21,587 & \multirow{9}{*}{ Group (1) >10,000 } \\
\hline UN03\# & 8,796 & 6,391 & 15,187 & \\
\hline UN19\# & 5,921 & 8,254 & 14,175 & \\
\hline UN23\# & 5,724 & 7,536 & 13,260 & \\
\hline UN07\# & 4,717 & 7,102 & 11,819 & \\
\hline UN09\# & 5,780 & 5,849 & 11,629 & \\
\hline UN22\# & 4,837 & 6,677 & 11,514 & \\
\hline UN21\# & 5,212 & 4,961 & 10,173 & \\
\hline UN12\# & 5,106 & 4,952 & 10,058 & \\
\hline UN18\# & 0 & 9,682 & 9,682 & \multirow{9}{*}{ Group (2) $10,000<5,000$} \\
\hline UN14\# & 5,769 & 2,622 & 8,391 & \\
\hline UN11\# & 3,123 & 4,638 & 7,761 & \\
\hline UN20\# & 5,181 & 2,555 & 7,736 & \\
\hline UN27\# & 2,473 & 4,976 & 7,449 & \\
\hline UN28\# & 3,440 & 3,830 & 7,270 & \\
\hline UN17\# & 2,577 & 3,812 & 6,389 & \\
\hline UN02\# & 2,683 & 3,281 & 5,964 & \\
\hline UN25\# & 1,532 & 3,913 & 5,445 & \\
\hline UN16\# & 1,999 & 2,463 & 4,462 & \multirow{7}{*}{ Group (3) 5,000<1,000 } \\
\hline UN04\# & 2,501 & 1,879 & 4,380 & \\
\hline UN01\# & 1,940 & 2,347 & 4,287 & \\
\hline UN26\# & 275 & 3,354 & 3,629 & \\
\hline UN05\# & 1,103 & 2,442 & 3,545 & \\
\hline UN15\# & 1,574 & 1,778 & 3,352 & \\
\hline UN10\# & 2,546 & 0 & 2,546 & \\
\hline
\end{tabular}




$\begin{array}{cccc}\text { UN06\# } & 2,490 & 0 & 2,490 \\ \text { UN08\# } & 1,687 & 708 & 2,395 \\ \text { UN13\# } & 673 & 714 & 1,387\end{array}$

Source: Higher Education Statistics. http://www.moe.gov.sa/ar/Ministry/Deputy-Ministry-for-Planning-and-Informationaffairs/HESC/Ehsaat/Pages/default.aspx

For universities location (UL), for $\mathrm{N}=28$, eight universities $(28.57 \%)$ are located in the Middle of Saudi Arabia. Six universities (21.43\%) are in the West Province. Five universities (17.86\%) are in the North and five universities $(17.86 \%)$ are in the South Provinces. Three universities (10.71\%) are in the East province. Finally, one university (3.57\%) represented the Electronic University.

Furthermore, for the Preparatory Year Programs date of establishment, for $\mathrm{N}=28$, three Preparatory Year Programs (10.71\%) were established in 2014. One Preparatory Year Program (3.57\%) was founded in 2013, two Preparatory Year Programs (7.14\%) in 2012, four Preparatory Year Programs (14.29\%) in 2011, one Preparatory Year Program (3.57\%) in 2010, six Preparatory Year Programs (21.43\%) established in 2009, four Preparatory Year Programs (14.29\%) in 2008, three Preparatory Year Programs (10.71\%) in 2007, three Preparatory Year Programs (10.71\%) in 2005, and one Preparatory Year Program (3.57\%) was established in 1963 and updated in 2007. The data analysis revealed that 27 universities (96.43\%) established its Preparatory Year Program between 2005 and 2014. The data indicated that the program is considered a new phenomenon in Saudi higher education context. Finally, it is worthy to mention that two universities $(7.14 \%)$ are male only universities while one university (3.57\%) is female only (see Table 3 ). For confidentiality reason the researcher conceal the universities code on table 3.

Table 3

Preparatory Year Programs Date of Establishment

\begin{tabular}{cccccc}
\hline UNs Total & $\begin{array}{c}\text { Date of } \\
\text { Establishment }\end{array}$ & Comments & \% & $\begin{array}{c}\text { Location } \\
\text { (Province) }\end{array}$ & Gender \\
\hline 1 university & 1963 & Updating the Program on 2007 & 3.57 & East & $\mathrm{M}$ \\
\hline \multirow{2}{*}{3 universities } & 2005 & & 10.71 & Middle & $\mathrm{M} / \mathrm{F}$ \\
\end{tabular}




\begin{tabular}{|c|c|c|c|c|c|}
\hline & & & & North & $\mathrm{M} / \mathrm{F}$ \\
\hline \multirow{3}{*}{3 universities } & \multirow{3}{*}{2007} & & \multirow{3}{*}{10.71} & North & $\mathrm{M} / \mathrm{F}$ \\
\hline & & & & West & $\mathrm{M} / \mathrm{F}$ \\
\hline & & & & Middle & $\mathrm{M} / \mathrm{F}$ \\
\hline \multirow{4}{*}{4 universities } & \multirow{4}{*}{2008} & & \multirow{4}{*}{14.29} & South & $\mathrm{M} / \mathrm{F}$ \\
\hline & & & & West & $\mathrm{M}$ \\
\hline & & & & East & $\mathrm{M} / \mathrm{F}$ \\
\hline & & & & North & $\mathrm{M} / \mathrm{F}$ \\
\hline \multirow{6}{*}{6 universities } & \multirow{6}{*}{2009} & & \multirow{6}{*}{21.43} & South & $\mathrm{M} / \mathrm{F}$ \\
\hline & & & & East & $\mathrm{M} / \mathrm{F}$ \\
\hline & & & & South & $\mathrm{M} / \mathrm{F}$ \\
\hline & & & & Middle & $\mathrm{M} / \mathrm{F}$ \\
\hline & & & & Middle & $\mathrm{F}$ \\
\hline & & & & West & $\mathrm{M} / \mathrm{F}$ \\
\hline 1 university & 2010 & & 3.57 & South & $\mathrm{M} / \mathrm{F}$ \\
\hline \multirow{4}{*}{4 universities } & \multirow{4}{*}{2011} & & \multirow{4}{*}{14.29} & North & $\mathrm{M} / \mathrm{F}$ \\
\hline & & & & Online & $\mathrm{M} / \mathrm{F}$ \\
\hline & & & & Middle & $\mathrm{M} / \mathrm{F}$ \\
\hline & & & & West & $\mathrm{M} / \mathrm{F}$ \\
\hline \multirow{2}{*}{2 universities } & \multirow{2}{*}{\multicolumn{2}{|c|}{2012}} & \multirow{2}{*}{7.14} & Middle & $\mathrm{M} / \mathrm{F}$ \\
\hline & & & & Middle & $\mathrm{M} / \mathrm{F}$ \\
\hline 1 university & 2013 & & 3.57 & West & $\mathrm{M} / \mathrm{F}$ \\
\hline \multirow{3}{*}{3 universities } & \multirow{3}{*}{2014} & University establishment date & & South & $\mathrm{M} / \mathrm{F}$ \\
\hline & & & 10.71 & West & $\mathrm{M} / \mathrm{F}$ \\
\hline & & University establishment date & & North & $\mathrm{M} / \mathrm{F}$ \\
\hline
\end{tabular}

Regarding the Preparatory Year Program's organizational structure, for N=28, data analysis revealed that 17 universities (60.71\%) established separate deanship for the program named Preparatory Year Deanship. Two universities (7.14\%) named the program Preparatory Year and Supporting Studies Deanship. Furthermore, two universities (7.14\%) placed the program within the Educational Services Deanship. One university $(3.57 \%)$ applied the Preparatory Year Program within College of Applied and Supporting Studies. One university (3.57\%) named the program Pre-Professional Program. Two universities (7.14\%) applied the program for specific bodies of students within selected colleges e.g. Science and Medical colleges. Two universities (7.14\%) structured the program as a unit named Preparatory Year Program Unit under the Admission and Registration Deanship. Finally, 
only one university $(3.57 \%)$ did not report the program structure on its website. Table 4 displays the organizational structure of the Preparatory Year Program in Saudi public universities.

\section{Table 4}

The organizational structure of Preparatory Year in Saudi Public Universities.

\begin{tabular}{|c|c|c|c|}
\hline UNs Total & Structure & Comments & Percent \\
\hline 1 university & College of Applied and Supporting Studies & & $3.57 \%$ \\
\hline 2 universities & Educational Services Deanship & Serve Faculty and Students & $7.14 \%$ \\
\hline 1 university & None & & $3.57 \%$ \\
\hline 1 university & Preparatory and Supporting Studies Deanship & & \\
\hline 1 university & $\begin{array}{l}\text { Preparatory Year and Supportive Studies } \\
\text { Deanship }\end{array}$ & & $7.14 \%$ \\
\hline 17 universities & Preparatory Year Deanship & & $60.7 \%$ \\
\hline \multirow[b]{2}{*}{2 universities } & \multirow[b]{2}{*}{ Preparatory Year Program within specific college } & Only for Medical Colleges & \multirow[b]{2}{*}{$7.14 \%$} \\
\hline & & $\begin{array}{l}\text { College of Arts and } \\
\text { Sciences }\end{array}$ & \\
\hline 1 university & Pre-Professional Program within specific college & $\begin{array}{l}\text { Independent Program within } \\
\text { bachelor programs }\end{array}$ & $3.57 \%$ \\
\hline 2 universities & Unit under Admission \& Registration & & $7.14 \%$ \\
\hline
\end{tabular}

For the program application policy, for $\mathrm{N}=28,14(50 \%)$ universities apply the program for all new coming students. Thirteen universities $(46.43 \%)$ apply the program for a specific body of students, in particular for Science and Medical Colleges students. One university $(3.57 \%)$ did not report program application on its website.

Table 5

Shows the application policy of the Preparatory Year Programs.

\begin{tabular}{llc}
\hline UNs Total & Application Policy & Percent \\
\hline 14 universities & Apply for all new students & $\mathbf{5 0 \%}$ \\
\hline 1 university & None & $\mathbf{5 7 \%}$ \\
\hline 13 universities & Not for all new students & $\mathbf{4 6 . 4 3 \%}$ \\
\hline
\end{tabular}

\section{Finding for the First Major Research Question}

For the first research question, "For each university, to what extent does the

Preparatory Year Program's vision, mission, and goals statements align with the Seven Principles of Students' Success in the first-year of university?" the data was generated 
through the Content Analysis of the Preparatory Year Programs' vision, mission, and goals statements at all Saudi public universities using Unit of Thoughts (UTs) and assessed its alignment with the principles of student success in the first-year of university as outlined in the Seven Central Principles of Student Success, advanced by Cuseo (2014). The researcher analyzed each university and category vision or mission or goals statements separately and matched unit of thoughts for each category with an appropriate principle and calculated the alignment percentage for each category and for all three categories using the following formula (vision UTs alignment + mission UTs alignment + Goals UTs alignment/3) as explained in chapter-3.

University UN01\#. UN01 has no vision or mission statements reported on its website. The website includes only general statements that express the Preparatory Year Program's objectives. For the goal statement alignment with the Seven Principles of Student's Success in the first-year, the data analysis revealed three Unit of Thoughts (UT) distributed between two principles as follows:

1- Self-Efficacy (S.E.):

a. Preparatory Year Program is for helping and directing students to select the future college that fits his/her abilities and interests.

b. Providing students with the necessary skills for the labor market and developmental plan of government.

\section{2- Self-Awareness (S.A.):}

a. Developing student learning, thinking, and scientific discussion skills.

The goal statement aligned with two $(28.57 \%)$ of the Seven Principles of Students Success. Overall, the result for UN01\# indicted that the alignment of the vision, mission, and goal statements combined with seven principles only was $(9.52 \%)$. 
University UN02\#. The vision statement has one UT that aligned with one (14.29\%) of the seven principles:

1- Self-Efficacy (S.E.):

a. Preparing students for university study.

The mission statement also has one UT that aligned with one (14.29\%) of the seven principles:

1- Self-Efficacy (S.E.):

a. Developing student's behavior, skills, and knowledge for college study.

The goal statement has five UTs that aligned with two $(28.57 \%)$ of the seven principles:

1- Self-Efficacy (S.E.):

a. Developing student's skills in English, science, computer, thinking, research, and communication.

b. Helping students to choose an appropriate major that fits their abilities and interests, and meets the labor market's needs.

2- Social Integration (S.I.):

a. Educating students about university regulation and policy.

b. Promoting student's awareness about social responsibility,

c. Preparing students to adapt to the university environment.

Overall, the results for UN02\# indicted that the alignment of the vision, mission, and goal statement combined with seven principles was (19.05\%).

University UN03\#. For the vision statement, there was no indicator about the seven principles and there was no alignment.

For the mission statement, there were two UTs that aligned with two $(28.57 \%)$ of the seven principles: 


\section{1- Self-Efficacy (S.E.):}

a. Preparing students to be able to adapt to scientific and technical development.

2- Social Integration (S.I.):

a. Participating actively in national, regional, and global development.

For the goal statement, five UTs aligned with two (28.57\%) of the seven principles:

1- Self-Efficacy (S.E.):

a. Raising the academic level of students to continue their education smoothly and with excellence.

b. Promoting student's skills in English, basic science, and computers.

c. Preparing students for university study.

d. Assessing student's performance to help them choose their major.

2- Self-Awareness (S.I.):

a. Changing student's thinking ways for more autonomy and criticism.

Overall, the result for UN03\# indicted that the alignment of the vision, mission, and goal statements combined with the seven principles was (19.05\%).

University UN04\#. UN04\# has no vision or goal statements reported on its website. The website only includes a mission statement. The mission statement recorded only one UT match with one $(14.29 \%)$ of the seven principles.

1- Self-Efficacy (S.E.):

a. A comprehensive and professional academic system to prepare students for university study.

Overall, UN04\#'s alignment of the vision, mission, and goal statement combined with seven principles was $(4.76 \%)$.

University UN05\#. UN05\# has no indicators or website information about the Preparatory Year Program's vision, mission, and goal statements. 
University UN06\#. This university has three UTs distributed within three categories for the vision, mission, and goals statements. The alignment of the vision with the seven principles was one (14.29\%):

1- Self-Efficacy (S.E.):

a. Preparing students for science colleges.

For the mission, the alignment was one (14.29\%):

1- Self-Efficacy (S.E.):

a. Developing student's the necessary knowledge and skills to engage in the science colleges successfully

For the goal statement, the alignment with the seven principles was one (14.29\%):

1- Self-Efficacy (S.E.):

a. Fill the knowledge gap between high school outputs and university requirements.

Overall, for UN06\#, the alignment of the vision, mission, and goals statements combined with the seven principles was (14.29\%).

University UN07\#. This university has no indicators in its vision regarding the Seven Principles of Students Success. For the mission statement, three UTs were recorded and matched with three $(42.86 \%)$ of the seven principles as follows:

1- Self-Efficacy (S.E.):

a. Emphasizing on high moral and ethical values.

2- Personal Meaning (P.M.):

a. Achieve an effective transition of high school graduates into university.

3- Social Integration (S.I.):

a. Contribute positively to the community and society. 
For the goal statements, seven UTs were paired with five $(71.43 \%)$ of the seven principles as follows:

1- Self-Efficacy (S.E.):

a. Enhancing student's self-confidence and leadership skills.

b. Developing student's skills in English, Information Technology, Mathematics... Communication, learning, and aptitudes.

c. Preparing students to excel academically and maximize their ability.

2- Personal Meaning (P.M.):

a. To enable them to compete for quality jobs.

3- Active Involvement (A.I.):

a. Instilling self-discipline, commitment, and responsibility.

4- Social Integration (S.I.):

a. Developing students socially...through student's activity on and off campus.

5- Self-Awareness (S.A.):

a. Improving students' health awareness and physical fitness.

Overall, for UN07\#, the alignment of the vision, mission, and goals statements combined with seven principles at (38.10\%).

University UN08\#. Although UN08\# has a Preparatory Year Program there was no vision, mission, or goals statements reported on its website.

University UN09\#. UN09\# has no vision or mission statements reported on its website but, has goals statement. Three UTs were matched to two $(42.86 \%)$ of the seven principles as follows:

1- Self-Efficacy (S.E.):

a. Improve students' skills and knowledge, especially in the English language, computer skills, communication skills, and research. 
2- Social-Integration (S.I.):

a. Show and define the university's regulations and systems.

3- Self-Awareness (S.A.):

a. Give a student an opportunity to discover his/her skills and knowledge within the university environment.

Overall, for UN09\#, the alignment of the vision, mission, and goals statements

combined with the seven principles was (14.29\%).

University UN10\#. Nine UTs were distributed among three categories of analysis of the vision, mission, and goals statements for UN10\#.

For the vision statement, two UTs matched two (28.57\%) of seven principles as follows:

1- Personal Meaning (P.M.):

a. ...... and future leaders in their field of study.

2- Social Integration (S.I.):

a. To ensure that high school graduates of the Kingdom of Saudi Arabia become successful participants in the KFUPM community.

For the mission statement, two UTs paired with two (28.57\%) of the seven principles as follows:

1- Self-Efficacy (S.E.):

a. To ensure that students attain the level of proficiency in academia necessary to participate fully as KFUPM students.

2- Self-Awareness (S.A.):

a. Preparatory Year Program ... seeks to develop students into well-rounded individuals. 
For the goal statements, five UTs paired with three $(42.86 \%)$ of the seven principles as follows:

1- Personal Validation (P.V.):

a. To enhance their opportunities for success and excellence.

2- Self-Efficacy (S.E.):

a. Improving students' English language proficiency to prepare them for university.

b. Reviewing and reinforcing student's knowledge of Mathematical and Analytical techniques.

c. Consolidating students' knowledge of basic science, and providing necessary skills for effective learning.

3- Personal Meaning (P.M.):

a. Assisting students in choosing their academic majors through career guidance, as well as promoting student's physical well-being.

Overall, for UN10\#, the alignment of the vision, mission, and goals statements combined with the seven principles was $(33.33 \%)$.

University UN11\#. University 11 reported 12 UTs spread among three categories of analysis of the vision, mission, and goals statements.

For the vision statement, one UT matched one (14.29\%) of the seven principles:

1- Personal Meaning (P.M.):

a. Prepare for university's academic study.

For the mission statement, three UTs paired with three $(42.86 \%)$ of the seven principles as follows:

1- Self-Efficacy (S.E.):

a. Raise the... efficiency and skills of graduates. 
2- Personal Meaning (P.M.):

a. Contribute in finding suitable jobs for university graduates.

3- Social Integration (S.I.):

a. To meet the needs of the community.

For the goals statements, eight UTs paired with four $(57.14 \%)$ of the seven principles as follows:

1- Personal Validation (P.V.):

a. Support students' ambitions in academic excellence.

2- Self-Efficacy (S.E.):

a. Students has fluent skills in both Arabic and English.

b. Students are able to use the main computer programs and applications.

c. Give a student the ability to solve basic mathematical problems.

d. Developing skills of self-education, communication, and planning.

e. Developing skills of self (thinking, research, communication, fitness).

3- Active Involvement (A.I.):

a. Active participation in sport, cultural and social development activities.

4- Social Integration (S.I.):

a. Help students integrate into the university community.

Overall, for UN11\#, the alignment of the vision, mission, and goals statements combined with the seven principles was $(38.10 \%)$.

University UN12\#. Although UN12 has the Preparatory Year Program for specific student bodies, there was no vision, mission, or goals statements reported on the website.

University UN13\#. This university has no vision or mission statements reported on its website. Four UTs reported on the goals statement paired with two $(28.57 \%)$ of the seven principles as follows: 
1- Self-Efficacy (S.E.):

a. Preparing high school graduates to pursue professional studies in health science.

b. It provides them with the language skills essential for studying and communicating in an English language medium.

c. It introduces them to the basic concepts of general and medical science necessary for higher-level education in health science.

2- Self-Awareness (S.A.):

a. It moves the students from high school didactic and passive learning into university student-centered education.

Overall, for UN13\#, the alignment of the vision, mission, and goals statements combined with the seven principles was $(9.52 \%)$.

University UN14\#. Although UN14\# has a vision and mission statement reported on its website, there were no UTs or alignment with the seven principles.

For the goals statement, two UTs paired with two $(28.57 \%)$ of the seven principles as follows:

1- Self-Efficacy (S.E.):

a. Enhancing students' capabilities.

2- Self-Awareness (S.A.):

a. Raising student's awareness and responsibility.

Overall, for UN14\#, the alignment of the vision, mission, and goal statements combined with the seven principles was $(9.52 \%)$.

University UN15\#. For the vision statement, no UTs were found so, none matched the Seven Principles of Students Success. 
For the mission statement, two UTs paired with two $(28.57 \%)$ of the seven principles as follows:

1- Self-Efficacy (S.E.):

a. Preparing balanced personalities with a high degree of distinctiveness and readiness for university study.

2- Social Integration (S.I.):

a. Contributes to developing the society.

For the goals statement, the Arabic version of the goals statements has eight goals, while the English version only has four goals. The researcher matched both versions to explore the differences and similarities between them. The data analysis revealed that six UTs paired with two $(28.57 \%)$ of the seven principles as follows:

1- Self-Efficacy (S.E.):

a. To qualify students for the specialized university.

b. To prepare distinctive, balanced personalities.

c. To enhance the skills of the students in dealing with the cognitive environment and technology.

d. Provide students self-learning skills.

e. Develop thinking skills.

2- Social Integration (S.I.):

a. Provide students life-skills to integrate into society.

Overall, for UN15\#, the alignment of the vision, mission, and goals statements combined with the seven principles was (19.05\%).

University UN16\#. For the vision statement, one UT paired with one (14.29\%) of the Seven Principles of Students Success as follows:

1- Self-Efficacy (S.E.): 
a. Preparing students of the Preparatory Year for university study.

For the mission statement, four UTs matched three $(42.86 \%)$ of the seven principles as follows:

1- Self-Efficacy (S.E.):

a. Providing essential training on English language skills.

b. Developing their personality, the skills of information technology and basic science and its applications.

2- Active Involvement (A.I.):

a. Students have an effective participation in fostering an academic community at the university.

3- Social Integration (S.I.):

a. Prove to be productive members of society.

For the goals statement, three UTs paired with two $(28.57 \%)$ of the seven principles as follows:

1- Self-Efficacy (S.E.):

a. Equip all students with basic knowledge and skills in basic science subjects to prepare distinctive, balanced personalities.

2- Self-Awareness (S.A.):

a. Enhance the level of awareness and telling of responsibility among the students.

Overall, for UN16\# the alignment of the vision, mission, and goals statements combined with the seven principles was $(28.57 \%)$.

University UN17\#. For the vision statement, there were no UTs that could be paired with any of the Seven Principles of Students Success. 
The mission statement reported one UT aligned with one (14.29\%) of the Seven Principles of Students Success.

1- Personal Meaning (P.M.):

a. To create an aware generation that can build their future and serve their nation.

For the goals statement, seven UTs paired with three $(42.86 \%)$ of the seven principles as follows:

1- Self-Efficacy (S.E.):

a. Developing students' skills in the English language and basic science.

b. Developing student's personality.

c. Encouraging students... and self-development.

d. Developing student's academic, social, and personal skills.

2- Personal Meaning (P.M.):

a. Instill the love of academic excellence in the minds of students.

3- Active Involvement (A.I.):

a. Preparing students to be involved in the university's environment.

b. Accustom students on discipline, seriousness, and commitment of the university's laws.

Overall, for UN17\#'s alignment of the vision, mission, and goals statements combined with the seven principles was $(19.05 \%)$.

University UN18\#. For the vision statement, one UT paired with one (14.29\%) of the Seven Principles of Students Success:

1- Self-Efficacy (S.E.):

a. Preparing the student for undergraduate education. 
The mission statement also has one UT that aligns with one (14.29\%) of the Seven Principles of Students Success:

1- Self-Efficacy (S.E.):

a. Building the skills, knowledge, and values of the students...

For the goals statement, three UTs paired with one (14.29\%) of the seven principles as follows:

1- Self-Efficacy (S.E.):

a. Developing students' skills in the English language.

b. Providing student's mathematical, and self-development skills.

c. Enhancing students' personal and leadership abilities to cope with the requirements of undergraduate education.

Overall, UN18\#'s alignment of the vision, mission, and goals statements combined with the seven principles was (14.29\%).

University UN19\#. For the vision statement, there were no UTs that could be paired with any of the Seven Principles of Students Success.

The mission statement has three UTs that aligned with two $(28.57 \%)$ of the Seven Principles of Students Success:

1- Self-Efficacy (S.E.):

a. Raising the student's capability and skills.

b. Preparing new students for their colleges.

1- Active Involvement (A.I.):

a. Help students adapt to the university's environment.

For the goals statement, three UTs were paired with two $(28.57 \%)$ of the seven principles as follows:

1- Self-Efficacy (S.E.): 
a. Developing students' skills in the English language, computer, mathematics, science...

b. Developing life-skills, e.g. leadership, collaboration, teamwork, etc..

1- Personal Meaning (P.M.):

a. Providing an academic advising service to help students adapt to university life....

Overall, UN19\#'s alignment of the vision, mission, and goals statements combined with the seven principles was (19.05\%).

University UN20\#. For the vision statement, two UTs were paired with one (14.29\%) of the Seven Principles of Students Success:

2- Self-Efficacy (S.E.):

a. Bringing students to the higher level of academic readiness.

b. ....and personality traits.

The mission statement has four UTs that aligned with two $(28.57 \%)$ of the Seven Principles of Students Success:

1- Personal Validation (P.V.):

a. Achieve excellent academic performance.

2- Self-Efficacy (S.E.):

a. Developing basic skills.

b. Widening academic knowledge.

c. Reinforcing positive attitude.

For the goals statement, four UTs were paired with one (14.29\%) of the seven principles:

2- Self-Efficacy (S.E.): 
a. Preparing students to continue their studies in available academic environments.

b. Developing students' basic skills in English, computers, and thinking.

c. Reinforcing positive attitudes towards learning.

d. Encouraging... self-development.

Overall, UN20\#'s alignment of the vision, mission, and goals statements combined with the seven principles was (19.05\%).

University UN21\#. For the vision statement, there was no UTs that could be paired with any of the Seven Principles of Students Success.

The mission statement has three UTs that aligned with two $(28.57 \%)$ of the Seven Principles of Students Success:

1- Self-Efficacy (S.E.):

a. Developing students capability, academic skills and morale.

b. Preparing students...for future studies.

1- Social Integration (S.I.):

a. Preparing students, socially, to communicate with his/her society. For the goals statement, 10 UTs were paired with four $(57.14 \%)$ of the seven principles as follows:

1- Self-Efficacy (S.E.):

a. Preparing students for excellence in academic achievement.

b. Improving language capacity and develop ability to analyze for university study.

c. Developing English language and technology skills.

d. Developing self-learning capacity and learning collaboration skills.

e. Promoting leadership skills and instill initiative. 
f. Encouraging...self-development.

g. Preparing students for university study.

1- Personal Meaning (P.M.):

a. Discovering student's capability and direct him/her.

1- Active Involvement (A.I.):

a. Consolidate the principles of discipline, commitment, and responsibility.

1- Social Integration (S.I.):

a. Help student to engage in their society.

Overall, for UN21\#, the alignment of the vision, mission, and goals statements combined with the seven principles was $(28.57 \%)$.

University UN22\#. For the vision statement, there were no UTs that could be matched to any of the Seven Principles of Students Success.

The mission statement has three UTs that aligned with two $(28.57 \%)$ of the Seven Principles of Students Success:

1- Self-Efficacy (S.E.):

a. Preparing college students to master language and technology skills.

b. Developing student's capability to create self-knowledge and to pursue his/her academic life effectively.

2- Personal Meaning (P.M.):

a. Developing a positive attitude towards learning.

For the goals statement, 10 UTs paired with three $(42.86 \%)$ of the seven principles as follows:

1- Self-Efficacy (S.E.):

a. Preparing students for university study. 
b. Developing student's skills to deal with a knowledge environment and technology.

c. Developing student's ability to create self-knowledge and self-reliance.

d. Developing English language skills.

e. Developing learning, thinking, and research skills.

f. Developing handicraft skills.

b. Developing planning skills, using resource and library skills, and personal skills.

1- Personal Meaning (P.M.):

a. Educating students about his/her major requirements, academic terminology and future study.

b. Help students to choose his/her future major of study.

1- Active Involvement (A.I.):

a. Developing discipline, commitment, and responsibility skills and respect for university laws.

Overall, for UN22\#, the alignment of the vision, mission, and goals statements combined with the seven principles was $(23.81 \%)$.

University UN23\#. There were no UTs in the vision statement matched any of the Seven Principles of Students Success.

The mission statement has two UTs that aligned with two $(28.57 \%)$ of the Seven Principles of Students Success:

1- Self-Efficacy (S.E.):

a. To provide students with educational skills and competencies.

2- Social Integration (S.I.):

a. To build a qualified student socially. 
For the goals statement, six UTs paired with three $(42.86 \%)$ of the seven principles as follows:

1- Self-Efficacy (S.E.):

a. Providing students with necessary skills and knowledge in the English language, computer...thinking, research, communication, and learning skills.

b. Developing critical thinking skills... and problem solving skills.

2- Personal Meaning (P.M.):

a. Contribute effectively in their careers after graduation.

b. Facilitating the admission procedures for students...to determine the appropriate discipline based on their abilities and skills.

b. Promoting self-development through infusion of the principles of commitment, discipline, and responsibility, and elevating their leadership skills and self-confidence.

3- Social Integration (S.I.):

a. Strengthening their partnership with the community.

Overall, for UN23\#, the alignment of the vision, mission, and goals statements combined with the seven principles was $(23.81 \%)$.

University UN24\#. For the vision statement, one UT paired with one (14.29\%) of the Seven Principles of Students Success:

1- Self-Efficacy (S.E.):

a. Preparing a creative generation of students.

The mission statement has five UTs that aligned with two $(28.57 \%)$ of the Seven Principles of Students Success:

1- Self-Efficacy (S.E.):

a. To develop the intellectual capabilities of students. 
b. Enable them to acquire technical, linguistic, cognitive and thinking skills.

c. To build a distinctive, balanced personality.

2- Social Integration (S.I.):

a. Participating actively and effectively in the progress and prosperity of the Saudi community.

b. Able to accept and co-exist with others under the governing values of developed communities.

For the goals statement, four UTs paired with two (28.57\%) of the seven principles as follows:

1- Self-Efficacy (S.E.):

a. Providing students numerous skills.

2- Personal Meaning (P.M.):

a. To be successful and prominent in their academic studies and their career life.

b. To assess students' capabilities... and help them to select their future college.

Overall, for UN24\#, the alignment of the vision, mission, and goals statements combined with the seven principles was $(23.81 \%)$.

University UN25\#. For the vision statement, one UT paired with one (14.29\%) of the Seven Principles of Students Success.

1- Self-Efficacy (S.E.):

a. Fully prepare our students, so that they have a successful and rewarding academic experience.

The mission statement has one UT aligned with one (14.29\%) of the Seven Principles of Students Success.

1- Self-Efficacy (S.E.):

a. Teach students the skills required... 
For the goals statement, five UTs paired with three $(42.86 \%)$ of the seven principles as follows:

1- Self-Efficacy (S.E.):

a. Prepare the students for the rigors of university life.

b. Develop the students' English language and computer skills.

c. Promote originality, ingenuity, and improve their learning, research, thinking and communication skills.

2- Active Involvement (A.I.):

a. Expanding students' capabilities and help them take a leading role in student activities.

3- Self-Awareness (S.A.):

a. Expanding students' awareness about health and fitness.

Overall, for UN25\#, the alignment of the vision, mission, and goals statements combined with the seven principles was $(23.81 \%)$.

University UN26\#. UN26\# has no indicators or website information about their Preparatory Year Program's vision, mission, and goals statements.

University UN27\#. For the vision statement, one UT paired with one (14.29\%) of the Seven Principles of Students Success:

1- Self-Efficacy (S.E.):

a. To provide new students with academic skills.

The mission statement has two UTs that aligned with one (14.29\%) of the Seven Principles of Students Success:

1- Self-Efficacy (S.E.):

a. Provide students the language, political science, technology, and selfdevelopment skills. 
b. To help students succeed in their university studies.

For the goals statement, five UTs paired with two (28.57\%) of the seven principles as follows:

1- Self-Efficacy (S.E.):

a. Providing students the necessary skills to pursue their undergraduate education.

b. Fill the unbridged gap between secondary and university education.

c. Build the students' personality.

d. Provide the students with the basics of language and computing, mathematics, science, and self-learning strategies.

2- Personal Reflection (P.R.):

a. Inspiring students to encounter academic challenges.

Overall, for UN27\#, the alignment of the vision, mission, and goals statements combined with the seven principles was (19.05\%).

University UN28\#. There were no UTs in the vision statement that aligned with any of the Seven Principles of Students Success.

The mission statement has two UTs that aligned with two (28.57\%) of the Seven Principles of Students Success:

1- Self-Efficacy (S.E.):

a. Providing students skills and knowledge to achieve excellence.

2- Social Integration (S.I.):

a. Developing... social skills...to achieve academic excellence....

For the goals statement, nine UTs paired with two $(28.57 \%)$ of the seven principles as follows:

1- Self-Efficacy (S.E.): 
a. Providing students necessary skills that are required for university studies.

b. Promoting leadership, self-confidence, and initiative skills....

c. Help students to make academic achievements....

d. Developing students' skills to deal with a knowledge environment and technology....

e. Mastering language basics in Arabic and English....

f. Developing students' skills in using computer software, applications, and libraries...

g. Developing students' skills in mathematics....

h. Developing students' skills in science......

2- Active Involvement (A.I.):

a. Consolidating the principles of discipline, commitment, and responsibility.... Overall, UN28\#'s alignment of the vision, mission, and goals statements combined with the seven principles was (19.05\%).

In summary, the universities total alignments with the Seven Principles of Students Success are reported as follows:

1. Universities 7 and $11(38.1 \%)$

2. University $10(33.33 \%)$

3. Universities 16 and $21(28.57 \%)$

4. Universities 22, 23, 24, and $25(23.81 \%)$

5. Universities $2,3,15,17,19,20,27$, and $28(19.05 \%)$

6. Universities 6, 9, and 18 (14.29\%)

7. Universities 1, 13, and 14 (9.52\%)

8. University $4(4.76 \%)$

9. Universities 5, 8, 12, and $26(0 \%)$ 
Table 6 displays the alignments of the vision, mission, and goals statements for each university with the Seven Principles of Students Success in the first-year of college/university and the alignment total for each university. 
Table 6

Summarizes the alignments of each university with the Seven Principles of Student's Success and the alignment total for the vision, mission, and goals statements combined

\begin{tabular}{|c|c|c|c|c|c|c|c|c|c|c|c|c|c|c|c|c|c|c|c|c|c|c|c|c|c|}
\hline \multirow{2}{*}{$\begin{array}{l}\text { Cata } \\
\text { UN }\end{array}$} & \multicolumn{7}{|c|}{ Vision } & \multirow{2}{*}{$\%$} & \multicolumn{7}{|c|}{ Mission } & \multirow{2}{*}{$\%$} & \multicolumn{7}{|c|}{ Goals } & \multirow{2}{*}{$\%$} & \multirow{2}{*}{$\begin{array}{l}\text { Alignment } \\
\text { Overall \% }\end{array}$} \\
\hline & P.V. & S.E. & P.M. & A.I. & P.R. & S.I. & S.A. & & P.V. & S.E. & P.M. & A.I. & P.R. & S.I. & S.A. & & P.V. & S.E. & P.M. & A.I. & P.R. & S.I. & S.A. & & \\
\hline $07 \#$ & $\mathrm{x}$ & $\mathrm{x}$ & $\mathrm{x}$ & $\mathrm{x}$ & $\mathrm{x}$ & $\mathrm{x}$ & $\mathrm{x}$ & $\mathbf{0}$ & $\mathrm{x}$ & $\sqrt{ }$ & $\sqrt{ }$ & $\mathrm{x}$ & $\mathrm{x}$ & $\sqrt{ }$ & $\mathrm{x}$ & 42.86 & $\mathrm{x}$ & $\sqrt{ }$ & $\sqrt{ }$ & $\sqrt{ }$ & $\mathrm{x}$ & $\sqrt{ }$ & $\sqrt{ }$ & 71.43 & 38.1 \\
\hline $11 \#$ & $\mathrm{x}$ & $\mathrm{x}$ & $\sqrt{ }$ & $\mathrm{x}$ & $\mathrm{x}$ & $\mathrm{x}$ & $\mathrm{x}$ & 14.29 & $\mathrm{x}$ & $\sqrt{ }$ & $\sqrt{ }$ & $\mathrm{x}$ & $\mathrm{x}$ & $\sqrt{ }$ & $\mathrm{x}$ & 42.86 & $\sqrt{ }$ & $\sqrt{ }$ & $\mathrm{x}$ & $\sqrt{ }$ & $\mathrm{x}$ & $\sqrt{ }$ & $\mathrm{x}$ & 57.14 & 38.1 \\
\hline $10 \#$ & $\mathrm{x}$ & $\mathrm{x}$ & $\sqrt{ }$ & $\mathrm{x}$ & $\mathrm{x}$ & $\sqrt{ }$ & $\mathrm{x}$ & 28.57 & $\mathrm{x}$ & $\sqrt{ }$ & $\mathrm{x}$ & $\mathrm{x}$ & $\mathrm{x}$ & $\mathrm{x}$ & $\sqrt{ }$ & 28.57 & $\mathrm{x}$ & $\sqrt{ }$ & $\sqrt{ }$ & $\mathrm{x}$ & $\sqrt{ }$ & $\mathrm{x}$ & $\mathrm{x}$ & 42.86 & 33.33 \\
\hline $16 \#$ & $\mathrm{x}$ & $\sqrt{ }$ & $\mathrm{x}$ & $\mathrm{x}$ & $\mathrm{x}$ & $\mathrm{x}$ & $\mathrm{x}$ & 14.29 & $\mathrm{x}$ & $\sqrt{ }$ & $\mathrm{x}$ & $\sqrt{ }$ & $\mathrm{x}$ & $\sqrt{ }$ & $\mathrm{x}$ & 42.86 & $\mathrm{x}$ & $\sqrt{ }$ & $\mathrm{x}$ & $\mathrm{x}$ & $\mathrm{x}$ & $\mathrm{x}$ & $\sqrt{ }$ & 28.57 & 28.57 \\
\hline $21 \#$ & $\mathrm{x}$ & $\mathrm{x}$ & $\mathrm{x}$ & $\mathrm{x}$ & $\mathrm{x}$ & $\mathrm{x}$ & $\mathrm{x}$ & $\mathbf{0}$ & $\mathrm{x}$ & $\sqrt{ }$ & $\mathrm{x}$ & $\mathrm{x}$ & $\mathrm{x}$ & $\sqrt{ }$ & $\mathrm{x}$ & 28.57 & $\mathrm{x}$ & $\sqrt{ }$ & $\sqrt{ }$ & $\sqrt{ }$ & $\mathrm{x}$ & $\sqrt{ }$ & $\mathrm{x}$ & 57.14 & 28.57 \\
\hline $22 \#$ & $\mathrm{x}$ & $\mathrm{x}$ & $\mathrm{x}$ & $\mathrm{x}$ & $\mathrm{x}$ & $\mathrm{x}$ & $x$ & 0 & $\mathrm{x}$ & $\sqrt{ }$ & $\sqrt{ }$ & $\mathrm{x}$ & $\mathrm{x}$ & $\mathrm{x}$ & $\mathrm{x}$ & 28.57 & $\mathrm{x}$ & $\sqrt{ }$ & $\sqrt{ }$ & $\sqrt{ }$ & $\mathrm{x}$ & $\mathrm{x}$ & $\mathrm{x}$ & 42.86 & 23.81 \\
\hline $23 \#$ & $\mathrm{x}$ & $\mathrm{x}$ & $\mathrm{x}$ & $\mathrm{x}$ & $\mathrm{x}$ & $\mathrm{x}$ & $\mathrm{x}$ & 0 & $\mathrm{x}$ & $\sqrt{ }$ & $\mathrm{x}$ & $\mathrm{x}$ & $\mathrm{x}$ & $\sqrt{ }$ & $\mathrm{x}$ & 28.57 & $\mathrm{x}$ & $\sqrt{ }$ & $\sqrt{ }$ & $\mathrm{x}$ & $\mathrm{x}$ & $\sqrt{ }$ & $\mathrm{x}$ & 42.86 & 23.81 \\
\hline $24 \#$ & $\mathrm{x}$ & $\sqrt{ }$ & $\mathrm{x}$ & $\mathrm{x}$ & $\mathrm{x}$ & $\mathrm{x}$ & $\mathrm{x}$ & 14.29 & $\mathrm{x}$ & $\sqrt{ }$ & $\mathrm{x}$ & $\mathrm{x}$ & $\mathrm{x}$ & $\sqrt{ }$ & $\mathrm{x}$ & 28.57 & $\mathrm{x}$ & $\sqrt{ }$ & $\sqrt{ }$ & $\mathrm{x}$ & $\mathrm{x}$ & $\mathrm{x}$ & $\mathrm{x}$ & 28.57 & 23.81 \\
\hline $25 \#$ & $\mathrm{x}$ & $\sqrt{ }$ & $\mathrm{x}$ & $\mathrm{x}$ & $\mathrm{x}$ & $\mathrm{x}$ & $\mathrm{x}$ & 14.29 & $\mathrm{x}$ & $\sqrt{ }$ & $\mathrm{x}$ & $\mathrm{x}$ & $\mathrm{x}$ & $\mathrm{x}$ & $\mathrm{x}$ & 14.29 & $\mathrm{x}$ & $\sqrt{ }$ & $\mathrm{x}$ & $\sqrt{ }$ & $\mathrm{x}$ & $\mathrm{x}$ & $\sqrt{ }$ & 42.86 & 23.81 \\
\hline 02\# & $\mathrm{x}$ & $\sqrt{ }$ & $\mathrm{x}$ & $\mathrm{x}$ & $\mathrm{x}$ & $\mathrm{x}$ & $\mathrm{x}$ & 14.29 & $\mathrm{x}$ & $\sqrt{ }$ & $\mathrm{x}$ & $\mathrm{x}$ & $\mathrm{x}$ & $\mathrm{x}$ & $\mathrm{x}$ & 14.29 & $\mathrm{x}$ & $\sqrt{ }$ & $\mathrm{x}$ & $\mathrm{x}$ & $\mathrm{x}$ & $\sqrt{ }$ & $\mathrm{x}$ & 28.57 & 19.05 \\
\hline 03\# & $\mathrm{x}$ & $\mathrm{x}$ & $\mathrm{x}$ & $\mathrm{x}$ & $\mathrm{x}$ & $\mathrm{x}$ & $\mathrm{x}$ & $\mathbf{0}$ & $\mathrm{x}$ & $\sqrt{ }$ & $\mathrm{x}$ & $\mathrm{x}$ & $\mathrm{x}$ & $\sqrt{ }$ & $\mathrm{x}$ & 28.57 & $\mathrm{x}$ & $\sqrt{ }$ & $\mathrm{x}$ & $\mathrm{x}$ & $\mathrm{x}$ & $\mathrm{x}$ & $\sqrt{ }$ & 28.57 & 19.05 \\
\hline $15 \#$ & $\mathrm{x}$ & $\mathrm{x}$ & $\mathrm{x}$ & $\mathrm{x}$ & $\mathrm{x}$ & $\mathrm{x}$ & $\mathrm{x}$ & $\mathbf{0}$ & $\mathrm{x}$ & $\sqrt{ }$ & $\mathrm{x}$ & $\mathrm{x}$ & $\mathrm{x}$ & $\sqrt{ }$ & $\mathrm{x}$ & 28.57 & $\mathrm{x}$ & $\sqrt{ }$ & $\mathrm{x}$ & $\mathrm{x}$ & $\mathrm{x}$ & $\sqrt{ }$ & $\mathrm{x}$ & 28.57 & 19.05 \\
\hline $17 \#$ & $\mathrm{x}$ & $\mathrm{x}$ & $\mathrm{x}$ & $\mathrm{x}$ & $\mathrm{x}$ & $\mathrm{x}$ & $\mathrm{x}$ & $\mathbf{0}$ & $\mathrm{x}$ & $\mathrm{x}$ & $\sqrt{ }$ & $\mathrm{x}$ & $\mathrm{x}$ & $\mathrm{x}$ & $\mathrm{x}$ & 14.29 & $\mathrm{x}$ & $\sqrt{ }$ & $\sqrt{ }$ & $\sqrt{ }$ & $\mathrm{x}$ & $\mathrm{x}$ & $\mathrm{x}$ & 42.86 & 19.05 \\
\hline 19\# & $\mathrm{x}$ & $\mathrm{x}$ & $\mathrm{x}$ & $\mathrm{x}$ & $\mathrm{x}$ & $\mathrm{x}$ & $x$ & $\mathbf{0}$ & $\mathrm{x}$ & $\sqrt{ }$ & $\mathrm{x}$ & $\sqrt{ }$ & $\mathrm{x}$ & $\mathrm{x}$ & $\mathrm{x}$ & 28.57 & $\mathrm{x}$ & $\sqrt{ }$ & $\sqrt{ }$ & $\mathrm{x}$ & $\mathrm{x}$ & $\mathrm{x}$ & $\mathrm{x}$ & 28.57 & 19.05 \\
\hline $20 \#$ & $\mathrm{x}$ & $\sqrt{ }$ & $\mathrm{x}$ & $\mathrm{x}$ & $\mathrm{x}$ & $\mathrm{x}$ & $\mathrm{x}$ & 14.29 & $\sqrt{ }$ & $\sqrt{ }$ & $\mathrm{x}$ & $\mathrm{x}$ & $\mathrm{x}$ & $\mathrm{x}$ & $\mathrm{x}$ & 28.57 & $\mathrm{x}$ & $\sqrt{ }$ & $\mathrm{x}$ & $\mathrm{x}$ & $\mathrm{x}$ & $x$ & $\mathrm{x}$ & 14.29 & 19.05 \\
\hline $27 \#$ & $\mathrm{x}$ & $\sqrt{ }$ & $\mathrm{x}$ & $\mathrm{x}$ & $\mathrm{x}$ & $\mathrm{x}$ & $\mathrm{x}$ & 14.29 & $\mathrm{x}$ & $\sqrt{ }$ & $\mathrm{x}$ & $\mathrm{x}$ & $\mathrm{x}$ & $\mathrm{x}$ & $\mathrm{x}$ & 14.29 & $\mathrm{x}$ & $\sqrt{ }$ & $\mathrm{x}$ & $\mathrm{x}$ & $\sqrt{ }$ & $\mathrm{x}$ & $\mathrm{x}$ & 28.57 & 19.05 \\
\hline $28 \#$ & $\mathrm{x}$ & $\mathrm{x}$ & $\mathrm{x}$ & $\mathrm{x}$ & $\mathrm{x}$ & $\mathrm{x}$ & $\mathrm{x}$ & $\mathbf{0}$ & $\mathrm{x}$ & $\sqrt{ }$ & $\mathrm{x}$ & $\mathrm{x}$ & $\mathrm{x}$ & $\sqrt{ }$ & $\mathrm{x}$ & 28.57 & $\mathrm{x}$ & $\sqrt{ }$ & $\mathrm{x}$ & $\sqrt{ }$ & $\mathrm{x}$ & $\mathrm{x}$ & $\mathrm{x}$ & 28.57 & 19.05 \\
\hline 06\# & $\mathrm{x}$ & $\sqrt{ }$ & $\mathrm{x}$ & $\mathrm{x}$ & $\mathrm{x}$ & $\mathrm{x}$ & $\mathrm{x}$ & 14.29 & $\mathrm{x}$ & $\sqrt{ }$ & $\mathrm{x}$ & $\mathrm{x}$ & $\mathrm{x}$ & $\mathrm{x}$ & $\mathrm{x}$ & 14.29 & $\mathrm{x}$ & $\sqrt{ }$ & $\mathrm{x}$ & $\mathrm{x}$ & $\mathrm{x}$ & $\mathrm{x}$ & $\mathrm{x}$ & 14.29 & 14.29 \\
\hline 09\# & $\mathrm{x}$ & $\mathrm{x}$ & $\mathrm{x}$ & $\mathrm{x}$ & $\mathrm{x}$ & $\mathrm{x}$ & $\mathrm{x}$ & $\mathbf{0}$ & $\mathrm{x}$ & $\mathrm{x}$ & $\mathrm{x}$ & $\mathrm{x}$ & $\mathrm{x}$ & $\mathrm{x}$ & $\mathrm{x}$ & $\mathbf{0}$ & $\mathrm{x}$ & $\sqrt{ }$ & $\mathrm{x}$ & $\mathrm{x}$ & $\mathrm{x}$ & $\sqrt{ }$ & $\sqrt{ }$ & 42.86 & 14.29 \\
\hline 18\# & $\mathrm{x}$ & $\sqrt{ }$ & $\mathrm{x}$ & $\mathrm{x}$ & $\mathrm{x}$ & $\mathrm{x}$ & $\mathrm{x}$ & 14.29 & $\mathrm{x}$ & $\sqrt{ }$ & $\mathrm{x}$ & $\mathrm{x}$ & $\mathrm{x}$ & $\mathrm{x}$ & $\mathrm{x}$ & 14.29 & $\mathrm{x}$ & $\sqrt{ }$ & $\mathrm{x}$ & $\mathrm{x}$ & $\mathrm{x}$ & $\mathrm{x}$ & $\mathrm{x}$ & 14.29 & 14.29 \\
\hline 01\# & $\mathrm{x}$ & $\mathrm{x}$ & $\mathrm{x}$ & $\mathrm{x}$ & $\mathrm{x}$ & $\mathrm{x}$ & $\mathrm{x}$ & $\mathbf{0}$ & $\mathrm{x}$ & $\mathrm{x}$ & $\mathrm{x}$ & $\mathrm{x}$ & $\mathrm{x}$ & $\mathrm{x}$ & $\mathrm{x}$ & $\mathbf{0}$ & $\mathrm{x}$ & $\sqrt{ }$ & $\mathrm{x}$ & $\mathrm{x}$ & $\mathrm{x}$ & $\mathrm{x}$ & $\sqrt{ }$ & 28.57 & 9.52 \\
\hline 13\# & $\mathrm{x}$ & $\mathrm{x}$ & $\mathrm{x}$ & $\mathrm{x}$ & $\mathrm{x}$ & $\mathrm{x}$ & $\mathrm{x}$ & $\mathbf{0}$ & $\mathrm{x}$ & $\mathrm{x}$ & $\mathrm{x}$ & $\mathrm{x}$ & $\mathrm{x}$ & $\mathrm{x}$ & $\mathrm{x}$ & $\mathbf{0}$ & $\mathrm{x}$ & $\sqrt{ }$ & $\mathrm{x}$ & $\mathrm{x}$ & $\mathrm{x}$ & $\mathrm{x}$ & $\sqrt{ }$ & 28.57 & 9.52 \\
\hline 14\# & $\mathrm{x}$ & $\mathrm{x}$ & $\mathrm{x}$ & $\mathrm{x}$ & $\mathrm{x}$ & $\mathrm{x}$ & $\mathrm{x}$ & $\mathbf{0}$ & $\mathrm{x}$ & $\mathrm{x}$ & $\mathrm{x}$ & $\mathrm{x}$ & $\mathrm{x}$ & $\mathrm{x}$ & $\mathrm{x}$ & $\mathbf{0}$ & $\mathrm{x}$ & $\sqrt{ }$ & $\mathrm{x}$ & $\mathrm{x}$ & $\mathrm{x}$ & $\mathrm{x}$ & $\sqrt{ }$ & 28.57 & 9.52 \\
\hline 04\# & $\mathrm{x}$ & $\mathrm{x}$ & $\mathrm{x}$ & $\mathrm{x}$ & $\mathrm{x}$ & $\mathrm{x}$ & $\mathrm{x}$ & $\mathbf{0}$ & $\mathrm{x}$ & $\sqrt{ }$ & $\mathrm{x}$ & $\mathrm{x}$ & $\mathrm{x}$ & $\mathrm{x}$ & $\mathrm{x}$ & 14.29 & $\mathrm{x}$ & $\mathrm{x}$ & $\mathrm{x}$ & $\mathrm{x}$ & $\mathrm{x}$ & $\mathrm{x}$ & $\mathrm{x}$ & $\mathbf{0}$ & 4.76 \\
\hline 05\# & $\mathrm{x}$ & $\mathrm{x}$ & $\mathrm{x}$ & $\mathrm{x}$ & $\mathrm{x}$ & $\mathrm{x}$ & $\mathrm{x}$ & $\mathbf{0}$ & $\mathrm{x}$ & $\mathrm{x}$ & $\mathrm{x}$ & $\mathrm{x}$ & $\mathrm{x}$ & $\mathrm{x}$ & $\mathrm{x}$ & $\mathbf{0}$ & $\mathrm{x}$ & $\mathrm{x}$ & $\mathrm{x}$ & $\mathrm{x}$ & $\mathrm{x}$ & $\mathrm{x}$ & $\mathrm{x}$ & 0 & $\mathbf{0}$ \\
\hline 08\# & $\mathrm{x}$ & $\mathrm{x}$ & $\mathrm{x}$ & $\mathrm{x}$ & $\mathrm{x}$ & $\mathrm{x}$ & $\mathrm{x}$ & $\mathbf{0}$ & $\mathrm{x}$ & $\mathrm{x}$ & $\mathrm{x}$ & $\mathrm{x}$ & $\mathrm{x}$ & $\mathrm{x}$ & $\mathrm{x}$ & $\mathbf{0}$ & $\mathrm{x}$ & $\mathrm{x}$ & $\mathrm{x}$ & $\mathrm{x}$ & $\mathrm{x}$ & $\mathrm{x}$ & $\mathrm{x}$ & $\mathbf{0}$ & $\mathbf{0}$ \\
\hline $12 \#$ & $\mathrm{x}$ & $\mathrm{x}$ & $\mathrm{x}$ & $\mathrm{x}$ & $\mathrm{x}$ & $\mathrm{x}$ & $\mathrm{x}$ & $\mathbf{0}$ & $\mathrm{x}$ & $\mathrm{x}$ & $\mathrm{x}$ & $\mathrm{x}$ & $\mathrm{x}$ & $\mathrm{x}$ & $\mathrm{x}$ & $\mathbf{0}$ & $\mathrm{x}$ & $\mathrm{x}$ & $\mathrm{x}$ & $\mathrm{x}$ & $\mathrm{x}$ & $\mathrm{x}$ & $\mathrm{x}$ & 0 & $\mathbf{0}$ \\
\hline $26 \#$ & $\mathrm{x}$ & $\mathrm{x}$ & $\mathrm{x}$ & $\mathrm{x}$ & $\mathrm{x}$ & $\mathrm{x}$ & $\mathrm{x}$ & $\mathbf{0}$ & $\mathrm{x}$ & $\mathrm{x}$ & $\mathrm{x}$ & $\mathrm{x}$ & $\mathrm{x}$ & $\mathrm{x}$ & $\mathrm{x}$ & $\mathbf{0}$ & $\mathrm{x}$ & $\mathrm{x}$ & $\mathrm{x}$ & $\mathrm{x}$ & $\mathrm{x}$ & $\mathrm{x}$ & $\mathrm{x}$ & $\mathbf{0}$ & 0 \\
\hline
\end{tabular}




\section{Finding for the Second Major Research Question}

For the second research question, "What common key elements cited in the Seven Central Principles of Students Success are most often included in the Preparatory Year Programs' vision, mission, and goals statements" the data retrieved from Table 7 used to answers this research question.

The total of Unit of Thoughts (UTs) aligned with the Seven Principles of Students Success in the first-year of university was 174. Self-Efficacy (S.E.) was recorded as the most cited principle in the vision, mission, and goals statements of the Preparatory Year Program in Saudi Arabian public universities, where they recorded nine (5.17\%) for the vision statement, $28(16.10 \%)$ for the mission statement, and $76(43.68 \%)$ for the goals statement. Overall, 113 (64.94\%) UTs of vision, mission, and goals statements aligned with the S.E. principle.

The principle of Social Integration (S.I.) placed in the second level of the most cited in the Preparatory Year Programs' vision, mission, and goals statements. Twenty $(11.49 \%)$ UTs paired with the S.I. principle. The Personal Meaning (P.M.) principle cited 18 (10.34\%) UTs and came in the third level of the most cited in the Preparatory Year Programs' vision, mission, and goals statements. The Active Involvement (A.I.) principle placed in the fourth level of matching at 10 (5.75\%) UTs. The Self-Awareness (S.A.) principle recorded nine (5.17\%) pairings with the Preparatory Year Programs' vision, mission, and goals statements. Lastly, the Personal Validation (P.V.) and Personal Reflection (P.R.) placed in the lowest level of matching with the Preparatory Year Programs' vision, mission, and goals statements where only two (1.15\%) UTs were cited for each principle.

Overall, the Seven Principles of Students Success frequently appeared in the goal and mission statements of Preparatory Year Programs' more than the vision statement, where 116 
(66.67\%) UTs were cited from the goals statements, 46 (26.44\%) UTs from the mission statements, and $12(6.90 \%)$ UTs from the vision statements. Table 7 summarizes the common key elements cited in the Seven Central Principles of Students Success that were most often included in the Preparatory Year Programs' vision, mission, and goals statements. 
Table 7

The Seven Principles of Student's Success as the most appeared in the Preparatory Year Programs' vision, mission, and goal statements

\begin{tabular}{|c|c|c|c|c|c|c|c|c|c|c|c|c|c|c|c|c|c|c|c|c|c|c|}
\hline \multirow{2}{*}{ Cata } & \multicolumn{3}{|c|}{ P.V. } & \multicolumn{3}{|c|}{ S.E. } & \multicolumn{3}{|c|}{ P.M. } & \multicolumn{3}{|c|}{ A.I. } & \multicolumn{3}{|c|}{ P.R. } & \multicolumn{3}{|c|}{ S.I. } & \multicolumn{3}{|c|}{ S.A. } & \multirow{2}{*}{ UTs } \\
\hline & $\mathrm{Vi}$ & Mi & Go & $\mathrm{Vi}$ & Mi & Go & Vi & $\mathrm{Mi}$ & Go & $\mathrm{Vi}$ & Mi & Go & $\mathrm{Vi}$ & $\mathrm{Mi}$ & Go & Vi & $\mathrm{Mi}$ & Go & $\mathrm{Vi}$ & $\mathrm{Mi}$ & Go & \\
\hline Total & 0 & 1 & 1 & 9 & 28 & 76 & 2 & 4 & 12 & 0 & 2 & 8 & 0 & 0 & 2 & 1 & 10 & 9 & 0 & 1 & 8 & 174 \\
\hline $01 \#$ & 0 & 0 & 0 & 0 & 0 & 2 & 0 & 0 & 0 & 0 & 0 & 0 & 0 & 0 & 0 & 0 & 0 & 0 & 0 & 0 & 1 & 3 \\
\hline 02\# & 0 & 0 & 0 & 1 & 1 & 2 & 0 & 0 & 0 & 0 & 0 & 0 & 0 & 0 & 0 & 0 & 0 & 3 & 0 & 0 & 0 & 7 \\
\hline 03\# & 0 & 0 & 0 & 0 & 1 & 4 & 0 & 0 & 0 & 0 & 0 & 0 & 0 & 0 & 0 & 0 & 1 & 0 & 0 & 0 & 1 & 7 \\
\hline $04 \#$ & 0 & 0 & 0 & 0 & 1 & 0 & 0 & 0 & 0 & 0 & 0 & 0 & 0 & 0 & 0 & 0 & 0 & 0 & 0 & 0 & 0 & 1 \\
\hline 05\# & 0 & 0 & 0 & 0 & 0 & 0 & 0 & 0 & 0 & 0 & 0 & 0 & 0 & 0 & 0 & 0 & 0 & 0 & 0 & 0 & 0 & 0 \\
\hline 06\# & 0 & 0 & 0 & 1 & 1 & 1 & 0 & 0 & 0 & 0 & 0 & 0 & 0 & 0 & 0 & 0 & 0 & 0 & 0 & 0 & 0 & 3 \\
\hline $07 \#$ & 0 & 0 & 0 & 0 & 1 & 3 & 0 & 1 & 1 & 0 & 0 & 1 & 0 & 0 & 0 & 0 & 1 & 1 & 0 & 0 & 1 & 10 \\
\hline 08\# & 0 & 0 & 0 & 0 & 0 & 0 & 0 & 0 & 0 & 0 & 0 & 0 & 0 & 0 & 0 & 0 & 0 & 0 & 0 & 0 & 0 & 0 \\
\hline 09\# & 0 & 0 & 0 & 0 & 0 & 1 & 0 & 0 & 0 & 0 & 0 & 0 & 0 & 0 & 0 & 0 & 0 & 1 & 0 & 0 & 1 & 3 \\
\hline $10 \#$ & 0 & 0 & 0 & 0 & 1 & 3 & 1 & 0 & 1 & 0 & 0 & 0 & 0 & 0 & 1 & 1 & 0 & 0 & 0 & 1 & 0 & 9 \\
\hline $11 \#$ & 0 & 0 & 1 & 0 & 1 & 5 & 1 & 1 & 0 & 0 & 0 & 1 & 0 & 0 & 0 & 0 & 1 & 1 & 0 & 0 & 0 & 12 \\
\hline 12\# & 0 & 0 & 0 & 0 & 0 & 0 & 0 & 0 & 0 & 0 & 0 & 0 & 0 & 0 & 0 & 0 & 0 & 0 & 0 & 0 & 0 & 0 \\
\hline 13\# & 0 & 0 & 0 & 0 & 0 & 3 & 0 & 0 & 0 & 0 & 0 & 0 & 0 & 0 & 0 & 0 & 0 & 0 & 0 & 0 & 1 & 4 \\
\hline $14 \#$ & 0 & 0 & 0 & 0 & 0 & 1 & 0 & 0 & 0 & 0 & 0 & 0 & 0 & 0 & 0 & 0 & 0 & 0 & 0 & 0 & 1 & 2 \\
\hline $15 \#$ & 0 & 0 & 0 & 0 & 1 & 5 & 0 & 0 & 0 & 0 & 0 & 0 & 0 & 0 & 0 & 0 & 1 & 1 & 0 & 0 & 0 & 8 \\
\hline $16 \#$ & 0 & 0 & 0 & 1 & 2 & 1 & 0 & 0 & 0 & 0 & 1 & 0 & 0 & 0 & 0 & 0 & 1 & 0 & 0 & 0 & 1 & 7 \\
\hline $17 \#$ & 0 & 0 & 0 & 0 & 0 & 4 & 0 & 1 & 1 & 0 & 0 & 2 & 0 & 0 & 0 & 0 & 0 & 0 & 0 & 0 & 0 & 8 \\
\hline $18 \#$ & 0 & 0 & 0 & 1 & 1 & 3 & 0 & 0 & 0 & 0 & 0 & 0 & 0 & 0 & 0 & 0 & 0 & 0 & 0 & 0 & 0 & 5 \\
\hline $19 \#$ & 0 & 0 & 0 & 0 & 2 & 2 & 0 & 0 & 1 & 0 & 1 & 0 & 0 & 0 & 0 & 0 & 0 & 0 & 0 & 0 & 0 & 6 \\
\hline $20 \#$ & 0 & 1 & 0 & 2 & 3 & 4 & 0 & 0 & 0 & 0 & 0 & 0 & 0 & 0 & 0 & 0 & 0 & 0 & 0 & 0 & 0 & 10 \\
\hline $21 \#$ & 0 & 0 & 0 & 0 & 2 & 7 & 0 & 0 & 1 & 0 & 0 & 1 & 0 & 0 & 0 & 0 & 1 & 1 & 0 & 0 & 0 & 13 \\
\hline $22 \#$ & 0 & 0 & 0 & 0 & 2 & 7 & 0 & 1 & 2 & 0 & 0 & 1 & 0 & 0 & 0 & 0 & 0 & 0 & 0 & 0 & 0 & 13 \\
\hline 23\# & 0 & 0 & 0 & 0 & 1 & 2 & 0 & 0 & 3 & 0 & 0 & 0 & 0 & 0 & 0 & 0 & 1 & 1 & 0 & 0 & 0 & 8 \\
\hline
\end{tabular}

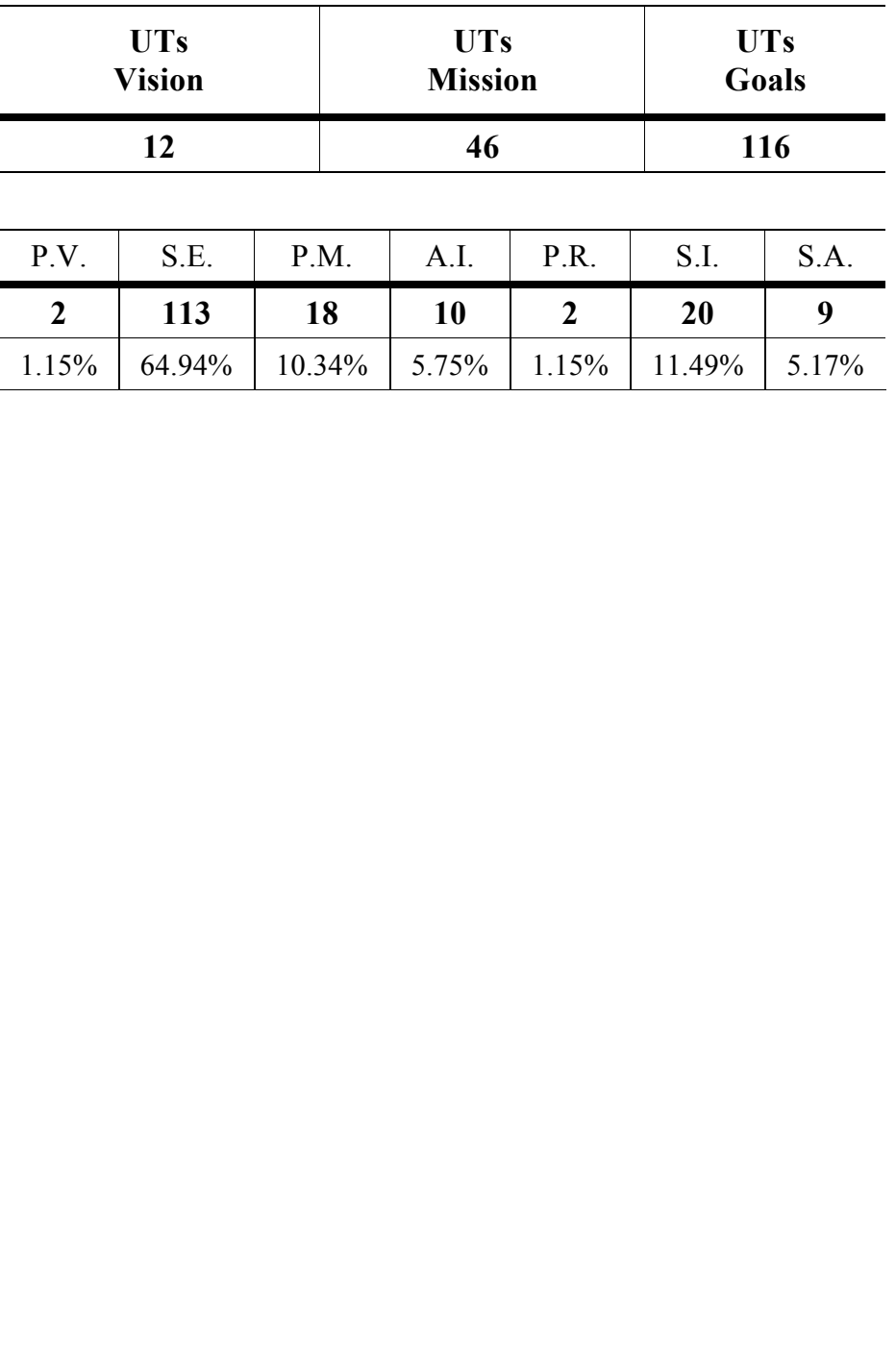




\begin{tabular}{c|ccc|ccc|ccc|cccc|ccc|ccc|ccc|c}
\hline $24 \#$ & 0 & 0 & 0 & 1 & 3 & 1 & 0 & 0 & 2 & 0 & 0 & 0 & 0 & 0 & 0 & 0 & 2 & 0 & 0 & 0 & 0 & 9 \\
\hline $25 \#$ & 0 & 0 & 0 & 1 & 1 & 3 & 0 & 0 & 0 & 0 & 0 & 1 & 0 & 0 & 0 & 0 & 0 & 0 & 0 & 0 & 1 & 7 \\
\hline $26 \#$ & 0 & 0 & 0 & 0 & 0 & 0 & 0 & 0 & 0 & 0 & 0 & 0 & 0 & 0 & 0 & 0 & 0 & 0 & 0 & 0 & 0 & 0 \\
\hline $27 \#$ & 0 & 0 & 0 & 1 & 2 & 4 & 0 & 0 & 0 & 0 & 0 & 0 & 0 & 0 & 1 & 0 & 0 & 0 & 0 & 0 & 0 & 8 \\
\hline $28 \#$ & 0 & 0 & 0 & 0 & 1 & 8 & 0 & 0 & 0 & 0 & 0 & 1 & 0 & 0 & 0 & 0 & 1 & 0 & 0 & 0 & 0 & 11 \\
\hline
\end{tabular}




\section{Finding for the Third Research Question}

For the third research question, "For all Saudi public universities, what are the format and the frequency of the vision, mission, and goals statements of the Preparatory Year Programs?" As mentioned in Step 3 in Chapter Three titled Coding Schemes, the coding form used with the Seven Principles of Students Success to assess its alignment with the Preparatory Year Programs' vision, mission, and goals statements. The researcher created an open code table to identify new themes that appeared in the Preparatory Year Program's vision, mission, and goals statements. The researcher coded the new themes as follows: Vision New Theme/s (NTV1; NTV2, NTV3, etc.); Mission New Theme/s (NTM1; NTM2, NTM3, etc.); and Goals New Theme/s (NTG1; NTG2, NTG3, etc.). For each categories vision, mission, and goals statements the researcher identified, counted, and coded them appropriately. Answering this research question has two main steps: 1) identify the format and the frequency of the themes of the vision, mission, and goals statements of the Preparatory Year Programs that aligned with the Seven Principles of Students Success; and 2) report any new themes that appeared but, did not align with the success principles.

For the vision statements for $\mathrm{N}=28, \mathrm{n}=21(75.00 \%)$ of the universities reported the Preparatory Year Program's vision statements on its website, while only seven $(25.00 \%)$ have no vision statements. Further, as mentioned in Research Questions a and b answers, there are only $12(6.90 \%)$ UTs that aligned with the Seven Principles of Students Success in the first-year of university. The common format and frequency of the vision statements associated with the seven principles was "Preparing students for university study" (n=11, 52.38\%) in UN02\#, UN04\#, UN06\#, UN10\#, UN11\#, UN16\#, UN18\#, UN20\#, UN24\#, UN25\#, and UN27\#.

Three main new themes appeared in the vision statements, for $\mathrm{n}=21$, as follows: 
1- NTV1: "Achieving leadership and excellence in developing the Preparatory Year Program" (n=17, 80.95\%) in UN02\#, UN03\#, UN04\#, UN06\#, UN07\#, UN14\#, UN15\#, UN16\#, UN17\#, UN18\#, UN19\#, UN21\#, UN22\#, UN23\#, UN24\#, UN25\#, and UN28\#.

2- NTV2: "Quality-based Preparatory Year Program" ( $n=4,19.05 \%)$ in UN02\#, UN03\#, UN04\#, and UN\#19.

3- NTV3: "Accredited Preparatory Year Programs locally and internationally" ( $n=10$, 47.62\%) frequency in UN03\#, UN04\#, UN06\#, UN\#07, UN17\#, UN21\#, UN22\#, UN23\#, UN24\#, and UN28\#.

Overall, the new themes appeared in the vision statements due to their focus on developing the Preparatory Year Program, instead of developing the Preparatory Year Programs' students' learning.

For the mission statements, for $\mathrm{N}=28$, only $\mathrm{n}=24(85.71 \%)$ universities have a mission statement, while four (14.29\%) do not have mission statements. The common themes associated with the Seven Principles of Students Success was as follows:

1- 'Developing student's knowledge, attitude, values, and academic skills including Mathematics, self-development skills, science, language skills, communication, technology, and thinking skills" ( $\mathrm{n}=19,79.17 \%)$ in UN02\#, UN03\#, UN06\#, UN07\#, UN10\#, UN11\#, UN13\#, UN14\#, UN16\#, UN18\#, UN19\#, UN20\#, UN21\#, UN22\#, UN23\#, UN24\#, UN25\#, UN27\#, and UN28\#.

2- "Preparing students for university study" ( $\mathrm{n}=12,50.00 \% \%)$ in UN02\#, UN04\#, UN06\#, UN10\#, UN15\#, UN18\#, UN19\#, UN21\#, UN22\#, UN23\#, UN27\#, and UN28\#. 
3- "Participating in the national, regional, and global development (Social Integration)" $(\mathrm{n}=10,41.67 \%)$ in UN03\#, UN07\#, UN11\#, UN15\#, UN16\#, UN17\#, UN21\#, UN23\#, UN24\#, and UN28\#.

4- "Developing student's personality" ( $n=6,25.00 \%)$ in UN10\#, UN11\#, UN15\#, UN16\#, UN20\#, and UN24\#.

5- "Providing students intensive and advanced English programs" $(\mathrm{n}=5,20.83 \%)$ in UN13\#, UN16\#, UN22\#, UN24\#, and UN27\#.

6- "Preparing students for labor-market" $(n=2,8.33 \%)$ in UN11\#, and UN16\#. The Content Analysis revealed five new themes in the mission statements as follows:

1- NTM1: "Provide a stimulating learning environment" ( $\mathrm{n}=10,41.67 \%)$ in UN02\#, UN06\#, UN14\#, UN15\#, UN16\#, UN21\#, UN23\#, UN24\#, UN27\#, and UN28\#.

2- NTM2: "Developing creativity and innovation" ( $\mathrm{n}=7,29.17 \%)$ in UN02\#, UN06\#, UN07\#, UN14\#, UN16\#, UN24\#, and UN25\#.

3- NTM3: "Providing academic services" ( $n=7,29.17 \%)$ in UN02\#, UN03\#, UN04\#, UN06\#, UN07\#, UN09\#, and UN19\#.

4- NTM4: "Developing the Preparatory Year Program on high quality-based" (n=7, 29.17\%) in UN06\#, UN11\#, UN14\#, UN19\#, UN20\#, UN23\#, and UN28\#.

5- NTM5: "Building excellent partnerships with the private sector to operate the Preparatory Year Program" (n=5, 20.83\%) in UN03\#, UN14\#, UN17\#, UN18\#, and UN24\#.

For the goals statements, for $\mathrm{N}=28,23(82.14 \%)$ universities have a goals statement, while five (17.86\%)do not have a goals statements. The common themes associated with the Seven Principles of Students Success are recorded as follows:

1- 'Developing students' knowledge, academic skills, technology skills, research and communication skills, self-confidence skills, leadership skills, self-development 
skills, and life-skills" ( $\mathrm{n}=18,78.26 \%)$ in UN01\#, UN02\#, UN07\#, UN09\#, UN10\#, UN11\#, UN13\#, UN15\#, UN16\#, UN17\#, UN18\#, UN19\#, UN20\#, UN21\#, UN22\#, UN23\#, UN27\#, and UN28\#.

2- "Developing English language skills" (n=16, 69.57\%) in UN03\#, UN07\#, UN09\#, UN10\#, UN11\#, UN13\#, UN17\#, UN18\#, UN19\#, UN20\#, UN21\#, UN22\#, UN23\#, UN25\#, UN27\#, and UN28\#.

3- "Preparing students for university study and life" ( $(\mathrm{n}=13,56.52 \%)$ in UN01\#, UN02\#, UN03\#, UN04\#, UN07\#, UN11\#, UN15\#, UN17\#, UN20\#, UN21\#, UN22\#, UN25\#, and UN28\#.

4- "Help students to enroll in a suitable college based on their performance" ( $n=7$, 29.17\%) in UN01\#, UN03\#, UN09\#, UN10\#, UN21\#, UN22\#, and UN23\#.

5- "Developing student's self-autonomy skills, responsibility, and self-discipline" (n=7, 29.17\%) in UN03\#, UN07\#, UN17\#, UN21\#, UN22\#, UN27\#, and UN28\#.

6- "Raising students awareness about social-responsibility" ( $n=4,17.39 \%)$ in UN02\#, UN14\#, UN15\#, and UN16\#.

7- "Preparing students for the labor-market" $(n=3,13.04 \%)$ in UN01\#, UN07\#, and UN23\#.

8- "Developing student's awareness and physical fitness" $(n=2,8.70 \%)$ in UN07\#, and UN25\#.

9- "Educating students about their rights, and university's regulations" ( $n=2,8.70 \%)$ in UN02\#, and UN09\#.

Furthermore, the Content Analysis of goals statements revealed seven new themes recorded as follows: 
1- NTG1: "Developing a stimulating learning environment to encourage innovation and creativity among students" ( $\mathrm{n}=11,47.83 \%)$ in UN02\#, UN07\#, UN14\#, UN15\#, UN16\#, UN17\#, UN18\#, UN20\#, UN23\#, UN24\#, and UN28\#.

2- NTG2: “Improving university's outcomes" (n=4, 17.39\%) in UN03\#, UN14\#, UN23\#, and UN24\#.

3- NTG3: "Fill the knowledge and skills gap between high school outcomes and university requirements" ( $\mathrm{n}=4,17.39 \%)$ in UN06\#, UN13\#, UN24\#, and UN27\#.

4- NTG4: "Unify university admission" ( $n=3,13.04 \%)$ in UN08\#, UN09\#, and UN23\#.

5- NTG5: "Build distinguished partnerships with the private sector to operate the program" $(\mathrm{n}=3,13.04 \%)$ in UN14\#, UN16\#, and UN23\#.

6- NTG6: "Developing student's assessment system" ( $\mathrm{n}=2,8.70 \%)$ in UN14\#, and UN19\#.

7- NTG7: "Developing excellent human resources" $(n=2,8.70 \%)$ in UN14\#, and UN16\#.

Overall, for vision statements category, new themes for the majority of universities focus on the development of the Preparatory Year Program and achieving leadership and excellence in the program's design. For the mission statements, the majority of the new themes emphasis developing a stimulating learning environment to encourage creativity and innovation and to provide high quality academic services. Finally, the goals statements common new themes concentration on developing a motivating learning environment and filling the knowledge and skills gap between high school outcomes and university requirements. Table 8 displays the format and the frequency of the vision, mission, and goals statements of the Preparatory Year Programs. 
Table 8

Displays the format and the frequency of vision, mission, and goals statements of the Preparatory Year Programs.

\begin{tabular}{|c|c|c|c|c|c|c|}
\hline Categories & Theme/s & $\begin{array}{l}\text { Aligned with } \\
\text { Seven Principles }\end{array}$ & $\begin{array}{l}\text { New } \\
\text { Theme }\end{array}$ & $n$ & $\%$ & Universities \\
\hline \multirow{7}{*}{ Vision } & Preparing students for university study & $\sqrt{ }$ & & 11 & 52.38 & $\begin{array}{l}\text { UN02\#, UN04\#, UN06\#, UN10\#, UN11\#, } \\
\text { UN16\#, UN18\#, UN20\#, UN24\#, UN25,, } \\
\text { UN27\# }\end{array}$ \\
\hline & $\begin{array}{l}\text { NTV1: Achieving leadership and } \\
\text { excellence in developing the Preparatory }\end{array}$ & & $\sqrt{ }$ & 17 & 80.95 & $\begin{array}{l}\text { UN02\#, UN03\#, UN04\#, UN06\#, UN07\#, } \\
\text { UN14\#, UN15\#, UN16\#, UN17\#, UN18\#, }\end{array}$ \\
\hline & Year Program & & & & & $\begin{array}{l}\text { UN19\#, UN21\#, UN22\#, UN23\#, UN24\#, } \\
\text { UN25\#, UN28\# }\end{array}$ \\
\hline & NTV2: Quality-based Preparatory Year & & $\sqrt{ }$ & 4 & 19.05 & UN02\#, UN03\#, UN04\#, UN19\# \\
\hline & Program & & & & & \\
\hline & NTV3: Accredited Preparatory Year & & $\sqrt{ }$ & 10 & 47.62 & UN03\#, UN04\#, UN06\#, UN07\#, UN17\#, \\
\hline & Program locally and internationally & & & & & UN21\#, UN22\#, UN23\#, UN24\#, UN28\# \\
\hline \multirow{4}{*}{ Mission } & $\begin{array}{l}\text { Developing student's knowledge, } \\
\text { attitude, values, and academic skills } \\
\text { including Mathematics, self-development } \\
\text { skills, science, language skills, } \\
\text { communication, technology, and thinking } \\
\text { skills }\end{array}$ & $\sqrt{ }$ & & 19 & 79.17 & $\begin{array}{l}\text { UN02\#, UN03\#, UN06\#, UN07\#, UN10\#, } \\
\text { UN11\#, UN13\#, UN14\#, UN16\#, UN18\#, } \\
\text { UN19\#, UN20\#, UN21\#, UN22\#, UN23\#, } \\
\text { UN24\#, UN25\#, UN27\#, and UN28\# }\end{array}$ \\
\hline & Preparing students for university study & $\sqrt{ }$ & & 12 & 50.00 & $\begin{array}{l}\text { UN02\#, UN04\#, UN06\#, UN10\#, UN15\#, } \\
\text { UN18\#, UN19\#, UN21\#, UN22\#, UN23, } \\
\text { UN27\#, UN28\# }\end{array}$ \\
\hline & $\begin{array}{l}\text { Participating in the national, regional, } \\
\text { and global development (Social } \\
\text { Intergradation) }\end{array}$ & $\sqrt{ }$ & & 10 & 41.67 & $\begin{array}{l}\text { UN03\#, UN07\#, UN11\#, UN15\#, UN16\#, } \\
\text { UN17\#, UN21\#, UN23\#, UN24\#, UN28\# }\end{array}$ \\
\hline & Developing student's personality & $\sqrt{ }$ & & 6 & 25.00 & UN10\#, UN11\#, UN15\#, UN16\#, UN20\#, \\
\hline
\end{tabular}


Providing students intensive and advanced English programs

Preparing students for the labor-market NTM1: Providing a stimulating learning environment

NTM2: Developing creativity and innovation

NTM3: Providing academic services

NTM4: Developing Preparatory Year Program on high quality-based NTM5: Building excellent partnerships with the private sector to operate the Preparatory Year Program Developing students' knowledge, academic skills, technology skills, research and communication skills, selfconfidence skills, leadership skills, selfdevelopment skills, and life-skills Developing English language skills

Goals

Preparing students for university study and life

Help students to enroll in a suitable

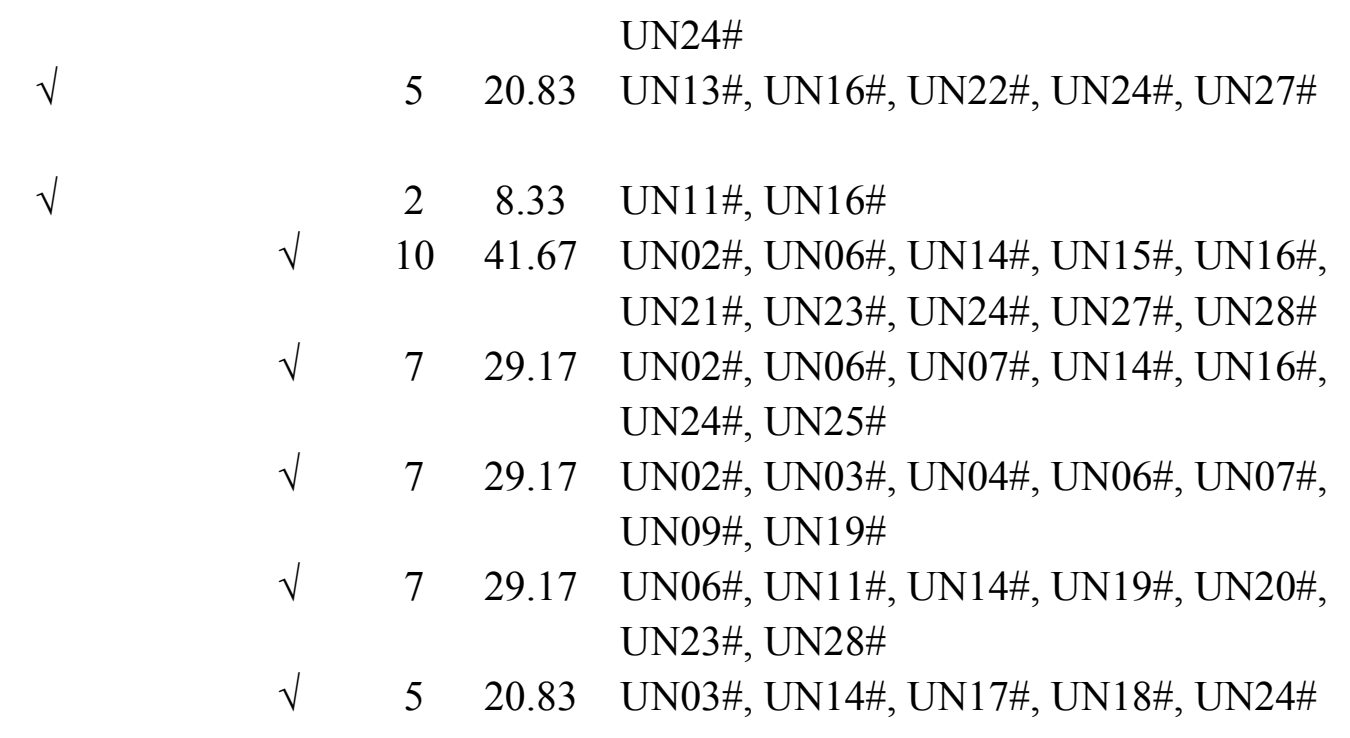

1878.26 UN01\#, UN02\#, UN07\#, UN09\#, UN10\#, UN11\#, UN13\#, UN15\#, UN16\#, UN17\#, UN18\#, UN19\#, UN20\#, UN21\#, UN22\#, UN23\#, UN27\#, UN28\#

$16 \quad 69.57$ UN03\#, UN07\#, UN09\#, UN10\#, UN11\#, UN13\#, UN17\#, UN18\#, UN19\#, UN20\#, UN21\#, UN22\#, UN23\#, UN25\#, UN27\#, UN28\#

1356.52 UN01\#, UN02\#, UN03\#, UN04\#, UN07\#, UN11\#, UN15\#, UN17\#, UN20\#, UN21\#, UN22\#, UN25\#, UN28\#

729.17 UN01\#, UN03\#, UN09\#, UN10\#, UN21\#, 
college based on their performance

Developing student's self-autonomy skills, responsibility, and self-discipline

Raising students awareness about socialresponsibility

Preparing students for the labor-market

Developing students awareness and

physical fitness

Educating students about their rights and university's regulations

NTG1: Developing a stimulating learning environment to encourage innovation and creativity among students

NTG2: Improving university's outcomes NTG3: Fill the knowledge and skills gap between high school outcomes and university requirements

NTG4: Unify university admission

NTG5: Build distinguished partnerships

with the private sector to operate the

program

NTG6: Developing student's assessment system

NTG7: Developing excellent human

resources
UN22\#, UN23\#

$7 \quad 29.17$ UN03\#, UN07\#, UN17\#, UN21\#, UN22\#, UN27\#, UN28\#

$4 \quad 17.39$ UN02\#, UN14\#, UN15\#, UN16\#

$3 \quad 13.04$ UN01\#, UN07\#, UN23\#

$2 \quad 8.70$ UN07\#, UN25\#

$2 \quad 8.70$ UN02\#, UN09\#

$\sqrt{ } 1147.83$ UN02\#, UN07\#, UN14\#, UN15\#, UN16\#, UN17\#, UN18\#, UN20\#, UN23\#, UN24\#, UN28\#

$\sqrt{ } 4 \quad 17.39$ UN03\#, UN14\#, UN23\#, UN24\#

$\sqrt{ } 417.39$ UN06\#, UN13\#, UN24\#, UN27\#

$\sqrt{ } 313.04 \quad$ UN08\#, UN09\#, UN23\#

$\sqrt{ } \quad 3 \quad 13.04$ UN14\#, UN16\#, UN23\#

$\sqrt{ } \quad 2 \quad 8.70 \quad$ UN14\#, UN19\#

$\sqrt{ } \quad 2 \quad 8.70 \quad$ UN14\#, UN16\# 


\section{Finding for the Fourth Research Question}

The last research question was "How do the Preparatory Year Programs' vision, mission, and goals statements differ in content between universities according to geographical location, size, Preparatory Year Programs date of establishment, and gender?" To answer this research question, the researcher used data generated through the previous three questions. For each theme produced, it either aligned with the Seven Principles of Students Success or it was considered a new theme. The similarities and differences were reported based on the four variables: geographical location, size, Preparatory Year Programs date of establishment, and gender.

For the vision statements analysis, $\mathrm{n}=21(75.00 \%)$ universities have vision statements. Four different themes were discovered in this analysis. To identify the similarities and differences among all 28 universities, the researcher divided the vision statements into three groups based on phrasing and targeting: 1) vision focus only on students; 2) vision emphasis is only on the program itself; and 3) vision concentrate on both the student and program.

The Preparatory Year Program's visions that focus only on the student, “Preparing students for university study”, include UN10\#, UN11\#, UN20\#, and UN27\# (n=4, 19.05\%). Visions that emphasis on the Preparatory Year Program's development comprises of UN03\#, UN04\#, UN07\#, UN15\#, UN17\#, UN19\#, UN21\#, UN22\#, UN23\#, and UN28\# (n=10, 47.62\%), for example "Achieving leadership and excellence in developing the Preparatory Year Program". The visions that focus on both the student and program development involve UN02\#, UN06\#, UN14\#, UN16\#, UN18\#, UN24\#, and UN25\# (n=7, 25.00\%), for example "leadership and excellence in preparing students".

For Group 1 (Student) (n=4, 19.05\%), two out of four universities involved in this group are located in the East of Saudi Arabia, and one of them is a single gender university. 
Of the other two universities, one was located in the North and the other represented an Online University.

The majority of universities included in this study are represented in Group 2 (Program) $(\mathrm{n}=10,47.62 \%)$ and have similar vision statements that emphasize on achieving excellence and leadership in developing the Preparatory Year Program; although, the difference among them are according to the four variables: location, size, date, and gender. Five out of 10 universities, including UNs $03 \#, 04 \#, 17 \#, 19 \#$, and $21 \#$ are located in the middle of Saudi Arabia and has a student enrollment range between 4,380-15,187 students in 2014-2015. Two universities, 22\# and 23\# are located in the West of Saudi Arabia. Two universities, 07\# and 15\# are located in the South and have a student enrollment range between 11,819-3,352 students respectively, and one is in the North UN28\#. Overall, all 10 universities provide education for both males and females.

In the second level of similarity, in terms of the number of universities involved, are represented by Group 3. They emphasize its statements on the development of the students and the program, which reported seven $(n=7,25.00 \%)$ and spread between two in the Middle, two in the North, two in the West, and one in the East. Universities size ranges between 2,490-21,587 students. Furthermore, UN06\# is a single gender university for males, and UN18\# is only for females, and the programs date of establishment ranges between 2007 and 2011. Table 9 displays these universities and the associated variables. 
Table 9

The Similarity and Differences of Vision Statements Based on geography location, size, Preparatory Year Programs date of establishment, and gender

\begin{tabular}{|c|c|c|c|c|c|c|c|c|c|c|c|c|}
\hline \multirow{2}{*}{ UN\# } & \multicolumn{4}{|c|}{ Group1 (Student) } & \multicolumn{4}{|c|}{ Group2 (Program) } & \multicolumn{4}{|c|}{ Group3 (Student \& Program) } \\
\hline & Location & Size & Date & Gender & Location & Size & Date & Gender & Location & Size & Date & Gender \\
\hline 10 & East & 2,546 & $\begin{array}{l}1963- \\
2007\end{array}$ & $\mathrm{M}$ & & & & & & & & \\
\hline 11 & East & 7,761 & 2009 & $\mathrm{M} / \mathrm{F}$ & & & & & & & & \\
\hline 20 & Online & 7,736 & 2011 & $\mathrm{M} / \mathrm{F}$ & & & & & & & & \\
\hline 27 & North & 7,449 & 2006 & $\mathrm{M} / \mathrm{F}$ & & & & & & & & \\
\hline 03 & & & & & Middle & 15,187 & 2012 & $\mathrm{M} / \mathrm{F}$ & & & & \\
\hline 04 & & & & & Middle & 4,380 & 2012 & $\mathrm{M} / \mathrm{F}$ & & & & \\
\hline 07 & & & & & South & 11,819 & 2009 & $\mathrm{M} / \mathrm{F}$ & & & & \\
\hline 15 & & & & & South & 3,352 & 2010 & $\mathrm{M} / \mathrm{F}$ & & & & \\
\hline 17 & & & & & Middle & 6,389 & 2009 & $\mathrm{M} / \mathrm{F}$ & & & & \\
\hline 19 & & & & & Middle & 14,175 & 2005 & $\mathrm{M} / \mathrm{F}$ & & & & \\
\hline 21 & & & & & Middle & 10,173 & 2011 & $\mathrm{M} / \mathrm{F}$ & & & & \\
\hline 22 & & & & & West & 11,514 & 2011 & $\mathrm{M} / \mathrm{F}$ & & & & \\
\hline 23 & & & & & West & 13,260 & 2013 & $\mathrm{M} / \mathrm{F}$ & & & & \\
\hline 28 & & & & & North & 7,270 & 2008 & $\mathrm{M} / \mathrm{F}$ & & & & \\
\hline 02 & & & & & & & & & North & 5,964 & 2007 & $\mathrm{M} / \mathrm{F}$ \\
\hline 06 & & & & & & & & & West & 2,490 & 2008 & $\mathrm{M}$ \\
\hline 14 & & & & & & & & & Middle & 8,391 & 2007 & $\mathrm{M} / \mathrm{F}$ \\
\hline 16 & & & & & & & & & North & 4,462 & 2011 & $\mathrm{M} / \mathrm{F}$ \\
\hline 18 & & & & & & & & & Middle & 9,682 & 2009 & $\mathrm{~F}$ \\
\hline 24 & & & & & & & & & West & 21,587 & 2009 & $\mathrm{M} / \mathrm{F}$ \\
\hline 25 & & & & & & & & & East & 5,445 & 2008 & $\mathrm{M} / \mathrm{F}$ \\
\hline
\end{tabular}


For the mission statements, $\mathrm{n}=24(85.71 \%)$ universities have a mission statement, while four (14.29\%) have no mission statements. The data generated from research question one were used to answer this question (see Tables $6 \& 7$ ). The Content Analysis revealed that the majority of Saudi public universities are similar in terms of the Preparatory Year Program emphasizing the area of study that focuses on the academic aspects such as developing student's academic skills and knowledge, such as developing English Language, SelfDevelopment skills, Mathematics and Science skills, despite the differences among them according to the four variables: geographical location, size, Preparatory Year Programs date of establishment, and gender.

Nineteen (79.17\%) of the Preparatory Year Programs' mission statements aligned with the Self-Efficacy (S.E.) principle (see Table 10). Further, 9 (37.5\%) aligned with the Social Integration (S.I.) principle. Four (16.67\%) aligned with the Personal Meaning (P.M.) principle. Two (8.33\%) aligned with the Active Involvement (A.I.) principle. One (4.17\%) aligned with the Personal Validation (P.V.) and Self-Awareness (S.A) principles for each. The principle of Personal Reflection (P.R.) did not align with any mission statement at all 28 universities. However, the data exposed that must of the Saudi universities design its Preparatory Year Program to improve students' skills and knowledge to meet the universities standards. Furthermore, the data revealed an overlapping between the mission and goals statements phrasing, which in some cases, the mission and goals statements have similar content, for example, UNs 7, 16, and 21. Table 10 displays 19 universities that are similar in terms of the Preparatory Year Program's purpose. Universities numbers were hidden for data confidentiality purpose. 
Table 10

The List of Saudi Universities that Aligned with Self-Efficacy Principle.

\begin{tabular}{cccc}
\hline Location & Size & Date & Gender \\
\hline North & 5,964 & 2007 & $\mathrm{M} / \mathrm{F}$ \\
Middle & 15,187 & 2012 & $\mathrm{M} / \mathrm{F}$ \\
Middle & 4,380 & 2012 & $\mathrm{M} / \mathrm{F}$ \\
West & 2,490 & 2008 & $\mathrm{M}$ \\
South & 11,819 & 2009 & $\mathrm{M} / \mathrm{F}$ \\
East & 2,546 & $1963-2007$ & $\mathrm{M}$ \\
East & 7,761 & 2009 & $\mathrm{M} / \mathrm{F}$ \\
South & 3,352 & 2010 & $\mathrm{M} / \mathrm{F}$ \\
North & 4,462 & 2011 & $\mathrm{M} / \mathrm{F}$ \\
Middle & 9,682 & 2009 & $\mathrm{~F}$ \\
Middle & 14,175 & 2005 & $\mathrm{M} / \mathrm{F}$ \\
Online & 7,736 & 2011 & $\mathrm{M} / \mathrm{F}$ \\
Middle & 10,173 & 2011 & $\mathrm{M} / \mathrm{F}$ \\
West & 11,514 & 2011 & $\mathrm{M} / \mathrm{F}$ \\
West & 13,260 & 2013 & $\mathrm{M} / \mathrm{F}$ \\
West & 21,587 & 2009 & $\mathrm{M} / \mathrm{F}$ \\
East & 5,445 & 2008 & $\mathrm{M} / \mathrm{F}$ \\
North & 7,449 & 2006 & $\mathrm{M} / \mathrm{F}$ \\
North & 7,270 & 2008 & $\mathrm{M} / \mathrm{F}$ \\
\hline
\end{tabular}

For the goals statements, $n=23(82.14 \%)$ universities have a goals statement, while five $(17.86 \%)$ do not. $23(100 \%)$ universities have similar statements of goals that aligned with the Self-Efficacy principles, despite the differences among them (see Table $6 \&$ 7). For example, "Developing students' knowledge, academic skills, technology skills, research and communication skills, self-confidence skills, leadership skills, self-development skills, and life-skills" or "Developing English language skills".

Furthermore, eight (34.78\%) universities have similar settings of goals aligned with the Personal Meaning principle. For example, "Preparing students for the labor-market" or "Developing a stimulating learning environment to encourage innovation and creativity among students". Besides, eight (34.78\%) universities have similar interests in developing the Social Integration principle, for instance, "Raising student's awareness about socialresponsibility". The Self-Awareness principle aligned with eight (34.78\%) universities that 
have similar trends for "Developing student's awareness and physical fitness". Moreover, seven (30.43\%) universities were developing their Preparatory Year Programs' goals to increase student's involvement within the university's environment, which aligned with the Active Involvement principle. For example, “Developing student's self-autonomy skills, responsibility, and self-discipline”. The Personal Validation and Personal Reflection principles aligned with only one goal statement (4.35\%) in UN11\#, and two goals statements (8.70\%) aligned with the Personal Reflection in UN10\#, and UN27\#.

Overall, the majority of the Preparatory Year Programs are similar in terms of their vision statements that focus on achieving leadership and excellence in developing the Preparatory Year Program, while only few universities phrase its vision to regard student's development. For the mission and goals statements, the content of a majority of Preparatory Year Programs set its goals and focus on the Self-Efficacy and Social Integration principles. The similarity among Saudi Preparatory Year Programs vision, mission, and goals statements were high despite the differences among them based on the four variables: geographical location, size, Preparatory Year Programs date of establishment, and gender (see Tables 2 \& 3).

\section{Additional Limitations of the Study}

This study has several limitations:

1. The alignment of the vision, mission, and goals statements with the Seven Principles of Students Success in the first-year of university has not been systematically studied by researchers in general and in a Saudi higher education context in particular but, is cited as a recommendation in some research studies conducted in the United States of America.

2. A limitation exists due to the nature of the vision, mission, and goals statements, because some institutions do not state their vision, mission, and goals statements in a 
way that exposes all practices and policies for the public. Bart and Tabone (1998) say that "mission statements not in sync with an organization's formal structure are often regarded as being of little value" (p. 57). However, using three categories: vision, mission, and goals statements, for this study may have reduced the effectiveness of this limitation because most of the data necessary to explore the program theory base includes these three categories.

3. The size and scope of this study is limited to public Saudi universities; therefore, the outcomes of this study cannot be generalized on private universities or 2-year institutions such as community colleges in Saudi Arabia. Therefore, more investigation is recommended in the future using the Seven Principles of Students Success within a different research methodology or in different universities. 


\section{Chapter Five}

\section{Summary, Discussion, Implications, and Future Research}

Chapter Five offers an overview of the study, summarizes the study's findings, discusses the potential implications, and recommendations for future research regarding First-Year Experiences and the Preparatory Year Program development.

\section{Overview of Study}

The first-year of college is critical for developing a foundation for successfully transitioning into college for all new students, and students' success is largely based on their first-year experiences (Ben-Avie, Kennedy,Unson, Li, Riccardi \& Mugno, 2012; Clark, 2005; Frazier, 2007: Mutch, 2005; Noel, Levitz, \& Saluri, 1985; Tinto \& Pusser, 2006; Upcraft, Gardner \& Barefoot, 2004).

Within the context of Saudi postsecondary education, the first-year programs are considered a new phenomenon, which the majority of Saudi universities established its Preparatory Year Programs for first-year students in 2005 or beyond. The current working models of the Preparatory Year Program encounter several challenges, including the absence of a theoretical and pedagogical base of the program and also "the preparatory year in Saudi universities lacks a Governing Concept philosophy” (Alaqeeli, 2014, p. 60). Furthermore, although the Preparatory Year Programs have been in existence for ten years at many of the Saudi public universities, there is a lack of research and evaluation studies to explore the Preparatory Year Programs models or to define an overall theoretical foundation or pedagogical philosophy of the programs.

As the current working models of Preparatory Year Program have no published or released documents that report a program theoretical and pedagogical base, this study used and analyzed the vision, mission, and goals statements of all 28 Preparatory Year Programs published on the official websites of all public Saudi universities. The vision statements of 
universities are considered to be a philosophical guide for what a particular university or college works toward achieving in the future (Abelman \& Dalessandro, 2008). The mission statements of universities or schools illustrate a set of values, principles, purposes, directions for individuals, and program functions (Boerema, 2006). Finally, the goals statements express the performance level of all university or school components, either educational, professional, students, curriculum, professional development, etc. (Gurley, Peters, Collins, \& Fifolt, 2014).

The main purpose of this study was to assess whether or not the Preparatory Year Programs incorporate the principles of student success in the first-year of university as outlined in the Seven Central Principles of Student Success advanced by Cuseo (2014). Further, this study explored the Preparatory Year Programs' Saudi universities trends through the most common key elements of the Seven Principles of Students Success included in the Preparatory Year Programs' vision, mission, and goals statements. This study explored the themes and formats of the Preparatory Year Programs in all 28 universities and the differences among these programs based on the university's geographical location, size, programs date of establishment, and gender. However, this study was not to evaluate the contents phrasing or structure of the vision, mission, and goals statements of the Preparatory Year Programs itself but, to assess its alignment with the First-Year Theory.

The target population consisted of 28 public universities managed and supervised by the Ministry of Education in Saudi Arabia (MOE, 2016). The nonrandom sampling process (purposive sampling) is utilized in this research. All Preparatory Year Programs that reported its vision, mission, and goal statements on the official websites were included in this study (see Appendix A \& D). As this study used public information published on the official Preparatory Year Programs' websites and has no human subject involved in the study's 
procedure, the approval of the Institutional Review Board (IRB) was not required prior to data collection and analysis.

To accomplish this study's goals, the researcher used government information published on the official Preparatory Year Programs' websites expressing the vision, mission, and goals statements in each public university. The nine steps of Content Analysis (CA) developed by Neuendorf (2002) were used for data collection and analysis. Furthermore, the Unit of Thoughts (UT) extracted from vision, mission, and goal statement were used to assess its alignment with the Seven Principles of Students Success. The Unit of Thoughts (UT) are defined by the number of sentences or paragraphs or words that belonged to or indicated the existence of the principle individually for each program. Any sentence or indication on the vision, mission, or goals statements was placed under an appropriate principle. Using UTs also assisted the researcher in identifying the pattern between the Preparatory Year Programs and the differences and similarities among universities.

This study adopted the Content Analysis definition advanced by Neuendorf:

Summarizing, quantitative analysis of messages that relies on the scientific method (including attention to objectivity-intersubjectivity, a prior design, reliability, validity, generalizability, replicability, and hypothesis testing) and is not limited as to the types of variables that may be measured or the context in which the message are created or represented. (p. 10)

All Saudi public universities vision, mission, and goals statements and the Seven Principles of Students Success were identified, coded, defined operationally, and reported. A pilot study was conducted on seven (25.00\%) Preparatory Year Programs to test the codebook's and coding form's reliability, validity, consistency, and understanding among two coders and the researcher. The validity resulted in 100\% agreement between the 
researcher and two coders, which means that the Content Analysis is valid and reliable (see Appendix C). This study attempted to answer the following research questions:

a. For each university, to what extent do the Preparatory Year Programs' vision, mission, and goals statements align with the Seven Principles of Students' Success in the first-year of university?

b. What common key elements cited in the Seven Central Principles of Students Success are most often included in the Preparatory Year Programs' vision, mission, and goals statements?

c. For all Saudi public universities, what is the format and frequency of the Preparatory Year Programs' vision, mission, and goals statements?

d. How do the Preparatory Year Programs' vision, mission, and goals statements compare or contrast in content between universities, according to geographical location, size, the Preparatory Year Programs' date of establishment, and gender?

\section{Summary of Finding}

In the $\mathrm{N}=28$ Saudi public universities, $\mathrm{n}=21$ (75.00\%) universities reporting vision statements for Preparatory Year Program on its website, while seven (25.00\%) have no vision statements. For the mission statements, $\mathrm{n}=24(85.71 \%)$ universities have a mission statement for its Preparatory Year Program, while four (14.29\%) have no mission statements. For the goals statements, $\mathrm{n}=23(82.14 \%)$ universities have a goals statement, while five or $(17.86 \%)$ have no goals statements.

For the universities size, for all $\mathrm{N}=28$ the number of students enrolled in the Preparatory Year Program in 2014-2015 was used to classify the universities into three groups. Group 1 includes nine (32.14\%) universities that enrolled a total of students above 10,000. Group 2 involves nine (32.14\%) universities that have $10,000<5,000$ students 
enrolled. Finally, Group 3 has 10 (35.71\%) universities that recorded 5,000<1,000 students total in the first-year (see Table 2).

For the universities geographical location for all 28 public universities, $\mathrm{N}=28$, eight (28.57\%) universities are located in the Middle of Saudi Arabia. Six (21.43\%) are located in the Western province. Five (17.86\%) are positioned in the North and five $(17.86 \%)$ in the Southern provinces. Three $(10.71 \%)$ are in the Eastern province, and one $(3.57 \%)$ is represented as an Online University (see Table 3). Furthermore, for the date of establishment of the Preparatory Year Programs, for $\mathrm{N}=28$, three (10.71\%) were established in 2014. One (3.57\%) was founded in 2013. Two (7.14\%) were established in 2012, four (14.29\%) in 2011, and one (3.57\%) in 2010. Six (21.43\%) were established in 2009, four (14.29\%) in 2008, three $(10.71 \%)$ in 2007 , three $(10.71 \%)$ in 2005 , and one $(3.57 \%)$ Preparatory Year Program was established in 1963 and updated in 2007 (see Table 3). The data analysis revealed that 27 (96.43\%) universities established its Preparatory Year Program between 2005-2014, which indicates that the program is considered a new phenomenon in the Saudi higher education context. Finally, for N=28 universities, two (7.14\%) universities, UN10\# and UN06\# are single gender universities for males, while one (3.57\%) is only for females (see Table 3).

For the organizational structure classifications of the Preparatory Year Program for $\mathrm{N}=28,17(60.71 \%)$ universities have a separate deanship named the Preparatory Year Deanship for the program. Two (7.14\%) named the program Preparatory Year and Supporting Studies Deanship. Two (7.14\%) universities placed the program under the Educational Services Deanship. One (3.57\%) university applies the Preparatory Year Program within the College of Applied and Supporting Studies. One (3.57\%) university calls the program Pre-Professional Program. Two (7.14\%) applied the program for specific bodies of students and within the colleges structure, e.g. for Science and Medical colleges. Two (7.14\%) built a unit named Preparatory Year and placed it under the Admission and 
Registration Deanship. Finally, only one (3.57\%) university did not report a program structure on its websites (see Table 4). Finally, for the program's application policy, for $\mathrm{N}=28,14(50 \%)$ universities apply the program for all new coming students and for all colleges, either Science, Health, or Humanities Colleges. 13 (46.43\%) apply the program for specific bodies of students for Science and Medical Colleges. One (3.57\%) did not report a program application on its website (see Table 5).

Summary of Results for Research Question One. "For each university, to what extent do the Preparatory Year Program's vision, mission, and goals statements align with the Seven Principles of Students Success in the first-year of university?" The data was generated through the Content Analysis of the Preparatory Year Programs' vision, mission, and goals statements and assessed its alignment with the Principles of Students Success in the first-year of university as outlined in the Seven Central Principles of Student Success advanced by Cuseo (2014) using the Unit of Thoughts (UT) within each category and the codebook and coding form designed for this study. The alignments total of the vision, mission, and goals statements of the Preparatory Year Programs at all 28 Saudi public universities with the Seven Principles of Students Success are reported as follows:

1. UN07\# and UN11\# (38.1\%)

2. UN10\# (33.33\%)

3. UN16\# and UN21\# (28.57\%)

4. UN22\#, UN23\#, UN24\#, and UN25\# (23.81\%)

5. UN02\#, UN03\#, UN15\#, UN17\#, UN19\#, UN20\#, UN27\#, and UN28\# (19.05\%)

6. UN06\#, UN09\#, and UN18\# (14.29\%)

7. UN01\#, UN13\#, and UN14\# (9.52\%)

8. UN04\# (4.76\%)

9. UN05\#, UN08\#, UN12\#, and UN26\# (0\%) (see Table $6 \&$ 7) 
Summary of Results for Research Question Two. "What common key elements cited in the Seven Central Principles of Students Success are most often included in the Preparatory Year Programs' vision, mission, and goals statements?" The data generated through the Content Analysis of the Preparatory Year Programs' vision, mission, and goals statements was used to assess the alignment of the Preparatory Year Programs with the Seven Principles of Students Success in the first-year of university advanced by Cuseo (2014), as represented in Table 6 and 7, and to answer this research question.

The total of Unit of Thoughts (UTs) aligned with the Seven Principles of Students Success in the first-year of university was 174. The Self-Efficacy (S.E.) principle is the most cited in the vision, mission, and goals statements of the Preparatory Year Program, since it was recorded nine $(5.17 \%)$ times for the vision statement, 28 (16.10\%) times for the mission statement, and $76(43.68 \%)$ times for the goals statement. Overall, $113(64.94 \%)$ UTs of the vision, mission, and goals statements matched the S.E. principle.

The Content Analysis of the Preparatory Year Programs' vision, mission, and goals statements placed the principle of Social Integration (S.I.) in the second level of alignment with 20 (11.49\%) UTs. The Personal Meaning (P.M.) principle cited 18 (10.34\%) UTs and placed in the third level of alignment. The Active Involvement (A.I.) principle placed in the fourth level of alignment with 10 (5.75\%) UTs. Nine (5.17\%) UTs aligned with the SelfAwareness (S.A.) principle. Lastly, the Personal Validation (P.V.) and Personal Reflection (P.R.) principles placed in the lowest level of alignment, where each principle was cited only twice $(1.15 \%)$. Overall, 116 out of $174(66.67 \%)$ UTs appeared to be extracted from the goals statements, $46(26.44 \%)$ UTs from the mission statements, and $12(6.90 \%)$ UTs from the vision statements (see Table 7).

Summary of Results for Research Question Three. "For all Saudi public universities, what are the format and the frequency of the vision, mission, and goals 
statements of the Preparatory Year Programs?" To answer this question, the researcher accomplished two main steps: 1) identified the format and the frequency of the themes of the vision, mission, and goals statements of the Preparatory Year Programs that aligned with the Seven Principles of Students Success; and 2) reported any new themes that appeared but, did not align with the student's success principles.

For the vision statements, for $\mathrm{N}=28, \mathrm{n}=21(75 \%)$ universities reporting the Preparatory Year Program's vision statements on its website, while only seven (25\%) had no vision statements. 12 (6.90\%) UTs aligned with the Seven Principles of Students Success in the first-year of university. The common format and frequency of the vision statements associated with seven principles was "Preparing students for university study" (n=11, 52.38\%) in UN02\#, UN04\#, UN06\#, UN10\#, UN11\#, UN16\#, UN18\#, UN20\#, UN24\#, UN25\#, and UN27\#. For new themes that appeared in the vision statements, for $n=21$, three main themes were recorded as follows:

1- NTV1: "Achieving leadership and excellence in developing the Preparatory Year Program" (n=17, 80.95\%) in UN02\#, UN03\#, UN04\#, UN06\#, UN07\#, UN14\#, UN15\#, UN16\#, UN17\#, UN18\#, UN19\#, UN21\#, UN22\#, UN23\#, UN24\#, UN25\#, and UN28\#.

2- NTV2: "Quality-based Preparatory Year Program" ( $\mathrm{n}=4,19.05 \%)$ in UN02\#, UN03\#, UN04\#, and UN19\#.

3- NTV3: "Accredited Preparatory Year Program locally and internationally" (n=10, 47.62\%) frequency in UN03\#, UN04\#, UN06\#, UN07\#, UN17\#, UN21\#, UN22\#, UN23\#, UN24\#, and UN28\#.

The new themes appeared in the vision statements focus on developing the Preparatory Year Program instead of developing the Preparatory Year Programs' students' performance. 
For the mission statements, for $\mathrm{N}=28, \mathrm{n}=24(85.71 \%)$ universities have a mission statement, while four (14.29\%) have no mission statements. The common themes associated with the Seven Principles of Students Success are as follows:

1- “Developing student's knowledge, attitude, values, and academic skills including Mathematics, self-development skills, science, language skills, communication, technology, and thinking skills" $(\mathrm{n}=19,79.17 \%)$ in UN02\#, UN03\#, UN06\#, UN07\#, UN10\#, UN11\#, UN13\#, UN14\#, UN16\#, UN18\#, UN19\#, UN20\#, UN21\#, UN22\#, UN23\#, UN24\#, UN25\#, UN27\#, and UN28\#.

2- "Preparing students for university study" ( $n=12,50.00 \% \%)$ in UN02\#, UN04\#, UN06\#, UN10\#, UN15\#, UN18\#, UN19\#, UN21\#, UN22\#, UN23\#, UN27\#, and UN28\#.

3- "Participating in the national, regional, and global development (Social Integration)" ( $\mathrm{n}=10,41.67 \%)$ in UN03\#, UN07\#, UN11\#, UN15\#, UN16\#, UN17\#, UN21\#, UN23\#, UN24\#, and UN28\#.

4- "Developing student's personality" ( $n=6,25.00 \%)$ in UN10\#, UN11\#, UN15\#, UN16\#, UN20\#, and UN24\#.

5- "Providing students intensive and advanced English programs" $(n=5,20.83 \%)$ in UN13\#, UN16\#, UN22\#, UN24\#, and UN27\#.

6- "Preparing students for the labor market" $(n=2,8.33 \%)$ in UN11\#, and UN16\#. The new themes appeared in the mission statement as follows:

1- NTM1: "Providing a stimulating learning environment" $(n=10,41.67 \%)$ in UN02\#, UN06\#, UN14\#, UN15\#, UN16\#, UN21\#, UN23\#, UN24\#, UN27\#, and UN28\#.

2- NTM2: "Developing creativity and innovation" ( $n=7,29.17 \%)$ in UN02\#, UN06\#, UN07\#, UN14\#, UN16\#, UN24\#, and UN25\#. 
3- NTM3: "Providing academic services" ( $\mathrm{n}=7,29.17 \%)$ in UN02\#, UN03\#, UN04\#, UN06\#, UN07\#, UN09\#, and UN19\#.

4- NTM4: "Developing Preparatory Year Program on high quality-based" (n=7, 29.17\%) in UN06\#, UN11\#, UN14\#, UN19\#, UN20\#, UN23\#, and UN28\#.

5- NTM5: "Building excellent partnerships with the private sector to operate the Preparatory Year Program $(n=5,20.83 \%)$ in UN03\#, UN14\#, UN17\#, UN18\#, and UN24\#.

For the goals statements, for $\mathrm{N}=28, \mathrm{n}=23(82.14 \%)$ universities have a goals statement, while five $(17.86 \%)$ universities have no goals statement. The common themes associated with the Seven Principles of Students Success are recorded:

1- 'Developing students' knowledge, academic skills, technology skills, research and communication skills, self-confidence skills, leadership skills, self-development skills, and life-skills" (n=18, 78.26\%) in UN01\#, UN02\#, UN07\#, UN09\#, UN10\#, UN11\#, UN13\#, UN15\#, UN16\#, UN17\#, UN18\#, UN19\#, UN20\#, UN21\#, UN22, UN23\#, UN27\#, and UN28\#.

2- "Developing English language skills" ( $\mathrm{n}=16,69.57 \%)$ in UN03\#, UN07\#, UN09\#, UN10\#, UN11\#, UN13\#, UN17\#, UN18\#, UN19\#, UN20\#, UN21\#, UN22\#, UN23\#, UN25\#, UN27\#, and UN28\#.

3- "Preparing students for university study and life" ( $n=13,56.52 \%)$ in UN01\#, UN02\#, UN03\#, UN04\#, UN07\#, UN11\#, UN15\#, UN17\#, UN20\#, UN21\#, UN22\#, UN25\#, and UN28\#.

4- "Help students to enroll in a suitable college based on their performance" (n=7, 29.17\%) in UN01\#, UN03\#, UN09\#, UN10\#, UN21\#, UN22\#, and UN23\#.

5- "Developing student's self-autonomy skills, responsibility, and self-discipline" (n=7, 29.17\%) in UN03\#, UN07\#, UN17\#, UN21\#, UN22\#, UN27\#, and UN28\#. 
6- "Raising student's awareness about social-responsibility" $(n=4,17.39 \%)$ in UN02\#, UN14\#, UN15\#, and UN16\#.

7- "Preparing students for the labor market" $(n=3,13.04 \%)$ in UN01\#, UN07\#, and UN23\#.

8- "Developing student's awareness and physical fitness" $(n=2,8.70 \%)$ in UN07\#, and UN25\#.

9- "Educating students about their rights, and university's regulations" ( $n=2,8.70 \%)$ in UN02\#, and UN09\#.

The new themes appeared in the goals statements:

1- NTG1: "Developing a stimulating learning environment to encourage innovation and creativity among students" ( $\mathrm{n}=11,47.83 \%)$ in UN02\#, UN07\#, UN14\#, UN15\#, UN16\#, UN17\#, UN18\#, UN20\#, UN23\#, UN24\#, and UN28\#.

2- NTG2: "Improving university's outcomes" (n=4, 17.39\%) in UN03\#, UN14\#, UN23\#, and UN24\#.

3- NTG3: "Fill the knowledge and skills gap between high school outcomes and university requirements" ( $\mathrm{n}=4,17.39 \%)$ in UN06\#, UN13\#, UN24\#, and UN27\#.

4- NTG4: "Unify university admissions" ( $\mathrm{n}=3,13.04 \%)$ in UN08\#, UN09\#, and UN23\#.

5- NTG5: "Build distinguished partnerships with the private sector to operate the program" (n=3, 13.04\%) in UN14\#, UN16\#, and UN23\#.

6- NTG6: "Developing student's assessment system" ( $\mathrm{n}=2,8.70 \%)$ in UN14\#, and UN19\#.

7- NTG7: "Developing excellent human resources" $(n=2,8.70 \%)$ in UN14\#, and UN16\#.

Overall, for the vision statements, the majority of new themes appeared to focus on the development of the Preparatory Year Program and achieving leadership and excellence in 
the program's design. For the mission statements, the popular new themes emphasize on developing a stimulating learning environment to encourage creativity and innovation, and to provide high quality academic services. Finally, the goals statement have common new themes concentrating on developing a motivated learning environment, and to fill the knowledge and skills gap between high school outcomes and university requirements (see Table 8).

Summary of Results for Research Question Four. "How do the Preparatory Year Programs' vision, mission, and goals statements differ in content between universities according to geographical location, size, Preparatory Year Programs date of establishment, and gender?" For the vision statements analysis, for $\mathrm{n}=21(75.00 \%)$ universities that have a vision statement. The researcher divided the vision statements into three groups based on the phrasing and targeting as follows: 1) visions focus only on students; 2) visions only emphasis on the program itself; and 3) visions that concentrates on both the students and program.

Group 1 recorded $(n=4,19.05 \%)$ Preparatory Year Programs that focus on the student including UN10\#, UN11\#, UN20\#, and UN27\#, for example, "Preparing students for university study". For Group 2 (n=7, 25.00\%) Preparatory Year Programs emphasize its vision statement on developing the Preparatory Year Program itself. This group comprises of UN03\#, UN04\#, UN07\#, UN15\#, UN17\#, UN19\#, UN21\#, UN22\#, and UN23\#. An example from this group statements is, “Achieving leadership and excellence in developing the Preparatory Year Program”. Group 3 focuses on both the student and program development ( $\mathrm{n}=7,25.00 \%$ ) including UN02\#, UN06\#, UN14\#, UN16\#, UN18\#, UN24\#, and UN25\#, for example, "leadership and excellence in preparing students" (see Table 9).

For the mission statements, $\mathrm{n}=24(85.71 \%)$ universities have a mission statement. 19 (79.17\%) of the Preparatory Year Programs' mission statements aligned with the SelfEfficacy (S.E.) principle, 9 (37.5\%) aligned with the Social Integration (S.I.) principle, four 
(16.67\%) aligned with the Personal Meaning (P.M.) principle, two (8.33\%) aligned with the Active Involvement (A.I.) principle, one (4.17\%) aligned with the Personal Validation (P.V.) and Self-Awareness (S.A.) principles for each, and finally the principle of Personal Reflection (P.R.) did not align with any mission statements of the 24 universities.

The Content Analysis revealed that most Saudi public universities are similar in terms of the Preparatory Year Program emphasizing the area of study, which focuses on academic aspects, such as developing student's academic skills and knowledge, despite the differences among them according to four variables: geographical location, size, Preparatory Year Programs date of establishment, and gender (see Table 10).

For the goals statements, $\mathrm{n}=23(82.14 \%)$ universities have a goals statement. 23 $(100 \%)$ universities have similar goals statements that aligned with the Self-Efficacy (S.E.) principles despite their differences (see Table 6 \& 7). Eight (34.78\%) universities have similar settings of goals that aligned with the Personal Meaning (P.M.) principle. Eight (34.78\%) universities have similar interests in developing the Social Integration (S.I.) principle. The Self-Awareness (S.A.) principle aligned with eight (34.78\%) universities that have a similar trend for "Developing student's awareness and physical fitness". Seven (30.43\%) universities developing their Preparatory Year Programs' goals to increase student's involvement within the university's environment, which aligned with the Active Involvement (A.I.) principle. The Personal Validation (P.V.) principle aligned with only one goal statement (4.35\%) in UN11\# and two goals statements (8.70\%) aligned with the Personal Reflection (P.R.) principle in UN10\# and UN27\# (see Tables 2 \& 3).

Overall, the majority of the Preparatory Year Programs are similar in terms of vision statements that focus on achieving leadership and excellence in developing the Preparatory Year Program, while only some universities phrase its vision to regard student's development. For the mission and goals statements content, many of the Preparatory Year 
Programs set its goals and focus on the Self-Efficacy (S.E.) and Social Integration (S.I.) principles. The similarity among Saudi Preparatory Year Programs vision, mission, and goals statements were high although there are differences among them based on the four variables: geographical location, size, Preparatory Year Programs date of establishment, and gender (see Tables 2, 3, $6 \& 7$ ).

The following section interprets and discusses the results of the study as they relate to the four areas of study: assessing the alignment of the Preparatory Year Programs' vision, mission, and goals statements with the Seven Principles of Students Success in the first-year of university, common key elements cited in the Seven Central Principles of Students Success that are most often included in the Preparatory Year Programs' vision, mission, and goals statements, the format and the frequency of the vision, mission, and goals statements of the Preparatory Year Programs, and the similarities and differences among Saudi public universities according to geographical location, size, Preparatory Year Programs date of establishment, and gender.

\section{Interpretation of Results}

Students' success in postsecondary institutions is largely based on their first-year of college experiences (Ben-Avie, Kennedy,Unson, Li, Riccardi \& Mugno, 2012; Clark, 2005; Frazier, 2007: Mutch, 2005; Noel, Levitz, \& Saluri, 1985; Tinto \& Pusser, 2006; Upcraft, Gardner \& Barefoot, 2004). Using a Content Analysis of the vision, mission, and goals statements of all Preparatory Year Programs at all 28 public Saudi universities to explore and assess the Preparatory Year Programs' alignment with the Seven Principles of Students Success in the first-year of college. This study proposed to Saudi Education Ministry and Saudi public universities a set of suggestions and outcomes as related to the four research questions and the theoretical base and trend of the Preparatory Year Programs that could support the Preparatory Year Programs' policymakers to develop the program in the future. 
The Alignment of Preparatory Year Programs' Vision, Mission, and Goals

Statements to the Seven Principles of Students' Success. As mentioned in Chapter One and Three, this study's concern was not to assess the content and quality of the vision, mission, and goals statements itself in terms of phrasing or structure, this study concern was to assess the alignment of the three categories' statements to the Seven Principles of Students Success advanced by Cuseo (2014). The Units of Thought/s (UTs) used to assess the alignment extent for each category and for all combined outcomes revealed that, overall, the highest percentage of alignment was (38.1\%) for UN07\# and UN11\#, and (33.33\%) for UN10\#. Six universities: $16,21,22,23,24$, and 25 , fell between $(23.81 \%) \geq(28.81 \%)$. Eleven universities: 02, 03, 06, 09, 15, 17, 18, 19, 20, 27, and 28 recorded alignment scores between $14.29 \% \geq 19.05 \%$. Four universities: $01,04,13$, and 14 , between $(4.76 \% \%) \geq$ (9.52\%). Finally, four universities: $05,08,12$, and 26 , did not align with any of the Seven Principles of Students Success (see Table 6 \& 7). In general, all universities reported an alignment percentage below (50\%), which is considered a weak matching with the First-Year Theory represented by the Seven Principles.

The total of Unit of Thoughts (UTs) aligned with the Seven Principles was 174 total. The Self-Efficacy (S.E.) principle was the most cited in the vision, mission, and goals statements of the Preparatory Year Program where it recorded nine UTs (5.17\%) for the vision statement, 28 UTs (16.10\%) for the mission statement, and 76 UTs (43.68\%) for the goals statement. Overall, 113 (64.94\%) out of 174 UTs of the vision, mission, and goals statements matched the Self-Efficacy (S.E.) principal, which exposed the universities trend in developing the Preparatory Year Programs. The majority of Saudi public universities developed its Preparatory Year Programs to improve students academically and to prepare them for university study in terms of knowledge and skills. This study could conclude that the majority of Saudi universities have an implicit theory base rooted in the Self-Efficacy 
(S.E.) principal, which most of the Preparatory Year Programs aim to develop the student's academic skills. For examples, "Developing student's skills in the English language and basic science", "Providing students the mathematical, and self-development skills", and "Preparing new students for college". As this trend is compatible with the first-year literature that focuses on academic preparation in which a number of high school graduates are not ready for college academically, especially in English, science, math, writing skills, etc. Most of those students have no experience with the nature of studying in college, in which students' need to spend more time studying and doing assignments. In addition, some academic skills such as taking notes, summarizing content, participating in classroom activities, etc. are missing (Conley, 2008; Erickson and Strommer, 2005).

For the remaining six principles, the principle of Social Integration (S.I.) is in the second level of alignment with 20 UTs (11.49\%), and the Personal Meaning (P.M.) principle cited 18 UTs (10.34\%) in the third level of alignment. The Active Involvement (A.I.) principle was placed in the fourth level of alignment with 10 UTs (5.75\%). Nine UTs (5.17\%) aligned with the Self-Awareness (S.A.) principle. Finally, the Personal Validation (P.V.) and Personal Reflection (P.R.) were recorded on the lowest level of alignment where only two UTs (1.15\%) cited each principle.

The Seven Principles of Students Success appeared most frequently in the goals statements with 116 UTs (66.67\%) out of 174 . For the mission statements, 46 UTs $(26.44 \%)$ aligned with the Seven Principles, and 12 UTs (6.90\%) were cited for the vision statements (see Table 7). These results indicated that the Preparatory Year Programs vision, mission, and goals statements concentrate on the Self-Efficacy (S.E.) principle, and the other principles have a lack or absence of concentration. This result's consensus with the fact that the majority of the Preparatory Year Program models in Saudi public universities have a main challenge that lack a governing philosophy, theoretical, pedagogical base of the program, and 
the capability of meeting students actual needs in the other aspects of development (Alaqeeli, 2014). Although Alaqeeli suggests developing the first-year students program to enhance the academic knowledge and skills associated with academic subjects (e.g. English, mathematics, science, social studies, world languages, and the arts), Conley (2008) also suggests several dimensions of development, including academic behavior, contextual skills and awareness, and key cognitive strategies.

Using explicit and comprehensive theoretical bases to develop the Preparatory Year Programs is essential to make first-year students successful in postsecondary institutes. Saudi universities may need to articulate the different aspects of success including intellectual, emotional, ethical, physical, and spiritual development in its vision, mission, and goals statements, which may lead to institutional learning practices, academic designs, and policies. For example, "the preparatory year in most American universities is based on a theoretically and practical structured vision. This is in terms of goals, programs, skills, strategies, learning dimensions, teaching strategies, and assessment styles" (Alaqeeli, 2014, p. 60). "Intentionally using student development theory to develop and deliver new students programs is critical to ensure that the needs of diverse students populations are addressed" (Cubarrubia and Schoen, 2010, p. 167).

Concentrating of the Preparatory Year Programs in one or two dimensions of development may cause learning or dropout problems for students. Skipper (2005) mentions, "many institutions already design and deliver interventions that assist students in resolving these and other tasks in the first college year and beyond, but these programs are frequently divorced from the student's classroom experiences and intellectual development" (p. 5). Barefoot (2004) states, “campuses have lacked any systematic, valid definition of, or standards for, first-year excellence that go beyond a single best-practice program to a broader characterization of a campus's total approach to the first-year" (p. 5). 
If we are to help freshmen succeed, we must know how various theories attempt to explain their development. To be sure, the theoretical underpinning of freshman development is a dynamic and constantly changing endeavor. The most recent challenges to include women, minorities, and older students in our theoretical concepts about student development will expand and make more valid our thinking about students. In spite of this continuing uncertainty about students-development theories, everything we do to enhance freshman success must be grounded in one or more of these theories. It is important that we take what we know about students from developmental theories and apply it to our teaching, counseling, advising, and programming for freshmen. (Upcraft \& Gardner, 1989, p. 52)

Koch and Gardner (2014) clarify that to create a successful Preparatory Year model, it is important to link the program's policy, structure, and practices with the university's mission. Therefore, postsecondary institutions "should work collectively to develop a research-based, comprehensive model of the first-year that is attainable and immediately usable to increase student learning, success, and retention" (p. 36).

In summary, the majority of Saudi universities articulated its vision, mission, and goals statements with a concentration on developing the Self-Efficacy (S.E.) principle with a lack of or absence of other principles associated with student's success, which indicates the weak alignment of the current statements with the Seven Principles of Students Success. These results may be due to the lack of knowledge about the first-year experience theories where the Preparatory Year Programs are considered a new phenomenon in most Saudi universities. Furthermore, the Preparatory Year Programs' vision, mission, and goals statements emphasize preparing first-year students for university study and that may result in neglecting the other aspects of the student's development. Moreover, the lack of a theoretical basis of the Preparatory Year Programs will make the program's development difficult, 
where faculty or policymakers have no enough assessment tools connected to specific theory that could inform them about the program's progression and its benefit on student's learning.

\section{Lack of Focus on Student Success as Preparatory Year Programs Vision and}

Mission. Once again, this study's purpose was not to evaluate the Preparatory Year Programs' vision and mission quality or content, this study's purpose was to explore and assess the Preparatory Year Programs' vision, mission, and goals statements alignment with the Seven Principles of Students Success.

For the vision statements, the Content Analysis revealed that only 12 UTs (6.90\%) aligned with the Seven Principles of Students Success in the first-year of university. The common format and frequency of the vision statements associated with the seven principles was "Preparing students for university study" $(\mathrm{n}=11,52.38 \%)$. Furthermore, three common new themes were extracted from the vision statements as follows: 1) NTV1: "Achieving leadership and excellence in developing the Preparatory Year Program" ( $\mathrm{n}=17,80.95 \%)$; 2) NTV2: “Quality-based Preparatory Year Program” (n=4, 19.05\%); and 3) NTV3: “Accredited Preparatory Year Program locally and internationally" (n=10, 47.62\%). On close examination of these themes revealed that the vision statements emphasize the Preparatory Year Program's development and neglected student's success for the majority.

For the mission statement's analysis, the common themes associated with the Seven Principles of Students Success are as follows: 1) “Developing student's knowledge, attitude, values, and academic skills including Mathematics, self-development skills, science, language skills, communication, technology, and thinking skills" (n=19, 79.17\%); 2) "Preparing students for university study" (n=12, 50.00\%\%); 3) "Participating in the national, regional, and global development (Social Integration)" ( $\mathrm{n}=10,41.67 \%) ; 4)$ "Developing student's personality" ( $\mathrm{n}=6,25.00 \%) ; 5)$ "Providing students intensive and advanced English programs" (n=5, 20.83\%); and 6) "Preparing students for the labor 
market" $(\mathrm{n}=2,8.33 \%)$. Furthermore, five new themes were extracted from the mission statements as follows: 1) NTM1: "Provide a stimulating learning environment" (n=10, 41.67\%); 2) NTM2: “Developing creativity and innovation” ( $\mathrm{n}=7,29.17 \%) ; 3)$ NTM3: "Providing academic services" (n=7, 29.17\%); 4) NTM4: "Developing the Preparatory Year Program on high quality-based" ( $\mathrm{n}=7,29.17 \%)$; and 5) NTM5: "Building excellent partnerships with the private sector to operate the Preparatory Year Program ” $(\mathrm{n}=5$, $20.83 \%$ ). Upon close analysis of the content of the mission statements articulations, the study found that the phrasing also revolved around the Preparatory Year Programs academic services, program development, and developing student's Self-Efficacy (S.E.) principle with limited or absent concentration on the other student's success principles.

Additionally, the Content Analysis revealed an overlap among the vision, mission, and goals statements, with many words/sentences, such as competency, skills, environment, etc. used frequently within the study sample. Besides, in some cases, the Preparatory Year Programs mission would exceed the Preparatory Year Programs' scope of work such as "Preparing students for the labor market" $(\mathrm{n}=2,8.33 \%)$ or consider an abnormal phrase such as NTM5: "Building excellent partnerships with the private sector to operate the Preparatory Year Program” $(n=5,20.83 \%)$. In the first case, the study is wondering what the Preparatory Year Programs' task is to prepare students for the labor market during the students' firstyear? What about the next four or five years of study at university? Labor market experts such as Paul Barton at the Educational Testing Service (ETS) and Peter Cappelli at the Wharton School argue, "being prepared for college is not the same as being prepared for successful transition into the workforce" (Stone III, Lewis, 2012, p. 14). However, Preparatory Year Programs may plan to develop its programs to be beyond the first-year in the future to achieve such a goal and this requires linking the program's design with the 
learning theory and possibly a business theory, and also study the future to anticipate job trends and demands.

For the second case, "Building excellent partnerships with the private sector to operate the Preparatory Year Program" as mentioned in Chapter One most Saudi public universities operate the program through the business sector, educational or training institutions, and this practice is considered unprecedented on the international level (Alaqeeli, Abouammoh, \& Alghamdi, 2014). The majority of these private sectors are new in the educational and training market in general, and in the field of first-year program operation in particular. Alaqeeli et al. (2014) note a lack of qualified faculty selected by the business sector to teach or deal with first-year students, which causes miscommunication between first-year students and university faculty, and may lead to learning and teaching quality problems or what is known as the "Commodification of Higher Education". Schroeder (1998) advocates that the collaboration with the business sector is considered the most challenging trend encountered in postsecondary institutions. Instead of building excellent partnerships with the business sector to operate the Preparatory Year Programs and state that as a mission of the program, Preparatory Year Programs may need to work to develop its internal and external proficiency and develop its mission to operate itself in the future.

However, if a vision or mission statement is proposed to clarify a singular and convincing purpose or to raise a reason for the program's existence, this study might expect the student's success principles or first-year theories components be a priority of Preparatory Year Programs future purposes. Upcraft, Gardner, and Barefoot (2005) mentioned some challenges encountered in the first-year experience movements, "there is no consensus about a clear sense of purpose in the first-year" (p. 2). The current context of the Preparatory Year Programs vision and mission statements concentrate on the Preparatory Year Programs development itself. For example, phrases such as achieving excellence or building high 
quality programs or building partnerships with private sectors, all these themes express the Preparatory Year Programs leaders desire to compete among other universities, while the most important target of the program (Student Success) considers the weakest focus point in this context although the fact that the programs were originally established to prepare students academically for university.

This study hopes that the Preparatory Year Programs' vision or mission statements might be phrased in a way that contributes to creating a shared vision among the Preparatory Year Programs' stakeholders, either students, faculty, or leaders about the student's success principles in particular and about First-Year Theories in general. "The preponderance of literature on strategic planning exhorts leaders to work toward defining a singular, organizational purpose in order to focus the efforts of organizational members toward a set of common goals" (Bardwell 2008; Bryson 2004; Crittenden and Crittenden 1997; Moore 2000 as cited in Gurley, Peters, Collins, \& Fifolt, 2014).

\section{Different Preparatory Year Programs with Similar Vision, Mission, and Goals}

Statements. The Content Analysis of the Preparatory Year Programs' vision statements classified vision statements under three main categories: 1) visions that focus on student development (n=4, 19.05\%) for example, "Preparing students for university study"; 2) visions that emphasize developing the Preparatory Year Programs itself ( $n=10,47.62 \%)$ for example, “Achieving leadership and excellence in developing Preparatory Year Program”; and 3) visions that focus on both student development and program development $(n=7$, $25.00 \%$ ) for example, "leadership and excellence in preparing students".

For the mission statements analysis, 19 Preparatory Year Programs' (79.17\%) aligned with the Self-Efficacy (S.E.) principle. Four (16.67\%) aligned with the Personal Meaning (P.M.) principle. Two (8.33\%) aligned with the Active Involvement (A.I.) principle. One (4.17\%) aligned with the Personal Validation (P.V.) and Self-Awareness (S.A.) principles for 
each. The principle of Personal Reflection (P.R.) did not align with any of the mission statements at all 24 universities. For the goals statements, 23 (100\%) Preparatory Year Programs goals aligned with the Self-Efficacy (S.E.) principle. For example, "Developing students' knowledge, academic skills, technology skills, research and communication skills, self-confidence skills, leadership skills, self-development skills, and life-skills" or "Developing English language skills". For the other remaining principles, the majority of the Preparatory Year Programs recorded alignment below 50\%.

Regardless of the differences among the 28 Saudi public universities in terms of histories, geographical location, gender, and sizes, the majority used similar vision, mission, and goals statements. Universities should identify their unique characteristics and emphasize them in their mission and vision statements. It is note-worthy that universities founded in different regions and under different conditions all have similar mission and vision statements. Each university or Preparatory Year Program should have unique needs and identities, which caters to its varied student population.

The success of the strategic plan depends on the correct formulation of mission and vision statements, and wide participation in their formulation. Mission and vision statements also contribute to the creation of the institutional identity of an organization. Mission statement introduces the organization to the public and distinguishes it from other organizations by emphasizing its unique characteristics. (Ozdem, 2011, p. 1992)

The fact of similarity among most of Saudi Preparatory Year Programs vision, mission, and goals statements may be due to the lack of knowledge and experience about the first-year and students development theories among the Preparatory Year Programs' educational planner at these universities. The Content Analysis showed that many Saudi public universities established its Preparatory Year Programs based on the assumption that 
the students coming from high school are academically unready for university although there are differences among Saudi students in terms of qualification and preparation at public education (K-12 education). Furthermore, another observation was made on the female-only institute. Similar results were found across the Preparatory Year Programs, which means the program's content is virtually the same, despite the segregation policy between females and males in Saudi higher education. For example, UN18\# (female-only university), its statements analysis showed that the content of the vision, mission, and goals statements are similar to the other universities.

However, to avoid such issues in the future, this study hopes that all Saudi universities might redesign its Preparatory Year Program on theory-based, not just relying on the best practices on the first-year experience. Barefoot (2004) states, "campuses have lacked any systematic, valid definition of, or standards for, first-year excellence that go beyond a single best-practice program to a broader characterization of a campus's total approach to the first-year" (p. 5). Transferring first-year programs or experiences from one culture to another under the best practices title, without sufficient knowledge about students' needs may lead to learning problems or an increase in student's attrition, each student and postsecondary institute has unique changeable needs (Pascarella and Terenzini, 1997).

The Gap between Theory and Practice (Personal Reflection). The researcher has previously worked in the Saudi public and higher education system for more than 18 years with experience in teaching and in educational administration in both sectors. The researcher spent eight years in the Preparatory Year Program at King Saud University. This study's finding exposed a gap between theory and practice at the Preparatory Year Programs. Using Content Analysis gave the researcher insight and answers to a critical question, why do most Saudi educational initiatives encounter problematic achievement or may conclude with results opposite to those of the educational policymaker and society's desire. 
In fact, establishing an educational initiative with no consideration to the theoretical base may lead to misunderstandings or incorrect practices that may lead to risky consequences. Furthermore, the majority of Saudi educational sectors tend to apply the a global experience or theory that emerged in different educational contexts with no thoughtfulness to its appropriateness for Saudi students and culture. This conclusion does not mean rejecting these practices or theories but, means that there is a need in testing the theory or practice before applying it on a wide range. Saudi educational policymakers may think to establish their own theory that fits their students' needs and supports the educational goals instead of relying on personal experience to develop or manage educational projects.

\section{Implication of Finding}

This study has several implications for Saudi universities and the Preparatory Year Programs developers.

Implication for Saudi Universities. This study used the Content Analysis of the vision, mission, and goals statements of all 28 Preparatory Year Programs that are applied at all Saudi public universities to assess its alignment with the Seven Principles of Students Success advanced by Cuseo (2014). The Content Analysis revealed that the majority of the Preparatory Year Programs vision, mission, and goals statements aligned with the SelfEfficacy (S.E.) principle, while there was lack or absence of alignment with the other six principles. Furthermore, this study exposed the similarity for a large extent among Saudi universities in terms of the vision, mission, and goals statements of the Preparatory Year Programs articulation, despite the differences among them regarding: geographical location, size, Preparatory Year Programs date of establishment, and gender.

These findings and others suggest that each Saudi university may need to reassess its actual needs and its student's needs in the first-year, before developing the program's purpose and goals. Furthermore, it is essential for Saudi universities to develop the 
Preparatory Year Programs on theory-based, which can support the university's endeavors to develop a holistic set of development for its students involving 1) intellectual development; 2) emotional development; 3) social development; 4) ethical development; 5) physical development; and 6) spiritual development. Developing the Preparatory Year Programs’ vision, mission, and goals statements on theory-based will create a shared vision of culture among the program's stakeholders such as leaders, faculty, students, parents, and society.

Implication for Preparatory Year Programs. The Content Analysis also revealed that many Preparatory Year Programs focus on developing student's academically to meet university requirements. Some sub-themes were raised, such as achieving excellence among other Preparatory Year Programs, building partnerships, developing a program on qualitybased, etc., such themes may encourage universities to compete with others, but this practice may not be the concentration point of the Preparatory Year Programs. These goals could be a secondary goal, while the main goal for the Preparatory Year Programs should be Students' Success in the first-year and beyond. Some Preparatory Year Programs state that they are preparing students for the labor market; this is considered a strategic goal for all colleges within the university, but for the Preparatory Year Program, this task may exceed the program's capacity and main goals. All students who complete the Preparatory Year Program will study four or five years in their colleges, which raises a question regarding the ambition goal, how can the Preparatory Year Program achieve such task, if its program is limited to one year and this year is the first-year for students at university. This study suggests that the Preparatory Year Programs vision, mission, and goals should link to the First-Year Theory and the Seven Principles of Students Success for better understanding the Preparatory Year Program's tasks and to provide common ground for the Preparatory Year Programs' policymakers, leaders, and faculty to develop the program's curriculum, policy, and goals. 
Implication for Saudi Educational Policymaker. This study showed that the majority of Saudi public universities established its Preparatory Year Program to develop students academically, improve their knowledge and skills, boost their English language skills, and to overcome the fact that new students may be unready for university. The nature of the vision, mission, and goals statements phrasing and the high percentage similarity among them revealed a gap between high school graduates and universities' requirements in Saudi Arabia. Although each university has autonomy to develop and design its programs and despite the differences among these universities, the vision, mission, and goals statements language may indicate a significantly common problem across the country regarding students' readiness for university. However, recently, on January 29, 2015, the Saudi government decided to combine the higher education and public education ministries into one ministry, named the Educational Ministry, and assigned one minister for both sectors. Historically, both ministries were separated since their establishment date.

Combining both sectors into one makes this study's outcomes more important, which will give the educational policymaker insights regarding the Preparatory Year Programs' actual tasks and concerns across the country. Furthermore, it may encourage the policymaker to study public schools programs and its capability to prepare students for future study at university. This study has a significant implication to create an academic cooperation project design on theory-base to link universities needs with the public education program and student's success principles.

\section{Recommendations for Future Research}

This study used the Content Analysis (CA) Methodology advanced by Neuendorf (2002). Generally, the preferred methodology in the Saudi Arabia educational context is quantitative studies, since studies utilizing Content Analysis are uncommon. Furthermore, analyzing Saudi organizations' vision, mission, and goals statements is a rare practice within 
Saudi educational research. The researcher recommends several future research studies for further investigation and to refine and evaluate the Preparatory Year Programs in Saudi Arabia, as well as to inform broader concerns regarding the Preparatory Year Programs development in postsecondary education.

1- Replicate this study using one or more of a wide variety of methods that are common in qualitative measurement such as interviews, case study, document analysis, observation, etc. to assess the Preparatory Year Programs, which will give a deep understanding to the program's practices and theoretical base.

2- As this study assessed the content of the Preparatory Year Programs' vision, mission, and goals statements and its alignment with the Seven Principles of Students Success. This study suggests that developing quantitative or qualitative measurements based on the Seven Principles of Students Success for all students, faculty, and Preparatory Year Programs' stakeholders to evaluate the universities and students' actual needs.

3- There may need to be some research studies in the future to assess each principle separately and use the outcomes for practices, curriculums, and policy development of the Preparatory Year Programs.

4- This study observed a lack of experience about the First-Year Theories within the Saudi higher education context, thus, this study needs more investigation on the Students' Development Theories and First-Year Theories, which is essential to establish for the culture among Saudi educators.

5- This study observed an overlap among three categories content for the vision, mission, and goals statements. Some studies may be required in the future to assess these statements' content from organizational perspectives. 
6- Finally, this study observed the lack or absence of caring in the vision, mission, and goals statements articulation in some universities. Research studies may be required to explore and develop solutions for this issue.

\section{Summary of the Study}

Students' success in university is largely based on their first-year experiences (BenAvie, Kennedy,Unson, Li, Riccardi \& Mugno, 2012; Clark, 2005; Frazier, 2007: Mutch, 2005; Noel, Levitz, \& Saluri, 1985; Tinto \& Pusser, 2006; Upcraft, Gardner \& Barefoot, 2004).

Many Saudi universities established its Preparatory Year Programs for first-year students in 2005 or beyond. The current working models of the Preparatory Year Program encounter several challenges including the absence of a theoretical and pedagogical base of the program. The current working models of the Preparatory Year Program have no published or released documents that report the program's theoretical and pedagogical base, thus, this study used and analyzed the vision, mission, and goals statements of all Saudi Preparatory Year Programs published on the official websites of all public Saudi universities to assess whether or not the Preparatory Year Programs incorporate the principles of student success in the first-year of university as outlined in the Seven Central Principles of Students Success advanced by Cuseo (2014).

This study explored the Saudi universities Preparatory Year Programs' trends through the most common key elements of the Seven Principles of Students Success included in the Preparatory Year Programs' vision, mission, and goals statements. The study also looked at the themes and formats of the Preparatory Year Programs in all 28 universities and the differences among all these programs based on university size, geographical location, programs date of establishment, and gender. This study was not to evaluate the phrasing 
content or structure of the vision, mission, and goals statements of the Preparatory Year Programs, but to assess its alignment with the First-Year Theory.

The three categories: vision, mission, and goals statements, used are considered as: 1) a philosophical guide for what a particular university or college works toward achieving in the future; 2) illustrate a set of values, principles, purpose, directions for individuals, and program functions; and 3) express the performance level of all university or school components, either educational, professional, students, curriculum, professional development, etc. (Gurley, Peters, Collins, \& Fifolt, 2014; Boerema, 2006; Abelman \& Dalessandro, 2008).

The target population consisted of 28 public universities managed and supervised by the Ministry of Education in Saudi Arabia (MOE, 2016). The nonrandom sampling process (purposive sampling) was utilized in this research. The nine steps of Content Analysis (CA) developed by Neuendorf (2002) were used for data collection and analysis. Furthermore, the Unit of Thoughts (UT) extracted from the vision, mission, and goals statements were used to assess its alignment with the Seven Principles of Students Success. The Unit of Thoughts (UT) are defined by the number of words or sentences or paragraphs that belonged or indicated the existence of the principle individually for each program. All vision, mission, and goals statements, and the Seven Principles of Students Success were identified, coded, defined appropriately, and reported. A pilot study was conducted on seven of the Preparatory Year Programs (25\%) to test the codebook's and coding form's reliability, validity, consistency, and to create a common understanding among the two coders and the researcher. The validity resulted in 100\% agreement between the researcher and two members, which means that the Content Analysis is valid and reliable.

In the $\mathrm{N}=28$ Saudi public universities, $\mathrm{n}=21(75.00 \%)$ universities reported their vision statements for the Preparatory Year Program on its website, while only seven 
$(25.00 \%)$ have no vision statements. For the mission statements, $\mathrm{n}=24(85.71 \%)$ universities that have a mission statement for its Preparatory Year Program, while four (14.29\%) do not have mission statements. For the goal statements, $n=23(82.14 \%)$ universities have a goals statement, while five $(17.86 \%)$ have none.

Upon student enrollment data from 2014-2015, the universities size were distributed into three groups. Group 1 has nine universities (32.14\%) with a total of enrolled students above 10,000. Group 2 nine universities (32.14\%) enrolled a total of students between $10,000<5,000$. Finally, Group 3 has 10 universities (35.71\%) that enrolled between $5,000<1,000$ students. The $\mathrm{N}=28$ universities distributed among six provinces as follows: 1 ) eight (28.57\%) universities in the Middle of Saudi Arabia; 2) six (21.43\%) in the West province; 3) five (17.86\%) in the North; 4) five (17.86\%) in the South provinces: 5) three $(10.71 \%)$ in the East province; and 6) one university (3.57\%) represented the Online University. The data analysis revealed that $\mathrm{n}=27$ universities $(96.43 \%)$ established its Preparatory Year Programs between 2005-2014, which indicates that the program is considered a new phenomenon in the Saudi higher education context. Finally, there are two male-only universities (7.14\%) and one female-only university (3.57\%).

For the organizational structure classifications of the Preparatory Year Program, 17 universities (60.71\%) established a separate deanship named Preparatory Year Deanship for the program. Two universities (7.14\%) named the program Preparatory Year and Supporting Studies Deanship. Two universities (7.14\%) placed the program under the Educational Services Deanship. One university (3.57\%) applies the Preparatory Year Program within College of Applied and Supporting Studies. One university (3.57\%) called the program PreProfessional Program. Two universities (7.14\%) applied the program for a specific body of students and within the colleges structure, e.g. for Science and Medical colleges. Two universities (7.14\%) built a unit named Preparatory Year and placed it under the Admission 
and Registration Deanship. Finally, only one university (3.57\%) did not report the program's structure on its websites (see Table 4). For the programs application policies, 14 universities (50\%) apply the program for all new students and for all colleges, either Science or Health or Human Colleges. 13 universities (46.43\%) apply the program for a specific body of students in either the Science or Medical Colleges. One university (3.57\%) did not report the program's application on its website.

This study assessed the alignment of the vision, mission, and goals statements for each university with the Seven Principles of Students Success separately using the Unit of Thoughts (UT) within each category, and the specially designed codebook and coding form for this study. The alignments total of the vision, mission, and goals statements of Preparatory Year Programs were generated using the formula: vision UTs alignment + mission UTs alignment + Goals UTs alignment/3, and the results are summarized as follows:

1. UN07\# and UN11\# (38.1\%)

2. UN10\# $(33.33 \%)$

3. UN16\# and UN21\# (28.57\%)

4. UN22\#, UN23\#, UN24\#, and UN25\# (23.81\%)

5. UN02\#, UN03\#, UN15\#, UN17\#, UN19\#, UN20\#, UN27\#, and UN28\# (19.05\%)

6. UN06\#, UN09\#, and UN18\# (14.29\%)

7. UN01\#, UN13\#, and UN14\# (9.52\%)

8. UN04\# $(4.76 \%)$

9. UN05\#, UN08\#, UN12\#, and UN26\# (0\%)

Furthermore, the total of Unit of Thoughts (UTs) aligned with the Seven Principles of Students Success in the first-year of university was 174 . The Self-Efficacy (S.E.) principle was the most cited in the vision, mission, and goals statements of the Preparatory Year Program where 113 UTs (64.94\%) matched the S.E. principle. The Social Integration (S.I.) 
recorded 20 UTs (11.49\%). The Personal Meaning (P.M.) principle cited 18 UTs (10.34\%) of alignment. The Active Involvement (A.I.) principle reported 10 UTs (5.75\%). Nine UTs (5.17\%) aligned with the Self-Awareness (S.A.) principle. Lastly, the Personal Validation (P.V.) and Personal Reflection (P.R.) placed in the lowest level of alignment, where they cited only two UTs (1.15\%) for each principle. Overall, 116 out of 174 UTs $(66.67 \%)$ were extracted from the goals statements, 46 UTs (26.44\%) from the mission statements, and 12 UTs $(6.90 \%)$ from the vision statements.

The common format and frequency of vision statements associated with the seven principles was "Preparing students for university study" (n=11, 52.38\%). Moreover, three main themes were recorded in the vision statements as follows:

1- "Achieving leadership and excellence in developing the Preparatory Year Program" $(\mathrm{n}=17,80.95 \%)$

2- “Quality-based Preparatory Year Program” (n=4, 19.05\%)

3- "Accredited Preparatory Year Program locally and internationally" ( $n=10,47.62 \%)$ For the mission statements, the common themes associated with the Seven Principles of Students Success are as follows:

1- “Developing student's knowledge, attitude, values, and academic skills including Mathematics, self-development skills, science, language skills, communication, technology, and thinking skills" (n=19, 79.17\%)

2- "Preparing students for university study" $(\mathrm{n}=12,50.00 \%)$

3- "Participating in the national, regional, and global development (Social Integration)" $(\mathrm{n}=10,41.67 \%)$

4- "Developing student's personality" $(n=6,25.00 \%)$

5- "Providing students intensive and advanced English programs" (n=5, 20.83\%)

6- "Preparing students for the labor market" $(n=2,8.33 \%)$ 
The new themes appeared in the mission statements as follows:

1- "Provide a stimulating learning environment" $(n=10,41.67 \%)$

2- "Developing creativity and innovation" $(n=7,29.17 \%)$

3- "Providing academic services" $(\mathrm{n}=7,29.17 \%)$

4- "Developing the Preparatory Year Program on high quality-based" ( $n=7,29.17 \%)$

5- "Building excellent partnerships with the private sector to operate the Preparatory Year Program" (n=5, 20.83\%)

For the goals statements, the common themes associated with the Seven Principles of Students Success are recorded as follows:

1- 'Developing students' knowledge, academic skills, technology skills, research and communication skills, self-confidence skills, leadership skills, self-development skills, and life-skills" (n=18, 78.26\%)

2- "Developing English language skills" (n=16, 69.57\%)

3- "Preparing students for university study and life" ( $n=13,56.52 \%)$

4- "Help students to enroll in a suitable college based on their performance" ( $n=7$, $29.17 \%)$

5- "Developing student's self-autonomy skills, responsibility, and self-discipline" ( $\mathrm{n}=7$, $29.17 \%)$

6- "Raising student's awareness about social-responsibility" (n=4, 17.39\%)

7- "Preparing students for the labor market" $(n=3,13.04 \%)$

8- "Developing student's awareness and physical fitness" $(n=2,8.70 \%)$

9- "Educating students about their rights and university's regulations" ( $\mathrm{n}=2,8.70 \%)$ The new themes that appeared in the goals statements are:

1- "Developing a stimulating learning environment to encourage innovation and creativity among students" ( $=11,47.83 \%)$ 
2- “Improving university's outcomes" $(n=4,17.39 \%)$

3- "Fill the knowledge and skills gap between high school outcomes and university requirements" $(\mathrm{n}=4,17.39 \%)$

4- "Unify university admission" ( $\mathrm{n}=3,13.04 \%)$

5- "Building distinguished partnerships with the private sector to operate the program" $(\mathrm{n}=3,13.04 \%)$

6- "Developing student's assessment system" $(\mathrm{n}=2,8.70 \%)$

7- "Developing excellent human resources" $(n=2,8.70 \%)$

Furthermore, this study divided the vision statements into three groups based on vision's phrasing and purposes as follows: 1) visions that focus only on the student; 2) visions that emphasis only on the program itself; and 3) visions that concentrate on both the student and program. Group 1 recorded $(n=4,19.05 \%)$ focus on student development. For Group $2(n=7,25.00 \%)$, the emphasis was on developing the Preparatory Year Program itself. Group 3 focuses on both the student's development and program's development ( $\mathrm{n}=7$, $25.00 \%$ ). For similarities and differences, the majority of the Preparatory Year Programs set their goals and academic focus on the Self-Efficacy (S.E.) and Social Integration (S.I.) principles. The similarity among Saudi's Preparatory Year Programs vision, mission, and goals statements were high despite the differences among them based on the four variables: geographical location, size, Preparatory Year Programs date of establishment, and gender. However, this study found that universities founded in different regions and under different conditions have similar mission and vision statements and each university or Preparatory Year Program should have a unique need and identity that fits its students' needs. 


\section{References}

(AAFAQ), P. M. (2013). The future plan of higher education in saudi arabia. Riyadh: Ministry of Higher Education.

Abelman, R., \& Dalessandro, A. (2008). An assessment of the institutional vision of catholic colleges and universities. Catholic Education: A Journal of Inquiry and Practice, 12(2), 221.

Abelman, R., Atkin, D., Dalessandro, A., Snyder-Suhy, S., \& Janstova, P. (2007). The trickle-down effect of institutional vision: Vision statements and academic advising. NACADA Journal, 27(1), 4-21.

About the center. (n. d.). In National Resource Center for the First-Year Experience \& Students in Transition at the University of South Carolina. Retrieved January 20, 2015, from http://sc.edu/fye/center/index.html.

Al Awsat, Asharq (2013, June, 24). Saudi Universities are ready to recive 376,000 high school gradute. Asharq Al Awsat Newspaper, 12627. Alriyadh, Saudi Arabia: Saudi Research and Marketing LTD (In Arabic).

Al Kathiri, S. N. (2014). Preparatory year (first year experience). The Saudi Journal of Higher Education (11), 65-70.

Al-Eisa, E. S., \& Smith, L. (2013). Governance in saudi higher education. In Higher Education in Saudi Arabia (pp. 27-35). Springer Netherlands.

Al-jarallah, A. (2014, August, 18). Saudi universities and the preparatory year dilemma. AlJazerah Newspaper, 15299. Riyadh, Saudi Arabia: Al-Jazerah .

Al-Swailem, O., \& Elliott, G. (2013). The learning experiences of saudi arabian higher education leadership: Characteristics for global success. In Higher Education in Saudi Arabia (pp. 37-47). Springer Netherlands. 
Alaqeeli, A. S. (2014). The preparatory year: Global Perspectives and local practices. The Saudi Journal of Higher Education (11), 45-64.

Alaqeeli, A., Abouammoh, A., \& Alghamdi, S. (2014). International experiences in the preparatory year: Highlight on the 33rd annual conference on the first-year experience in the United State of America. Riyadh: Ministry of Higher Education (In Arabic).

Alatas, A. (2012, November, 4). An ambitious action plan at Shqra university to improve the educational outcomes and provide better academic and training services to students: Preparatory year investing on minds of young people to promote knowledge-based society. Al-Riyadh Newspaper, 16204. Riyadh, Saudi Arabia: Alyamama Press Est (In Arabic).

Aldana, U. S. (2014). Moving beyond the college-preparatory high school model to a college-going culture in urban catholic high schools. Catholic Education: A Journal of Inquiry and Practice, 17 (2). Retrieved from http://digitalcommons.lmu.edu/ce/vol17/iss2/9

Alexander, B. C., García, V., González, L., Grimes, G., \& O'Brien, D. (2007). Barriers in the transfer process for Hispanic and Hispanic immigrant students. Journal of Hispanic Higher Education, 6(2), 174-184.

Alexander, R. J. (2001). Culture and pedagogy: International comparisons in primary education. Blackwell publishing.

Alhosin, M. (2010, January, 9). Preparatory year works to raise the level of academic preparation of graduates to achieve the developmental requirements and to meet labor market demand. Al-Riyadh Newspaper, 15174. Riyadh, Saudi Arabia: Alyamama Press Est (In Arabic). 
Alhosini, K. (2012, April, 14). The preparatory year frustration. Al-Riyadh Newspaper, 16000. Riyadh, Saudi Arabia: Alyamama Press Est (In Arabic).

Alkhazim, M. (2007, July, 26). Preparatory year or the year of guillotine? Al-Riyadh Newspaper, 14276. Riyadh, Saudi Arabia: Alyamama Press Est (In Arabic). .

Alkhazim, M. (2013, October, 6). Preparatory year and king Fahd university of petroleum and minerals. Al-Jazirah Newspaper, 14983. Riyadh, Saudi Arabia: Al-Jazirah (In Arabic).

Almaliki, S. (2011, September, 13). Al-shura council board tends to abolish the preparatory year in Saudi universities. Sabq Electronic Newspaper. Riyadh, Saudi Arabia: Sabq (In Arabic).

Alnahdi, G. H. (2013). Educational change. In saudi arabia. Journal of International Education Research (JIER), 10(1), 1-6.

Alnassar, S. A., \& Dow, K. L. (2013). Delivering high-quality teaching and learning for university students in saudi arabia. In Higher Education in Saudi Arabia (pp. 49-60). Springer Netherlands.

Alnofaie, H. (2013). A framework for implementing critical thinking as a language pedagogy in EFL preparatory programs. Thinking Skills and Creativity, 10, 154-158.

Alqahtani, M. (2010, March, 30). Preparatory year function [powerpoint]. The fourth periodic meeting for academic affairs deputy of Saudi universities. Riyadh: King Saud University.

Alqassim, U. (2010, March, 31). Highlight on the preparatory Year Program at the university of qassim: Challenges and experience. The fourth periodic meeting for academic affairs deputy of Saudi universities. Riyadh: King Saud University. 
Alsalim, H. (2012, March, 10). Dilemma of public education outputs need to a solutions better than Disablement: Fourth of secondary school or preparatory year. Al-Riyadh Newspaper, 15965. Riyadh, Saudi Arabia: Alyamama Press Est (In Arabic).

Alshamri, T. (2010, March, 31). Highlight on the preparatory year program at Al-jouf university. The fourth periodic meeting for academic affairs deputy of Saudi universities. Riyadh: King Saud University.

Alsoltan, A. (2012, April, 17). Preparatory year hinder educational reform. Al-Jazirah Newspaper, 14446. Riyadh, Saudi Arabia: Al-Jazirah (In Arabic).

Altowjry, A. (2005). Reforming higher education in Saudi Arabia: The use of telecommunications technology.

Amaral, A. and A. Magalhães (2002). The emergent role of external stakeholders in european higher education governance. In A. Amaral, G.A. Jones and B. Karseth (eds.) Governing Higher Education: National Perspectives on Institutional Governance, Higher Education Dynamics 2, Dodrecht, Boston and London, Luwer Academic Publishers, pp. 279-298.

Andrade, M. (2005). International students and the first year of college. Journal of the FirstYear Experience \& Students in Transition, 17(1), 101-129.

Arnold, K. D., Lu, E. C., \& Armstrong, K. J. (2012). The ecology of college readiness. ASHE Higher Education Report. Volume 38, Number 5. John Wiley \& Sons.

Asta, L. A. (2009). A content analysis of induction policies in seven selected Florida school districts. Doctoral dissertation, University of Florida. Retrieved from http://search.proquest.com/docview/304874287?accountid=2837

Astin, A. W. (1977). Four critical years. effects of college on beliefs, attitudes, and knowledge. 
Astin, A. W. (1984). Student involvement: A developmental theory for higher education. Journal of College Student Personnel, 25(4), 297-308.

Astin, A. W. (1985). Achieving educational excellence: A critical assessment of priorities and practices in higher education. Jossey-Bass.

Astin, A. W. (1993). What matters in college?: Four critical years revisited (Vol. 1). San Francisco: Jossey-Bass.

Astin, A. W. (1999). Student involvement: A developmental theory for higher education. Journal of College Student Development, 40(5), 518-29.

Astin, A. W., \& Panos, R. J. (1969). The educational and vocational development of college students. Washington: American Council on Education.

Astin, A. W., Oseguera, L., Sax, L.J., Korn, W.S. (2002). The American freshman: Thirtyfive year trends, Los Angeles: Higher Education Research Institute, UCLA.

Augusta-Dupar, C. M. (2003). The mission and vision statements of ten historically black colleges and universities: A content analysis

Azizi, S., \& Hosseinabadi, V. (2014). A content analysis of the mission statements of iran, turkey, india and united states pharmaceutical companies. Management \& Marketing Journal, 15(1).

Bagazi, A. (2010, June, 28). King saud university treat the inadequacy of educational outcomes for the labor market by preparatory year. Asharq Al-Awsat Newspaper, 11535. Al-Riyadh, Saudi Arabia: Saudi Research and Marketing LTD (In Arabic).

Bailey, T. R. (2005). Paths to persistence: An analysis of research on program effectiveness at community colleges.

Bailey, T. R., \& Alfonso, M. (2005). Paths to persistence: An analysis of research on program effectiveness at community colleges. Indianapolis, IN: Lumina Foundation for Education. 
Baker, L., Meyer, K., \& Hunt, S. (2005). First year students' perception of power and use of persuasive techniques: A comparison of learning community versus traditional classes. Journal of the First-Year Experience \& Students in Transition, 17(2), 23-48.

Bakoğlu, R., \& Aşkun, B. (2007). Mission statements of socially responsible firms: A content analysis. Journal of Global Strategic Management, 1(1), 66-74.

Bakry, S. H., \& Al-Ghamdi, A. (2008). A framework for the knowledge society ecosystem: A tool for development. In the open Knowledge Society. A Computer Science and Information Systems Manifesto (pp. 32-44). Springer Berlin Heidelberg.

Barefoot, B. (1998). A brief introduction to student development theory; Special issues pertaining to the first year. Faper presented at the Annual Conference on The FirstYear Experience, Columbia SC.

Barefoot, B. (2004). Foundations of excellence: A new model for first-year assessment. Assessment update, 16(2), 5-7.

Barefoot, B. O. (1992). Helping first-year college students climb the academic ladder. Report of a national survey of freshman seminar programming in american higher education. Unpublished doctoral dissertation, College of William and Mary, Williamsburg, VA.

Barefoot, B. O. (2000). The first-year experience. About Campus, 4(6), 12-18.

Barefoot, B. O. (2005). Achieving and sustaining institutional excellence for the first year of college. San Francisco, CA: Jossey-Bass.

Barefoot, B. O. (2005). Current institutional practices in the first college year. In M. L. Upcraft, J. N. Gardner, \& B. O. Barefoot (Eds), Challenging and supporting the firstyear student: A handbook for improving the first year of college, 47-63. San Francisco: Jossey-Bass.

Barefoot, B. O., \& Fidler, P. P. (1992). 1991 national survey of freshman seminar programming. (Monograph No. 10). Columbia, SC: University of South Carolina, 
National Resource Center for The Freshman Year Experience.

Barefoot, B. O., Gardner, J. N., Cutright, M., Morris, L. V., Schroeder, C. C., Schwartz, S. W., Siegel, M. L., \& Swing, R. L. (2010). Achieving and sustaining institutional excellence for the first year of college. John Wiley \& Sons. New Jersey, United States.

Barrows, S., \& Goodfellow, M. (2005). Learning effect on first-year students success in a general chemistry course. The Journal of The First-Year Experience \& Students in Transition, 17(2), 11-22.

Bart, C. K., \& Tabone, J. C. (1998). Mission statement rationales and organizational alignment in the not-for-profit health care sector. Health Care Management Review, 23(4), 56-71.

Bauer, K. W., \& Liang, Q. (2003). The effect of personality and precollege characteristics on first-year activities and academic performance. Journal of College Student Development, 44(3), 277-290.

Beerkens, E. (2008). University policies for the knowledge society: Global standardization, local reinvention. Perspectives on global development and technology, 7(1), 15-36.

Beers, R. E. (1998). The first-year university experience: An international student perspective. Retrieved from http://search.proquest.com/docview/304490691?accountid=2837

Ben-Avie, M., Kennedy, M., Unson, C., Li, J., Riccardi, R. L., \& Mugno, R. (2012). Firstyear experience: A comparison Study. Journal of Assessment and Institutional Effectiveness, 2(2), 143-170.

Benoit, William L. (2011). Content analysis in political communication. In Bucy, E. P., \& Holbert, R. L. The sourcebook for political communication research: Methods, measures, and analytical techniques (pp. 268-279). New York: Routledge. 
Bess, J. L., \& Dee, J. R. (2008). Understanding college and university organization: Dynamics of the system (Vol. 2). Stylus Publishing, LLC.

Bielavitz, T. (2011). A content analysis of the strategic plans of the coalition of urban serving universities' academic libraries.

Bindé, J., \& Matsuura, K. (2005). Towards knowledge societies (Vol. 1). UNESCO.

Birnbaum, R. (1992). How academic leadership works: Understanding success and failure in the college presidency. San Francisco: Jossey-Bass.

Blackhurst, A., Akey, L., \& Bobilya, A. (2003). A qualitative investigation of student outcomes in a residential learning community. Journal of the First-Year Experience \& Students in Transition, 15(2), 35-59.

Boerema, A. J. (2006). An analysis of private school mission statements. Peabody Journal of Education, 81(1), 180-202. doi:10.1207/S15327930pje8101_8

Bogard, M., Helbig, T., Huff, G., \& James, C. (2011). A comparison of empirical models for predicting student retention. White paper. Office of Institutional Research, Western Kentucky University.

Bolman, L. G., \& Deal, T. E. (2008). Reframing organizations: Artistry, choice, and leadership, fourth edition Jossey-Bass. San Francisco, United States.

Bosse, S., Duncan, K., Gapp, S., \& Newland, L. (2011). Supporting american indian students in the transition to postsecondary education. Journal of the First-Year Experience \& Students in Transition, 23(2), 33-51.

Boylan, H. R., Bonham, B. S., \& White, S. R. (1999). Developmental and remedial education in postsecondary education. New Directions for Higher Education, 108, 87-101.

Brătianu, C., \& Bălănescu, G. V. (2008). Vision, mission and corporate values. A comparative analysis of the top 50 US companies. Management \& Marketing, 3(3), $19-38$. 
Braxton, J. M. (2000). Reworking the student departure puzzle. Nashville: Vanderbilt University Press.

Braxton, J. M., \& McClendon, S. A. (2001). The fostering of social integration and retention through institutional practice. Journal of College Student Retention: Research, Theory \& Practice, 3(1), 57-71.

Braxton, J. M., Hirschy, A. S., \& McClendon, S. A. (2011). Understanding and reducing college student departure. ASHE-ERIC higher education report, volume 30, number 3. Hoboken: Jossey-Bass.

Brislin, R. W. (1970). Back-translation for cross-cultural research. Journal of cross-cultural psychology, 1(3), 185-216.

Brooman, S., \& Darwent, S. (2012). 'Yes, as the articles suggest, I have considered droppingout: Self-awareness literature and the first-year student. Studies in Higher Education, 37(1), 19-31.

Cetinavci, U. R., \& Topkaya, E. Z. (2012). A contrastive qualitative evaluation of two different sequential programs launched at the school of foreign languages of a turkish university. Online Submission, 3(3), 82-101. Chicago

Chickering, A. W., \& Gamson, Z. F. (1987). Seven principles for good practice in undergraduate education. AAHE bulletin.

Chickering, A. W., \& Reisser, L. (1993). Education and identity. San Francisco: Jossey-Bass Publishers.

Chomey, L. (1994). Concept mapping and the role of the elementary school counselor. Master's Thesis in Counselling Psychology. University of Alberta.

Christensen, C. M. (1997). The innovator's dilemma: The revolutionary book that will change the way you do business. Collins Business Essentials. 
Clark, M. R. (2005). Negotiating the freshman year: Challenges and strategies among firstyear college students. Journal of College Student Development, 46(3), 296-316.

Cohen, M. D., March, J. G., \& Olsen, J. P. (1972). A garbage can model of organizational choice. Administrative Science Quarterly, 1-25.

College of Applied Medical Sciences. (n. d.). Home. In the college of applied medical sciences. Retrieved March 18, 2015, from http://cams.ksu.edu.sa/en.

College of Business administration. (n. d.). Vision. In the college of business administration. Retrieved March 18, 2015, from http://cba.ksu.edu.sa/en/content/vision\#.

College Of Education. (n. d.). Vision. In the college of education. Retrieved March 18, 2015, from http://education.ksu.edu.sa/en.

College of Engineering. (n. d.). Vision. In the college of engineering. Retrieved March 18, 2015, from http://engineering.ksu.edu.sa/Arabic/en/Pages/default.aspx.

Comeaux, E., \& Harrison, C. K. (2011). A conceptual model of academic success for student-athletes. Educational Researcher, 40(5), 235-245.

Commander, N., Valeri-Gold, M., \& Darnell, K. (2004). The strategic thinking and learning community: An innovative model for providing academic assistance. Journal of the First-Year Experience \& Students in Transition, 16(1), 61-76.

Conley, D. T. (2008). Rethinking college readiness. New Directions For Higher Education, 2008(144), 3-13. doi:10.1002/he.321.

Conley, D. T. (2010). College and career ready: Helping all students succeed beyond high school. John Wiley \& Sons. New Jersey, United States.

Conley, D. T. (2013). Getting ready for college, careers, and the Common Core: What every educator needs to know. John Wiley \& Sons. New Jersey, United States.

Corneo, G. (2011). Stakeholding as a new development strategy for Saudi Arabia. Review of Middle East Economics and Finance, 7(1), 1-19. 
Creamer, E. G., \& Ghoston, M. (2013). Using a mixed methods content analysis to analyze mission statements from colleges of engineering. Journal of Mixed Methods Research, 7(2), 110-120. doi:10.1177/1558689812458976

Crews, T. B., Wilkinson, K., \& Neill, J. K. (2015). Principles for good practice in undergraduate education: Effective online course design to assist students' success. Journal of Online Learning and Teaching, 11(1), 87.

Crissman Ishler, J. L. (2005). Today’s first-year students. In M. L. Upcraft, J. N. Gardner, \& B. O. Barefoot (Eds), Challenging and supporting the first-year student: A handbook for improving the first year of college, 15-26. San Francisco: Jossey-Bass.

Crissman, J. (2001). Clustered and non-clustered first-year seminars: New students' firstsemester experiences. Journal of the First-Year Experience \& Students in Transition, 13(1), 69-88.

Crosling, G., Thomas, L., \& Heagney, M. (2008). Introduction: Student success and retention. Improving student retention in higher education, 1-13.

Cubarrubia, A. P. \& Schoen, J. C. (2010). Creating a developmental framework for new student orientation to address the needs of diverse population. In J. A. Ward-Roof (Ed), Designing Successful Transitions: A Guide for Orienting Students to College. (Monograph No. 13, $3^{\text {rd }}$ ed.). Columbia, SC: University of South Carolina, National Resource Center for The First-Year Experience and Students in Transition.

Curtis, S. M., \& Harte, J. (1991). A freshman retention project at borough of Manhattan community college.

Cuseo, J. (2011). Assessment of the first-year seminar: Research-based guidelines for course \& program evaluation. Indiana University. Retrieved from http://resources.uc.iupui.edu/Articles.aspx 
Cuseo, J. (2014). Student success: Definition, outcomes, principles and practices. The Big Picture: E-source for College Transitions. Indiana University. Retrieved from http://resources.uc.iupui.edu/Articles.aspx

Cuseo, J. (n. d.). The first year experience \& students-in-transition movement: What is its appeal? what are its ideals?. Indiana University. Retrieved from http://resources.uc.iupui.edu/Articles.aspx

Cuseo, J. (n. d.). Seven powerful properties \& principles of effective first-year program delivery. Indiana University. Retrieved from http://resources.uc.iupui.edu/Articles.aspx

Cuseo, J., Fecas, V. S., \& Thompson, A. (n.d.). What all first-year students should know: The most potent, research-based principles of college success. Indiana University. Retrieved from http://resources.uc.iupui.edu/Articles.aspx

Cutright, M. (2002). What are research universities doing for first-year students?. About Campus, 7(4), 16-20.

Cutright, M., \& Rodems, M. (2003). Annotated bibliography on assessment of the first college year. Policy Center on the First Year of College.

Deanship, P. Y. (2014). Student handbook 2014-2015. Riyadh: King Saud University. Demetriou, C., \& Schmitz-Sciborski, A. (2011). Integration, motivation, strengths and optimism: Retention theories past, present and future. In the 7th National Symposium on Student Retention, Charleston, Norman, OK: The University of Oklahoma.

DeVilbiss, Samantha E. (2014). The transition experience: Understanding the transition from high school to college for conditionally-admitted students using the lens of Schlossberg's transition theory. University of Nebraska - Lincoln.

DeWitz, S. J., Woolsey, M. L., \& Walsh, W. B. (2009). College student retention: An exploration of the relationship between self-efficacy beliefs and purpose in life among 
college students. Journal of College Student Development, 50(1), 19-34. doi:10.1353/csd.0.0049

Dillon, J. J. (2003). Bringing counseling to the classroom and the residence hall: The university learning community. The Journal of Humanistic Counseling, Education and Development, 42(2), 194-208.

DiRamio, D., \& Jarvis, K. (2011). Transition 2.0: Using Tinto's model to understand studentveteran persistence. ASHE Higher Education Report, 37(3), 35-49.

Division of Public Administration, \& Development Management. (2005). Understanding knowledge societies: In twenty questions and answers with the index of knowledge societies. United Nations Publications.

Draper, S. (2005). Tinto's model of student retention.

Drucker, P. (2012). Managing in the next society. Routledge.

Drucker, P. F. (1969). The age of discontinuity: Guidelines to our changing society. New York: Harper \& Row.

Drucker, P. F. (1993). The rise of the knowledge society. The Wilson Quarterly (1976-), $17(2), 52-71$.

Drucker, P. F. (1999). Management challenges for the 21st century. New York: Harper Business.

Drucker, P. F., \& Drucker, P. F. (1994). Post-capitalist society. Routledge.

Drucker, P. F., \& Wartzman, R. (2010). The drucker lectures: Essential lessons on management, society and economy: Part VI: 1990s: Chapter 22: Manage yourself and then your company 1996. Sebastopol: Safari Books Online LLC

Duderstadt, J. J., \& Weber, L. E. (2006). Universities and business: Partnering for the knowledge society. Economica. 
DuFour, R., \& Eaker, R. (1998). Professional learning communities at work: Best practices for enhancing student achievement. Bloomington: National Education Service.

Dwyer, J. O. (1989). A historical look at the freshman year experience. In Upcraft, M. L., \& Gardner, J. N. The freshman year experience: Helping students survive and succeed in college. San Francisco, Calif: Jossey-Bass Publishers.

Eddie, C., \& C, K. H. (2011). A conceptual model of academic success for studentathletes. Educational Researcher, 40, (5), 235-245.

Elo, S., \& Kyngäs, H. (2008). The qualitative content analysis process. Journal of advanced nursing, 62(1), 107-115.

Elyas, T., \& Picard, M. (2013). Critiquing of higher education policy in saudi arabia: Towards a new neoliberalism. Education, Business and Society. Contemporary Middle Eastern Issues, 6(1), 31-41.

Erickson, B. L., \& Strommer, D. W. (2005). In M. L. Upcraft, J. N. Gardner, \& B. O. Barefoot (Eds), Challenging and supporting the first-year student: A handbook for improving the first year of college, 241-256. San Francisco: Jossey-Bass.

Ernest T. Pascarella, \& Patrick T. Terenzini. (2005). How college affects students: a third decade of research. Jossey-Bass.

Estanek, S. M., James, M. J., \& Norton, D. A. (2006). Assessing Catholic identity: A study of mission statements of catholic colleges and universities. Catholic Education: A Journal of Inquiry \& Practice, 10(2), 199-217.

Evans, N. J., Forney, D. S., \& Guido-DiBrito, F. (1998). Student development in college: Theory, research, and practice. San Francisco: Jossey-Bass Publishers.

Evenbeck, S. E., Jackson, B., Smith, M., Ward, D., \& Associates. (2010). Organizing for student success: The university college model (Monograph No. 53). Columbia, SC: 
University of South Carolina, National Resource Center for the First-Year Experience \& Students in Transition,

Falduto, V. R. (2008). A content analysis of contemporary college algebra textbooks:

Applications of visualization strategies. Retrieved from http://search.proquest.com/docview/304830257?accountid=2837

Fashola, O. S., \& Slavin, R. E. (1998). Effective dropout prevention and college attendance programs for students placed at risk. Journal of Education for Students Placed at Risk, 3, 159-183.

Feldman, R. S. (Ed.). (2005). Improving the first year of college: Research and practice. Psychology Press.

Feldman, R. S., \& Zimbler, M. S. (2011). Engendering college student success: Improving the first year and beyond. Massachusetts: The McGraw-Hill Research Foundation.

Female Student Campus. (n. d.). Home. In the female student campus. Retrieved March 18, 2015, from http://womencampus.ksu.edu.sa/en.

Field, A. (2009). Discovering statistics using SPSS. Sage.

Fielstein, L., \& Bush, L. (1998). Remedial students' perceptions: Pre-college decisionmaking, satisfaction with the freshman year, and self-perceptions of academic abilities. Journal of the First-Year Experience \& Students in Transition, 10(2), 41-55.

Foot, S. M., Hinkle, S. E., Kranzow, J., Pistilli, M. D., Rease Miles, L., \& Simmons, J. G. (2013). College students in transition: An annotated bibliography. Columbia, SC: University of South Carolina, National Resource Center for the First-Year Experience and Students in Transition.

Foster, N. M. (2015). Alignment of mission statements with hiring and evaluation processes of faculty at higher education institutions approved by the academic quality 
improvement program (AQIP). Doctoral Dissertation, Western Michigan University.

Franklin, K. (2000). Shared and connected learning in a freshman learning community. Journal of the First-Year Experience \& Students in Transition, 12(2), 3360.

Fraser, K. M. (1993). Theory based use of concept mapping in organization development: Creating shared understanding as a basis for the cooperative design of work changes and changes in working relationships. Cornell University. New York, United States.

Frazier, K. G. (2007). First year experience collaboration among academic affairs and student affairs at public state university. Georgia State University. Atlanta, United States.

Fullan, M. (1993). Change forces: Probing the depths of educational reform. School Development and the Management of Change Series 10. London: Falmer.

Fuller, S. (2003). Can universities solve the problem of knowledge in society without succumbing to the knowledge society? Policy Futures in Education, 1(1), 106-124.

Gallarotti, G. M., Filali, A., \& Yahia, I. (2013). Smart development: Saudi Arabia's quest for a knowledge economy. International Studies.

Gardner, J. (2007). An interview with John Gardner. In student success: The Newsletter for Higher Education Professionals, November 2007.

Gardner, J. N., \& Barefoot, B. O. (2011). Your College Experience: Strategies for Success. Macmillan. London, United Kingdom.

Gardner, J. N., \& Koch, A. K. (2014). A history of the first-year experience in the united states during the twentieth and twenty-first centuries: Past practices, current Approches, and future directions. The Saudi Journal of Higher Education (11), 11-44.

Gardner, J. N. (1998, February). Current trends in the first college year. Faculty House 
Dinner Workshop conducted at the National Conference on the Freshman Year Experience, Columbia, South Carolina.

General Department for Planning Statistics. (2011). Higher education and building knowledge society: An international evaluation. Riyadh: Education, Ministry of Higher. Retrieved December 1, 2014, from http://www.mohe.gov.sa

General Department for Planning Statistics. (2013). Higher education and building knowledge society: An international evaluation. Riyadh: Ministry of Higher Education. Retrieved December 1, 2014, from http://www.mohe.gov.sa

Gengler-Dunn, D. (2007). A narrative inquiry of four female first-year, first-generation student perspectives of the university experience.

Giles, C., \& Hargreaves, A. (2006). The sustainability of innovative schools as learning organizations and professional learning communities during standardized reform. Educational Administration Quarterly, 42(1), 124-156.

Gold, J., Miller, M., \& Rotholz, J. (2001). Grief experiences of first-year women students in the transition to college: Implications for individual and systemic interventions. Journal of the First-Year Experience \& Students in Transition, 13(2), 37-54.

Golde, C. M., \& Pribbenow, D. A. (2000). Understanding faculty involvement in residential learning communities. Journal of College Student Development, 41(1), 27-40.

Gordon, V., \& Steele, G. (2003). Undecided first-year students: A 25-year longitudinal study. Journal of the First-Year Experience \& Students in Transition, 15(1), 19-38.

Gore, P. A., Jr., \& Carter, L. P. (Eds.). (2011). Students in transition: Research and practice in career development (Monograph No. 55). Columbia, SC: University of South Carolina, National Resource Center for the First-Year Experience and Students in Transition. 
Greenfield, G. M., Keup, J. R., \& Gardner, J. N. (2013). Developing and sustaining successful first-year programs: A guide for practitioners. John Wiley \& Sons. New Jersey, United States.

Gurley, D. K., Peters, G. B., Collins, L., \& Fifolt, M. (2015). Mission, vision, values, and goals: An exploration of key organizational statements and daily practice in schools. Journal of Educational Change, 16(2), 217-242.

Habib, H. (2010, 9 21). Preparatory year is a transition phase for student: Its benefits exceed on just academic chance. Al-Riyadh Newspaper, 15429. Riyadh, Saudi Arabia: Alyamama Press Est (In Arabic).

Halvorsen, T., \& Skauge, T. (2004). Constructing knowledge societies? The World Bank and the new lending policy for tertiary education. Journal of Higher Education in Africa, 2(3), 140.

Hamdan, A. (2005). Women and education in Saudi Arabia: Challenges and achievements. International Education Journal, 6(1), 42-64.

Hanley, G., \& Olson, S. (1996). Preparing incoming students for the university educational process: From the students' perspective and retrospective. Journal of the First-Year Experience \& Students in Transition, 8(1), 47-77.

Hargreaves, A. (2003). Teaching in the knowledge society: Education in the age of insecurity. Teachers College Press. New York.

Haring, M. J. (2005). Preparing for college: Nine elements of effective outreach. Middletown: American Library Association CHOICE.

Hensheid, J. M., \& Keup, J. R. (2011). Crafting and conducting research on student transitions. National Resource Center for the First-Year Experience and Students in Transition, University of South Carolina. 
Hidayat, I. (2011). A content analysis of Indonesian hotel website. Master Thesis, University of Nevada, United States.

Higgins, M. (2010). The first year experience. Kansas State University, Department of Counseling and Student Development. Manhattan: College of Education.

Higher Education Statistics in Details (2015, January 10). Retrieved from https://he.moe.gov.sa/ar/Ministry/Deputy-Ministry-for-Planning-and-Informationaffairs/HESC/Ehsaat/Pages/default.aspx (In Arabic).

Hill, M., \& Sedlacek, W. (1995). Freshman counseling interests. In M. L. Upcraft, J. N. Gardner, \& B. O. Barefoot (Eds), Challenging and supporting the first-year student: A handbook for improving the first year of college, 27-38. San Francisco: JosseyBass.

Hollands, A. L. C. (2012). Fostering hope and closing the academic gap: An examination of college retention for African-American and Latino students who participate in the louis stokes alliance minority participation program (learning community) while enrolled in a predominately white institution.

Hollands, A. L. C. (2012). Fostering Hope and Closing the Academic Gap: An Examination of College Retention for African-American and Latino Students Who Participate in the Louis Stokes Alliance Minority Participation Program (Learning Community) While Enrolled in a Predominately White Institution. Ann Arbor, MI. Retrieved from http://www.proquest.com/en-US/products/dissertations/individuals.shtml.

Holosko, M. J., Winkel, M., Crandall, C., \& Briggs, H. (2015). A Content analysis of mission statements of our top 50 schools of social work. Journal of Social Work Education, 51(2), 222-236.

Hornidge, A. K. (2011), 'Knowledge Society' as Academic Concept and Stage of Development - A Conceptual and Historical Review. In the Menkhoff, H.-D. Evers, 
Chay Y. W. and Eng F. P. (eds.), Beyond the Knowledge Trap: Developing Asia's Knowledge-based Economies. Hackensack, NJ, et al.: World Scientific Publishing, pp. 87128 .

Hossler, D., Kuh, G. D., \& Olsen, D. (2001). Finding (more) fruit on the vines: Using higher education research and institutional research to guide institutional policies and strategies (Part II). Research in Higher Education, 42(2), 223-235.

Hsieh, H. F., \& Shannon, S. E. (2005). Three approaches to qualitative content analysis. Qualitative Health Research, 15(9), 1277-1288.

Hunter, M. S. (2006). Fostering student learning and success through first-year programs. Peer Review, 8(3).

Information Technology unit. (2014). Internal statistical report of preparatory year. Preparatory year deanship. Riyadh, King Saud University.

Information, D. F. (2010). Ministry of higher education's plan to achieve excellence in science and technology. Riyadh: Ministry of Higher Education.

Information, M. D. (2013). The current status of higher education in the kingdom of saudi arabia . General Department for Planning and Statistics . Riyadh: Ministry of Higher Education.

Int J FYHE. (n. d.). The international journal of the first year in higher education. Retrieved January 20, 2015, from https://fyhejournal.com.

Jackson, C. K. (2014). Do college-preparatory programs improve long-term outcomes?. Economic Inquiry, 52(1), 72-99.

Jacob, M. (2000). 'Mode 2' in context: The contract researcher, the university and the knowledge society”, in M. Jacob and T. Hellström (eds) The Future of Knowledge Production in the Academy, Buckingham, SRHE and Open University Press, pp. 1127. 
Jamelske, E. (2009). Measuring the impact of a university first-year experience program on student GPA and retention. Higher Education, 57(3), 373-391.

Jamjoom, F. B., \& Kelly, P. (2013). Higher education for women in the kingdom of Saudi Arabia. In Higher Education in Saudi Arabia (pp. 117-125). Springer Netherlands.

Jamjoom, Y. (2012). Understanding private higher education in saudi arabia-emergence, development and perceptions. University of London.

Jazan, U. (2010, March 31). Preparatory year program at jazan university. The fourth periodic meeting for academic affairs deputy of Saudi universities. Riyadh: King Saud University.

John N. Gardner Institute for Excellence in Undergraduate Education. (n. d.). First year focus - foundational dimensions ${ }^{\circledR}$. In John N. Gardner Institute for Excellence in Undergraduate Education. Retrieved March 12, 2015, from http://www.jngi.org/foeprogram/foundational-dimensions/four-year-first-year-focus/.

Johnson, J. L. (2000). Learning communities and special efforts in the retention of university students: What works, what doesn't, and is the return worth the investment. Journal of College Student Retention, 2(3), 219-238.

Johnston, B. (2010). The First Year at University: Teaching Students in Transition. McGrawHill International. New York, United State.

Joseph, D. D. (2004). Hispanic dropouts speak out: A study of Hispanic youth and their experiences in the public school system. Retrieved from http://search.proquest.com/docview/305126398?accountid=2837.

Kearns, P. (2004). Education research in the knowledge society: Key trends in europe and north america. National Centre for Vocational Education Research Ltd. PO Box 8288, Stational Arcade, Adelaide, SA 5000, Australia.

Keeling, S. (2003). Advising the millennial generation. NACADA Journal, 23(1-2), 30-36. 
Kelly, J. T., Kendrick, M. M., Newgent, R. A., \& Lucas, C. J. (2007). Strategies for student transition to college: A proactive approach. College Student Journal, 41(4), 1021.

Kelly, L. J. (1996). Implementing Astin's I-E-O model in the study of student retention: A multivariate time dependent approach. New London, CT: U.S. Coast Guard Academy, Center for Advanced Studies.

Kempland, M. L. (2009). A comparative analysis of academic advising mission statements of large four year institutions and their alignment with CAS Standards' goals and objectives. University Saint Louis University).

Ketterer, M. L. (2015). Analysis of university mission statements and the missions and strategic plans of athletic departments. The University of North Carolina at Chapel Hill.

Keup, J. (2013). Twenty-five years of scholarship on students in transition: Celebrations and reflections. Journal of the First-Year Experience and Students in Transition, 25(1), 911.

Kezar, A. (2001). Understanding and facilitating organizational change in the 21 st century. ASHE-ERIC Higher Education Report, 28(4), 147.

Kim, I., \& Kuljis, J. (2010, June). Applying content analysis to Web based content. In Information Technology Interfaces (ITI), 2010 32nd International Conference on (pp. 283-288). IEEE.

King Abdulaziz City for Science and Technology (2014). Transition to knowledge society in saudi arabia: Tracing the rise of the knowledge economy in the kingdom of saudi arabia in 2014. Riyadh: Alani, D. I., Mrayati M., Al Kamil, A. K., \& M. Alghamdi, M.

Kirst, M. W., \& Venezia, A. (2004). From high school to college: Improving opportunities for success in postsecondary education. San Francisco, CA: Jossey-Bass 
Koch, A. K., Foote, S. M., Hinkle, S. E., Keup, J., \& Pistilli, M. D. (Eds). (2007). The firstyear experience in american higher education: An annotated bibliography (4th ed.). Columbia, SC: University of South Carolina, National Resource Center for the FirstYear Experience and Students in Transition.

Krahenbuhl, K. (2012). Analysis of social and academic integration in a public university's first year experience seminar. Northern Arizona University.

Krause, K. (2006, October). On being strategic about the first year. In keynote presentation, Queensland University of Technology First Year Forum (Vol. 5).

Krippendorff, K. (2004). Content analysis: An introduction to its methodology (2nd ed.). Thousand Oaks, CA: Sage.

Kronour, J. P. (2004). Preservice teaching standards: What skills should first-year teachers possess as they enter the field. Retrieved from http://search.proquest.com/docview/305093604?accountid=2837.

KSUnews (n. d.). King saud univeristy portal. Retrieved Feburuary 12, 2015, from http://ksu.edu.sa.

Kuh, G. D., Kinzie, J., Buckley, J. A., Bridges, B. K., \& Hayek, J. C. (2006). What matters to student success: A review of the literature commissioned report for the national symposium on postsecondary student success: Spearheading a dialog on student success. Washington DC: National Postsecondary Education Cooperative.

Kuh, G. D., Kinzie, J., Schuh, J. H., \& Whitt, E. J. (2005). Assessing conditions to enhance educational effectiveness: The inventory for student engagement and success. San Francisco: Jossey-Bass.

Kuh, G. D., Kinzie, J., Schuh, J. H., \& Whitt, E. J. (2011). Student success in college: Creating conditions that matter. John Wiley \& Sons. New Jersey, United State. 
Kutnowski, M. (2005). In practice-this is why we teach: Igniting a passion for learning in linked courses. About Campus, 10(1), 23-26.

Lane, R. E. (1966). The decline of politics and ideology in a knowledgeable society. American Sociological Review, 5 (31), 649-62.

Larmar, S. \& Lodge, J. (2014). Making sense of how i learn: Metacognitive capital and the first year university student. The International Journal of the First Year in Higher Education, 5(1). 93-105. doi: 10.5204/intjfyhe.v5i1.193

Leggat, S. G., \& Holmes, M. (2015). Content analysis of mission, vision and value statements in Australian public and private hospitals: Implications for healthcare management. Asia Pacific Journal of Health Management, 10 (1), 46.

Lewis, B. (1996). Mission statements: Don't write a word until your ideas are clear to all. InfoWorld, 18(5), 99. Retrieved from http://search.proquest.com/docview/194323144?accountid=2837

Linton, R. (1989). Conceptualizing feminism: Clarifying social science concepts. Evaluation and program planning, 12(1), 25-29.

Long, D. (2012). Theories and models of student development. In L Hincliffe \& M.A. Wong (Eds.), Environments for student growth and development: Librarians and student affairs in collaboration, (pp. 41-55). Chicago, IL: Association of College Research Libraries.

Loza, P. P. (2003). A system at risk: College outreach programs and the educational neglect of underachieving Latino high school students. Urban Review, 35, 43-57.

Ludwig, S. R. (1996). Abused women's experience with the justice system: Concept mapping. Retrieved from http://search.proquest.com/docview/193484835?accountid=2837 Lyons, A. L. (2007). An assessment of social and academic integration among track and field student-athletes of the Atlantic Coast Conference. The Florida State University. 
MacGregor, J., \& Smith, B. (2005). Where are learning communities now? National leaders take stock. About Campus, 10(2), 2-8.

Mahmood, A. (2010, March, 30). Preparatory year's students' problems in some of Saudi universities [PowerPoint]. The fourth periodic meeting for academic affairs deputy of Saudi universities. Riyadh: King Saud University.

Malawi, A. (2010, March, 30). Preparatory year system at the university of the northern border between reality and expectations. The fourth periodic meeting for academic affairs deputy of Saudi universities. Riyadh: King Saud University.

Marifh, F. (2013, June, 29). The Preparatory year: Proposals and solutions. Al-Riyadh Newspaper, 16441. Riyadh, Saudi Arabia: Alyamama Press Est (In Arabic). .

Mayhew, M. J., Vanderlinden, K., \& Kim, E. K. (2010). A multi-level assessment of the impact of orientation programs on student learning. Research in Higher Education, $51(4), 320-345$.

McCubbin, I. (2003). An examination of criticisms made of Tinto's 1975 student integration model of attrition. Retrieved July 2, 2008.

http://www.psy.gla.ac.uk/ steve/localed/icubb.pdf

Menkhoff, T., Evers, H. D., \& Wah, C. Y. (Eds.). (2011). Beyond the knowledge trap: Developing asia's knowledge-based economies. World Scientific. New Jersey, United State.

Mertes, S. (2013). Exploring the construct of social integration in a community college environment. University of Nebraska - Lincoln.

Messman-Mandicott, E. M. (2012). the use of concept mapping/pattern matching to determine the content domain for information literacy in baccalaureate education. West Virginia University Libraries. 
Michalski, G. V. (1999). Stakeholder variation in perceptions about training program evaluation. Retrieved from http://search.proquest.com/docview/304565041?accountid=2837

Miller, C. E. (2011). Choosing foundations of excellence: Three profiles in institutional change and first-year student success. University of Georgia.

Ministry of Higher Education, Kingdom of Saudi Arabia. (2014). The king abdullah scholarship program. Retrieved December 1, 2014, from http://www.mohe.gov.sa

Ministry, H. E. (2015, January, 28). Higher education news. Retrieved 4 22, 2015, from Selfoperating of preparatory year is a priority for Saudi universities: http://he.moe.gov.sa/ar/news/Pages/28-01-2015.aspx

MOE, Ministry of Education (2016, November, 2). Universities and colleges. Retrieved from http://www.moe.gov.sa/ar/Pages/default.aspx

Moon, B., Hoffman, R. R., Novak, J., \& Canas, A. (Eds.). (2011). Applied concept mapping: Capturing, analyzing, and organizing knowledge. CRC Press.

Moon, S., Sullivan, E., Hershey, J., Walker, S., Bosangue, M., Filowitz, M., ... Delgado, V. (2013). High-impact educational practices as promoting student retention and success. Proceedings of the 9th Annual National Symposium, United State. Retrieved from http://www..edu/analyticalstudies presentations/CSRDE2013_hip_moon_et_al.pdf.

Morphew, C. C., \& Hartley, M. (2006). Mission statements: A thematic analysis of rhetoric across institutional type. The Journal of Higher Education, 77 (3), 456-471.

Mullendore, R., \& Banahan, L. (2005). Designing orientation programs. In M. L. Upcraft, J. N. Gardner, \& B. O. Barefoot (Eds), Challenging and supporting the first-year student: A handbook for improving the first year of college, 391-409. San Francisco: Jossey-Bass. 
Mutch, C., (2005). The transition from high school to university: An analysis of advice for students, faculty and administration. 名古屋高等教育研究第 5 号, pp. 143-66.

Neuendorf, K. A. (2002). The content analysis guidebook. Thousand Oaks, California: Sage Publications.

Newcomb, T. M. (1979). Four critical years: Effects of college on beliefs, attitudes, and knowledge. The American Association for Higher Education, the Ohio State University Press.

Newton, F. B. (2000). The new student. About Campus, 5(5), 8-15.

Noel, L., Levitz, R., \& Saluri, D. (1985). Increasing student retention: Effective programs and practices for reducing the dropout rate. San Francisco, CA: Jossey- Bass.

Norwani, N. M. (2005). Learning outcomes at higher learning institutions: Do institutional environments matter?. Forum of the Australasian Association for Institutional Research, Australia.

Nutt, D., \& Calderon, D. (2009). The first-year experience: An international perspective. University of South Carolina/University of Teeside: National Resource Centre.

Oates, K. K., \& Leavitt, L. H. (2003). Service-learning and learning communities: Tools for integration and assessment. Association of American Colleges and Universities, 1818 R Street NW, Washington, DC 20009-1604.

Orsi, R. (2011). Using concept mapping as tool for program theory development. Retrieved from http://search.proquest.com/docview/889091487?accountid=2837

Owen, G. T. (2014). Qualitative methods in higher education policy analysis: Using interviews and document analysis. The Qualitative Report, 19(52), 1-19. 
Ozdem, G. (2011). An analysis of the mission and vision statements on the strategic plans of higher education institutions. Educational Sciences: Theory and Practice, 11(4), 1887-1894.

Papulova, Z. (2014). The significance of vision and mission development for enterprises in slovak republic. Journal of Economics, Business and Management, 2(1), 12-16.

Pascarella, E. T. (1985). College environmental influences on learning and cognitive development: A critical review and synthesis. Higher education: Handbook of Theory and Research, 1(1), 1-61.

Pascarella, E. T. (2006). How college affects students: Ten directions for future research. Journal of College Student Development, 47(5), 508-520.

Pascarella, E. T., \& Chapman, D. W. (1983). Validation of a theoretical model of college withdrawal: Interaction effects in a multi-institutional sample. Research in Higher Education, 19(1), 25-48. doi:10.1007/BF00977337

Pascarella, E. T., \& Terenzini, P. T. (1991). How college affects students: Findings and insights from twenty years of research. San Francisco: Jossey-Bass Publishers.

Pascarella, E. T., \& Terenzini, P. T. (1997). Studying college students in the 21 st century: Meeting new challenges. The Review of Higher Education, 21(2), 151-165.

Pascarella, E. T., \& Terenzini, P. T. (2005). How college affects students. A third decade of research. San Francisco: Jossey-Bass.

Pascarella, E. T., \& Terenzini, P. T. (2005). How college affects students (Vol. 2). K. A. Feldman (Ed.). San Francisco, CA: Jossey-Bass.

Pavan, A. (2014). The new Saudi educational renaissance: In between the "capacity to aspire" and the "capacity to remember". Higher Education Studies. 4(5), 37-46. Retrieved from http://dx.doi.org/10.5539/hes.v4n5p37 
Pavel, D. M. (1991). Assessing the fit of Tinto's model of institutional departure with American Indian and Alaskan native national longitudinal data. (Doctoral dissertation, Arizona State University).

Pegoraro, A. (2006). Using university websites for student recruitment: A study of Canadian university home pages examining relationship marketing tactics and website usability. The University of Nebraska-Lincoln.

Pekarsky, D. (2007). Vision and education: Arguments, counterarguments, rejoinders. American Journal of Education. 113(3), 423-450. doi:10.1086/512739

Pelosky, C. B. (2005). Content analysis of undergraduate courses and course content on the Armenian genocide in United States higher education. Lynn University. Retrieved from ProQuest Digital Dissertations database.

Perrine, R. (2001). College stress and persistence as a function of attachment and support. Journal of the First-Year Experience \& Students in Transition, 13(1), 7-22.

Peters, M. A. (2007). Knowledge economy, development and the future of higher education. Rotterdam: Sense Publishers.

Peterson, M. W. (2007). The study of colleges and universities as organizations. Sociology of Higher Education. Contributions and Their Contexts, 147-188.

Plan, M. O. (2014). KSU strategic plan 2030. Riyadh: King Saud University.

Planning, M. O. (2010). The Ninth Development Plan. Retrieved from http://www.mep.gov.sa/themes/GoldenCarpet/\#1429708335943

Poisel, M. A., \& Joseph, S. (Eds.). (2011). Transfer students in higher education: Building foundations for policies, programs, and services that foster student success (Monograph No. 54). Columbia, SC: University of South Carolina, National Resource Center for the First-Year Experience and Students in Transition. 
Preparatory Year Strategic Plan 2011-2016 (2011). Preparatory year deanship. King saud university. www.py.ksu.edu.sa

Prosser, M., \& Pitkethly, A. (2001). The first year experience project: A model for university-wide change. Higher Education Research \& Development, 20(2), 185-198. doi:10.1080/758483470

Pryor, J. H., Hurtado, S., Saenz, V. B., Lindholm, J. A., Korn, W. S., \& Mahoney, K. M. (2005).The american freshman: National norms for fall 2005. Los Angeles: Higher Education Research Institute, UCLA.

Raymond, L., \& Napoli, R. (1998). An explanation of the impact of a freshman seminar course on student academic outcomes. Journal of Applied Research in the Community College, $6(1), 27-34$.

Reason, R. D. (2009). An examination of persistence research through the lens of a comprehensive conceptual framework. Journal of College Student Development, 50(6), 659-682. doi:10.1353/csd.0.0098

Rendón, L. I., Jalomo, R. E., \& Nora, A. (2000). Theoretical considerations in the study of minority student retention in higher education. Reworking the student departure puzzle, 1, 127-156.

Resalh, U. (2011, 5 21). King saud university portal. Retrieved 4 22, 2015, from University launches its strategic plan KSU 2030: http://rs.ksu.edu.sa/48796.html

Riley, R. W. (1998). It's time to "GEAR UP'” for college! Schools in the Middle, 8, 39-41.

Rios-Maldonado, B. (2000). The strategic alignment of information technology with academic strategy: A content analysis of university web sites. Boston College.

Ritchie, B. W., Burns, P. M., \& Palmer, C. A. (Eds.). (2005). Tourism research methods: Integrating theory with practice. Wallingford, Oxfordshire, United Kingdom: CABI. 
Ritter, J. K., \& Lee, K. (2009). Explicit goals, implicit values, and the unintentional stifling of pluralism: An examination of a social studies teacher education vision statement. Theory \& Research in Social Education, 37(1), 75-100. doi:10.1080/00933104.2009.10473388

Riyadh Valley Company. (n. d.). Home. In Riyadh Valley Company. Retrieved March 18, 2015, from http://rvc.com.sa/.

Rode, L., \& Cawthon W., (2010). Theoretical perspective on orientation. In J. A. Ward-Roof (Ed). Designing successful transitions: A guide for orienting students to college. (Monograph No. 13, $3^{\text {rd }}$ ed.). Columbia, SC: University of South Carolina, National Resource Center for The First-Year Experience and Students in Transition.

Roos, R. D. (2012). Relationship between first-year student retention, noncognitive risk factors, and student advising. Logan, Utah: Utah State University.

Rowley, J. (2000). Is higher education ready for knowledge management? The International Journal of Educational Management, 14(7), 325-333.

Rozycki, E. G. (2004). Mission and vision in education. Educational Horizons, 82(2), 94-98.

Saleh, M. A. (1986). Development of higher education in Saudi Arabia. Higher Education, 15(1-2), 17-23.

Salmi, J. (2003). Constructing knowledge societies: New challenges for tertiary education. Higher Education in Europe, 28(1), 65-69.

Sándorová, Z. (2014). Content analysis as a research method in investigating the cultural components in foreign language textbooks. Journal of Language and Cultural Education, 2 (1), 95-128.

Schlossberg, J., Waters, R., \& Goodman, P. (1995). Counseling adults in transition (2 ${ }^{\text {nd }}$ ed.). New York: Springer. 
Schlossberg, N. K., \& Nicolay, R. C. (1984). Counseling adults in transition. Psyccritiques, $30(10), 823$.

Schrader, P. G., \& Brown, S. W. (2008). Evaluating the first year experience: Students' knowledge, attitudes, and behaviors. Journal of Advanced Academics, 19(2), 310-343.

Schreiner, L. A., Louis, M. C., \& Nelson, D. D. (Eds.). (2012). Thriving in transitions: A research-based approach to college student success. University of South Carolina, National Resource Center for the First-Year Experience and Students in Transition.

Schroeder, C. C. (1998). Developing collaborative partnerships that enhance student learning and educational attainment. ACPA Senior Scholars Trend Analysis Draft Essays.

Senge, P. M. (2006). The fifth discipline: The art and practice of the learning organization (Rev. and updat ed.). New York: Doubleday/Currency.

Senge, P. M. (2014). The fifth discipline fieldbook: Strategies and tools for building a learning organization. New York: Currency, Doubleday.

Shimp, U. R. (2008). Evaluation of the distance education literature: A content analysis using the institute for higher education policy benchmarks and selected bibliometric methods. (Doctoral dissertation, Oklahoma State University).

Shin, J. Y. (2013). Improving first-year intervention strategies at universities by focusing on meaning and purpose in life. Colorado State University.

Skipper, T. L. (2005). Student development in the first college year: A primer for college educators. National Resource Center for the First-Year Experience and Students in Transition, University of South Carolina.

Smith, L., \& Abouammoh, A. (2013). Higher education in saudi arabia: Reforms, challenges and priorities. In Higher Education in Saudi Arabia (pp. 1-12). Springer Netherlands.

Smith, L., \& Abouammoh, A. (2013). Higher education in saudi arabia: conclusions. In Higher Education in Saudi Arabia (pp. 181-190). Springer Netherlands. 
Soldner, L., Lee, Y., \& Duby, P. (1999). Welcome to the block: Developing freshman learning communities that work. Journal of College Student Retention, 1(2), 115-129.

Sörlin, S., \& Vessuri, H. (2007). Knowledge society vs. knowledge economy: Knowledge, power, and politics. Basingstoke: Palgrave Macmillan.

Sperber, A. D., Devellis, R. F., \& Boehlecke, B. (1994). Cross-cultural translation methodology and validation. Journal of Cross-Cultural Psychology, 25(4), 501-524.

Stehr, N. (1994). Knowledge societies. London: Sage.

Stemler, S. E., Bebell, D., \& Sonnabend, L. A. (2010). Using school mission statements for reflection and research. Educational Administration Quarterly. 47(2), 383-420. $0013161 X 10387590$.

Stone, J. R., \& Lewis, M. V. (2012). College and career ready in the 21st century: Making high school matter. Teachers College Press. New York, United State.

Storey, K. L. (2010). Bridging the gap: Linking co-curricular activities to student learning outcomes in community college students. OASIS: The NLY Digital Commons.

Stovall, M. (2000). Using success courses for promoting persistence and completion. New Directions for Community Colleges, 2000 (112), 45-54.

Strauss, W., \& Howe, N. (2000). Millennials rising: The next great generation. New York: Vintage Books.

Streeter, C. L., Franklin, C., Kim, J. S., \& Tripodi, S. J. (2011). Concept mapping: An approach for evaluating a public alternative school program. Children and Schools, 33(4), 197-214.

Stuart, G. R., Rios-Aguilar, C., \& Deil-Amen, R. (2014). How much economic value does my credential have?: Reformulating Tinto's model to study students' persistence in community colleges. Community College Review, 42(4), 327-341. 
Stuart, J. M. (2002). Client perceptions of emotional experience in counselling. Retrieved from http://search.proquest.com/docview/305472405?accountid=2837

Studdert, T. P. (2013). The development of a comprehensive First-Year Experience program for the University of Southern California: Using an innovation gap analysis model. University of Southern California.

Student Success. (November, 2007). The Newsletter for Higher Education Professionals.

Suciu, M. C., Drăgulănescu, I. V., Ghiţiu-Brătescu, A., Picioruş, L., Imbrişcă, C., Şerbu, V. M., \& Grigore, C. (2011). Universities role in knowledge-based economy and society. Implications for romanian economics higher education. The Economic Amphitheater, 13, 420-437.

Swail, W. S. (2000). Preparing america's disadvantaged for college: Programs that increase college opportunity. New Directions for Institutional Research, 107, 85-101.

Swing, R. L. \& Alexander-Hamilton, J. H. (2010). University colleges: Flexible structures for serving undergraduate students. In S. E. Evenbeck, B. Jackson, M. Smith, D. Ward, \& Associates, Organizing for student success: The university college model (Monograph No. 53, pp. 1-23). Columbia, SC: University of South Carolina, National Resource Center for the First-Year Experience \& Students in Transition.

Tabuk, U. (2010, March, 31). The application Mechanism of preparatory year: Tabuk university model. The fourth periodic meeting for academic affairs deputy of Saudi universities. Riyadh: King Saud University.

Tashakkori, A., \& Teddlie, C. (2003). Handbook of mixed methods in social and behavioral research. Thousand Oaks, CA: Sage Publications, Inc.

Terenzini, P. T., \& Reason, R. D. (November, 2005). Parsing the first year of college: A conceptual framework for studying college impacts. Paper presented at the annual meeting of the Association for the Study of Higher Education, Philadelphia, PA. 
Tinto, V. (1975). Dropout from higher education: A theoretical synthesis of recent research. Review of Educational Research, 45(1), 89-125. Doi: 10.3102/00346543045001089 Tinto, V. (1987). Leaving college: Rethinking the causes and cures of student attrition. Chicago, IL: University of Chicago Press.

Tinto, V. (1988). Stages of student departure: Reflections on the longitudinal character of student leaving. The Journal of Higher Education, 59(4), 438-455.

Tinto, V. (1993). Leaving college: Rethinking the causes and cures of student attrition (2nd ed.). Chicago, IL: University of Chicago Press.

Tinto, V. (1996). Reconstructing the first year of college. Planning for Higher Education, 25(1), 1-6.

Tinto, V. (2000). Linking learning and leaving: Exploring the role of the college classroom in student departure. In J. M. Braxton (Ed.), Reworking the student departure puzzle (81-94). Nashville, TN: Vanderbilt University Press.

Tinto, V. (2006). Research and practice of student retention: what next?. Journal of College Student Retention, Research, Theory and Practice, 8(1), 1-19.

Tinto, V. (2006). The assessment of student retention programs. Faculty Convocation at Maricopa College, Phoenix, AZ. Retrieved September, 22, 2009.

Tinto, V. (2007). Taking student retention seriously. Syracuse University.

Tinto, V. (2010). From theory to action: Exploring the institutional conditions for student retention. In Smart, J. C. (2010). Higher education: Handbook of theory and research (pp. 51-89). Springer Netherlands.

Tinto, V. (July 01, 1988). Stages of student departure: Reflections on the longitudinal character of student leaving. Journal of Higher Education, 59, 4, 438-55. 
Tinto, V., \& Pusser, B. (2006). Moving from theory to action: Building a model of institutional action for student success. National Postsecondary Education Cooperative, 1-51.

Torres, V., \& LePeau, L. (2013). Making the connection: The use of student development theory in first-year and transition programs. Journal of the First-Year Experience \& Students in Transition, 25(2), 13-26.

Transition (n. d.). In S. Abbott (Ed.), the glossary of education reform. Retrieved March 17, 2015, from http://edglossary.org/transition/

Trilling, B. (2007). Toward learning societies and the global challenges for learning with ict. Australian Educational Computing, 22(1), 10-16.

Troxel, W. G., \& Cuttright, M. (Eds.). (2008). Exploring the evidence: Initiatives in the first college year (Monograph No. 49). Columbia, SC: University of South Carolina, National Resource Center for the First-Year Experience and Students in Transition.

Tzotzes, K. (2012). A content analysis of women's safety websites: Rape myths and the Internet. (Doctoral dissertation, UOIT).

University of Dammam (2015, April). The recommendations of the first national conference for prep year in saudi universities. Paper presented at the First National Conference for Prep Year in Saudi Universities, Al-Dammam, Saudi Arabia.

University of Dammam. (n. d.). Conference themes. In the first national conference for preparatory year in saudi arabia. Retrieved January 20, 2015, from http://prep1sa.uod.edu.sa/common/article.aspx?articleId=2.

Upcraft M. L. (2005). Assessing the first year of college. In M. L. Upcraft, J. N. Gardner, \& B. O. Barefoot (Eds), Challenging and supporting the first-year student: A handbook for improving the first year of college, 469-485. San Francisco: Jossey-Bass.

Upcraft, M. L., \& Gardner, J. N. (1989). A comprehensive approach to enhancing freshman 
success. In M. L. Upcraft \& J. N. Gardner (Eds.), the freshman year experience (pp. 1-12). San Francisco, CA: Jossey-Bass.

Upcraft, M. L., \& Gardner, J. N. (1989). The freshman year experience: Helping students survive and succeed in college. San Francisco, Calif: Jossey-Bass Publishers.

Upcraft, M. L., Gardner, J. N., \& Barefoot, B. O. (2004). Meeting challenges and building support: Creating campus climates for first-year student success. San Francisco: Jossey-Bass.

Upcraft, M. L., Gardner, J. N., \& Barefoot, B. O. (2005). Challenging and supporting the first-year student: A handbook for improving the first year of college. San Francisco: Jossey-Bass.

Välimaa, J., \& Hoffman, D. (2008). Knowledge society discourse and higher education. Higher Education, 56(3), 265-285.

Van Weert, T. (2005) Lifelong learning in the knowledge society: Implications for education. Education and the Knowledge Society, 161, 15-25.

Van Weert, T. (Ed.). (2004). Education and the knowledge society: Information technology supporting human development (Vol. 161). Springer Science \& Business Media.

Varela-Petito, G. (2012). System and policy in the planning of higher education in Mexico. Creative Education, 3(6), 980.

Vassilieva, E. (2012). Web content authorship: Academic librarians in web content management.

Vaughan, A., Parra, J., \& Lalonde, T. (2014). First-generation college student achievement and the first-year seminar: A quasi-experimental design. Journal of the First-Year Experience \& Students in Transition, 26(2), 51-67. 
Vega, A. L. (2010). Investigation of alignment between goals of schooling relevant to Georgia and the Georgia performance standards. Retrieved from http://search.proquest.com/docview/577434198?accountid=2837

Verma, H. V. (2009). Mission statements-a study of intent and influence. Journal of Services Research, 9(2), 153.

Vlieger, E., \& Leydesdorff, L. (2011). Content analysis and the measurement of meaning: The visualization of frames in collections of messages. Public Journal of Semiotics, 3(1), 28-50.

Walker, A. (2003). Learning communities and their effect on students' cognitive abilities. Journal of the First-Year Experience \& Students in Transition, 15(2), 11-33.

Wang, J., Gibson, A. M., Salinas, L., Solis, F., \& Slate, J. R. (2007). Thematic differences in mission statements between four-year public institutions and two-year colleges in Texas. 11 (1). IEJLL: International Electronic Journal for Leadership in Learning, 11(1), 1-17

Ward-Roof, J. A. (2010). Designing successful transitions: A guide for orienting students to college. (Monograph No. 13, $3^{\text {rd }}$ ed.). Columbia, SC: University of South Carolina, National Resource Center for the First-Year Experience and Students in Transition.

Watt, K. M., Huerta, J., \& Lozano, A. (2007). A comparison study of AVID and GEAR UP 10th grade students in two high schools in the Rio Grande Valley of Texas. Journal of Education for Students Placed at Risk, 12, 185-212.

Watts, W. (n. d.). The power of words: A guide to the latest terminology in student affairs. The Mentor.

Webb, N. L. (1997). Criteria for alignment of expectations and assessments in mathematics and science education. Research Monograph No. 6. 
Weber, L. E., \& Duderstadt, J. J. (2006). Universities and business: Partnering for the knowledge society. London: Economica.

Welton, J., \& Cook, B. (1997). Institutional vision: A prerequisite for fund raising success. Garden City: Hoke Communications, Inc.

White, J., \& Weathersby, R. (2005). Can universities become true learning organizations? The Learning Organization: An International Journal, 12(3), 292-298.

Wilson, M. E., \& Association for the Study of Higher Education. (2011). College student development theory. Boston, MA: Pearson Learning Solutions.

Wolf-Wendel, L., Tuttle, K., \& Keller-Wolff, C. (1999). Assessment of a freshman summer transition program in an open-admissions institution. Journal of the First-Year Experience \& Students in Transition, 11(2), 7-32.

World Economic Forum. (2004). Towards an Arab renaissance. Presented at the annual meeting.

Yanto, H., Mula, J. M., \& Kavanagh, M. H. (2011, November). Developing student's accounting competencies using Astin's I-E-O model: an identification of key educational inputs based on Indonesian student perspectives. In Proceedings of the RMIT Accounting Educators' Conference, 2011: Accounting Education or Educating Accountants?. University of Southern Queensland.

Young, D. G., \& Hopp, J. M. (2014). 2012-2013 national survey of first-year seminars: exploring high-impact practices in the first college year (Research Report No. 4). Columbia, SC: University of South Carolina, National Resource Center for the FirstYear Experience and Students in Transition.

Yushau, B., \& Omar, M. H. (2007). Preparatory year program courses as predictors of first calculus course grade. Mathematics and Computer Education, 41(2), 92-108. 
Zafft, C., Kallenbach, S., \& Spohn, J. (2006). Transitioning adults to college: Adult basic education program models. National Center for the Study of Adult Learning and Literacy, Harvard Graduate School of Education. Chapter One

Zhang, A. (2014). Evaluation of first year experience program at georgia southern university. International Journal of Learning, Teaching and Educational Research, 8(1), 68-75. 


\section{Appendices}

Appendix A: The Preparatory Year Programs' Vision, Mission, and Goals Statements in Saudi Public Universities

\begin{tabular}{|c|c|c|c|}
\hline Univeristy & Vision & Mission & Goals \\
\hline Al Baha University & None & None & 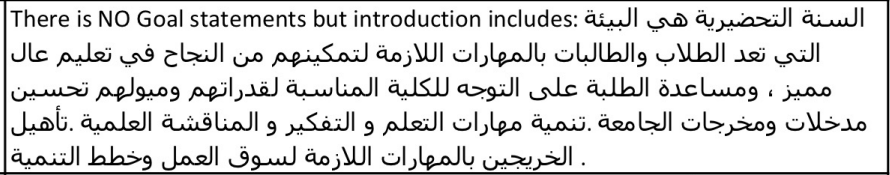 \\
\hline Al Jouf University & الطلاب للدراسة الجامعية وفق معايير الجودة. الألاديمي & 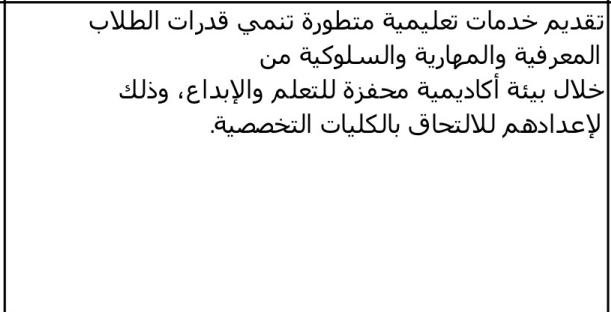 & 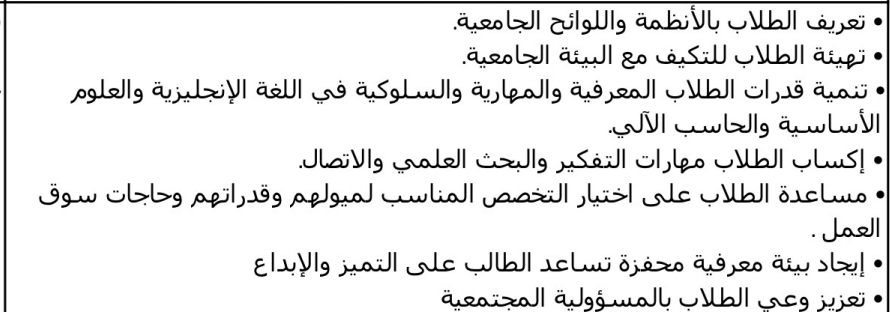 \\
\hline $\begin{array}{l}\text { Al Imam Muhammad Ibn Saud Islamic } \\
\text { University }\end{array}$ & 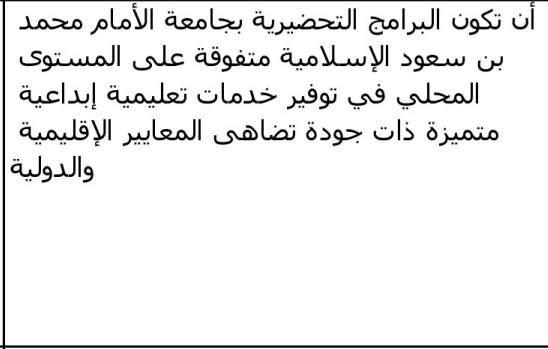 & 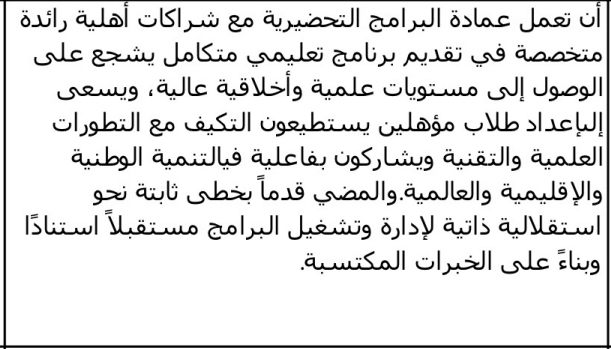 & 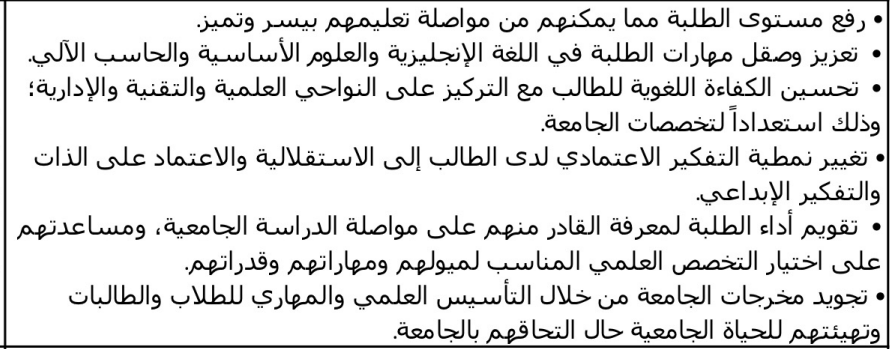 \\
\hline Almajmaah University & 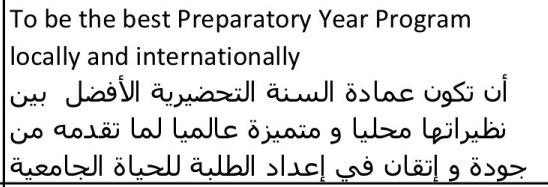 & $\begin{array}{l}\text { To provide a distinguished educational service and } \\
\text { better prepare students for their specialty in their } \\
\text { respective colleges in the framework of a } \\
\text { comprehensive and professional academic system. }\end{array}$ & None \\
\hline Bisha University & None & None & None \\
\hline
\end{tabular}




\begin{tabular}{|c|c|c|c|}
\hline Islamic University & 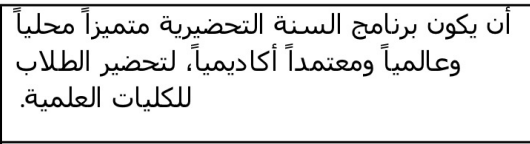 & 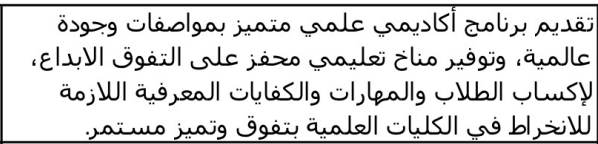 & 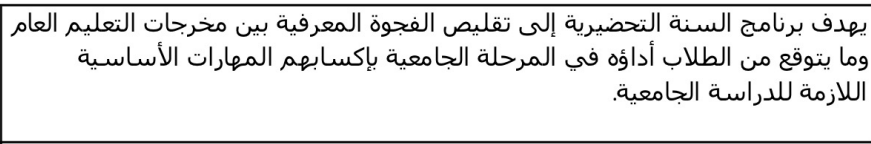 \\
\hline Jazan University & 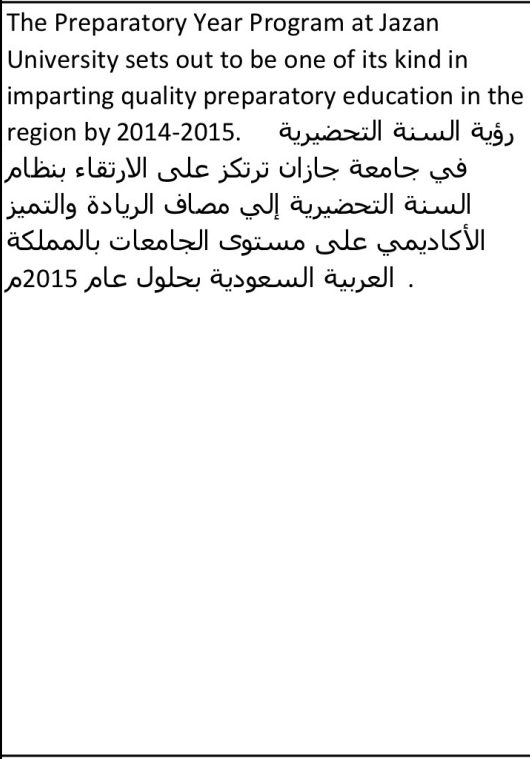 & 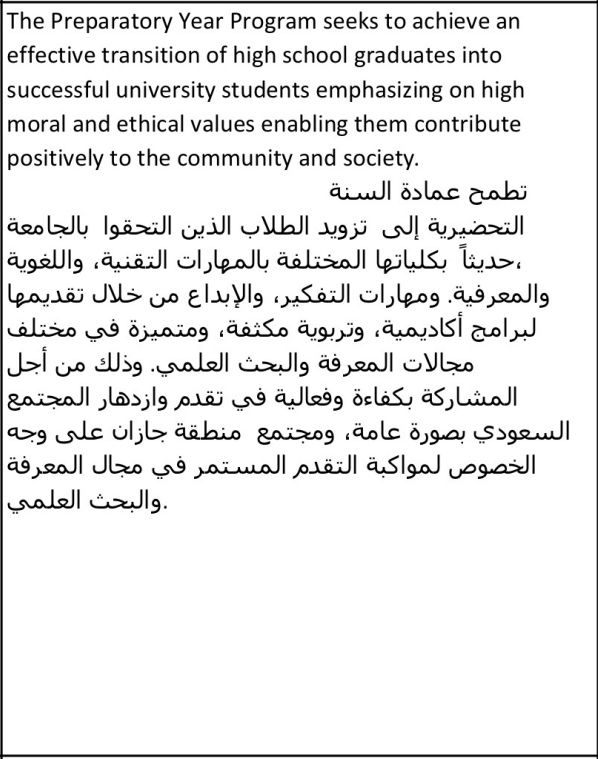 & 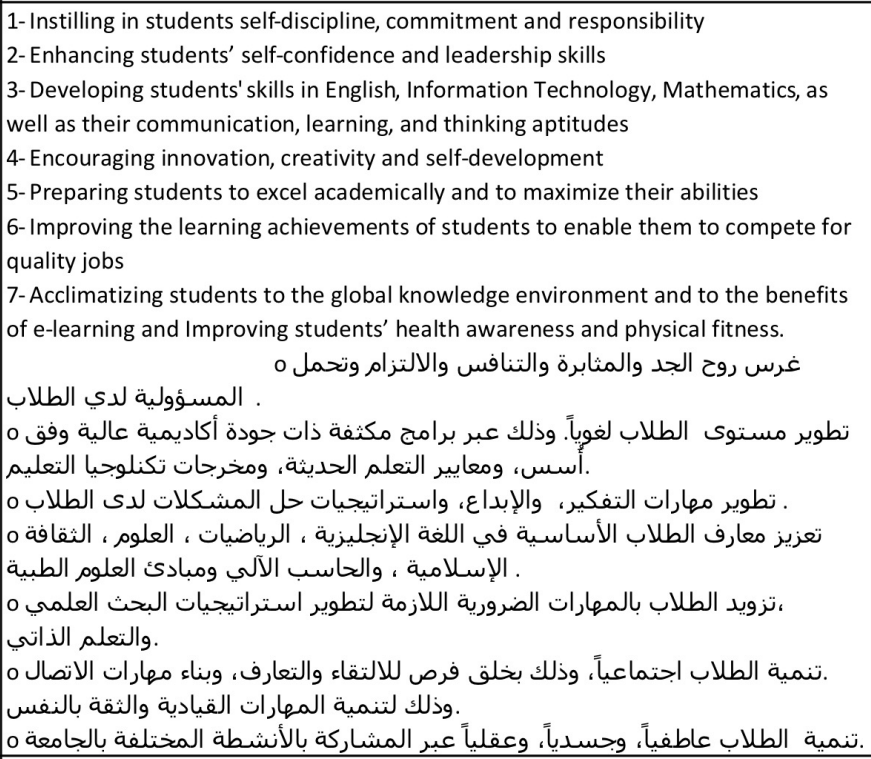 \\
\hline Jeddah University & None & 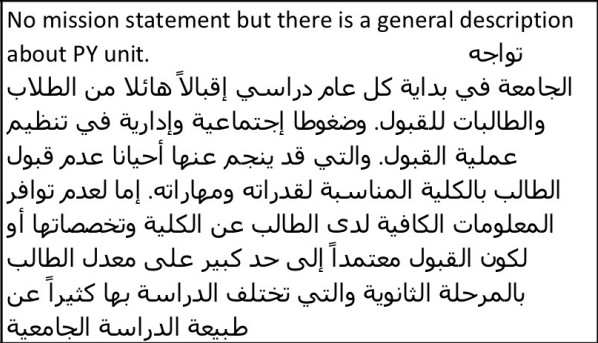 & None \\
\hline
\end{tabular}




\begin{tabular}{|c|c|c|c|}
\hline King Abdulaziz University & None & 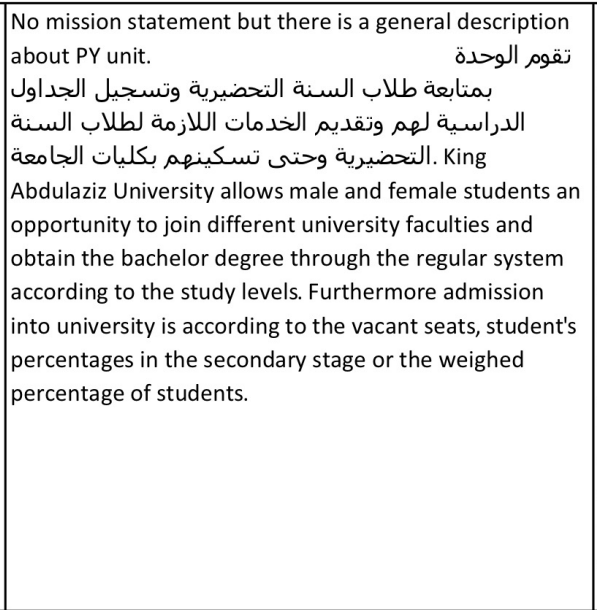 & 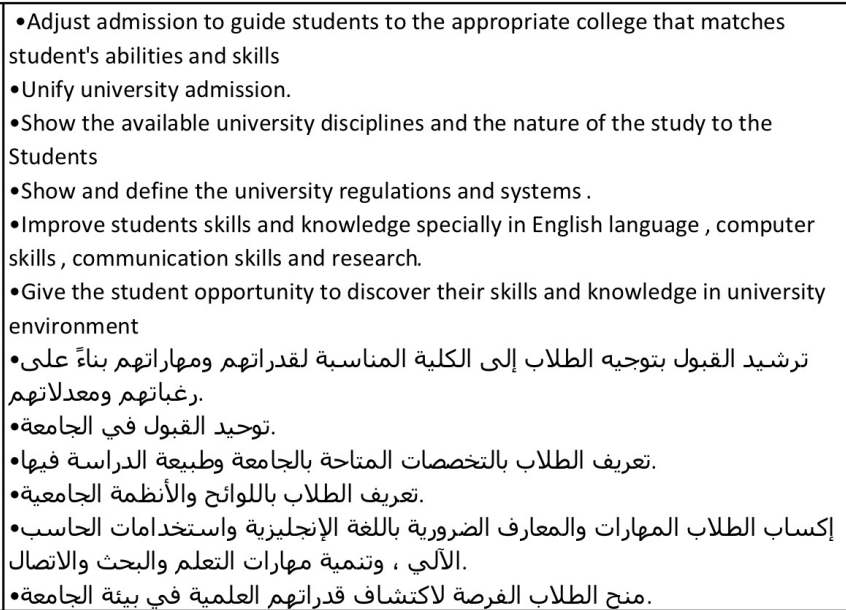 \\
\hline $\begin{array}{l}\text { King Fahd University of Petroleum and } \\
\text { Minerals }\end{array}$ & $\begin{array}{l}\text { The Prep Year Program (PYP) strives to ensure } \\
\text { that high school graduates of the Kingdom of } \\
\text { Saudi Arabia become successful participants in } \\
\text { the KFUPM community and future leaders in } \\
\text { their fields of study. }\end{array}$ & $\begin{array}{l}\text { The PYP aims to ensure that students attain the level of } \\
\text { proficiency in academia necessary to participate fully as } \\
\text { KFUPM students. While academic skills are important, } \\
\text { PYP provides students not only with a sound basis in } \\
\text { academic skills, but also seeks to develop students into } \\
\text { well-rounded individuals. The curriculum is designed to } \\
\text { ensure that each student maintains a sense of pride in } \\
\text { his native culture. }\end{array}$ & $\begin{array}{l}\text { The PYP program at KFUPM prepares newly admitted students for undergraduate } \\
\text { studies at the University and aims to enhance their opportunities to succeed and } \\
\text { excel through: } \\
\text { 1. Improving students' English language proficiency to prepare them for University } \\
\text { studies } \\
\text { 2. Reviewing and reinforcing students' knowledge of Mathematical and analytical } \\
\text { techniques through problem solving and their ability to relate to various Math } \\
\text { concepts. } \\
\text { 3. Consolidating students' knowledge of basic sciences, providing necessary skills } \\
\text { for effective learning, assisting students in choosing their academic majors through } \\
\text { career guidance, as well as promoting student's physical well-being }\end{array}$ \\
\hline King Faisal University & 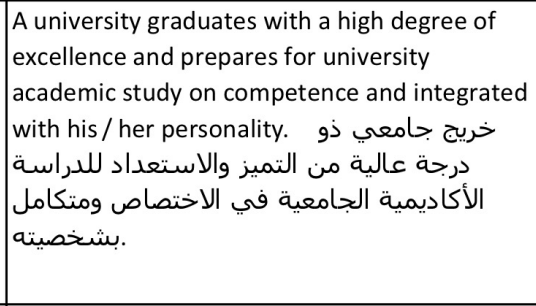 & 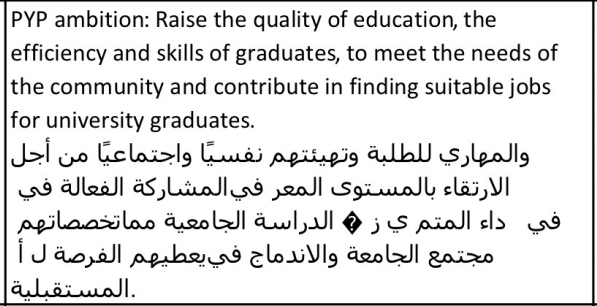 & $\begin{array}{l}\text { 1- Support student ambitions in academic excellence. } \\
\text { 2- Students fluent skills in both Arabic and English. } \\
\text { 3- Students use the main computer programs and applications. } \\
\text { 4- Give the student the ability to solve basic mathematical problems. } \\
\text { 5- Help students integrate into the university community. } \\
\text { 6- Active participation in sports, cultural and social development activities. } \\
\text { 7- Develop the skills of self-education, communication and planning. } \\
\text { 8- Develop the skills of self (thinking, research, communication, fitness). }\end{array}$ \\
\hline King Khalid University & None & None & None \\
\hline
\end{tabular}




\begin{tabular}{|c|c|c|c|}
\hline $\begin{array}{l}\text { King Saud bin Abdulaziz University for } \\
\text { Health Sciences }\end{array}$ & None & \begin{tabular}{|l|} 
All KSAU-HS students have same study plan in their first \\
three semesters. In the fourth semester, students start \\
taking courses closely related to their health science \\
specialties. \\
Courses in this program cover intensive and advanced \\
English, Arabic language, Islamic culture, biology, \\
general and organic chemistry, physics, biochemistry, \\
biostatistics \& EBM, behavioral sciences, computer \\
applications health informatics, anatomy \& physiology, \\
principles of diseases, basic pharmacology, health \\
profession education, medical ethics \& patient safety.
\end{tabular} & 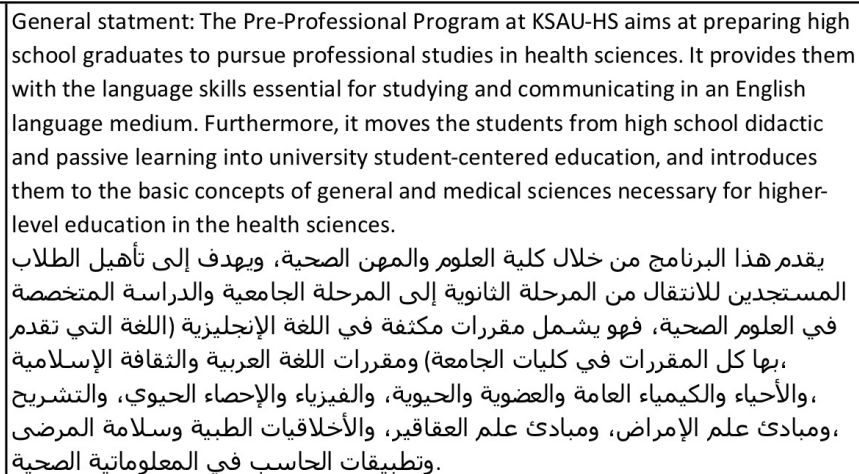 \\
\hline King Saud University & $\begin{array}{l}\text { To achieve leadership and excellence in } \\
\text { providing knowledge generation }\end{array}$ & \begin{tabular}{|l|} 
To provide a quality education in an environment \\
incentive to learning and creativity supported by optimal \\
utilization of state-of-the-art technologies and excellent \\
partnerships.
\end{tabular} & $\begin{array}{l}\text { 1- Raising awareness and responsibility } \\
\text { 2- Developing and maintaining excellent human resources } \\
\text { 3- Fostering creativity and innovation while enhancing students' capabilities } \\
\text { 4- Adopting a rigorous system for student assessment } \\
\text { 5- Creating a knowledge stimulating environment } \\
\text { 6- Improving quality control practices } \\
\text { 7- Building distinguished partnerships }\end{array}$ \\
\hline Najran University & $\begin{array}{l}\text { Securing a leading position among the } \\
\text { Preparatory Year Deanships }\end{array}$ & $\begin{array}{l}\text { Preparing balanced personalities with high degree of } \\
\text { distinctiveness and readiness for the university study } \\
\text { through a developed educational environment that } \\
\text { contributes to developing the society. }\end{array}$ & 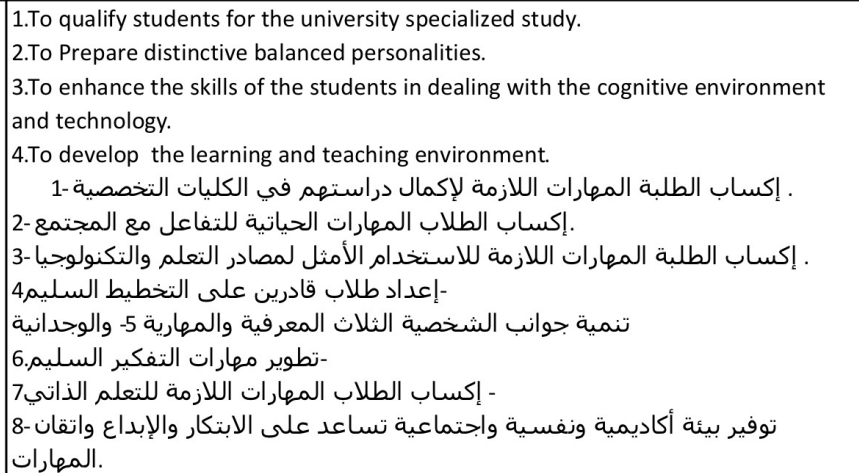 \\
\hline Northern Borders University & $\begin{array}{l}\text { Pioneering and achieving superiority in } \\
\text { preparaing the students of the preparatory } \\
\text { year for their studies at the university }\end{array}$ & \begin{tabular}{|l|} 
The deanship is dedicated to provide the students of the \\
preparatory year through motivational environment of \\
learning and creativity with essential training in English \\
language skilss, personality-development, information \\
technology, and basic sciences and their application, so \\
that the students have an effective participation in \\
fostering and academic community at the univeristy and \\
prove to be productive members of the society
\end{tabular} & $\begin{array}{l}\text { 1- enhance th elevel of awareness and teeling of responsibility among the students } \\
\text { 2- Equip all students with basic knowledge and skills in basic sciencesubjects. } \\
\text { 3- discover and support talents and the creative abilities of the students } \\
\text { 4- create a conductive educational environment } \\
\text { 5- build distinctive partnership inside and outside the univeristy } \\
\text { 6- work towards achieving the goals of quality nd academic excellence }\end{array}$ \\
\hline
\end{tabular}




\begin{tabular}{|c|c|c|c|}
\hline Prince Sattam bin Abdulaziz University & 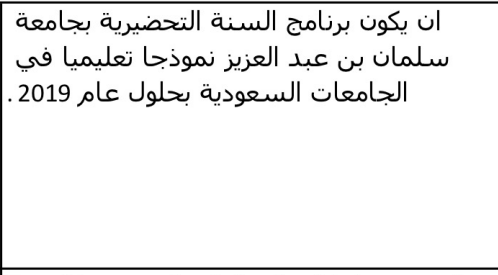 & 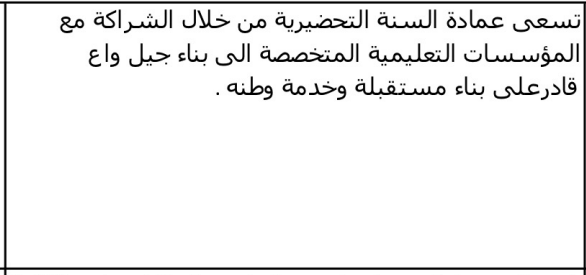 & 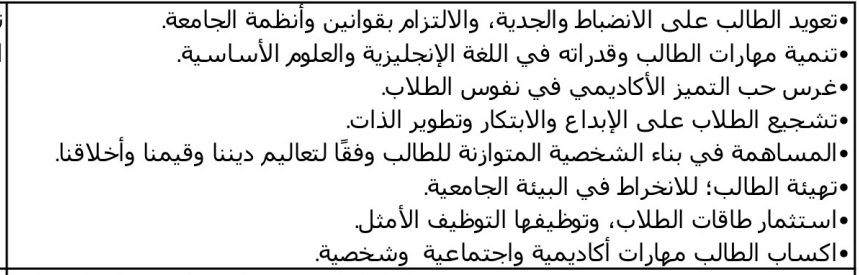 \\
\hline $\begin{array}{l}\text { Princess Nora bint Abdulrahman } \\
\text { University }\end{array}$ & $\begin{array}{l}\text { To achieve academic leadership in preparing } \\
\text { the student for Undergraduate Education. }\end{array}$ & \begin{tabular}{|l|}
$\begin{array}{l}\text { Building the skills, knowledge and values of the students' } \\
\text { personalities in order to be able to cope with the } \\
\text { requirements of the university through strategic } \\
\text { partnerships and optimal use of the latest technology. }\end{array}$ \\
\end{tabular} & $\begin{array}{l}\text { 1. Developing students' skills in English language. } \\
\text { 2. Providing students with mathematical, and self-development skills. } \\
\text { 3. Encouraging entrepreneurship and innovation. } \\
\text { 4. Enhancing students' personal and leadership abilities to cope with the } \\
\text { requirements of undergraduate education. }\end{array}$ \\
\hline Qassim University & 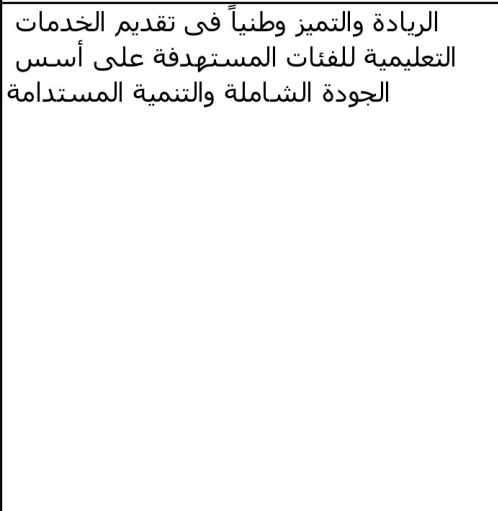 & 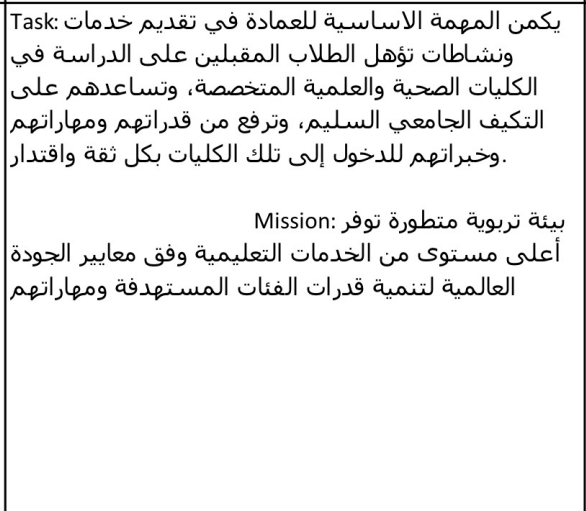 & 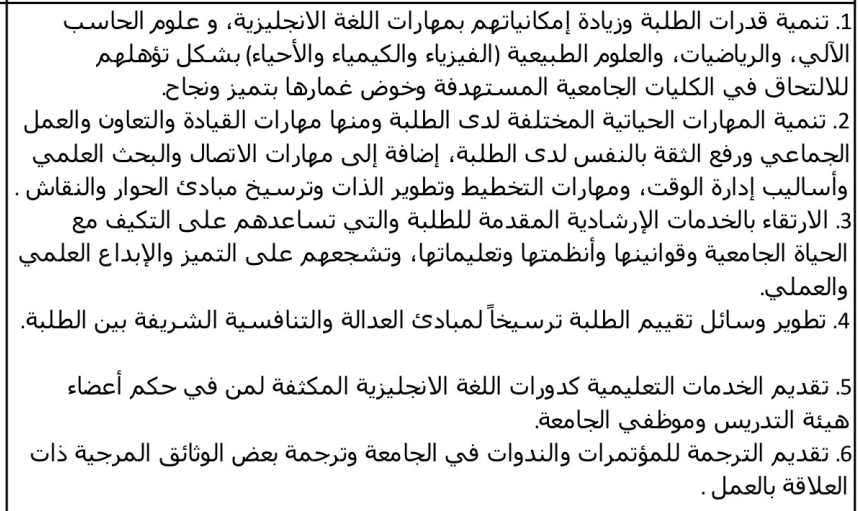 \\
\hline Saudi Electronic University & $\begin{array}{l}\text { Bringing students to the higher level of } \\
\text { academic readiness and personality traits. }\end{array}$ & $\begin{array}{l}\text { To offer high-quality programs that develop basic skills, } \\
\text { widen academic knowledge and reinforce positive } \\
\text { attitude to help achieve excellent academic } \\
\text { performance. }\end{array}$ & $\begin{array}{l}\text { 1- Preparing students to continue their studies in available academic courses, and } \\
\text { pass, achieving a high GPA. } \\
\text { 2- Developing students' basic skills in English, computer and thinking. } \\
\text { 3- Widening necessary educational background vital for reinforcing knowledge } \\
\text { economy, which is founded on the acquisition, generation and spread of } \\
\text { knowledge. } \\
\text { 4- Reinforcing positive attitude towards learning, particularly self-teaching and self- } \\
\text { management. } \\
\text { 5- Cultivating e-learning environment habit-formation. } \\
\text { 6- Encouraging creativity and self-development. } \\
\end{array}$ \\
\hline
\end{tabular}




\begin{tabular}{|c|c|c|c|}
\hline Shaqra University & 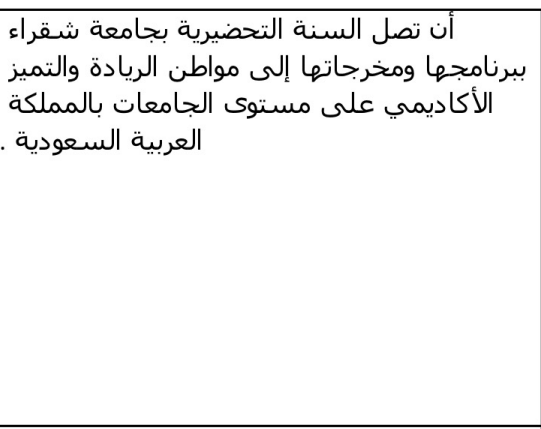 & 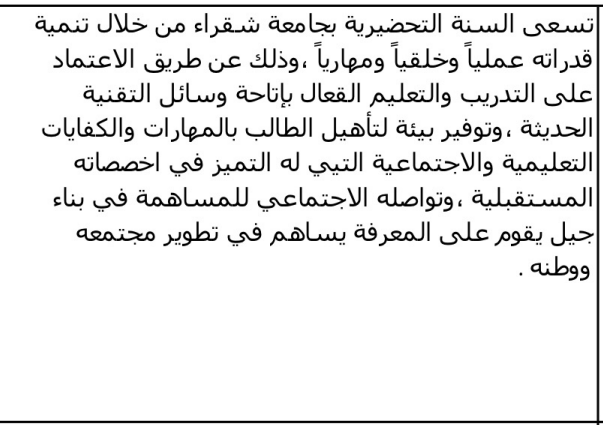 & 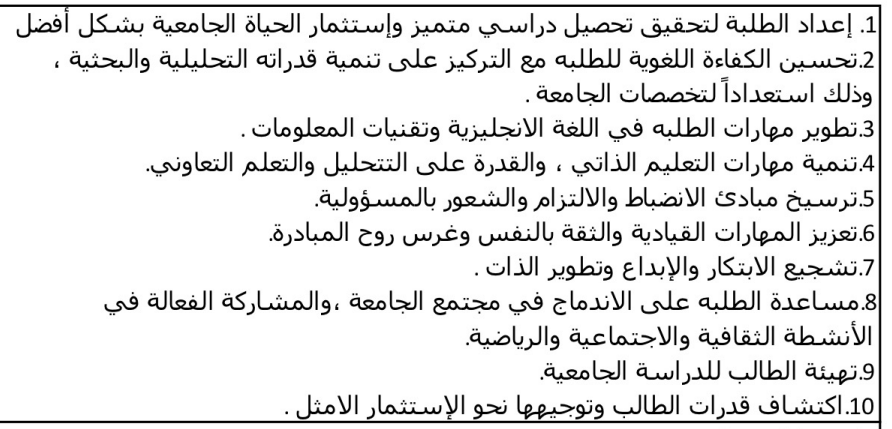 \\
\hline
\end{tabular}




\begin{tabular}{|c|c|c|c|}
\hline Taif University & \begin{tabular}{|l|} 
Offering distinguished university preparatory \\
programs accredited locally and internationally.
\end{tabular} & 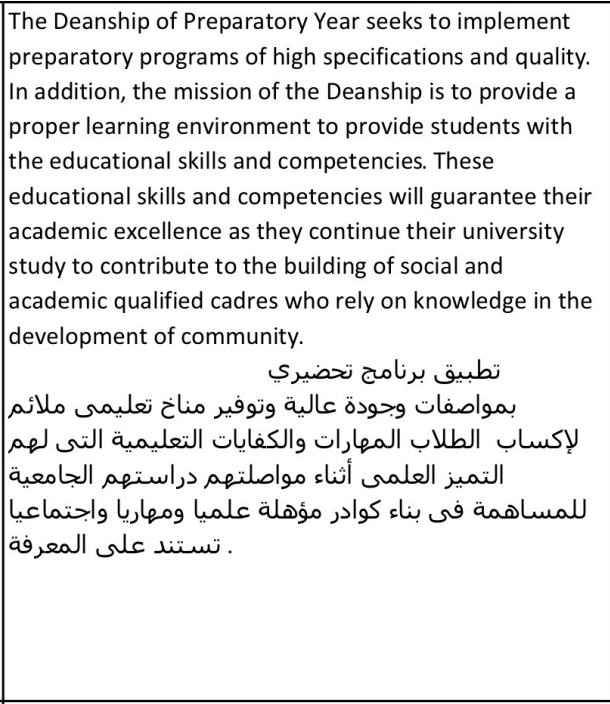 & $\begin{array}{l}\text { 1. Providing students with the necessary skills and knowledge in English language, } \\
\text { and computer. In addition to developing thinking and learning skills, research and } \\
\text { communication, which enables students to succeed in their university studies and } \\
\text { contribute effectively in their careers after graduation in the future. } \\
\text { 2. Facilitating the admission procedures for students and giving an opportunity to } \\
\text { determine the appropriate discipline based on their abilities and skills before } \\
\text { directed to the college in which students will complete their study. Therefore, these } \\
\text { procedures minimize college dropouts and get students accustomed to the } \\
\text { university circumstances before joining colleges through preparing them skillfully } \\
\text { and psychologically. } \\
\text { 3. Preparing the way towards the output of university education, for supplying the } \\
\text { labor market with distinctive competencies that reinforce the development process } \\
\text { in the Kingdom. } \\
\text { 4. Promoting self-development through infusing the principles of commitment and } \\
\text { discipline and responsibility, and elevating the leadership skills and self-confidence. } \\
\text { As well as, instilling initiatives in students. } \\
\text { 5. Encouraging creativity and innovation through developing students ' skills in } \\
\text { dealing with knowledge environment, new technologies and software. } \\
\text { 6. Strengthening partnerships with the community in various fields. } \\
\text { 7. Developing critical thinking skills, examining and problem solving }\end{array}$ \\
\hline Umm Al-Qura University & \begin{tabular}{|l|} 
To be distinguished leaders in preparing a \\
creative generation of students that enables \\
the UQU Deanship of Preparatory Year to \\
become top-ranked among other deanships of \\
preparatory year throughout the Saudi \\
universities. \\
\end{tabular} & $\begin{array}{l}\text { To develop the intellectual capabilities of students of the } \\
\text { Deanship of Preparatory Year, enable them to acquire } \\
\text { technical, linguistic, cognitive and thinking skills. This can } \\
\text { be achieved through an advanced environment that } \\
\text { motivates students to learn and be creative. Such } \\
\text { environment should be supported by optimal utilization } \\
\text { of technologies and distinguished partnerships. We seek } \\
\text { to instill the value of loyalty and sense of belonging in all } \\
\text { students. We seek to build a balanced personality } \\
\text { capable of participating actively and effectively in the } \\
\text { progress and prosperity of the Saudi community and } \\
\text { able to accept and co-exist with the other under the } \\
\text { governing values of the developed communities. }\end{array}$ & $\begin{array}{l}\text { 1. Provide students with numerous skills that will help them - God willing - to be } \\
\text { successful and prominent in their academic studies and their career life. } \\
\text { 2. Bridge the gap between the secondary stage and the undergraduate stage. } \\
\text { 3. Measure students' capabilities based on their performance during the } \\
\text { preparatory year and help them select the college that best suits their capabilities } \\
\text { as per the criteria adopted by colleges. } \\
\text { 4. Improve the quality of the input of the colleges participating in the preparatory } \\
\text { year. } \\
\text { 5. Improve educational environment, make necessary effort to achieve academic } \\
\text { quality and use new technologies in teaching. } \\
\text { 6. Develop creativity and innovation in students. } \\
\text { 7. Participate in improving the outcomes of the University. } \\
\text { 8. Engage students in the environment of electronic transactions and dealings } \\
\text { through digital educational curricula as per the international companies. }\end{array}$ \\
\hline
\end{tabular}




\begin{tabular}{|c|c|c|c|}
\hline University of Dammam & 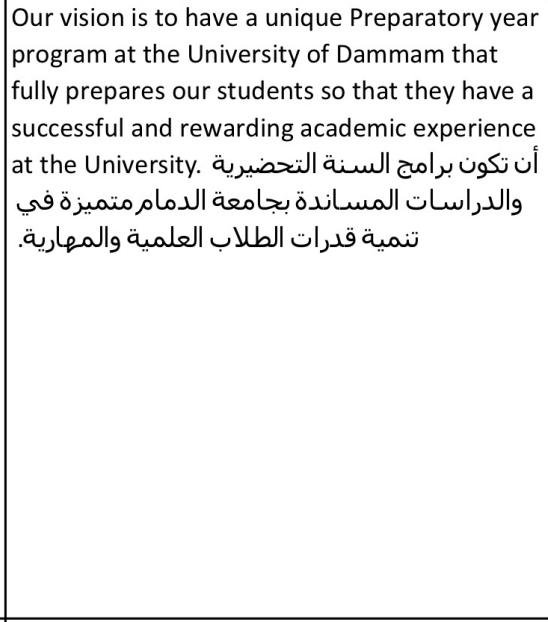 & 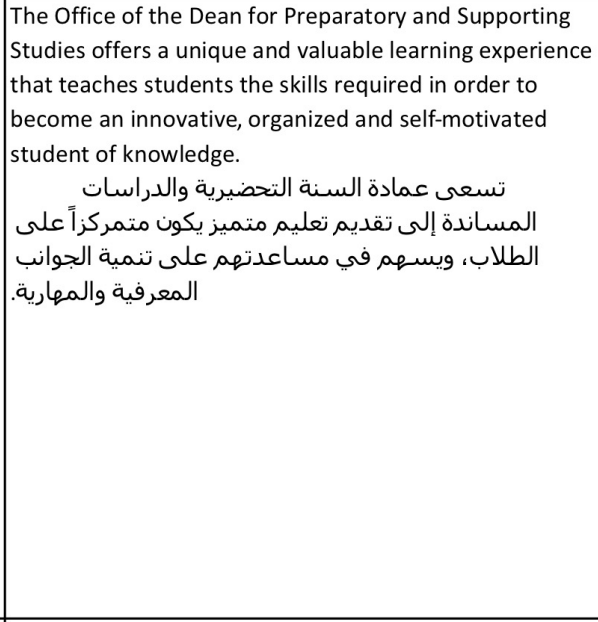 & 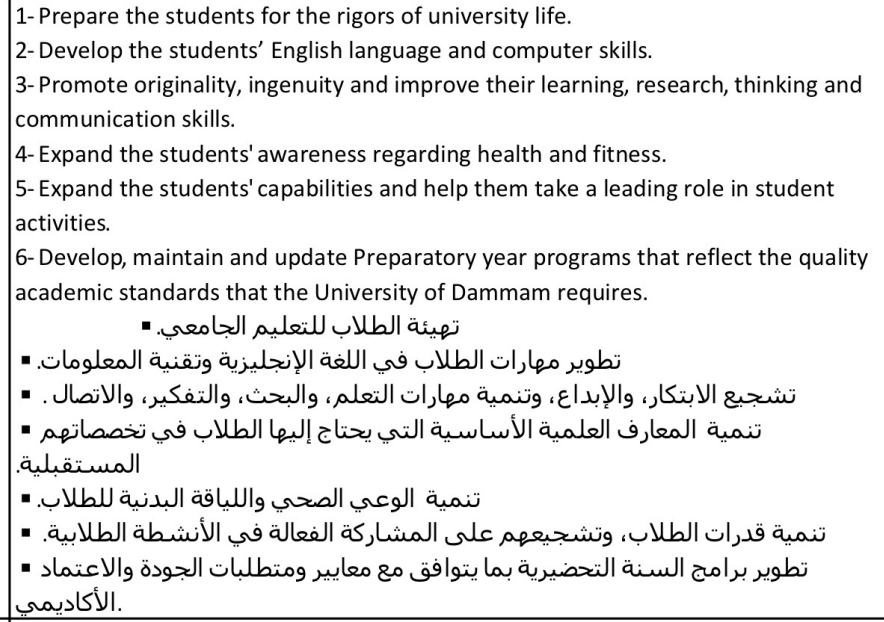 \\
\hline University of Hafr AlBatin & None & None & None \\
\hline University of Hail & 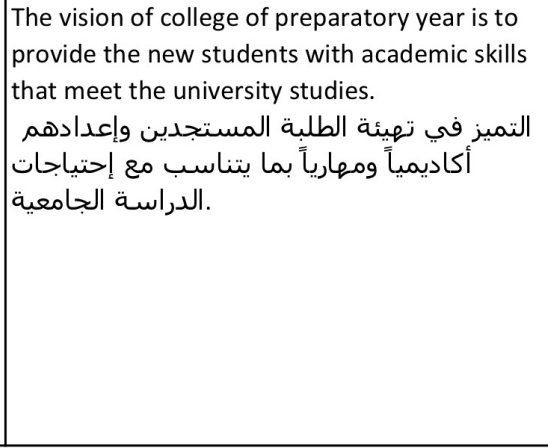 & 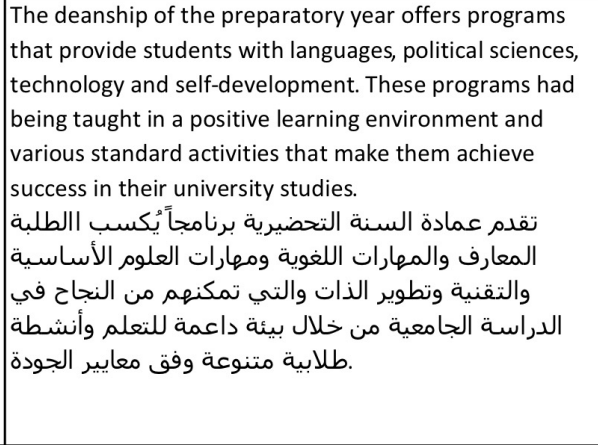 & 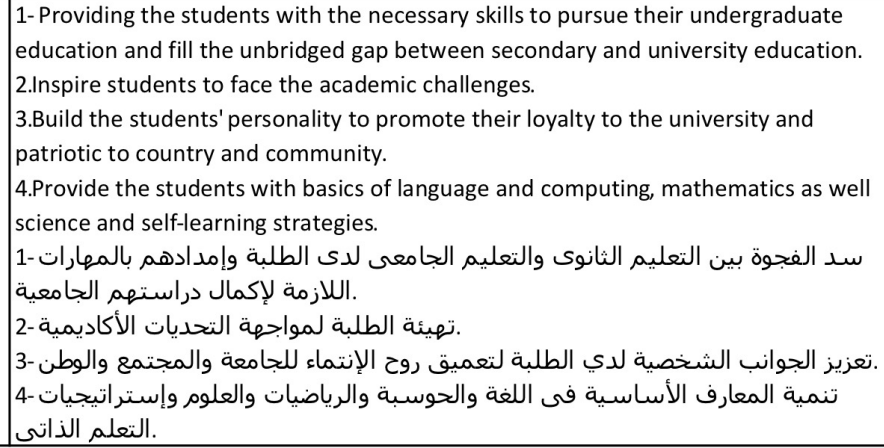 \\
\hline
\end{tabular}




\begin{tabular}{|c|c|c|c|}
\hline University of Tabuk & 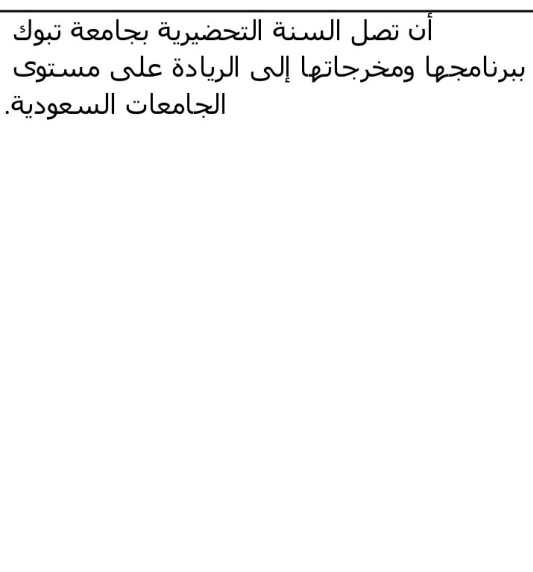 & 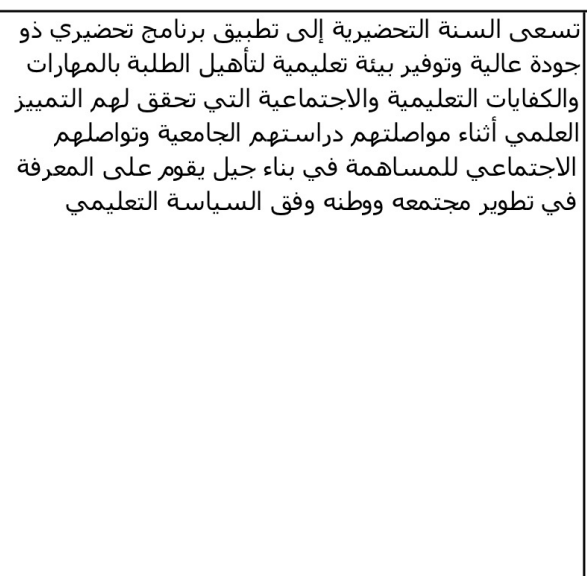 & 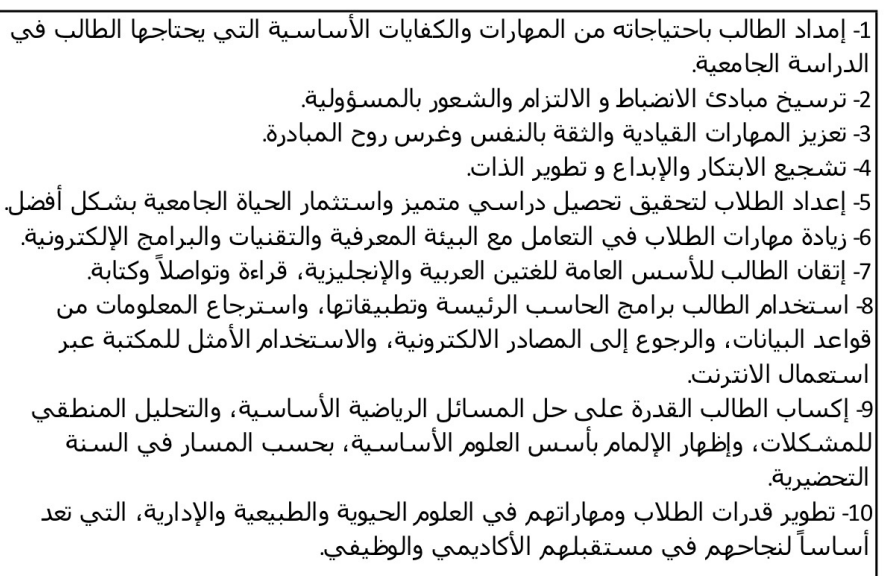 \\
\hline
\end{tabular}


Appendix B: The Codebook Form

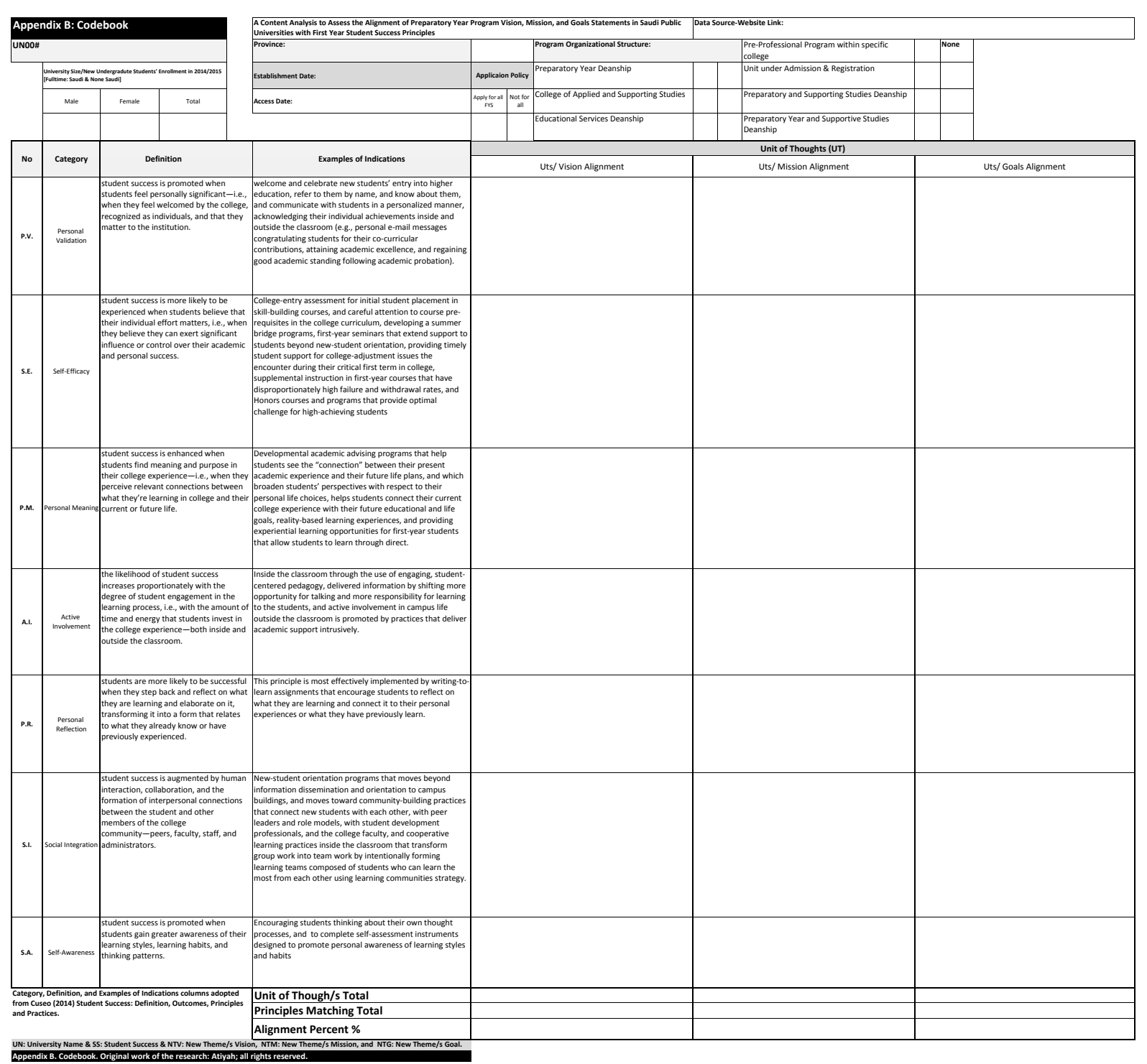

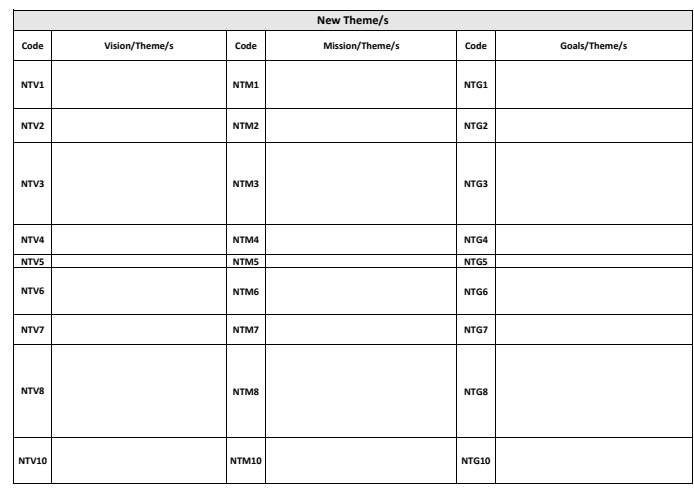


Appendix C: The Coding Form

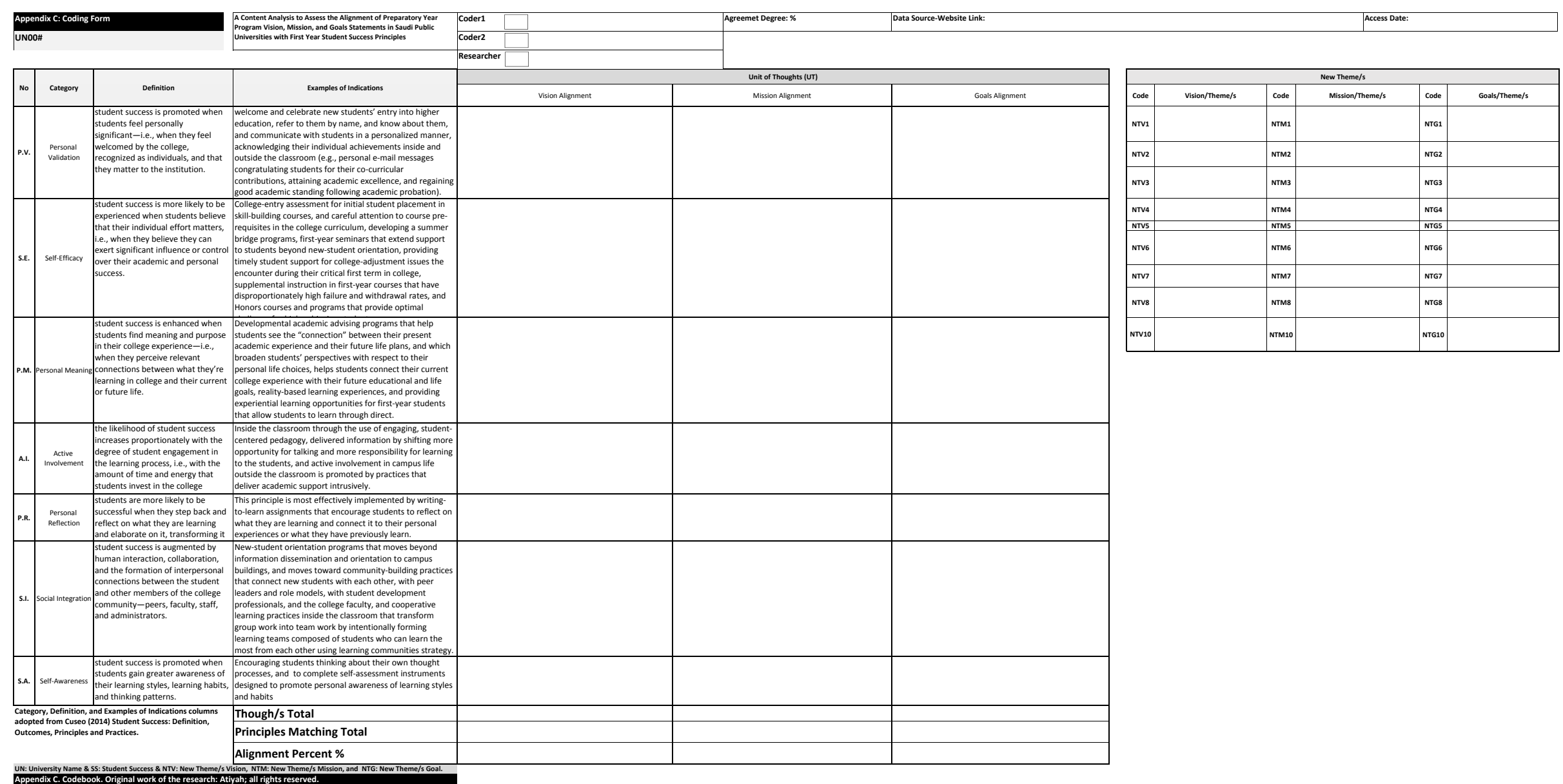


Appendix D: Saudi Public Universities List and the Links to Preparatory Year Programs

\begin{tabular}{|c|c|c|}
\hline Univeristy UN\# & Univeristy Website Links & PYP's Website Link \\
\hline Al Baha University & http://www.bu.edu.sa & http://www.bu.edu.sa/web/14807859/home \\
\hline Al Jouf University & http://www.ju.edu.sa & http://www.ju.edu.sa/index.php?id=402 \\
\hline Al Imam Muhammad Ibn Saud Islamic University & https://units.imamu.edu.sa & https://units.imamu.edu.sa/deanships/Preperation/profile/Pages/default.aspx \\
\hline Almajmaah University & https://www.mu.edu.sa & $\begin{array}{l}\text { https://www.mu.edu.sa/ar/\%D8\%B9\%D9\%85\%D8\%A7\%D8\%AF\%D8\%A9- } \\
\text { \%D8\%A7\%D9\%84\%D8\%B3\%D9\%86\%D8\%A9- } \\
\text { \%D8\%A7\%D9\%84\%D8\%AA\%D8\%AD\%D8\%B6\%D9\%8A\%D8\%B1\%D9\%8A\%D8\%A9/\% } \\
\text { D8\%A7\%D9\%84\%D8\%B9\%D9\%85\%D8\%A7\%D8\%AF\%D8\%A7\%D8\%AA }\end{array}$ \\
\hline Bisha University & http://ub.edu.sa/ & None \\
\hline Islamic University & http://www.iu.edu.sa & http://www.iu.edu.sa/colleges/AppliedSci/Pages/default.aspx \\
\hline Jazan University & http://deanships.jazanu.edu.sa & http://deanships.jazanu.edu.sa/prep.tear/Pages/Default.aspx \\
\hline Jeddah University & http://darnj.uj.edu.sa & $\begin{array}{l}\text { http://darnj.uj.edu.sa/Pages-\%d9\%85\%d8\%a7\%d9\%87\%d9\%8a- } \\
\text { \%d8\%a7\%d9\%84\%d8\%b3\%d9\%86\%d8\%a9- } \\
\% \text { d8\%a7\%d9\%84\%d8\%aa\%d8\%ad\%d8\%b6\%d9\%8a\%d8\%b1\%d9\%8a\%d8\%a9.aspx }\end{array}$ \\
\hline King Abdulaziz University & http://founyear.kau.edu.sa & http://founyear.kau.edu.sa/Default.aspx?Site_ID=210100\&Lng=AR \\
\hline King Fahd University of Petroleum and Minerals & http://www.bu.edu.sa & http://www.bu.edu.sa/web/14807859/home \\
\hline King Faisal University & https://www.kfu.edu.sa & $\begin{array}{l}\text { https://www.kfu.edu.sa/en/Deans/PreparatoryYear/Pages/En-Vision-and- } \\
\text { Goals.aspx }\end{array}$ \\
\hline King Khalid University & http://www.kku-a.com & None \\
\hline King Saud bin Abdulaziz University for Health Sciences & http://www.ksau-hs.edu.sa & $\begin{array}{l}\text { http://www.ksau- } \\
\text { hs.edu.sa/English/Academic/Pages/ThePreProfessionalProgram.aspx }\end{array}$ \\
\hline King Saud University & http://www.ksu.edu.sa & http://py.ksu.edu.sa/ \\
\hline Najran University & http://www.nu.edu.sa & http://dpy.nu.edu.sa/en/131 \\
\hline Northern Borders University & https://www.nbu.edu.sa & $\begin{array}{l}\text { https://www.nbu.edu.sa/en/Deanships/PreparatoryYearDeanshipstudiessupport/P } \\
\text { ages/Objectives.aspx }\end{array}$ \\
\hline Prince Sattam bin Abdulaziz University & https://www.psau.edu.sa & https://dpy.psau.edu.sa/ar/vision-mission/1-9 \\
\hline Princess Nora bint Abdulrahman University & http://www.pnu.edu.sa & http://www.pnu.edu.sa/en/Deanships/PreparatoryYear/Pages/Intro/Vision.aspx \\
\hline Qassim University & http://www.des.qu.edu.sa & http://www.des.qu.edu.sa/About/Pages/لرؤية.aspx \\
\hline Saudi Electronic University & https://www.seu.edu.sa & https://www.seu.edu.sa/sites/en/deanships/py/Pages/GoalsAndTasks.aspx \\
\hline Shaqra University & http://www.su.edu.sa & http://deanships.su.edu.sa/DOPY/About/Pages/Main.aspx \\
\hline Taibah University & https://www.taibahu.edu.sa & https://www.taibahu.edu.sa/Pages/AR/Sector/SectorPage.aspx?ID=42\&Pageld=59 \\
\hline Taif University & http://www.tu.edu.sa & http://deanships.tu.edu.sa/en/DoPY/About/Pages/default.aspx \\
\hline Umm Al-Qura University & https://www.uqu.edu.sa & https://uqu.edu.sa/en/pre-edu/2161 \\
\hline University of Dammam & http://www.uod.edu.sa & $\begin{array}{l}\text { http://www.uod.edu.sa/en/administration/deanships/deanship-of-preparatory-and- } \\
\text { supporting-studies/about }\end{array}$ \\
\hline University of Hafr AlBatin & http://www.uohb.edu.sa & None \\
\hline University of Hail & http://www.uoh.edu.sa & http://www.uoh.edu.sa/en/Subgates/Deans/Prep-Year/About/Pages/Default.aspx \\
\hline University of Tabuk & https://www.ut.edu.sa & https://www.ut.edu.sa/ar/web/deanship-of-academic-services/11 \\
\hline
\end{tabular}

